Forschungszentrum Karlsruhe Technik und Umwelt

Wissenschatmiche Berichte

FZKA 5588

\title{
Thermal Properties of Water
}

\section{K. Thurnay}

Institut für Neutronenphysik und Reaktortechnik

Projekt Nukleare Sicherheitsforschung 


\title{
Forschungszentrum Karlsruhe
}

Technik und Umwelt

Wissenschaftliche Berichte

FZKA 5588

\section{Thermal Properties of Water}

\author{
K. Thurnay \\ Institut für Neutronenphysik und Reaktortechnik \\ Projekt Nukleare Sicherheitsforschung
}

Forschungszentrum Karlsruhe $\mathrm{GmbH}$, Karlsruhe 1995 
Als Manuskript gedruckt

Für diesen Bericht behalten wir uns alle Rechte vor

Forschungszentrum Karlsruhe $\mathrm{GmbH}$

Postfach 3640, 76021 Karlsruhe

ISSN 0947-8620 


\begin{abstract}
The report describes AQUA, a code developed in the Forschungszentrum Karlsruhe to calculate thermal properties of the water in steam explosions. AQUA bases on the H.G.K. water code, yet supplies - besides of the pressure and heat capacity functions also the thermal conductivity, viscosity and the surface tension. AQUA calculates in a new way the thermal properties in the two phase region, which is more realistic as the one used in the H.G.K. code. AQUA is equipped with new, fast runnig routines to convert temperature-density dependent states into temperature-pressure ones.

AQUA has a version to be used on line and versions adapted for batch calculations.

A complete description of the code is included.
\end{abstract}

Thermische Eigenschaften des Wassers.

Zusammenfassung.

Der Bericht befaßt sich mit dem Code AQUA. AQUA wurde im Forschungszentrum Karlsruhe entwickelt um bei der Untersuchung von Dampfexplosionen die thermischen Eigenschaften des Wassers zu liefern. AQUA ist eine Fortentwicklung des H.G.K.-Wassercodes, aber er berechnet - neben Druck- und Wärmeeigenschaften - auch die Wärmeleitfähigket, die Viskosität und die Oberflächenspannung. Im Zweiphasengebiet beschreibt AQUA die thermischen Eigenschaften mit einer neuen Methode, die realistischer ist, als das in der H.G.K.-Code dargebotene Verfahren. AQUA verfügt über schnell laufende Hilfsprogramme, die die Umwandlung der Temperatur-Dichte Darstellungen in die Druck-Dichte Darstellungen ermöglichen.

AQUA kann man sowohl im Dialogbetrieb benutzen als auch beim rechnen im Stapelverfahren.

Eine ausführliche Beschreibung des Programmsystems rundet den Bericht ab. 


\begin{tabular}{|c|c|c|}
\hline Name & Code & Description \\
\hline A & A & specific free energy $[\mathrm{J} / \mathrm{kg}]$ \\
\hline$A^{0}$ & & $A /\left(R_{g a s} \cdot T\right)$ \\
\hline$\alpha$ & ALF & -0.1 , critical exponent for the heat capacity \\
\hline$\beta$ & BET & 0.325, critical exponent for the density \\
\hline \multirow[t]{3}{*}{$c_{v}$} & $\mathrm{CV}$ & heat capacity at constant volume $[J /(\mathrm{kg} \cdot \mathrm{K})]$ \\
\hline & CVL & heat capacity at constant volume of the liquid $\left[R_{g a s}\right]$ \\
\hline & CVV & heat capacity at constant volume of the vapor $\left[R_{g a s}\right]$ \\
\hline$C_{v}^{0}$ & cvo & $C_{v} / R_{g a s}$ \\
\hline$C_{p}$ & $C P$ & heat capacity at constant pressure $[\mathrm{J} /(\mathrm{kg} \cdot \mathrm{K})]$ \\
\hline \multirow[t]{2}{*}{$C_{P}^{0}$} & CPO & $C_{P} / R_{\text {gas }}$ \\
\hline & $\mathrm{CPC}$ & $C_{P} / C_{V}$ \\
\hline \multirow[t]{4}{*}{$\gamma$} & GAM & 1.24, critical exponent for $\partial P / \partial \rho$ \\
\hline & $\mathrm{DL}$ & density of the liquid $\left[\mathrm{g} / \mathrm{cm}^{3}\right]$ \\
\hline & DV & density of the vapor $\left[\mathrm{g} / \mathrm{cm}^{3}\right]$ \\
\hline & DX & density in $\mathrm{g} / \mathrm{cm}^{3}$ \\
\hline$\eta$ & ETA & dynamic viscosity $[\mathrm{Pa} \cdot \mathrm{sec}]$ \\
\hline \multirow[t]{3}{*}{$\boldsymbol{\eta}_{c}$} & ETC & critical viscosity, $3.95 \cdot 10^{-5} \mathrm{~Pa} \cdot \mathrm{sec}$ \\
\hline & ETL & dynamic viscosity of the liquid $[\mathrm{Pa} \cdot \mathrm{sec}]$ \\
\hline & ETV & dynamic viscosity of the vapor $[\mathrm{Pa} \cdot \mathrm{sec}]$ \\
\hline G & G & specific Gibbs function $[\mathrm{J} / \mathrm{kg}]$ \\
\hline $\mathbf{G}^{\times}$ & $G L$ & $G$ in the saturated states \\
\hline \multirow[t]{2}{*}{$\mathbf{G}^{0}$} & GO & $G /\left(R_{g a s} \cdot T\right)$ \\
\hline & GASCON & the gas-law constant of the water in $\mathrm{J} / \mathrm{g} \cdot \mathrm{K}$ \\
\hline H & $\mathrm{H}$ & specific enthalpy $[\mathrm{J} / \mathrm{kg}]$ \\
\hline$H^{0}$ & $\mathrm{HO}$ & $H /\left(R_{g o s} \cdot T\right)$ \\
\hline$H_{\rho}$ & H1P & $\partial H / \partial P, \quad$ pressure derivative of $\mathrm{H}$ \\
\hline$H_{\rho}$ & & $\partial H / \partial \rho$, density derivative of $H$ \\
\hline
\end{tabular}




\begin{tabular}{|c|c|c|}
\hline Name & Code & Description \\
\hline$\chi_{r}$ & CHIT & reduced isothermal compressibility (s. Eq. [3.9]) \\
\hline IAPS & & The International Association for the Properties of Steam \\
\hline \multirow[t]{4}{*}{$\lambda$} & XLMB & thermal conductivity $[W /(m \cdot K)]$ \\
\hline & $\mathrm{XLL}$ & thermal conductivity of the liquid $[W /(m \cdot K)]$ \\
\hline & XLV & thermal conductivity of the vapor $[W /(m \cdot K)]$ \\
\hline & MW & Molal mass ( $18.0152 \mathrm{~g} / \mathrm{mol})$ \\
\hline $\mathbf{P}$ & $P$ & pressure $[\mathrm{Pa}]$ \\
\hline$P_{c}$ & PC & critical pressure, $22.0549 \mathrm{MPa}$ \\
\hline$P^{\times}$ & PS & vapor pressure \\
\hline$P_{s L}$ & PSL & pressure on the liquid spinodal \\
\hline$P_{s v}$ & PSV & pressure on the vapor spinodal \\
\hline \multirow[t]{3}{*}{$P_{\rho}$} & P1R & $\partial P / \partial \rho$, density derivative of the pressure \\
\hline & PL1R & density derivative of the pressure in the saturated liquid \\
\hline & PV1R & density derivative of the pressure in the saturated vapor \\
\hline$P_{\rho}^{0}$ & P1R0 & $P_{\rho} /\left(R_{g a s} \cdot T\right)$ \\
\hline$\partial P /\left.\partial \rho\right|_{s}$ & P1RS & density derivative of the pressure at constant entropy \\
\hline \multirow[t]{3}{*}{$P_{r}$} & $\mathrm{P} 1 \mathrm{~T}$ & $\partial P / \partial T$, temperature derivative of the pressure \\
\hline & PL1T & temperature derivative of the pressure in the saturated liquid \\
\hline & PV1T & temperature derivative of the pressure in the saturated vapor \\
\hline$P_{T}^{0}$ & Р1T0 & $P_{T} /\left(R_{\text {gas }} \cdot \rho\right)$ \\
\hline \multirow[t]{2}{*}{$P^{\#}$} & PRN & Prandt। number, $\quad C_{P} \cdot(\eta / \lambda)$ \\
\hline & Q & pressure in MPa-s \\
\hline $\boldsymbol{R}_{\text {gas }}$ & RGAS & gas-law constant of the water, $\quad 461.522 \mathrm{~J} /(\mathrm{kg} \cdot \mathrm{K})$ \\
\hline$\rho$ & $\mathrm{RH}$ & density $\left[\mathrm{kg} / \mathrm{m}^{3}\right]$ \\
\hline$\rho_{c}$ & $\mathrm{RHC}$ & critical density, $\quad 322 . \mathrm{kg} / \mathrm{m}^{3}$ \\
\hline$\rho_{s L}$ & RHSL & density of the liquid spinodal \\
\hline$\rho_{s v}$ & RHSV & density of the vapor spinodal \\
\hline$\rho_{r}^{0}$ & R1T0 & reduced temperature-derivative of the density, $\quad T / \rho \cdot \partial \rho / \partial T$ \\
\hline
\end{tabular}




\begin{tabular}{|c|c|c|}
\hline Name & Code & Description \\
\hline$r_{L}$ & RL1TO & $\begin{array}{l}\text { reduced temperature-derivative of the density } \\
\text { of the saturated liquid, } T / \rho \cdot d \rho_{L} / d T\end{array}$ \\
\hline$r_{v}$ & RV1T0 & $\begin{array}{l}\text { reduced temperature-derivative of the density } \\
\text { of the saturated vapor, } T / \rho \cdot d \rho_{v} / d T\end{array}$ \\
\hline $\mathbf{s}$ & $\mathrm{s}$ & specific entropy $[J /(k g \cdot K)]$ \\
\hline$S_{c}$ & $\mathrm{sc}$ & critical entropy, $\quad 9.43 \cdot R_{\text {gos }}=435.244 \mathrm{~J} /(\mathrm{kg} \cdot \mathrm{K})$ \\
\hline$\sigma$ & $\begin{array}{l}\text { SRFTS } \\
\text { SL }\end{array}$ & $\begin{array}{l}\text { surface tension }[N / M] \\
\text { specific entropy of the liquid }[\mathrm{J} /(\mathrm{kg} \cdot \mathrm{K})]\end{array}$ \\
\hline & SREF & $7.6180802 \cdot R_{\text {ges }}$ \\
\hline$S^{0}$ & so & $S / R_{\text {gas }}$ \\
\hline $\mathbf{T}$ & $T$ & temperature $[\mathrm{K}]$ \\
\hline$T_{\mathrm{c}}$ & $\begin{array}{l}\text { TC } \\
\text { TPS1T }\end{array}$ & $\begin{array}{l}\text { critical temperature, } 647.126 \mathrm{~K} \\
T \cdot d P^{\times} / d T[\mathrm{~Pa}]\end{array}$ \\
\hline & TTPS2T & $T \cdot T \cdot d^{2} P^{x} / d T^{2} \quad[P a]$ \\
\hline$d T / d P^{x}$ & TS1P & inverse of the derivative of the vapor pressure $[\mathrm{K} / \mathrm{Pa}]$ \\
\hline$\tau$ & $\mathrm{Y}$ & scaled temperature, $1-T / T_{\mathrm{c}}$ \\
\hline $\mathbf{u}$ & $u$ & specific internal energy $[J / k g]$ \\
\hline & UREF & $-4328.455039 \cdot R_{g a s} \cdot T$ \\
\hline$U^{0}$ & Uo & $U /\left(R_{\text {gas }} \cdot T\right)$ \\
\hline$U_{\rho}$ & U1R & $\partial U / \partial \rho$, density derivative of $U$ \\
\hline $\mathbf{v}$ & v & specific volume, $1 / \rho$ \\
\hline$v_{s}$ & VS & velocity of sound, $v_{s}^{2}=\partial P /\left.\partial \rho\right|_{s}$ \\
\hline & VQ & vapor quality, $\frac{m_{v}}{m_{L}+m_{v}}$ \\
\hline $\mathbf{w}$ & W & $\sqrt{\tau}$ \\
\hline $\mathbf{z}$ & $z$ & factor of reality, $(P \cdot V) /\left(R_{g a s} \cdot T\right)$ \\
\hline
\end{tabular}


2.0 A short description of the H.G.K.-code $\ldots \ldots \ldots \ldots \ldots \ldots \ldots$

2,1 The Helmholtz function $\ldots \ldots \ldots \ldots \ldots \ldots \ldots \ldots$

2.2 The base function $\ldots \ldots \ldots \ldots \ldots \ldots \ldots \ldots \ldots \ldots$

2.3 The ideal gas function $\ldots \ldots \ldots \ldots \ldots \ldots \ldots \ldots \ldots \ldots$

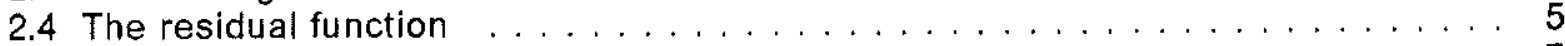

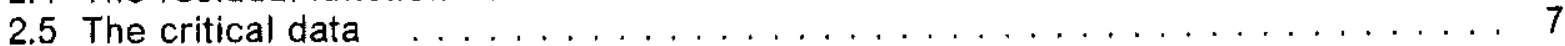

2.6 The validity domain $\ldots \ldots \ldots \ldots \ldots \ldots \ldots \ldots$

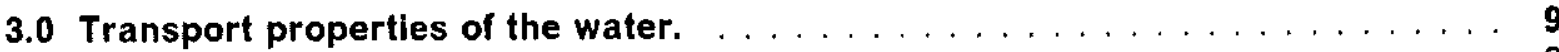

Reduced variables $\ldots \ldots \ldots \ldots \ldots \ldots \ldots \ldots \ldots$

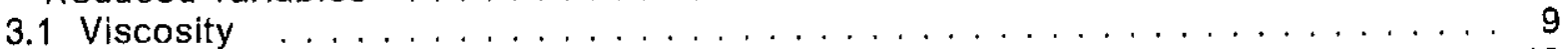

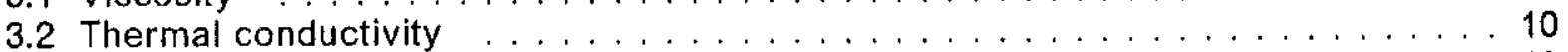

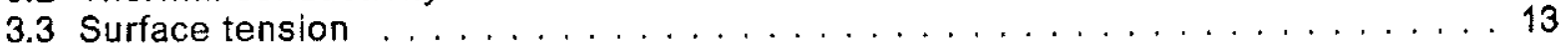

4.0 Thermal properties in the two phase region $\ldots \ldots \ldots \ldots \ldots$

4.1 Thermal states of the subcritical water $\ldots \ldots \ldots \ldots \ldots \ldots \ldots$

4.2 Water properties in the region of instability $\ldots \ldots \ldots \ldots \ldots \ldots$

5.0 Describing the water properties in the saturated states $\ldots \ldots \ldots \ldots$

5.1 Describing the saturation line of the water $\ldots \ldots \ldots \ldots \ldots \ldots \ldots \ldots$

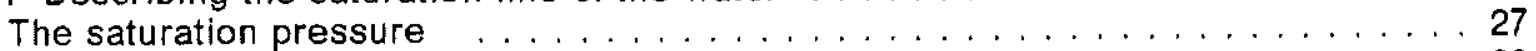

The saturation line . . . . . . . . . . . . . . . . . . . . 29

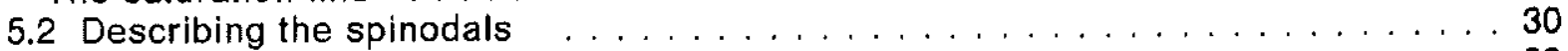

Calculating the spinodals of the water. $\ldots \ldots \ldots \ldots \ldots \ldots \ldots \ldots \ldots$

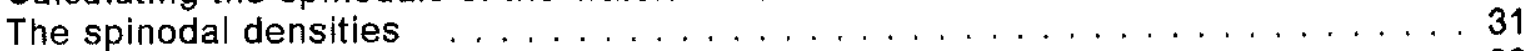

The spinodal pressures . . . . . . . . . . . . . . . . . . 33

5.3 The entropy on the saturation line $\ldots \ldots \ldots \ldots \ldots \ldots \ldots \ldots \ldots$

5.4 The transport properties on the saturation line $\ldots \ldots \ldots \ldots \ldots \ldots$

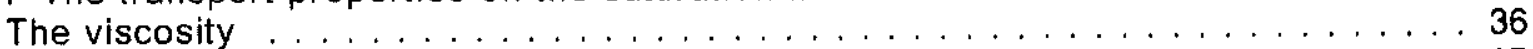

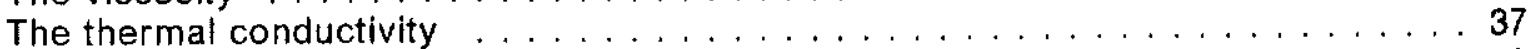

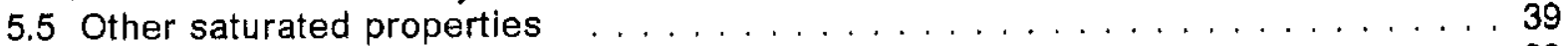

The density derivative of the pressure $\ldots \ldots \ldots \ldots \ldots \ldots \ldots \ldots$

The temperature derivative of the pressure $\ldots \ldots \ldots \ldots \ldots \ldots \ldots$

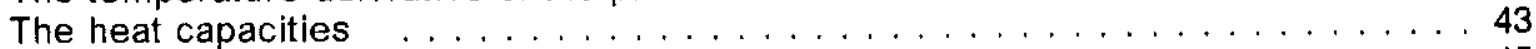

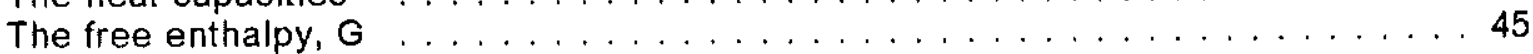

6.0 Calculating the densities from the pressures $\ldots \ldots \ldots \ldots$

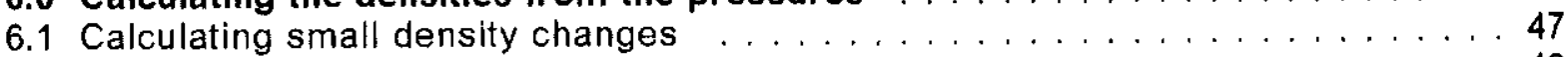

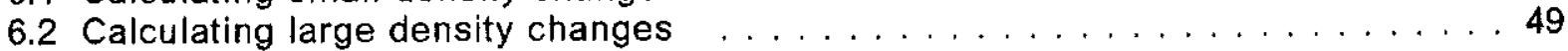

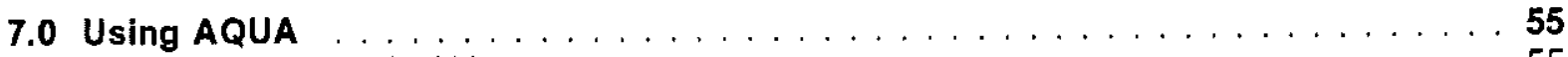

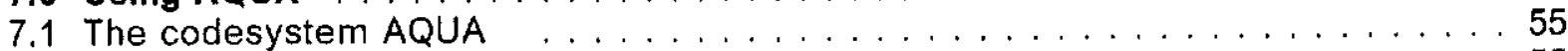

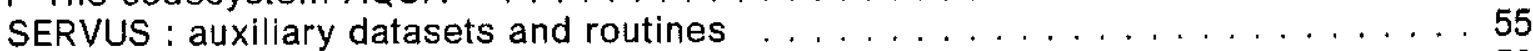

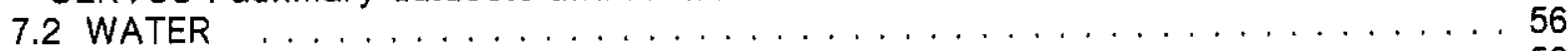

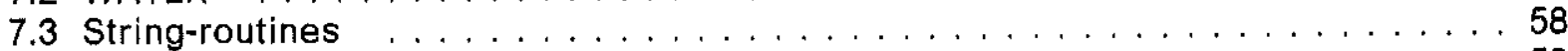

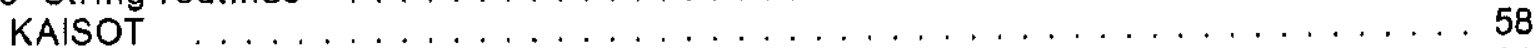

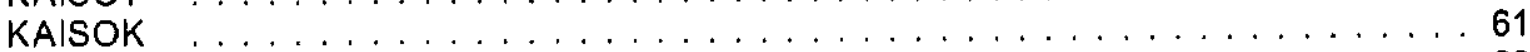

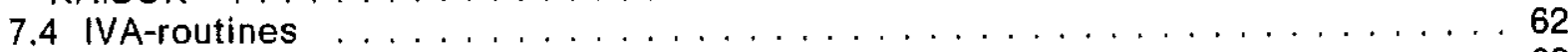

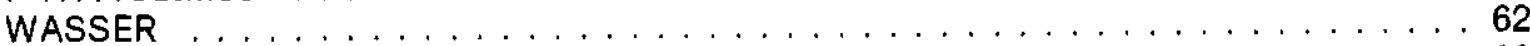

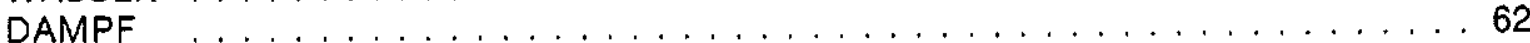

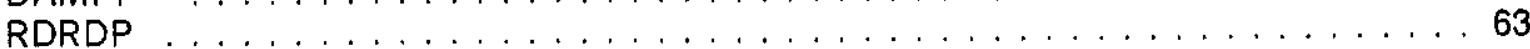

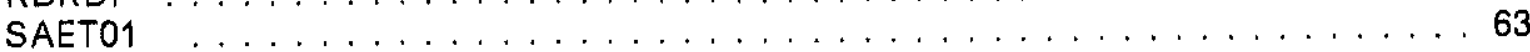




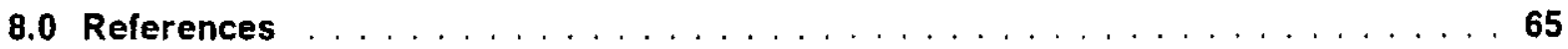

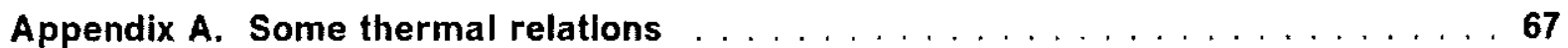

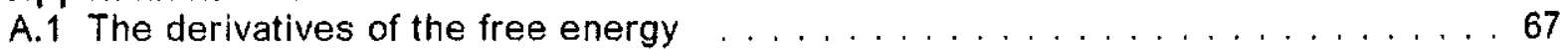

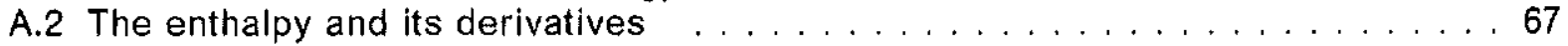

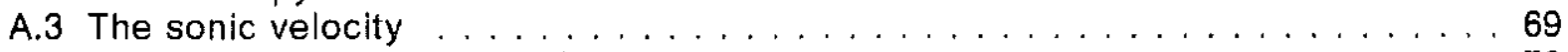

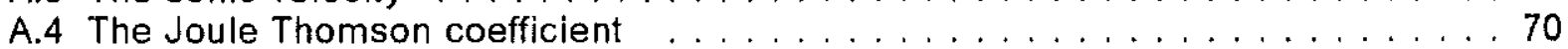

Appendix B. Derivatives of some saturated properties $\ldots \ldots \ldots \ldots \ldots \ldots$

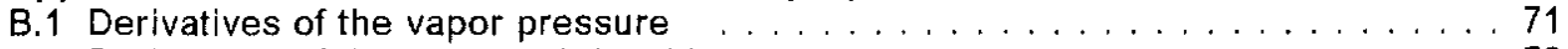

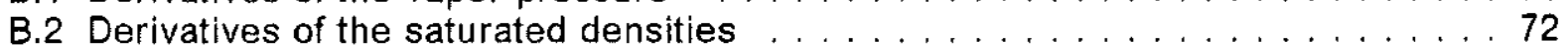

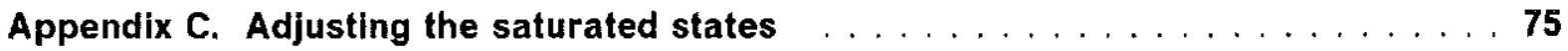

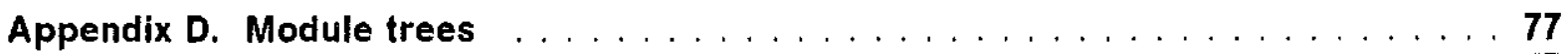

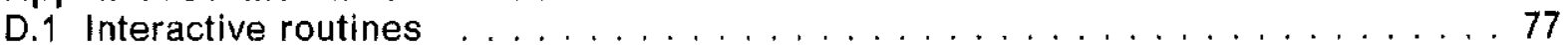

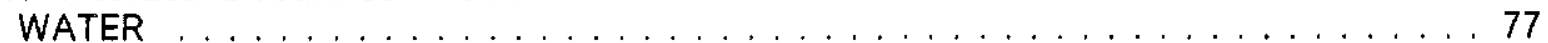

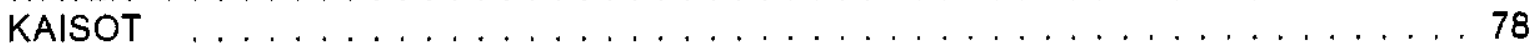

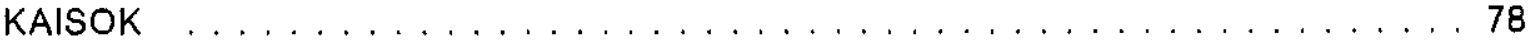

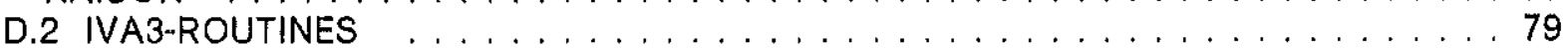

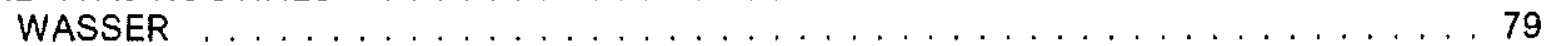

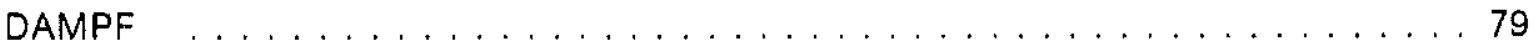

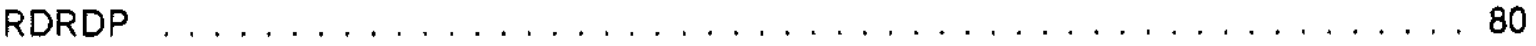

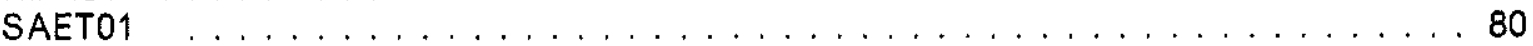

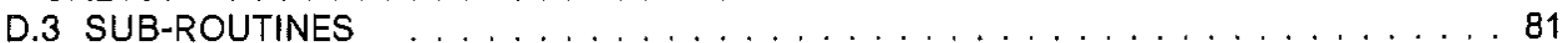

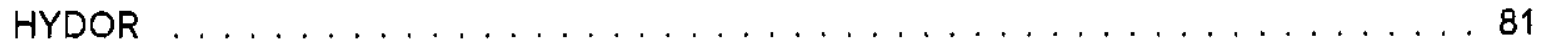

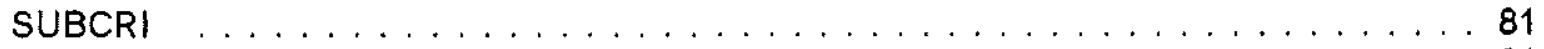

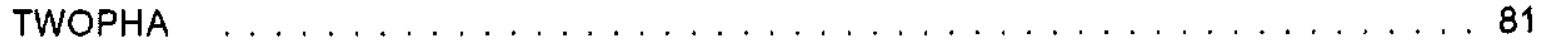

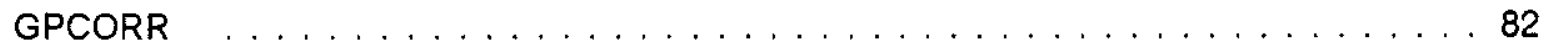

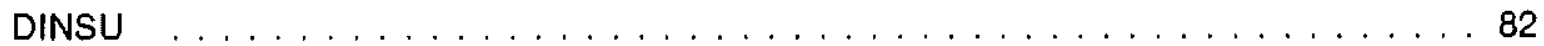

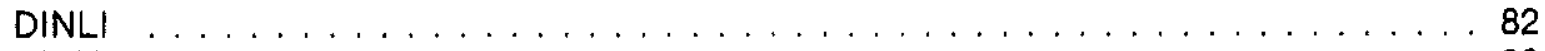

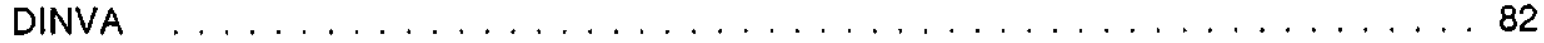

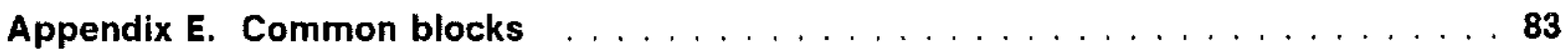

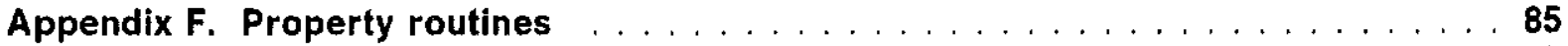

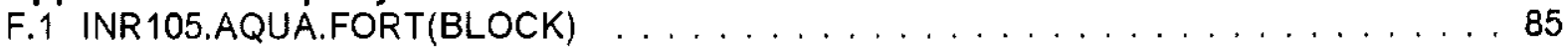

F.2 INR105.AQUA.FORT(ONLYT) $\ldots \ldots \ldots \ldots \ldots$

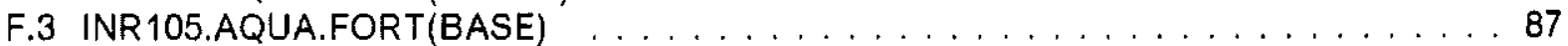

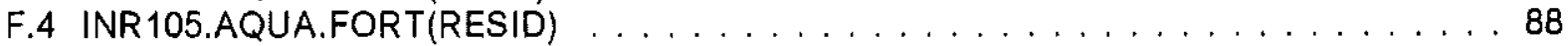

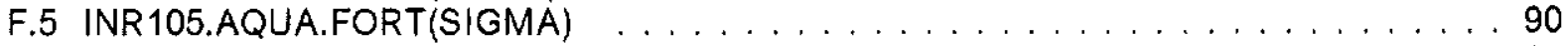

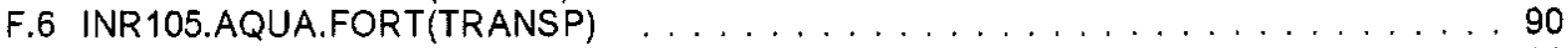

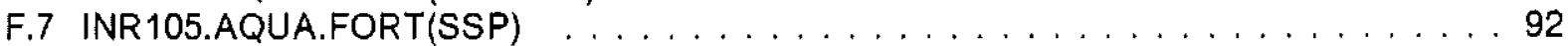

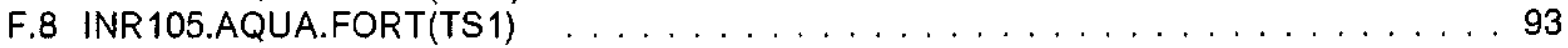

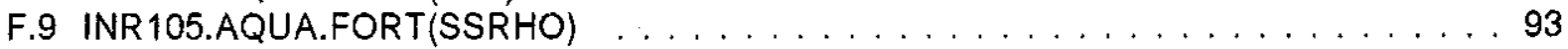

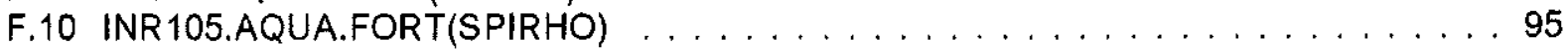

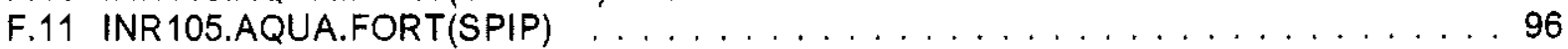

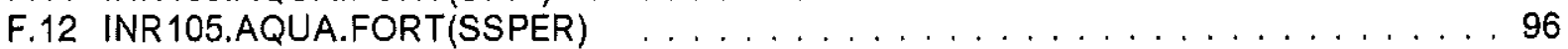

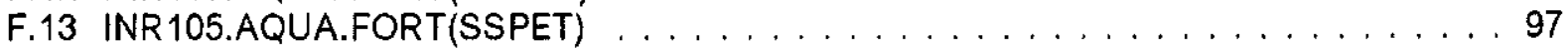

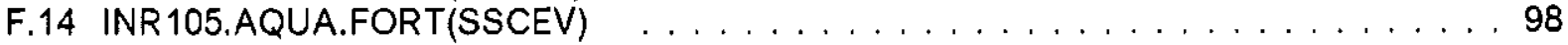

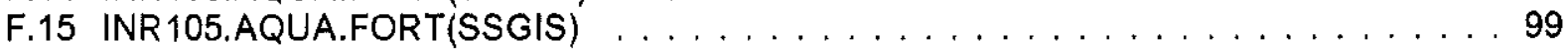

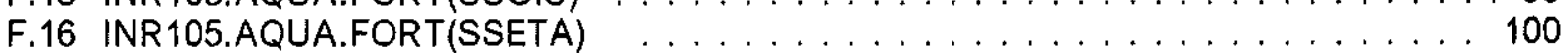

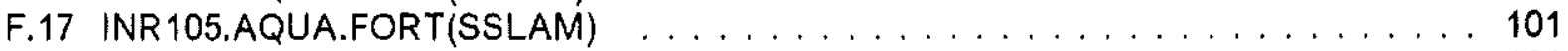

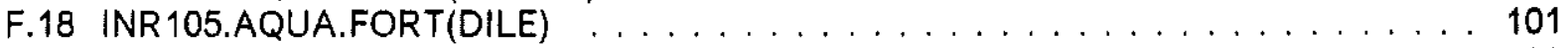

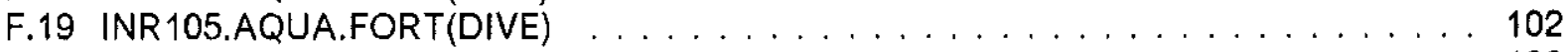

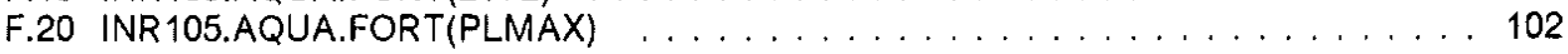




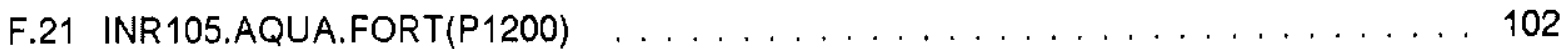

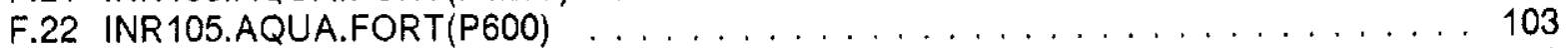

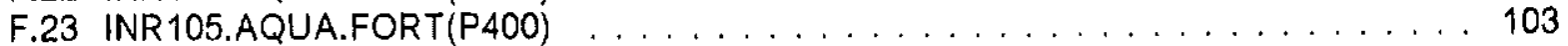

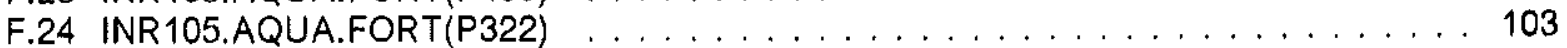

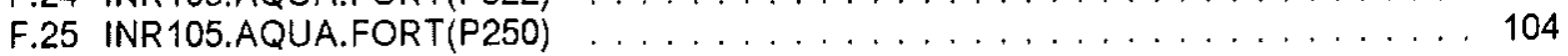

Appendix G. Secondary routines $\ldots \ldots \ldots \ldots \ldots \ldots \ldots \ldots$

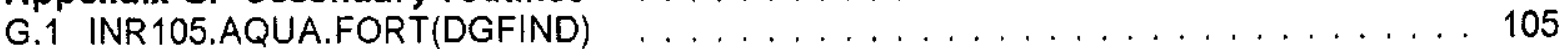

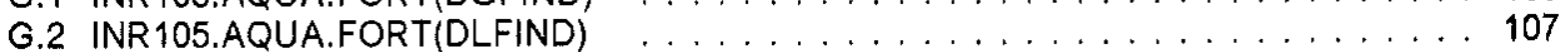

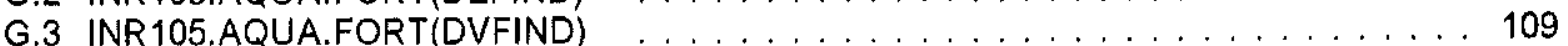

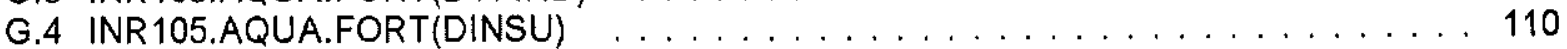

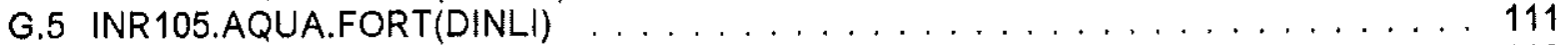

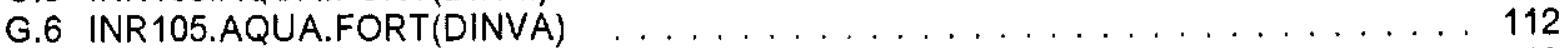

G.7 INR105.AQUA.FORT(QUADO) $\ldots \ldots \ldots \ldots \ldots \ldots \ldots \ldots \ldots$

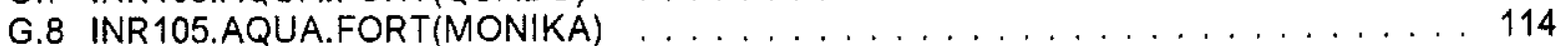

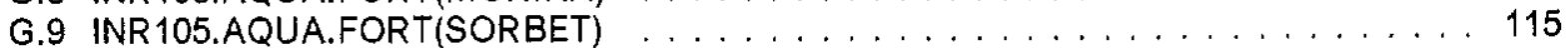

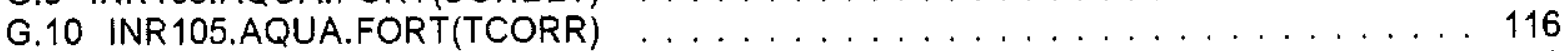

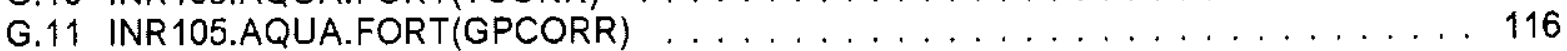

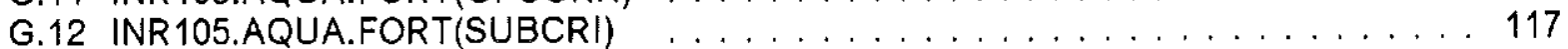

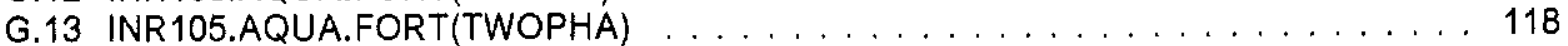

G.14 INR105.AQUA.FORT(REDUK) $\ldots \ldots \ldots \ldots \ldots \ldots \ldots \ldots \ldots \ldots$

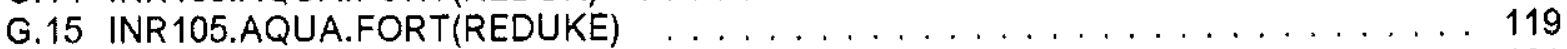

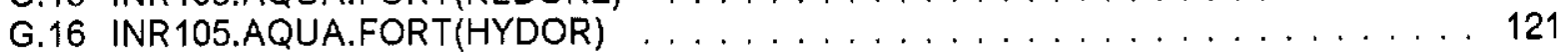

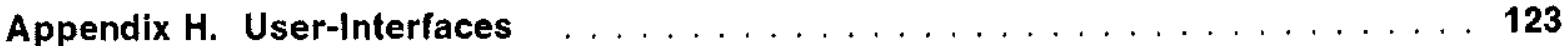

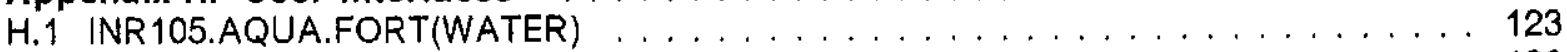

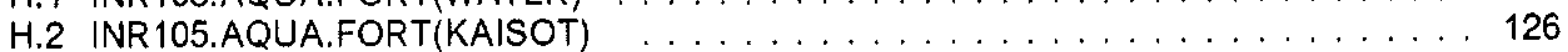

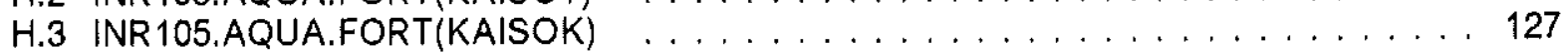

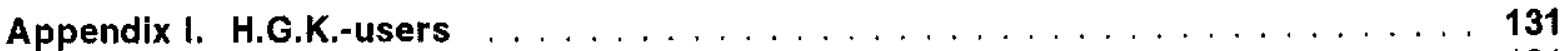

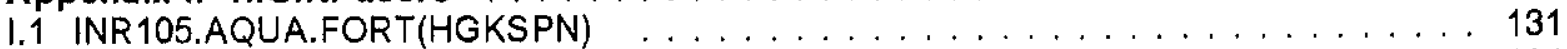

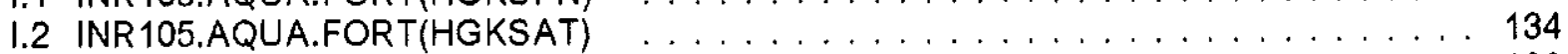

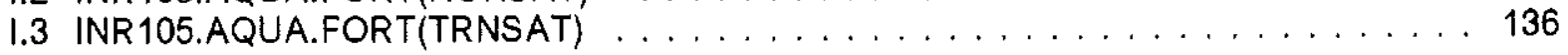

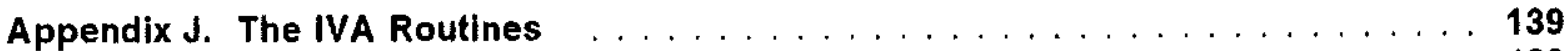

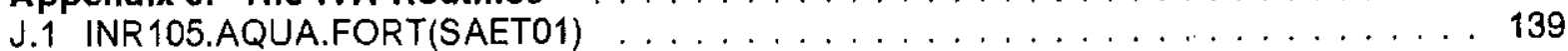

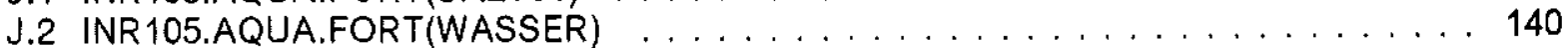

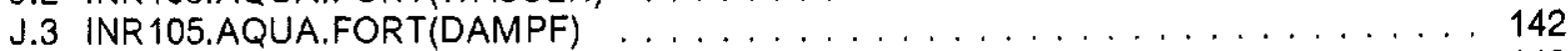

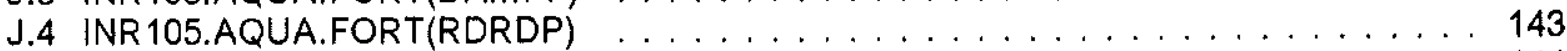

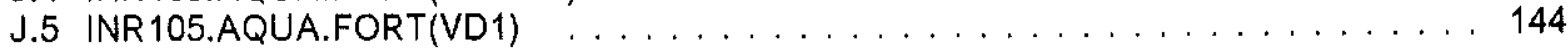

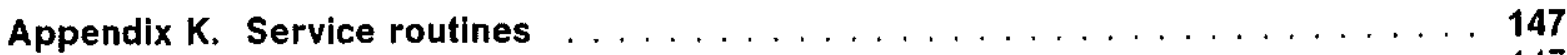

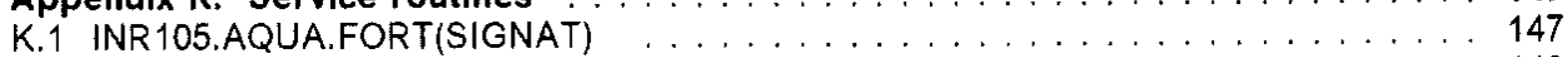

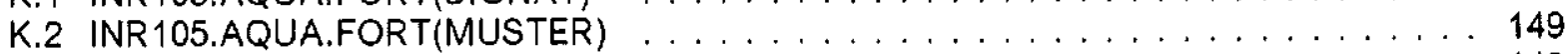

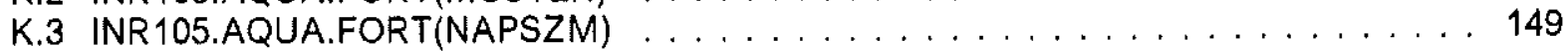

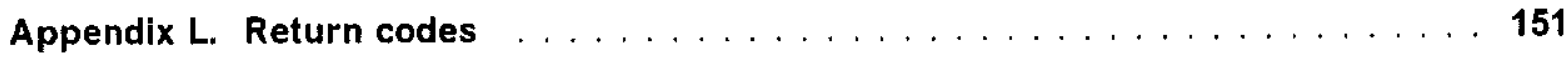

Appendix M. TSO-procedures, calculating thermal properties of the water $\ldots \ldots 153$

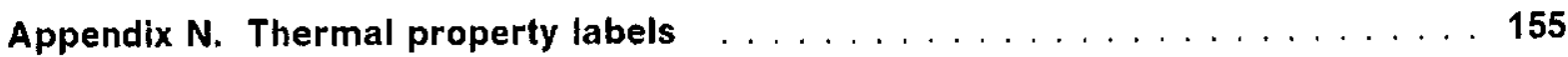


1. Thermal conductivity of the steam in the critical region as a function of density at constant pressures ......................... 10

2. Thermal conductivity of the water on supercritical isotherms $\ldots \ldots \ldots \ldots 12$

3. Pressure surface of the water. H.G.K.-code $\ldots \ldots \ldots \ldots \ldots \ldots \ldots$

4. Sketch of $P, V$ diagram with saturation and spinodal lines. $V=1 / \rho \ldots \ldots 15$

5. Pressure of the water in the two phase region. $T=500 \mathrm{~K} \ldots \ldots \ldots \ldots$

6. Water pressures in the superheated liquid state $\ldots \ldots \ldots \ldots \ldots \ldots \ldots \ldots$

7. Free enthalpy of the water in the two phase region. $T=500 \mathrm{~K} \ldots \ldots \ldots$

8. Entropy of the water in the two phase region. $\mathrm{T}=500 \mathrm{~K} \ldots \ldots \ldots \ldots$

9. Free energy of the water in the two phase region. $T=500 \mathrm{~K} \ldots \ldots \ldots$

10. Sonic velocity of the water in the two phase region. $T=500 \mathrm{~K} \ldots \ldots \ldots$

11. Heat capacity $-C_{Y}$ - of the water in the two phase region. $T=500 \mathrm{~K} \ldots \ldots 21$

12. Thermal conductivity of the water in the two phase region. $T=500 \mathrm{~K} \ldots 22$

13. Viscosity of the water in the two phase region. $T=500 \mathrm{~K} \ldots \ldots \ldots 23$

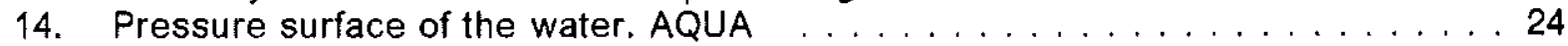

15. Heat capacity surface of the water. AQUA. View from the cold side. . . . . . . . 25

16. Heat capacity surface of the water. AQUA. View from the liquid side. . . . . . 26

17. Vapor pressure formula of Wagner and Saul . . . . . . . . . . . . . . . 28

18. Spinodal densities in the vicinity of the critical point $\ldots \ldots \ldots \ldots \ldots \ldots$

19. Saturation and spinodal densities of the water $\ldots \ldots \ldots \ldots \ldots \ldots \ldots$

20. Pressures on the spinodals of the water $\ldots \ldots \ldots \ldots \ldots \ldots \ldots$

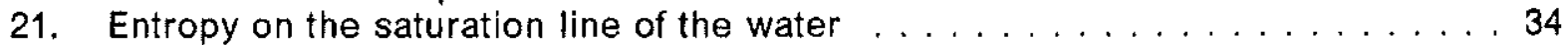

22. Entropy of the saturated states in the vicinity of $T_{c} \ldots \ldots \ldots \ldots$

23. Viscosity of the water in the saturated states . . . . . . . . . . . 36

24. Thermal conductivity of the water as function of the temperature . . . . . . . 38

25. Density derivatives of the pressure in the saturated states . . . . . . . . . 39

26. Density derivatives of the pressure in the vicinity of $T_{c} \ldots \ldots \ldots \ldots \ldots$

27. Temperature derivatives of the pressure in the saturated states . . . . . . 41

28. Temperature derivatives of the pressure in the vicinity of $T_{c} \ldots \ldots \ldots \ldots 2$

29. Heat capacities of the water in the saturated states. . . . . . . . . . . . 43

30. Heat capacities of the water in the vicinity of $T_{c} \ldots \ldots \ldots \ldots \ldots$

31. Free enthalpy $-G$ - of the water in the saturated states . . . . . . . . 45

32. Water pressures on the $647 \mathrm{~K}$ isotherm . . . . . . . . . . . . . . 48

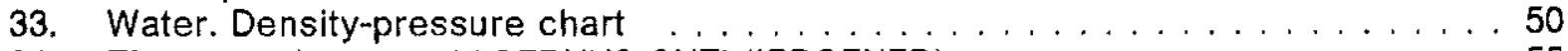

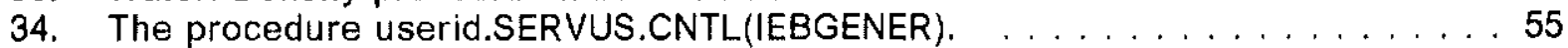

35. The procedure userid.AQUA.CLIST(KAISOT) $\ldots \ldots \ldots \ldots \ldots \ldots$

36. The procedure userid.AQUA.CLIST(KAISOK) $\ldots \ldots \ldots \ldots \ldots \ldots$

37. Module tree for the procedure WATER $\ldots \ldots \ldots \ldots \ldots \ldots \ldots \ldots$

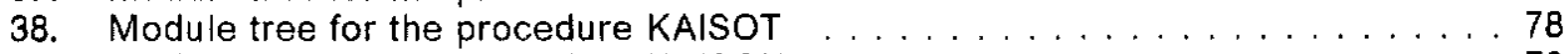

39. Module tree for the procedure KAISOK $\ldots \ldots \ldots \ldots \ldots \ldots \ldots$

40. Module tree for the procedure WASSER $\ldots \ldots \ldots \ldots \ldots \ldots \ldots$

41. Module tree for the procedure DAMPF $\ldots \ldots \ldots \ldots \ldots \ldots \ldots$

42. Module tree for the procedure RDRDP $\ldots \ldots \ldots \ldots \ldots \ldots$

43. Module tree for the procedure SAET01 $\ldots \ldots \ldots \ldots \ldots \ldots$

44. Module tree for the procedure HYDOR $\ldots \ldots \ldots \ldots \ldots \ldots$

45. Module tree for the procedure SUBCRI $\ldots \ldots \ldots \ldots \ldots \ldots \ldots$

46. Module tree for the procedure TWOPHA $\ldots \ldots \ldots \ldots \ldots \ldots \ldots$

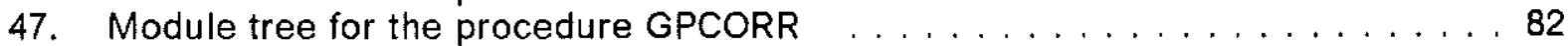

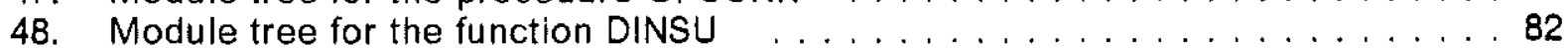

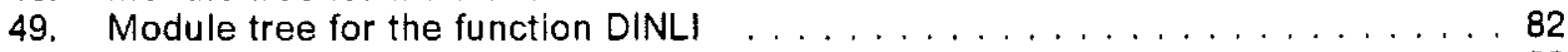

50. Module tree for the function DINVA $\ldots \ldots \ldots \ldots \ldots \ldots$ 
1. The coeficients of the base function $\ldots \ldots \ldots \ldots \ldots \ldots \ldots \ldots$

2. The coeficients of the ideal gas function $\ldots \ldots \ldots \ldots \ldots \ldots \ldots$

3. The exponents $i(1)-i(40)$ of the residual function $\ldots \ldots \ldots \ldots \ldots$

4. The exponents $k(1)-k(40)$ of the residual function . . . . . . . . . . . 5

5. The coefficients of the near-critical description in the residual function . . . . . 5

6. The coefficients $g(1)-g(40)$ of the residual function $\ldots \ldots \ldots \ldots \ldots$

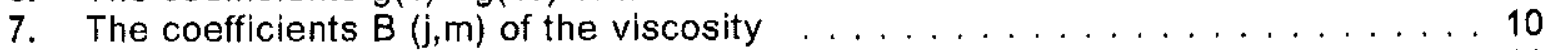

8. The coefficients $b(i, n)$ of the thermal conductivity . . . . . . . . . . . 11

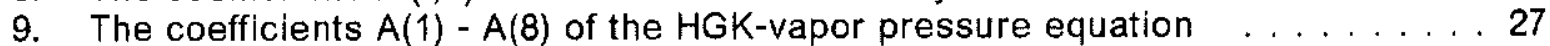

10. The coefficients $A(1)-A(12)$ in the Eq. of the saturated liquid . . . . . . . 29

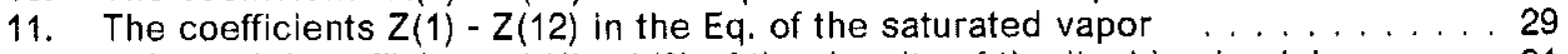

12. Polynomial coefficients $A(1)-A(9)$ of the density of the liquid spinodal . . . . 31

13. Polynomial coefficients $C(1)-C(7)$ of the density of the vapor spinodal $\ldots \ldots 31$

14. Polynomial coefficients $A(1)-A(9)$ of the pressure of the liquid spinodal . . . . 33

15. Polynomial coefficients $C(1)-C(8)$ of the pressure of the vapor spinodal . . . 34

16. Polynomial coefficients $A(1)-A(9)$ of the entropy of the saturated liquid . . . 35

17. Polynomial coefficients $A(1)-A(11)$ of the viscosity in the saturated liquid . . 37

18. Polynomial coefficients $C(1)-C(9)$ of the viscosity in the saturated vapor . . . 37

19. Coefficients $A(1)-A(8)$ of the thermal conductivity in the saturated liquid . . . 37

20. Coefficients $C(1)-C(9)$ of the thermal conductivity in the saturated vapor $\ldots .38$

21. Polynomial coefficients $A(1)-A(12)$ of $\partial P / \partial \rho$ in the saturated liquid . . . . . 39

22. Polynomial coefficients $C(1)-C(9)$ of $\partial P / \partial \rho$ in the saturated vapor . . . . . . 40

23. Polynomial coefficients $A(1)-A(12)$ of $\partial P / \partial T$ in the saturated liquid $\ldots \ldots . .41$

24. Polynomial coefficients $C(1)-C(10)$ of $\partial P / \partial T$ in the saturated vapor $\ldots \ldots . .42$

25. Polynomial coefficients $A(1)-A(12)$ of $C_{v}$ in the saturated liquid . . . . . . 43

26. Polynomial coefficients $C(1)-C(10)$ of $C_{V}$ in the saturated vapor . . . . . . 44

27. Polynomial coefficients $A(1)-A(9)$ of the free enthalpy of the saturated states 45

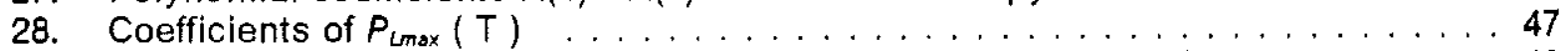

29. Polynomial coefficients $U(1)-U(9)$ of the correcting term for $P^{\prime}{ }_{s L} \ldots \ldots \ldots . \ldots 49$

30. Polynomial coefficients $W(1)-W(6)$ of the correcting term for $P^{\prime} s y \ldots \ldots 9$

31. Polynomial coefficients $A(1)-A(8)$ of $P_{250}(T) \ldots \ldots \ldots \ldots$

32. Polynomial coefficients $A(1)-A(10)$ of $P_{322}(T) \ldots \ldots \ldots \ldots$

33. Polynomial coefficients $A(1)-A(10)$ of $P_{400}(T) \ldots \ldots \ldots \ldots \ldots$

34. Polynomial coefficients $A(1)-A(10)$ of $P_{500}(T) \ldots \ldots \ldots \ldots 2$

35. Polynomial coefficients $A(1)-A(10)$ of $P_{800}(\mathrm{~T}) \ldots \ldots \ldots 2$

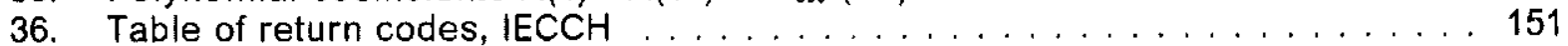

37. TSO-procedures in the dataset INR105.AQUA.CLIST . . . . . . . . . . . 154

38. Thermal property labels "KLASSE" used in AQUA.DATA . . . . . . . . . 156 


\subsection{Introduction}

Water is the most commonly used working substance in chemistry and engineering. It is also the cooling medium of the pressurized and boiling water nuclear reactors. Therefore a solid knowledge of the thermophysical properties of the water in the range of possible temperatures, pressures and densities is essential to calculate hazardous events - which may emerge once in a while in a normally operating reactor.

In the Institut für Neutronenphysik und Reaktortechnik we are presently developing a thermohydrodynamical code, IVA3, $/ 21 /$ to be able to calculate the consequences of some hypothesized reactor failures. To supply IVA3 with the thermophysical properties of the water we adopted the H.G.K.-equation of state, developed in the years 1981-84 by Haar, Gallagher and Kell, $/ 10 /$ and recommended by the IAPS ( s. /12/). The H.G.K.-equation of state calculates the various thermal properties via a continuous Helmholtz free energy function, which is defined over the whole range of the fluid states of water and is fitted to the available experimental data.

The corresponding computer code described in $/ 10 /$ has some drawbacks and doesn't fit well to our IVA3-code. Item 1 : the code doesn't describe the properties viscosity, thermal conductivity and surface tension. Item $2:$ the description of the properties in the mixed state is unphysical. Item 3: IVA3 needs the thermophysical properties as functions of the temperature and pressure, whereas the H.G.K.-code supplies them as functions of the temperature and density. Although there is a modul in the H.G.K.-code, DFIND, which turns temperature-pressure states of water into corresponding temperature-density ones, yet DFIND consumes too much time during the iteration - needed for the conversion of these states.

In the following the code AQUA will be presented.

AQUA is an extension of the H.G.K.-code, modified to suit our special conditions. In the largest part of the temperature-density domain AQUA returns the same thermophysical property values as the H.G.K.-code, but in the unstable part of the two phase region the H.G.K.-properties are substituted with physically meaningful two phase state values.

AQUA calculates at a given $(T, \rho)$ state besides of the pressure also the following thermal properties of the water:

- $S$, the specific entropy,

- the energy functions

$U$, the specific energy,

$H$, the specific enthalpy,

$A$, the specific free energy,

$G$, the specific free enthalpy ,

- the pressure derivatives $\partial P / \partial \rho$ and $\partial P / \partial T$,

- the heat capacities $C_{P}$ and $C_{y}$,

- the derivatives $\partial H / \partial P$ and $\partial \rho / \partial T$

- the viscosity $\eta$ and the thermal conductivity $\dot{\lambda}$,

- the Joule Thomson coefficient, $\partial T / \partial P \mid H$,

- the surface tension, the velocity of sound and the PrandtI number.

AQUA calculates the properties also as temperature-pressure dependent functions. It incorporates additional functions and procedures to speed up the $(T, P) \rightarrow(T, \rho)$ conversion.

AQUA has a set of routines ( SAET01, WASSER, DAMPF, RDRDP, VD1) which serve to adjust AQUA to the conditions of the code IVA3.

AQUA needs and returns all the properties in SI-units.

AQUA calculates reasonable property-values if the temperature exceeds $260.00 \mathrm{~K}$ and if the density remains below $1200 \mathrm{~kg} / \mathrm{m}^{3}$. Trying to convert pressures to densities above $5000 \mathrm{~K}$ may lead to dissatisfaction. 



\subsection{A short description of the H.G.K.-code}

\subsection{The Helmholtz function}

Haar, Gallagher and Kell developed and tested - in close cooperation with the International Association for the Properties of Steam (IAPS) - an analytic description for the thermal and caloric properties of the water, $/ 10 /$ to replace the standard tables used formerly. The resulting properties are the Provisional IAPS Formulation 1982 for the Thermodynamic Properties of Ordinary Water Substance for Scientific and General Use.

Haar, Gallagher and Kell constructed their algorithm by developing a mathematical description for the Helmholtz function ( alias free energy) $A(\rho, T)$. Using Eq. [A.4 A.5] one can develop from $A$ all the needed thermal and caloric properties (s. Appen$\operatorname{dix}$ A, "Some thermal relations").

The description of the Helmholtz function consist from a simple base function to describe the liquid and supercritical states, of an additional residual function for a proper fitting in the mixed states and of a solely temperature-dependent term for the ideal gas states.

$$
A(\rho, T)=A_{\text {base }}(\rho, T)+A_{\text {residual }}(\rho, T)+A_{\text {idealgas }}(T) \quad .
$$

\subsection{The base function}

is a simple analytic equation

$$
\begin{aligned}
A_{\text {base }}(\rho, T)=R_{\text {gas }} \cdot T & {\left[-\ln (1-y)-\frac{\beta-1}{1-y}+\frac{\alpha+\beta+1}{2 \cdot(1-y)^{2}}+\right.} \\
& \left.+4 y\left(\frac{\bar{B}}{b}-\gamma\right)-\frac{\alpha-\beta+3}{2}+\ln \left(\frac{\rho \cdot R_{\text {gas }} \cdot T}{P_{0}}\right)\right]
\end{aligned}
$$

In the above eq.

$$
y=\frac{b(T) \cdot \rho}{4}
$$

is a dimensionless density,

$$
b=b_{1}-b_{2} \cdot \ln \frac{T_{0}}{T}+\sum_{j=3}^{7} b_{j} \cdot\left(\frac{T_{0}}{T}\right)^{j-2}
$$

is the 2nd virial and

$$
\bar{B}=B_{1}+\sum_{j=3}^{7} B_{j} \cdot\left(\frac{T_{0}}{T}\right)^{j-2}
$$

is the excluded volume. The pressure and temperature coefficients are

$$
P_{0}=1.01325 \mathrm{bar} \quad \text { resp. } \quad T_{0}=647.073 \mathrm{~K}
$$


and the greek letters mean

$$
\alpha=11 . \quad, \quad \beta=133 / 3 \quad \text { and } \quad \gamma=3.5
$$

The coefficients of the Eq.s $[2.4],[2.5]$ are the following ones:

\begin{tabular}{|c|c|c|}
\hline Table 1. The coeficients of the base function & $\boldsymbol{B}_{j}\left(\mathbf{c m}^{\mathbf{3}} / \mathbf{g}\right)$ \\
\hline $\boldsymbol{b}_{\boldsymbol{i}}\left(\mathbf{c m}^{\mathbf{3}} / \mathbf{g}\right)$ & $\mathbf{j}$ & 1.1278334 \\
\hline 0.7478629 & 1 & 0.0 \\
\hline-0.3540782 & 2 & -0.5944001 \\
\hline 0.0 & 3 & -5.010996 \\
\hline 0.0 & 4 & 0.0 \\
\hline 0.007159876 & 5 & 0.63684256 \\
\hline 0.0 & 6 & 0.0 \\
\hline-0.003528426 & 7 & \\
\hline
\end{tabular}

Note: The descriptions given in $/ 10 /$ for the 2 nd virial and for the excluded volume are not in accordance with those, used in the routine BB. I describe here the properties in accordance with the routine BB.

\subsection{The ideal gas function}

has the following form :

$$
\begin{gathered}
A_{\text {idealgas }}(T)=-R_{\text {gas }} \cdot T\left[1+\left(\frac{C_{1}}{T_{R}}+C_{2}\right) \ln \left(T_{R}\right)+\sum_{i=3}^{18} C_{l} \cdot T_{R}{ }^{i-6}\right] \\
\text { with } \quad T_{R} \equiv T / 100 \mathrm{~K} .
\end{gathered}
$$

The $\mathrm{C}-\mathrm{s}$ are given in the table below.

\begin{tabular}{|c|c|c|c|}
\hline \multicolumn{5}{|c|}{ Table 2. The coeficients of the ideal gas function } \\
\hline $\mathbf{j}$ & $\boldsymbol{C}_{\boldsymbol{i}}$ & $\mathrm{J}$ & $\boldsymbol{C}_{\boldsymbol{i}}$ \\
\hline 1 & 19.730271018 & 10 & $4.1238460633 \cdot 10^{-3}$ \\
\hline 2 & 20.9662681977 & 11 & $-2.7929052852 \cdot 10^{-4}$ \\
\hline 3 & -0.483429455355 & 12 & $1.4481695261 \cdot 10^{-6}$ \\
\hline 4 & 6.05743189245 & 13 & $-5.6473658748 \cdot 10^{-7}$ \\
\hline 5 & 22.56023885 & 14 & $1.6200446 \cdot 10^{-8}$ \\
\hline 6 & -9.87532442 & 15 & $-3.303822796 \cdot 10^{-10}$ \\
\hline 7 & -4.3135538513 & 16 & $4.51916067368 \cdot 10^{-12}$ \\
\hline 8 & $4.58155781 \cdot 10^{-1}$ & 17 & $-3.70734122708 \cdot 10^{-14}$ \\
\hline 9 & $-4.7754901883 \cdot 10^{-2}$ & 18 & $1.37546068238 \cdot 10^{-16}$ \\
\hline
\end{tabular}




\subsection{The residual function}

has two parts :

$$
\begin{aligned}
A_{\text {resi }}(\rho, T) & =\sum_{i=1}^{36} \frac{g_{i}}{k(i)}\left(\frac{647.073}{T}\right)^{(i)}\left[1-e^{-\rho}\right]^{k(i)}+ \\
& +\sum_{i=37}^{40} g_{i} \delta_{i}^{k(i)} \cdot \exp \left(-\alpha_{i} \delta_{i}^{k(i)}-\beta_{i} \tau_{i}^{2}\right)
\end{aligned}
$$

The first 36 terms are needed to fit the description to the experimental data in the low temperature mixed states, the remainig 3 terms correct the function in the vicinity of the critical point.

$$
\delta_{i}=\frac{\rho-\rho_{i}}{\rho_{i}} \quad \text { and } \quad \tau_{i}=\frac{T-T_{i}}{T_{i}}
$$

are reduced densities and temperatures. The coefficients used by the residual function are given in the following tables:

\begin{tabular}{|c|c|c|c|c|c|c|c|c|c|}
\hline \multicolumn{2}{|c|}{ Table 3. The exponents $\mathbf{i ( 1 )}-\mathbf{i}(\mathbf{4 0})$ of the residual function } \\
\hline 0 & 0 & 0 & 0 & 1 & 1 & 1 & 1 & 2 & 2 \\
\hline 2 & 2 & 3 & 3 & 3 & 3 & 4 & 4 & 4 & 4 \\
\hline 5 & 5 & 5 & 5 & 6 & 6 & 6 & 6 & 8 & 8 \\
\hline 8 & 8 & 2 & 2 & 0 & 4 & 2 & 2 & 2 & 4 \\
\hline
\end{tabular}

Table 4. The exponents $k(1)-k(40)$ of the residual function

\begin{tabular}{|l|l|l|l|l|l|l|l|l|l|}
\hline 2 & 3 & 5 & 7 & 2 & 3 & 5 & 7 & 2 & 3 \\
\hline 5 & 7 & 2 & 3 & 5 & 7 & 2 & 3 & 5 & 7 \\
\hline 2 & 3 & 5 & 7 & 2 & 3 & 5 & 7 & 2 & 3 \\
\hline 5 & 7 & 1 & 4 & 4 & 4 & 0 & 2 & 0 & 0 \\
\hline
\end{tabular}

Table 5. The coefficients of the near-critical description in the residual function

\begin{tabular}{|c|c|c|c|c|}
\hline $\mathbf{1}$ & $\mathbf{3 7}$ & $\mathbf{3 8}$ & $\mathbf{3 9}$ & $\mathbf{4 0}$ \\
\hline$\alpha_{i}$ & 34. & 40. & 30. & 1050. \\
\hline$\beta_{i}$ & 20000 & 20000 & 40000 & 25. \\
\hline$\rho_{i}$ & 0.319 & 0.319 & 0.319 & 1.550 \\
\hline$T_{i}$ & 640. & 640. & 641.6 & 270. \\
\hline
\end{tabular}




\begin{tabular}{|c|c|c|c|c|}
\hline \multicolumn{6}{|l}{ Table 6. The coefficients $\mathbf{g}(\mathbf{1}) \mathbf{g}(\mathbf{4 0})$ of the residual function } \\
\hline$-.53062968529023 \cdot 10^{3}$ & $.22744901424408 \cdot 10^{4}$ & $.78779333020687 \cdot 10^{3}$ & $-.69830527374994 \cdot 10^{2}$ & $.17863832875422 \cdot 10^{5}$ \\
\hline$-.39514731563338 \cdot 10^{5}$ & $.33803884280753 \cdot 10^{5}$ & $-.13855050202703 \cdot 10^{5}$ & $-.25637436613260 \cdot 10^{6}$ & $.48212575981415 \cdot 10^{5}$ \\
\hline$-.34183016969660 \cdot 10^{5}$ & $.12223156417448 \cdot 10^{6}$ & $.11797433655832 \cdot 10^{7}$ & $-.21734810110373 \cdot 10^{7}$ & $.10829952168620 \cdot 10^{7}$ \\
\hline$-.25441998064049 \cdot 10^{6}$ & $-.31377774947767 \cdot 10^{7}$ & $.52911910757704 \cdot 10^{7}$ & $-.13802577177877 \cdot 10^{7}$ & $-.25109914369001 \cdot 10^{6}$ \\
\hline $.46561826115608 \cdot 10^{7}$ & $-.72752773275387 \cdot 10^{7}$ & $.41774246148294 \cdot 10^{6}$ & $.14016358244614 \cdot 10^{7}$ & $-.31555231392127 \cdot 10^{7}$ \\
\hline $.47929666384584 \cdot 10^{7}$ & $.40912664781209 \cdot 10^{6}$ & $-.13626369388386 \cdot 10^{7}$ & $.69625220862664 \cdot 10^{5}$ & $-.10834900096447 \cdot 10^{7}$ \\
\hline$-.22722827401688 \cdot 10^{6}$ & $.38365486000660 \cdot 10^{6}$ & $.68833257944332 \cdot 10^{4}$ & $.21757245522644 \cdot 10^{5}$ & $-.26627944829770 \cdot 10^{4}$ \\
\hline$-.70730418082074 \cdot 10^{5}$ & -.225 & -1.68 & 0.055 & -93.0 \\
\hline
\end{tabular}


The following figures display the contributions of the basic, ideal and residual functions to the total pressure respective to the total heat capacity at the boiling point and at the temperatures $500 \mathrm{~K}$ and $800 \mathrm{~K}$.
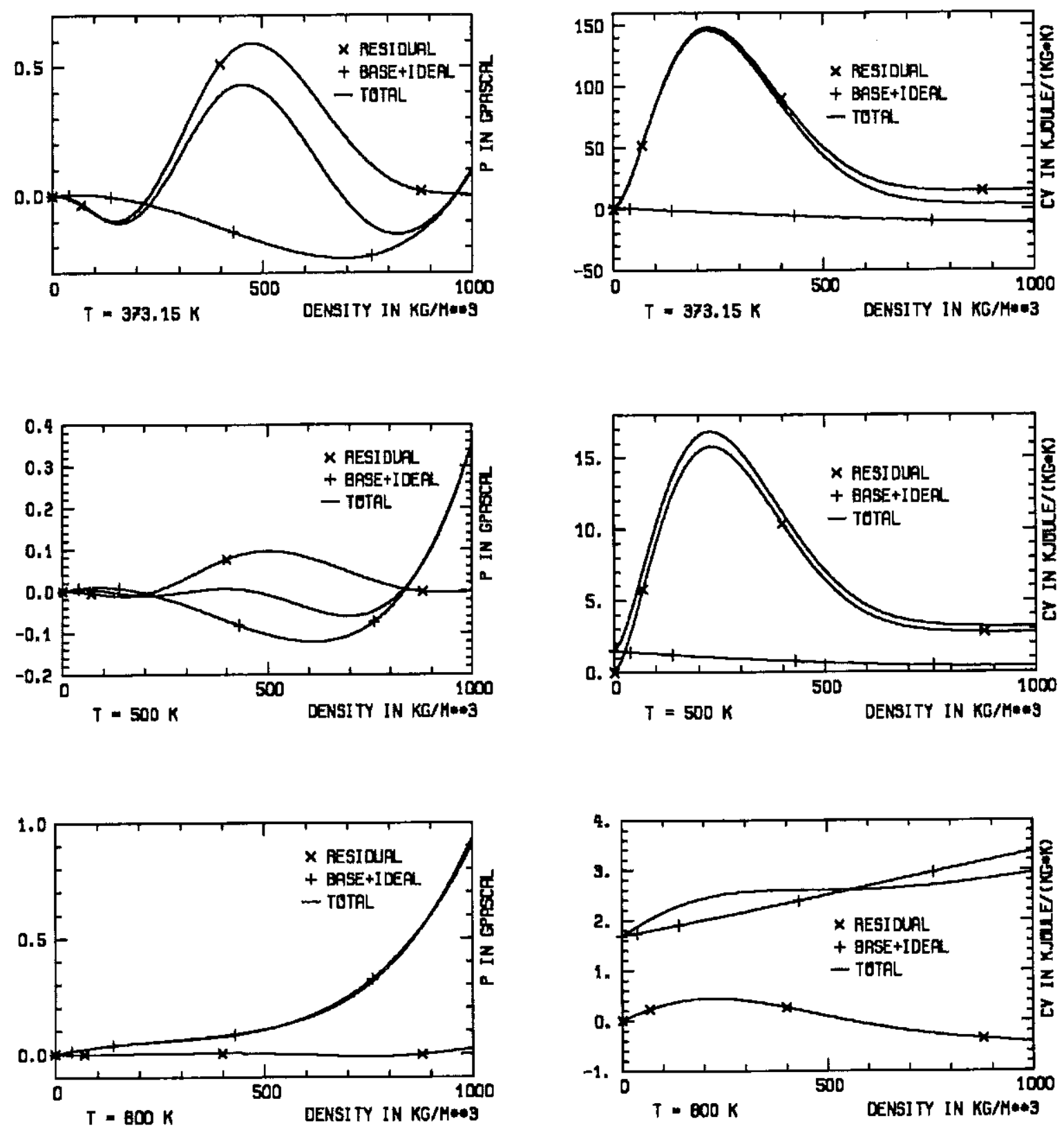

Figure 3 on page 14 displays the water pressure calculated by the H.G.K.-code as a surface of the temperature and the density.

\subsection{The critical data}

The H.G.K.-code uses the following values as critical data of the water : 


$$
T_{c}=647.126 \mathrm{~K}, P_{c}=22.0549 \mathrm{MPa}, \rho_{c}=322 \mathrm{~kg} / \mathrm{m}^{3} \text {. }
$$

\subsection{The validity domain}

Haar and Gallagher, /13/ give - in accordance with the IAPS - the the following validity limits for the H.G.K.-code :

$$
\begin{gathered}
273 K \leq T \leq 1273 K \\
P \leq 1500 \mathrm{MPa}
\end{gathered}
$$

Note: The density should be lower than $1200 \mathrm{~kg} / \mathrm{m}^{3}$ especially at low temperatures to avold getting negative values for the heat capacities and the pressure derivatives $\partial P / \partial T$ ! 


\subsection{Transport properties of the water.}

For the description of the viscosity, of the thermal conductivity and of the surface tension AQUA uses the IAPS-82 equations, recommended on the VIII. International Conference on the Properties of Steam /9/ ( see also /10/, /11/ and /16/).

\section{Reduced variables}

In describing the transport properties of the water it is convenient to introduce the following reduced variables :

$$
\begin{array}{lll}
\tilde{r} \equiv \frac{\rho}{\rho_{k}} & , & \rho_{k}=317.763 \mathrm{~kg} / \mathrm{m}^{3} \\
\tilde{t} \equiv \frac{T}{T_{k}} & , & T_{k}=647.27 \mathrm{~K} \\
\tilde{p} \equiv \frac{P}{P_{k}} & , & P_{k}=22.115 \mathrm{MPa}
\end{array}
$$

along with the "ideal temperature" :

$$
T_{\text {id }} \equiv \frac{P_{k}}{R_{\text {gas }} \cdot \rho_{k}}=150.7965 \mathrm{~K}
$$

\subsection{Viscosity}

With the reduced variables the viscosity can be described as

$$
\eta(\rho, T) \equiv \eta_{0}(T) \cdot \exp \left[\tilde{r} \cdot \sum_{j=0}^{5} \sum_{m=0}^{4} B_{j m} \cdot\left(\frac{1}{\tilde{t}}-1\right)^{j} \cdot(\tilde{r}-1)^{m}\right]
$$

with the temperature-dependent amplitude :

$$
\eta_{0}(T) \equiv \frac{10^{-6} \cdot \sqrt{\tilde{t}}}{\sum_{i=0}^{3} \frac{A_{1}}{\tilde{t}^{\prime}}}
$$

The coefficients of the amplitude are

$$
\mathrm{A} 0=0.0181583, \mathrm{~A} 1=0.0177624, \mathrm{~A} 2=0.0105287, \mathrm{~A} 3=-0.0036744 .
$$

For the B-s in Eq. [3.3] see the table supplied. 


\begin{tabular}{|c|c|c|c|c|c|}
\hline \multicolumn{7}{|c|}{ Table 7. The coefficients B $(\mathbf{j}, \mathbf{m})$ of the viscosity } \\
\hline $\mathbf{j}$ & $\mathbf{m}=\mathbf{0}$ & $\mathbf{1}$ & $\mathbf{2}$ & $\mathbf{3}$ & $\mathbf{4}$ \\
\hline 0 & 0.501938 & 0.235622 & -0.274637 & 0.145831 & -0.0270448 \\
\hline 1 & 0.162888 & 0.789393 & -0.743539 & 0.263129 & -0.0273093 \\
\hline 2 & -0.130353 & 0.673665 & -0.959456 & 0.347247 & -0.0267758 \\
\hline 3 & 0.907919 & 1.207552 & -0.687343 & 0.213486 & -0.08 \\
\hline 4 & -0.551119 & 0.0670665 & -0.497089 & 0.100754 & 0.0602253 \\
\hline 5 & 0.146543 & -0.084337 & 0.195286 & -0.032932 & -0.0202595 \\
\hline
\end{tabular}

\subsection{Thermal conductivity}

The thermal conductivity of all fluids reaches in the vicinity of the critical temperature anomalously high values (s. e. g. /4/). The following figure of Sengers - presented in $116 /$ - shows the thermal conductivity in the water on isobars, nearing the critical one from the high-pressure side. The data points - compared here with the corresponding IAPS calculations - are measurements of Sirota and al., /7/.

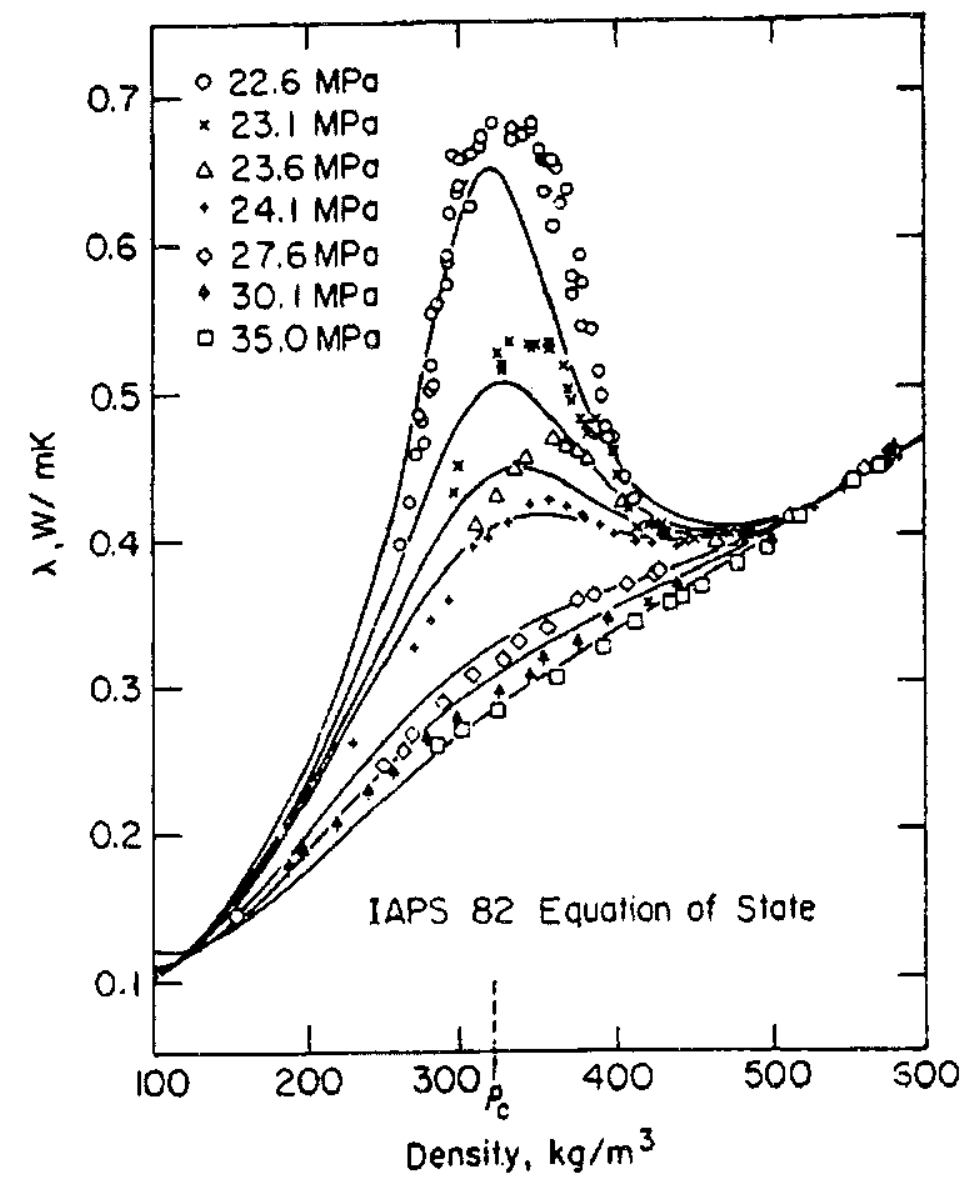

Figure 1. Thermal conductivity of the steam in the critical region as a function of density at constant pressures 
Cosequently Basu and Sengers proposed a two-termed description for the thermal conductivity. The first - regular - term of this description has the same form as the viscosity, the second term describes the near critical inflation of the thermal conductivity :

$$
\lambda(\rho, T) \equiv \lambda_{R}(\rho, T)+\Delta \lambda(\rho, T) .
$$

The regular term is

$$
\lambda_{R}(\rho, T) \equiv \lambda_{0}(T) \cdot \exp \left[\tilde{r} \cdot \sum_{i=0}^{4} \sum_{n=0}^{5} b_{i n} \cdot\left(\frac{1}{\tilde{t}}-1\right)^{i} \cdot(\tilde{r}-1)^{n}\right]
$$

with the amplitude

$$
\lambda_{0}(T) \equiv \frac{\sqrt{\tilde{t}}}{\sum_{k=0}^{3} \frac{a_{k}}{\tilde{t}^{k}}}
$$

The coefficients of the amplitude are

$$
\mathrm{a} 0=2.02223, \mathrm{a} 1=14.11166, \mathrm{a} 2=5.25597, \mathrm{a} 3=-2.01870 \quad .
$$

The b-s of the Eq. [3.6] are tabulated as follows :

Table 8 . The coefficients $b(i, n)$ of the thermal conductivity

\begin{tabular}{|c|c|c|c|c|c|}
\hline $\mathbf{n}$ & $\mathbf{i}=\mathbf{0}$ & $\mathbf{1}$ & $\mathbf{2}$ & $\mathbf{3}$ & $\mathbf{4}$ \\
\hline 0 & 1.329304600 & 1.7018363 & 5.2246158 & 8.7127675 & -1.8525999 \\
\hline 1 & -0.404524370 & -2.2156845 & -10.124111 & -9.5000611 & 0.9340469 \\
\hline 2 & 0.244094900 & 1.6511057 & 4.9874687 & 4.3786606 & 0.0 \\
\hline 3 & 0.018660751 & -0.76736002 & -0.27297694 & -0.91783782 & 0.0 \\
\hline 4 & -0.129610680 & 0.37283344 & -0.43083393 & 0.0 & 0.0 \\
\hline 5 & 0.044809953 & -0.11203160 & 0.13333849 & 0.0 & 0.0 \\
\hline
\end{tabular}

The nonregular term of the thermal conductivity is

$$
\begin{aligned}
& \Delta \lambda(\rho, T) \equiv \\
& \frac{C}{\eta(\rho, T)} \cdot\left(\frac{\tilde{t}}{\tilde{r}} \cdot \frac{\partial \tilde{p}}{\partial \tilde{t}}\right)^{2} \cdot\left(\chi_{T}\right)^{\omega} \cdot \sqrt{\tilde{r}} \cdot \exp \left[-A \cdot(\tilde{t}-1)^{2}-B \cdot(\tilde{r}-1)^{4}\right]
\end{aligned}
$$

Sengers call the property

$$
\chi_{T} \equiv \tilde{r} \cdot \frac{\partial \tilde{r}}{\partial \tilde{p}}
$$

"reduced isothermal compressibility". Actually, $\chi_{T}$ is the factor of the nonregular term, which inflates the thermal conductivity, since 


$$
\frac{\partial \tilde{r}}{\partial \tilde{p}} \propto \frac{1}{\partial P / \partial \rho}
$$

turns infinite at the critical point.

With the relation

$$
\frac{\partial \tilde{p}}{\partial \tilde{r}}=\frac{\rho_{k}}{P_{k}} \cdot \frac{\partial P}{\partial \rho}
$$

$\chi_{\tau}$ can be converted to

$$
\chi_{T}=\frac{P_{k}}{\rho_{k}^{2}} \cdot \frac{\rho}{\partial P / \partial \rho}=\frac{\tilde{r}}{\left(T / T_{i d}\right) \cdot P_{\rho}^{0}}
$$

and the pressure derivative in Eq. [3.8] to

$$
\frac{\tilde{t}}{\tilde{r}} \cdot \frac{\partial \tilde{p}}{\partial \tilde{t}}=\frac{T}{\tilde{r} \cdot P_{k}} \frac{\partial P}{\partial T}=\frac{T}{T_{i d}} \cdot P_{T}^{0}
$$

The coefficients of the Eq. [3.8] are

$$
A=18.66, B=1.0, C=3.7711 \cdot 10^{-8} \mathrm{~Pa}^{\star} \mathrm{sec} * W /\left(K^{\star} \mathrm{m}\right), \omega=0.4678 .
$$

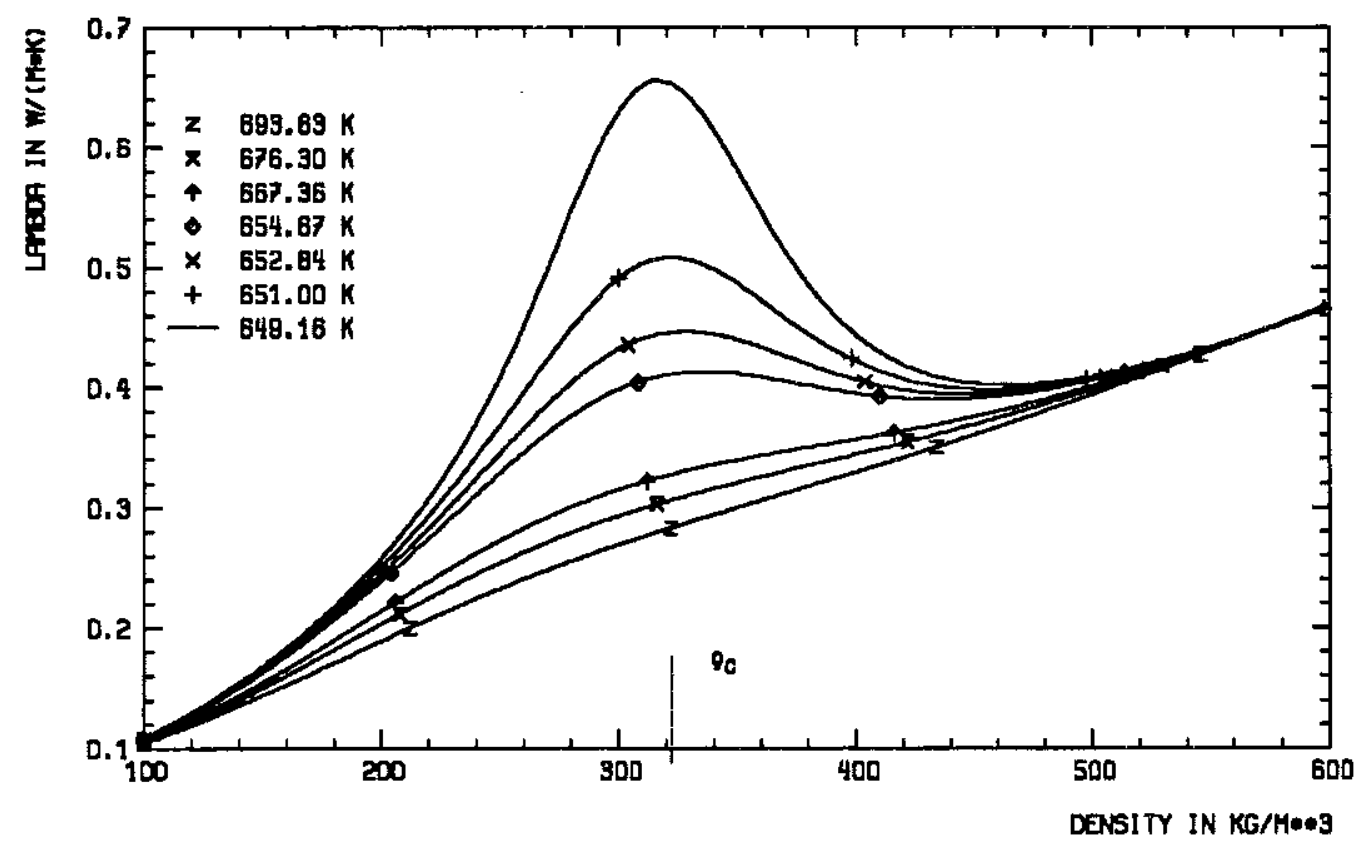

Figure 2. Thermal conductivity of the water on supercritical isotherms

Figure 2 shows the thermal conductivity on some supercritical isotherms. The isothermal pressures at the critical density are:

\begin{tabular}{|c|c|c|c|c|c|c|c|}
\hline $\mathrm{T} / \mathrm{K}$ & 693.63 & 676.36 & 667.36 & 654.67 & 652.84 & 651.00 & 649.16 \\
\hline $\mathrm{P} 322 / \mathrm{MPa}$ & 35.0 & 30.1 & 27.6 & 24.1 & 23.6 & 23.1 & 22.6 \\
\hline
\end{tabular}




\subsection{Surface tension}

According to the IAPS Working Group III, 1975, /9/ the surface tension of the water can be described as

$$
\sigma(T)=B \cdot\left(\frac{T_{q}-T}{T_{q}}\right)^{\mu} \cdot\left(1+b \frac{T_{q}-T}{T_{c}}\right)
$$

with $T_{q}=647.15 \mathrm{~K}, \quad \mathrm{~B}=0.2358 \mathrm{~N} / \mathrm{M}, \quad \mathrm{b}=-0.625$ and $\mu=1.256$.

Note: AQUA uses as well in Eq. [3.1] as in Eq. [3.12] as critical temperature the now usually accepted value $T_{c}=647.126 \mathrm{~K}$. An attempt, to replace in Eq. [3.1] $\rho_{k}=$ $317.763 \mathrm{~kg} / \mathrm{m}^{3}$ with the correct value $\rho_{c}=322 . \mathrm{kg} / \mathrm{m}^{3}$ resulted in a drastic decrease of the thermal conductivity of the water at high densities and had been given up. 


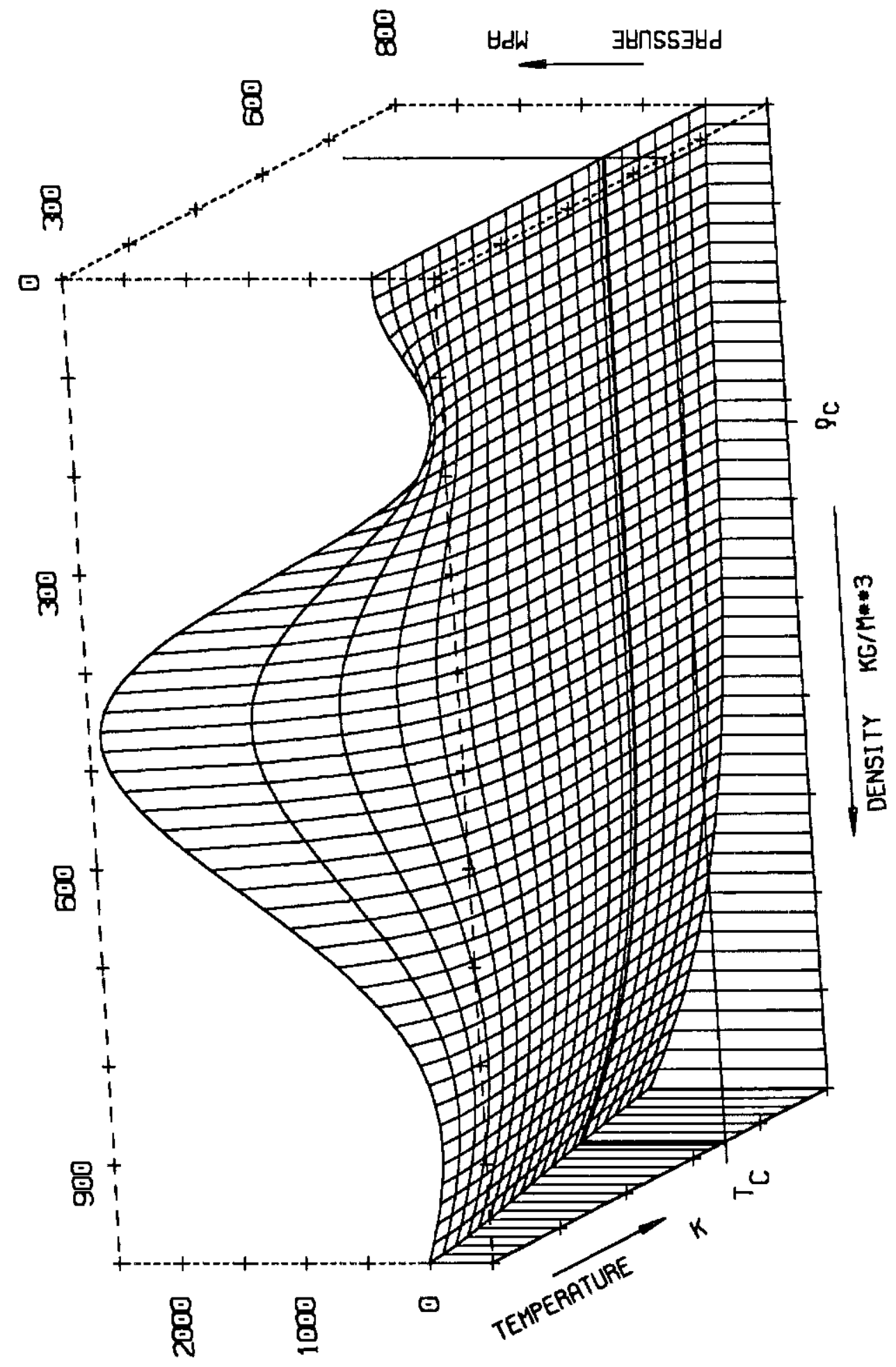

Figure 3, Pressure surface of the water, H.G.K.-code 


\subsection{Thermal properties in the two phase region}

\subsection{Thermal states of the subcritical water}

At temperatures above the melting and below the critical Point water can be present not only as liquid or vapor but also as a mixture of both of them. This part of the subregion, the two phase region, or the "saturation dome" is bounded by the "saturation line ", which is a collection of the saturated liquid and the saturated vapor states. Outside the saturation dome the water is either a compressed liquid or an expanded vapor.

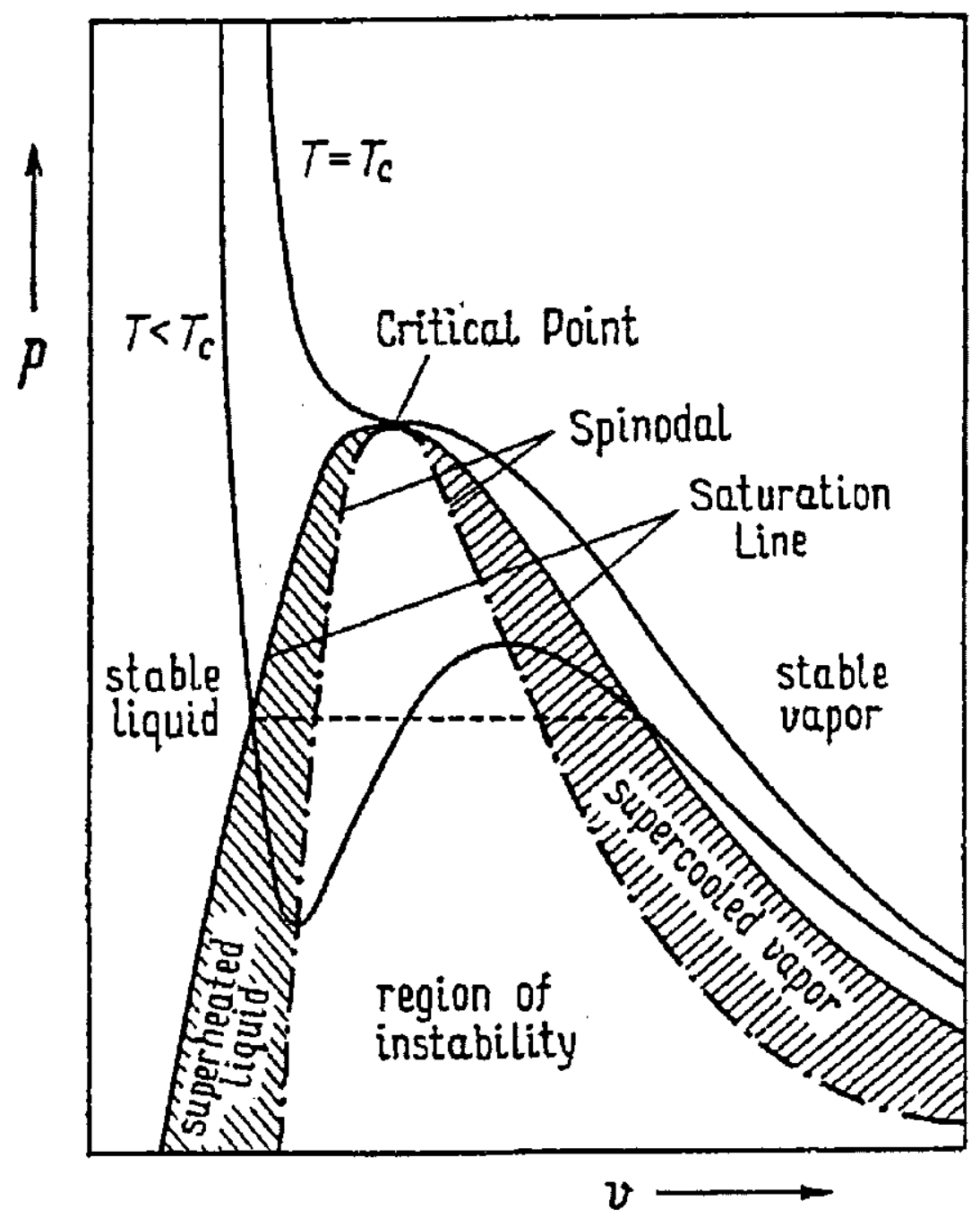

Figure 4. Sketch of $P, V$ diagram with saturation and spinodal lines. $V=1 / \rho$

Normally an isothermal expansion of the water beyond the saturated density ( $\rho=\rho_{L}$ ) results in vaporizing the water. A part of the water - as large, as needed to restore the vapor pressure, $P^{\times}$(dashed line on the sketch ) - turns into vapor, to suffice the equilibrium conditions : 


$$
\begin{gathered}
P^{\times}(T)=P\left(\rho_{L}, T\right)=P\left(\rho_{V}, T\right), \\
G\left(\rho_{L}, T\right)=G\left(\rho_{V}, T\right),
\end{gathered}
$$

Under particular circumstances ( rapid expansion, very clean water) one can expand the saturated water to a distinct degree, without turning it into vapor and reach a state with a pressure below the $P^{x}$ ( for a detailed description $s$ e. g. /15/). This expanded water is known as superheated (liquid) water. The superheated water is metastable : it tends to turn into a mixture of saturated liquid and vapor with the equilibrium pressure $P^{\times}$. The theoretical limit of the expasion of the liquid water is given by the highest density value on the isotherm, for which it holds:

$$
\frac{\partial P}{\partial \rho}(T, \rho)=0
$$

and is known as the (liquid) spinodal density, $\rho_{S L}$.

Similarly normal compression of the saturated vapor results in turning a part of it into liquid water. By carefully chosen conditions the vapor also can be compressed in some extent above the saturated vapor density without developing water droplets in it and the vapor can reach an overheated state with a pressure higher as $P^{\times}$. Again, the limiting density is the smallest density, which fulfills Eq. [4.3] and is called the (vapor ) spinodal density, $\rho_{s v}$.

On the remaining part of the isotherm - lying between the spinodal densities ( region of instability on Figure 4) - the water can occur only as a mixture of saturated liquid and vapor.

\subsection{Water properties in the region of instability}

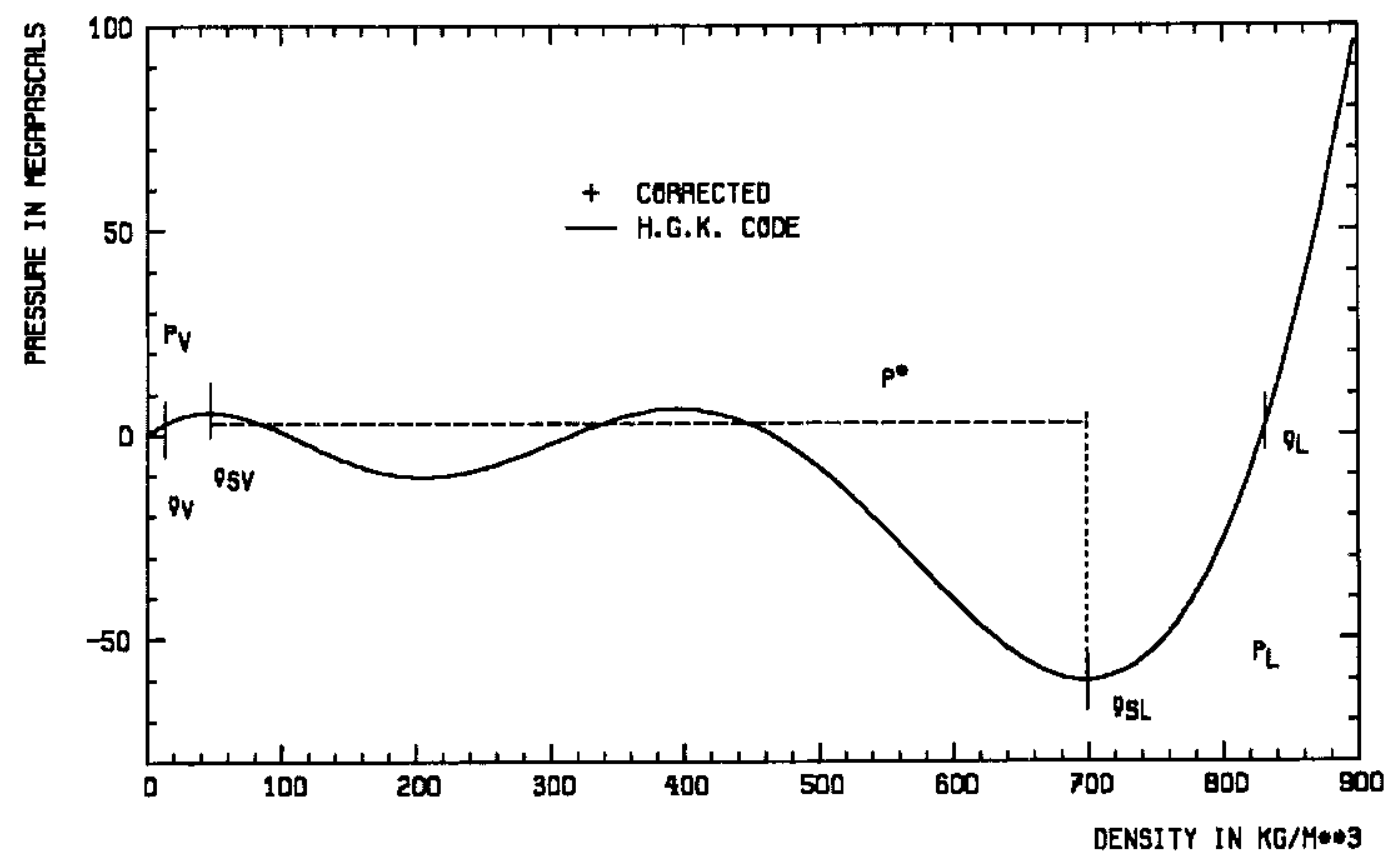

Figure 5. Pressure of the water in the two phase region. $T=500 \mathrm{~K}$ 
Figure 5 shows the water pressure along a typical isotherm as calculated by the codes H.G.K. resp. AQUA.

The code AQUA follows the pressure description of the H.G.K.-code from zero density till the density of the vapor-spinodal and from the liquid spinodal onward. But in the instable region, between the spinodal points AQUA describes the water as a two phase mixture :

$$
\begin{aligned}
P(\rho, T) & =P^{\times}(T) \\
\frac{\partial P}{\partial T}(\rho, T) & =\frac{d P^{\times}(T)}{d T} \\
\frac{\partial P}{\partial \rho}(\rho, T) & =0
\end{aligned}
$$

(s. dashed line on Figure 5 ). A 3D-diagram of the pressure of the water - as AQUA calculates it - is depicted on Figure 14 on page 24.

Note: AQUA still idealizes the progress of the water pressure along the isotherm. In reality no liquid can be streched to reach $\rho_{S L}$ and no vapor can be compressed to have the density $\rho_{s v}$. The limiting values of the superheated pressure in the water can be seen on Figure 6 . The measured points are from $/ 3 /$.

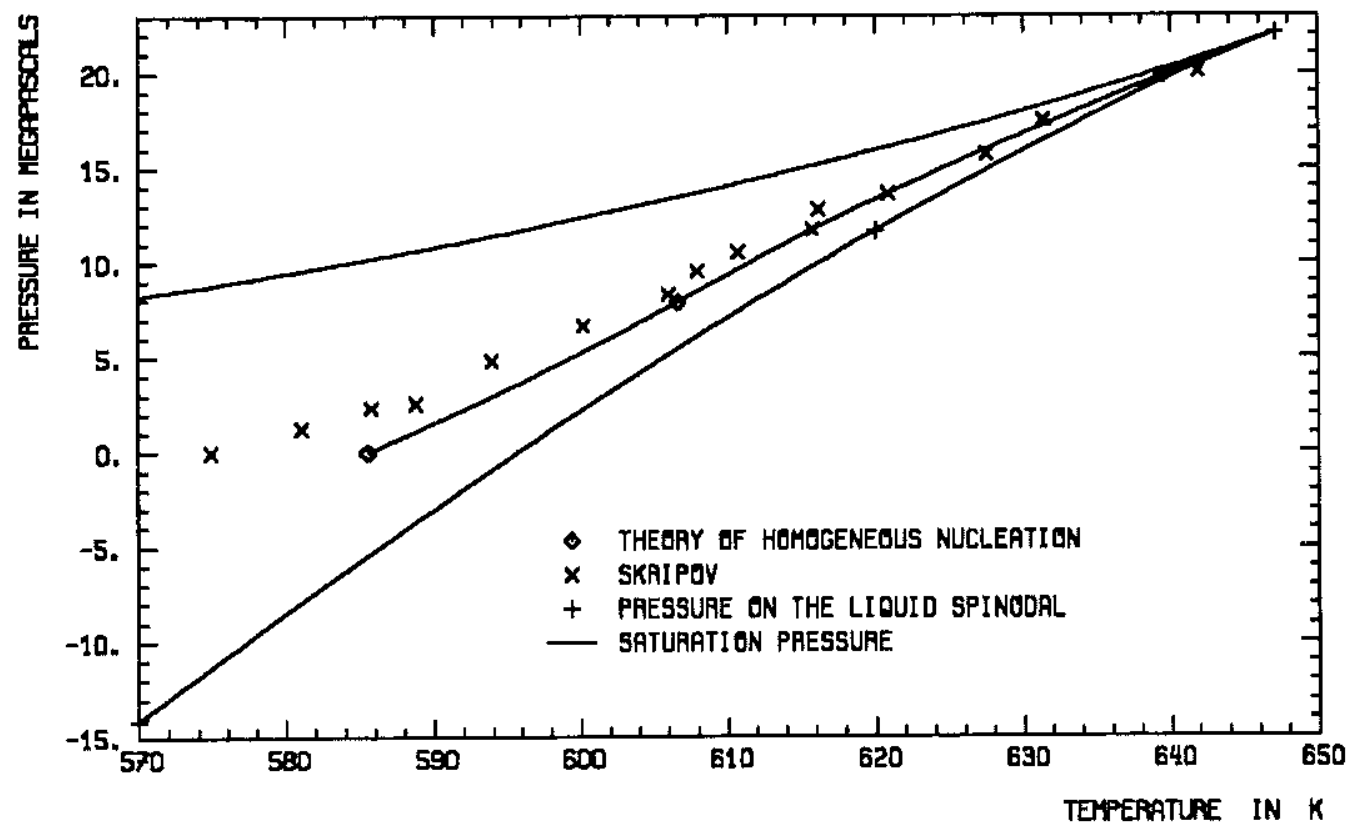

Figure 6. Water pressures in the superheated liquid state

The Figure 7 on page 18 shows the free enthalpy of the water along the same isotherm. Here again outside of the region of instability AQUA and H.G.K. calculate identical values, between the spinodal points $A Q U A$ sets $G$ equal to the common free enthalpy value:

$$
G(\rho, T)=G_{L}(T)=G_{V}(T)
$$




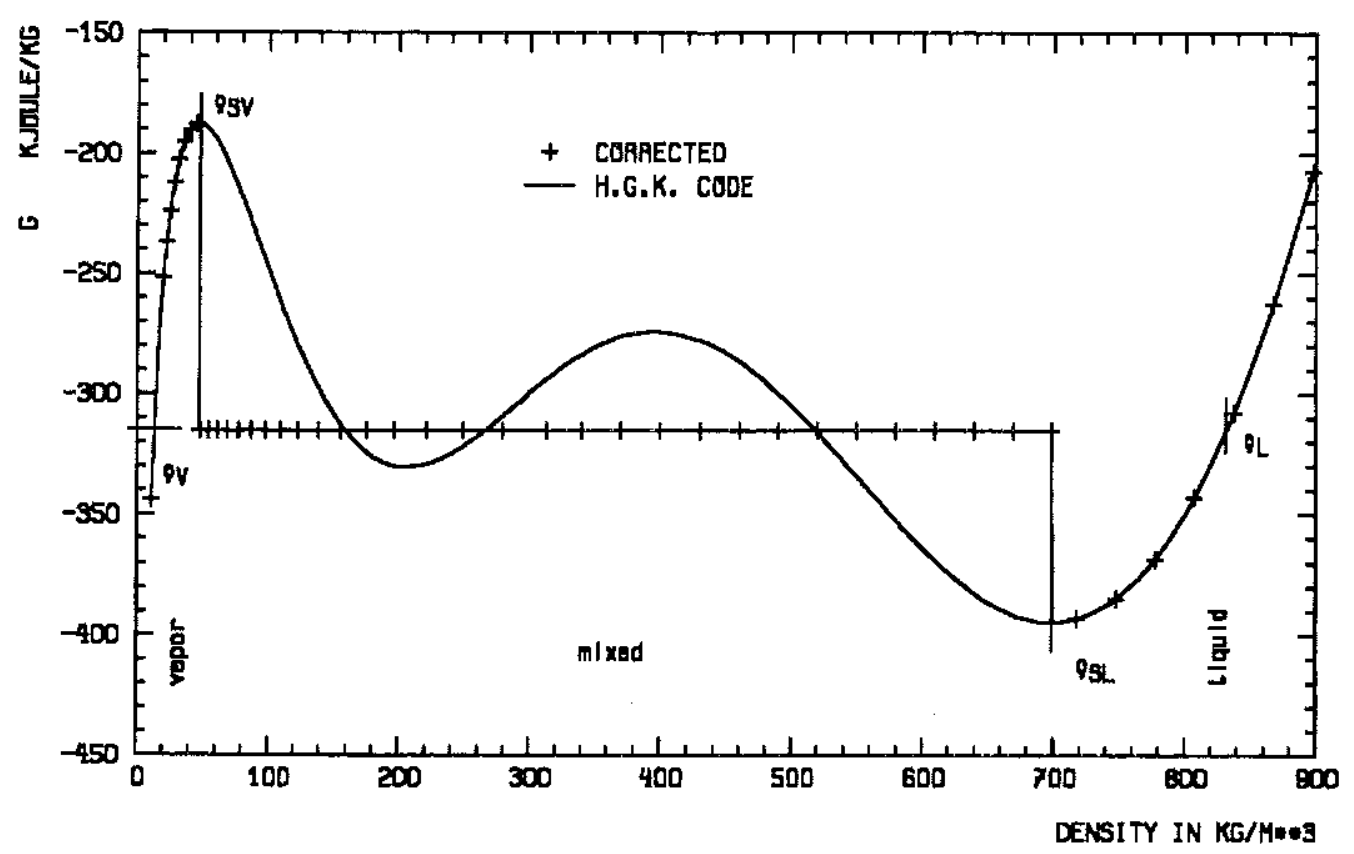

Figure 7. Free enthalpy of the water in the two phase region. $\mathrm{T}=500 \mathrm{~K}$

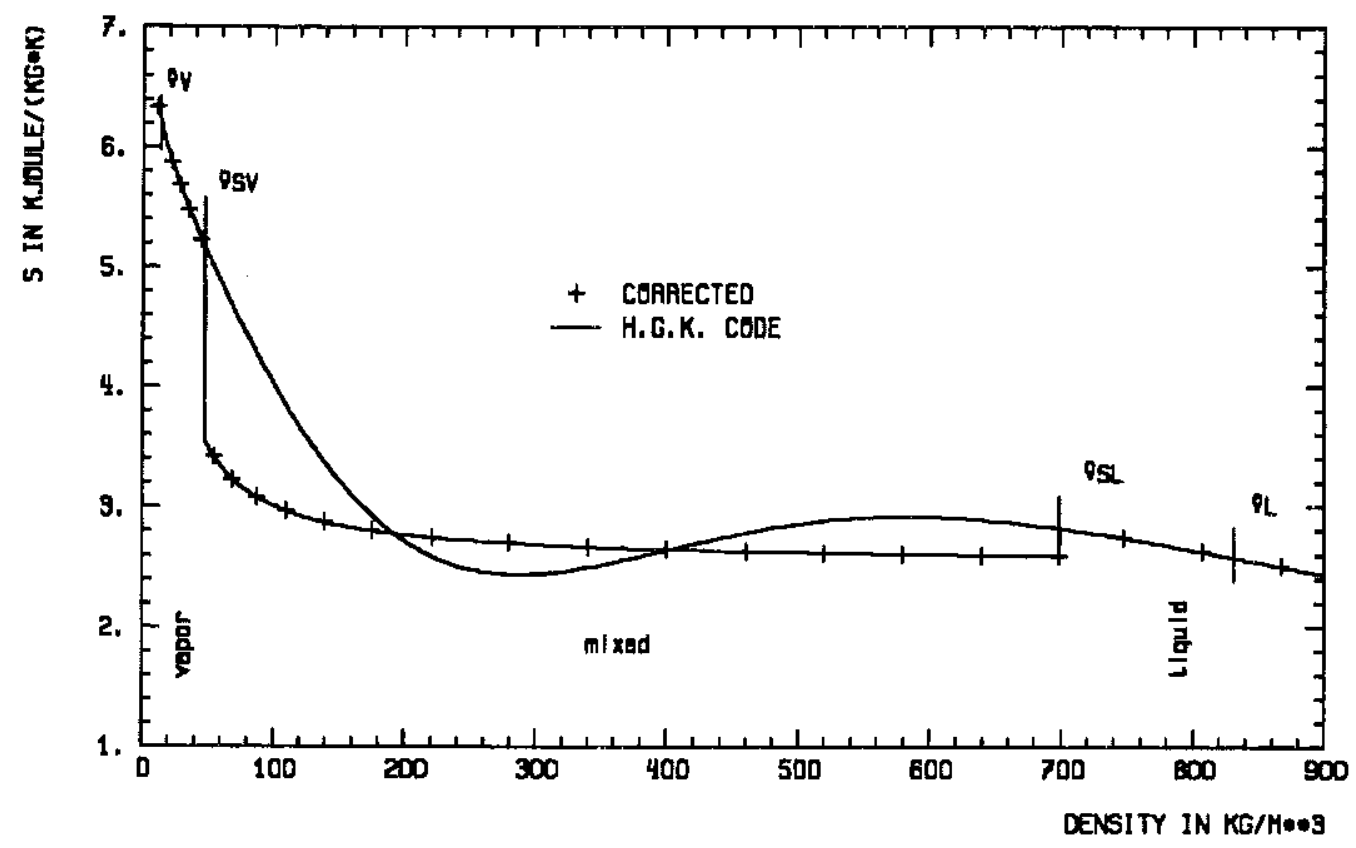

Figure 8. Entropy of the water in the two phase region. $\mathrm{T}=500 \mathrm{~K}$

As regards to the entropy, one can calculate this property in the mixed state using the density derivative [A.22]

$$
\frac{\partial S}{\partial \rho}=-\frac{1}{\rho^{2}} \frac{\partial P}{\partial T}=-\frac{1}{\rho^{2}} \frac{d P^{x}}{d T}
$$


which gives in the region of instability the following density dependence:

$$
S(\rho, T)=S_{L}(T)+\left[V-V_{L}(T)\right] \cdot \frac{d P^{\times}(T)}{d T}
$$

The free energy in the region of instability ( $s$. Figure 9) AQUA calculates from the pressure and free enthalpy via

$$
A=G-P / \rho \quad .
$$

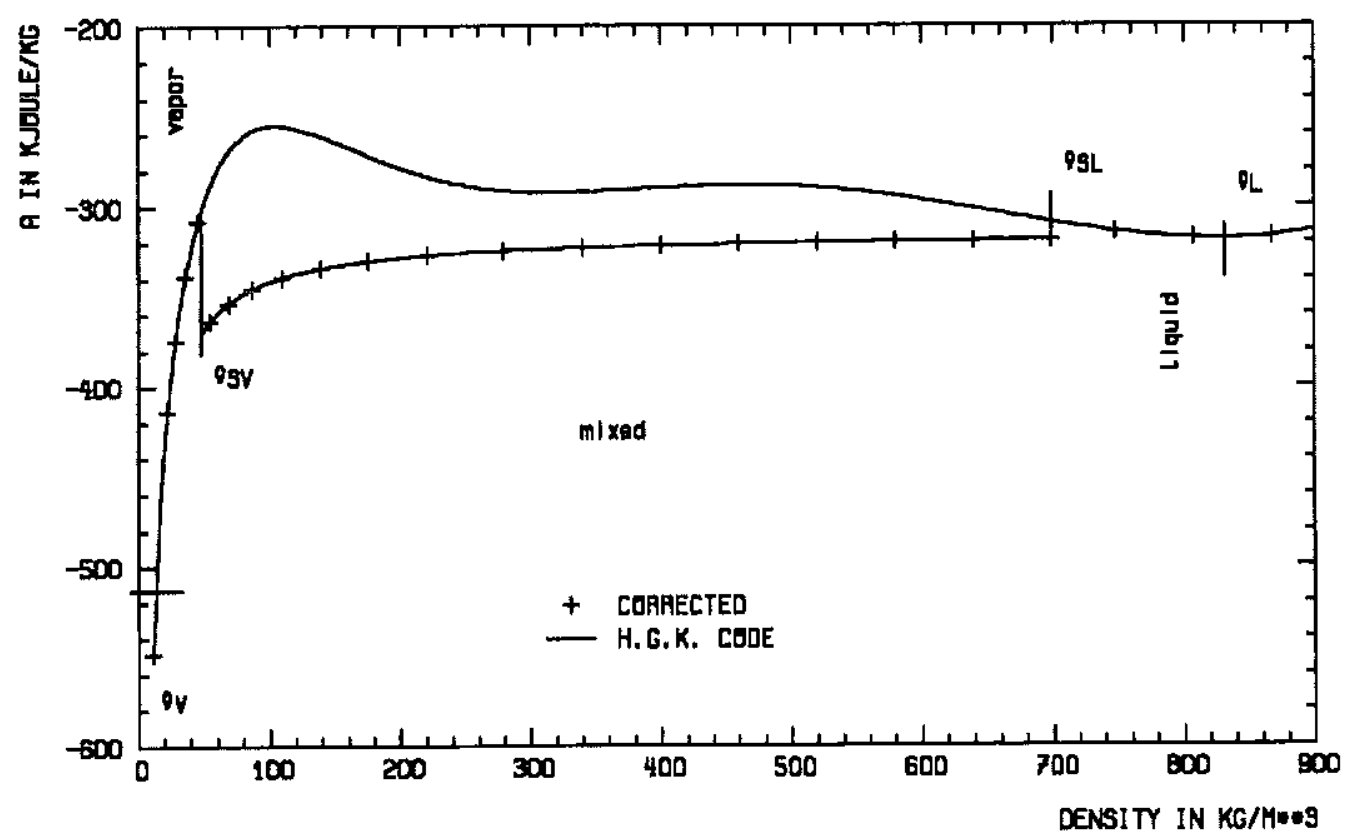

Figure 9. Free energy of the water in the two phase region. $\mathrm{T}=500 \mathrm{~K}$

For the enthalpy and the energy AQUA uses the equations

$$
H=G+S \cdot T
$$

respectively

$$
U=H-P / \rho \quad \text {. }
$$

The density derivative of the energy is given by

$$
\frac{\partial U}{\partial \rho}=\frac{1}{\rho^{2}}\left(P-T \cdot \frac{\partial P}{\partial T}\right)=\frac{1}{\rho^{2}}\left(P^{\times}-T \cdot \frac{d P^{\times}}{d T}\right) .
$$

In the two phase region the derivatives $\partial H / \partial P$ and $C_{P}$ are not defined altogether.

For the sonic velocity in the region of instability the first version of the Eq. [A.23] can be used :

$$
\left.\frac{\partial P}{\partial \rho}\right|_{S}=\frac{\partial P}{\partial \rho}+\frac{T}{C_{V}}\left(\frac{\partial P / \partial T}{\rho}\right)^{2}=\frac{T}{C_{V}}\left(\frac{1}{\rho} \frac{d P^{\times}}{d T}\right)^{2}
$$


with

$$
v_{s}=\sqrt{\left.\frac{\partial P}{\partial \rho}\right|_{s}}=\frac{1}{\rho} \frac{d P^{\times}}{d T} \sqrt{\frac{T}{C_{V}}}
$$

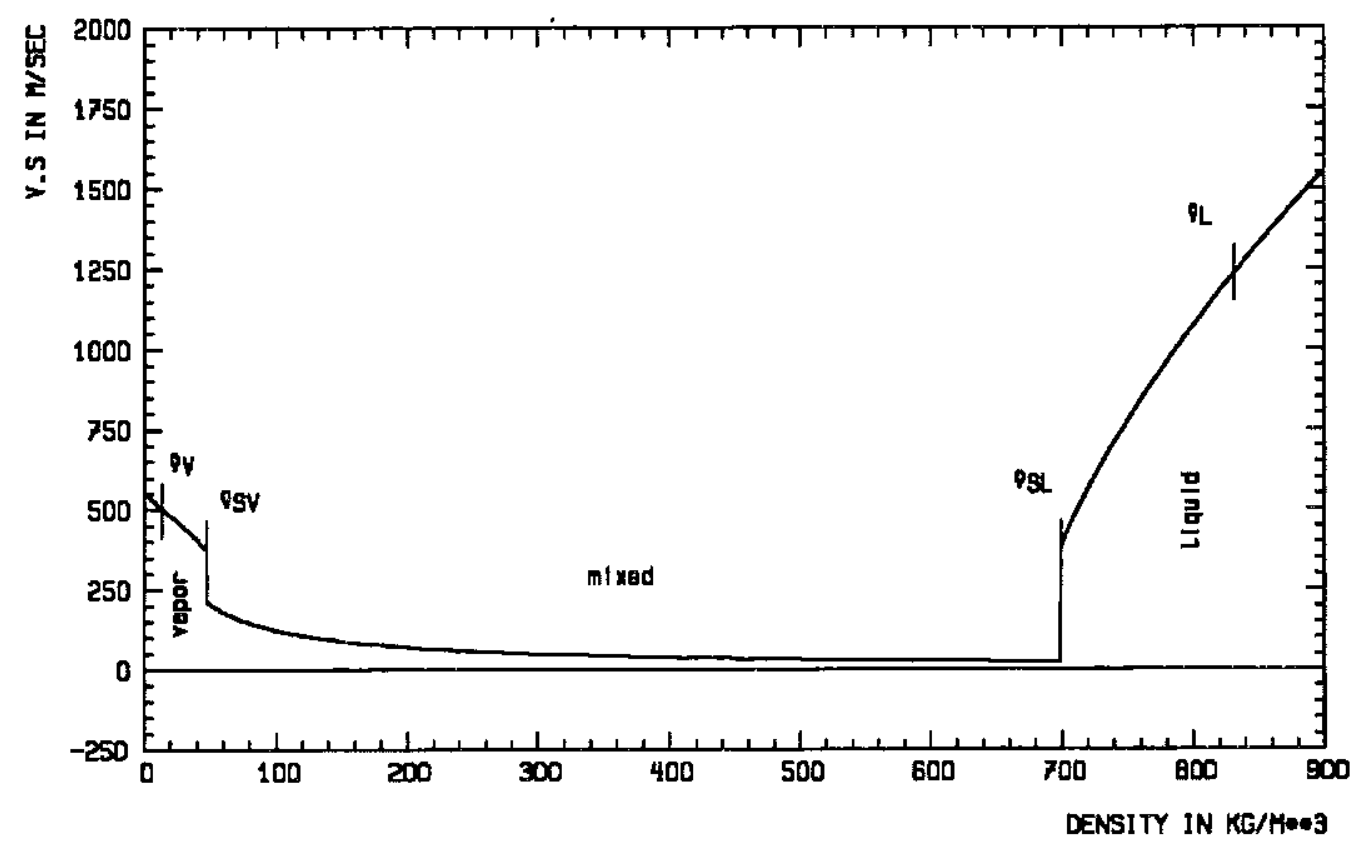

Figure 10. Sonic velocity of the water in the two phase region. $T=500 \mathrm{~K}$

Not so easy is to calculate the constant volume heat capacity in the region of instability. The density derivative in the two phase region

$$
\frac{\partial C_{V}}{\partial \rho}=\frac{\partial(T \cdot \partial S / \partial T)}{\partial \rho}=-\frac{T}{\rho^{2}} \frac{\partial^{2} P}{\partial T^{2}}=-\frac{T}{\rho^{2}} \frac{d^{2} P^{x}}{d T^{2}}
$$

suplies here the difference term :

$$
\Delta C_{V}\left(\rho, \rho_{L}\right)=T \frac{d^{2} P^{\times}}{d T^{2}}\left(V-V_{L}\right)
$$

Besides of the difference term, one has also to account for the $C_{V}$ - jumps, at the places, where the isotherm crosses the saturation line resp. where the liquid or the vapor turns into a vapor-liquid mixture (s. $/ 1 /, / 2 /, / 5 /, / 8 /$ ). Since $\partial P / \partial T$ shows here a discontinuity, so does also $C_{y}$. At the saturated liquid this discontinuity amounts to

$$
c_{V}\left(\rho_{L}-0\right)-c_{V}\left(\rho_{L}\right)=\frac{r_{L}}{\rho_{L}}\left[\frac{d P^{\times}}{d T}-\frac{\partial P}{\partial T}\left(\rho_{L}\right)\right]
$$

$r_{L}$ in the above eq. is the logarithmic derivative of the saturation line:

$$
r_{L} \equiv \frac{T}{\rho_{L}} \cdot \frac{d \rho_{L}}{d T}
$$


The following figure displays such $C_{Y}$-jumps, measured in nitrogen along different isochores.

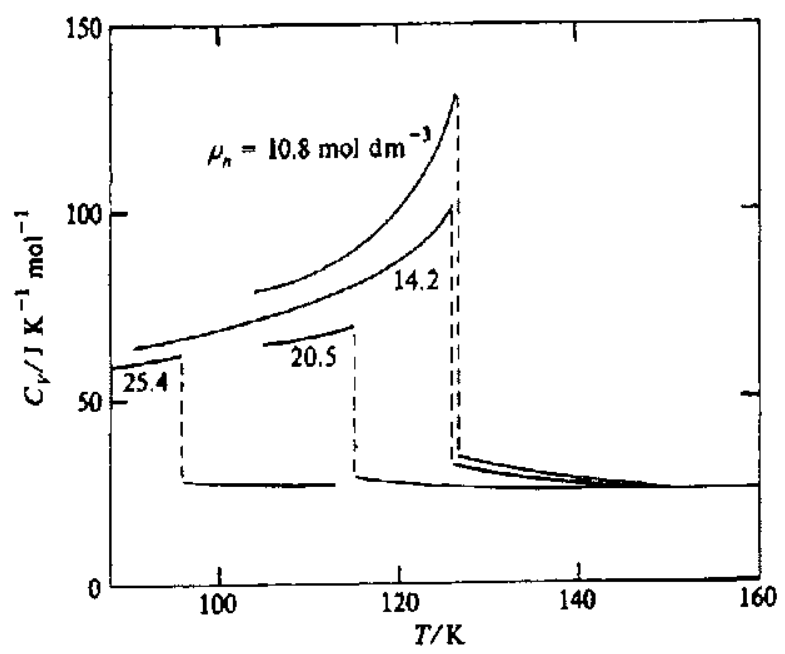

One- and two phase

$C_{y}$ results

for nitrogen

at several

amount-of-substance

densities.

after L. A. Weber, /6/.

The Eqs. [4.15], [4.16] together give the following heat capacity function in the region of instability:

$$
C_{V}(\rho)=C_{V}\left(\rho_{L}\right)+\frac{r_{L}}{\rho_{L}}\left[\frac{d P^{\times}}{d T}-\frac{\partial P}{\partial T}\left(\rho_{L}\right)\right]+\left(\frac{1}{\rho}-\frac{1}{\rho_{L}}\right) T \frac{d^{2} P^{\times}}{d T^{2}}
$$

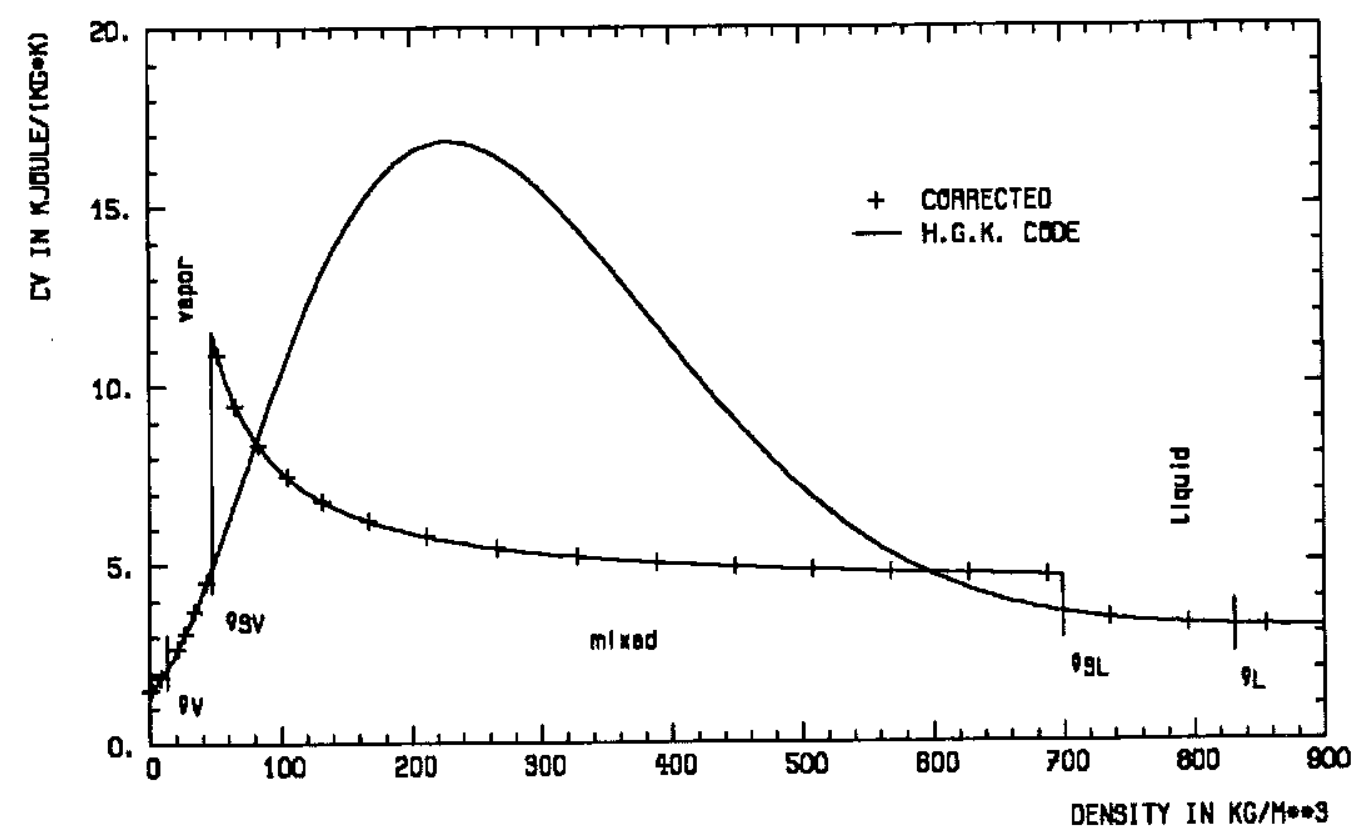

Figure 11. Heat capacity $-C_{V}-$ of the water in the two phase region. $\mathrm{T}=500 \mathrm{~K}$

For a $(T, \rho)$ - surface of the heat capacity of the water - calculated by AQUA - see Figure 15 on page 25 resp. Figure 16 on page 26. 
In calculating the thermal conductivity in the two phase region AQUA uses in the different subregions different algorithms. In the superheated liquid and subcooled vapor the function - described in 3.0, "Transport properties of the water." , Eq. [3.5] ff. - is used as well as outside the saturation dome.

In the region of instability AQUA calculates the thermal conductivity using the following approximation: the liquid part of the water in this subregion is distributed homogeneously - as a multitude of tiny droplets - in the vapor part of the water. This mixture is furthermore static in its behaviour, so the convective part of the heat transfer can be neglected. The approximation above allows to calculate in the region of instability the thermal conductivity from the thermal conductivities of the saturated states $-\lambda_{L}, \lambda_{Y}$ - as follows :

$$
\frac{1}{\lambda}=\frac{1-x}{\lambda_{L}}+\frac{x}{\lambda_{V}+x^{2} \cdot\left(\lambda_{L}-\lambda_{V}\right)}
$$

(s. /5/, Eq. 71 ). $x$ in the eq. above is

$$
x=\sqrt[3]{\frac{\rho-\rho_{V}}{\rho_{L}-\rho_{V}}}
$$

Figure 12 shows the thermal conductivity of the water along the $500 \mathrm{~K}$ - isotherm. The spikes in the vicinity of the spinodal points are a consequence of the description [3.8], using $\partial P / \partial \rho$ - which vanishes at the spinodals - in the denominator.

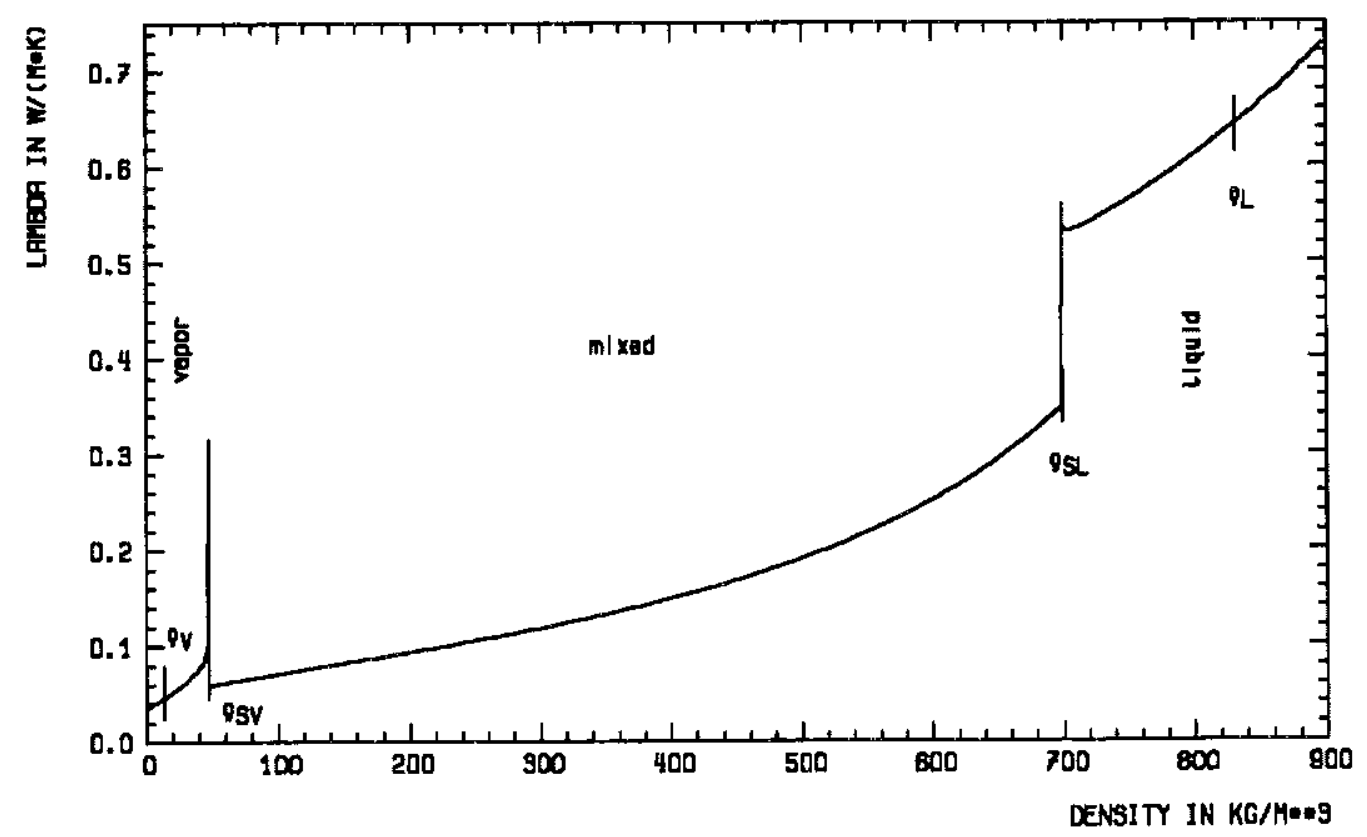

Figure 12. Thermal conductivity of the water in the two phase region. $\mathrm{T}=500 \mathrm{~K}$

As well as the thermal conductivity, the viscosity is also a transport process, the transport of the monentum. So AQUA calculates the viscosity by a procedure, very similar to the one, used for the calculation of the thermal conductivity.

At the saturation densities the $\eta$ function Eq. [3.3]- [3.4] - will be continued until the spinodals are reached. In the region of instability AQUA uses the same fluid-model, as in the case of the thermal conductivity to calculate the viscosity from the saturated viscosities $\eta_{L}, \eta_{V}$. The resulting equation is: 


$$
\frac{1}{\eta}=\frac{1-x}{\eta_{L}}+\frac{x}{\eta_{V}+x^{2} \cdot\left(\eta_{L}-\eta_{V}\right)}
$$

Figure 13 shows the water-viscosity as calculated by AQUA along the $500 \mathrm{~K}$ - isotherm.

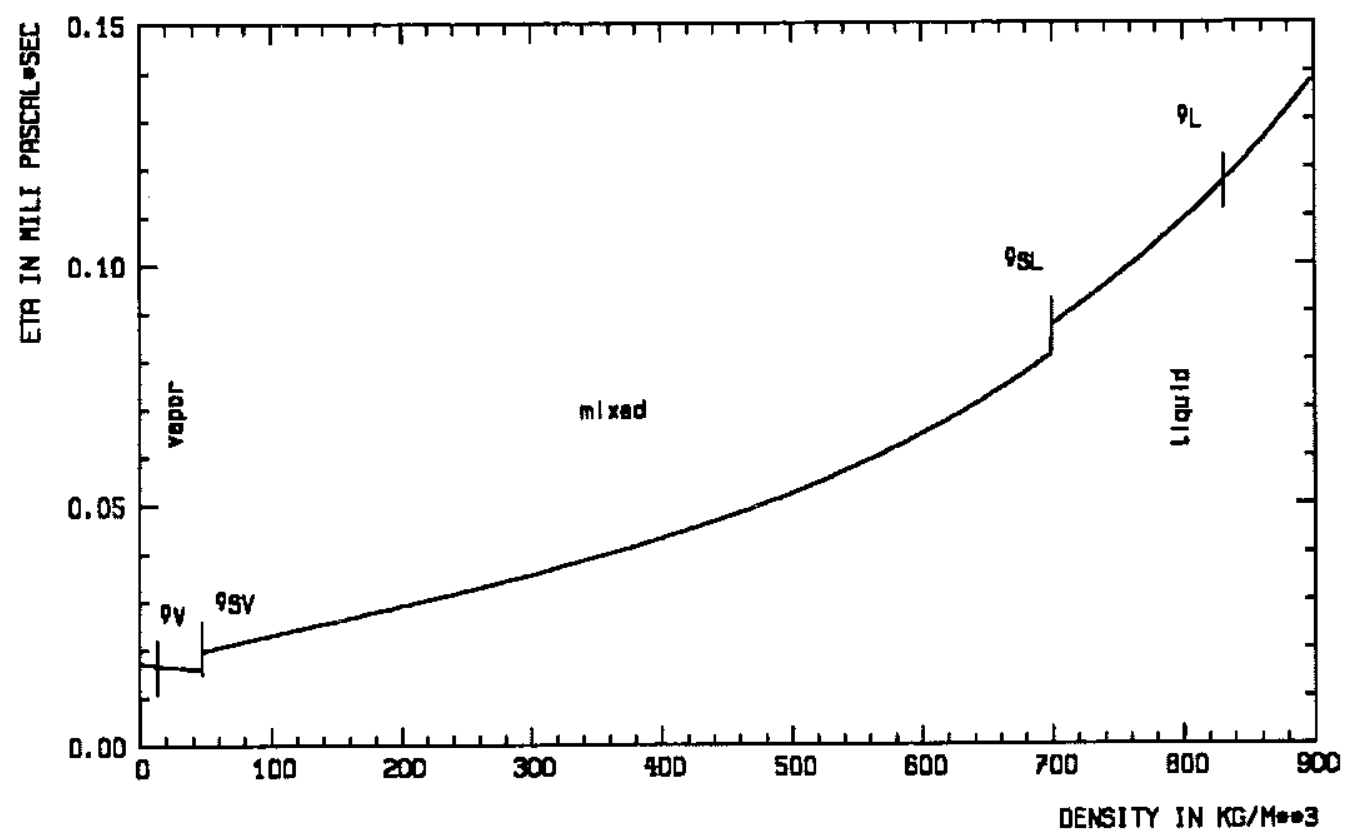

Figure 13. Viscosity of the water in the two phase region. $T=500 \mathrm{~K}$ 


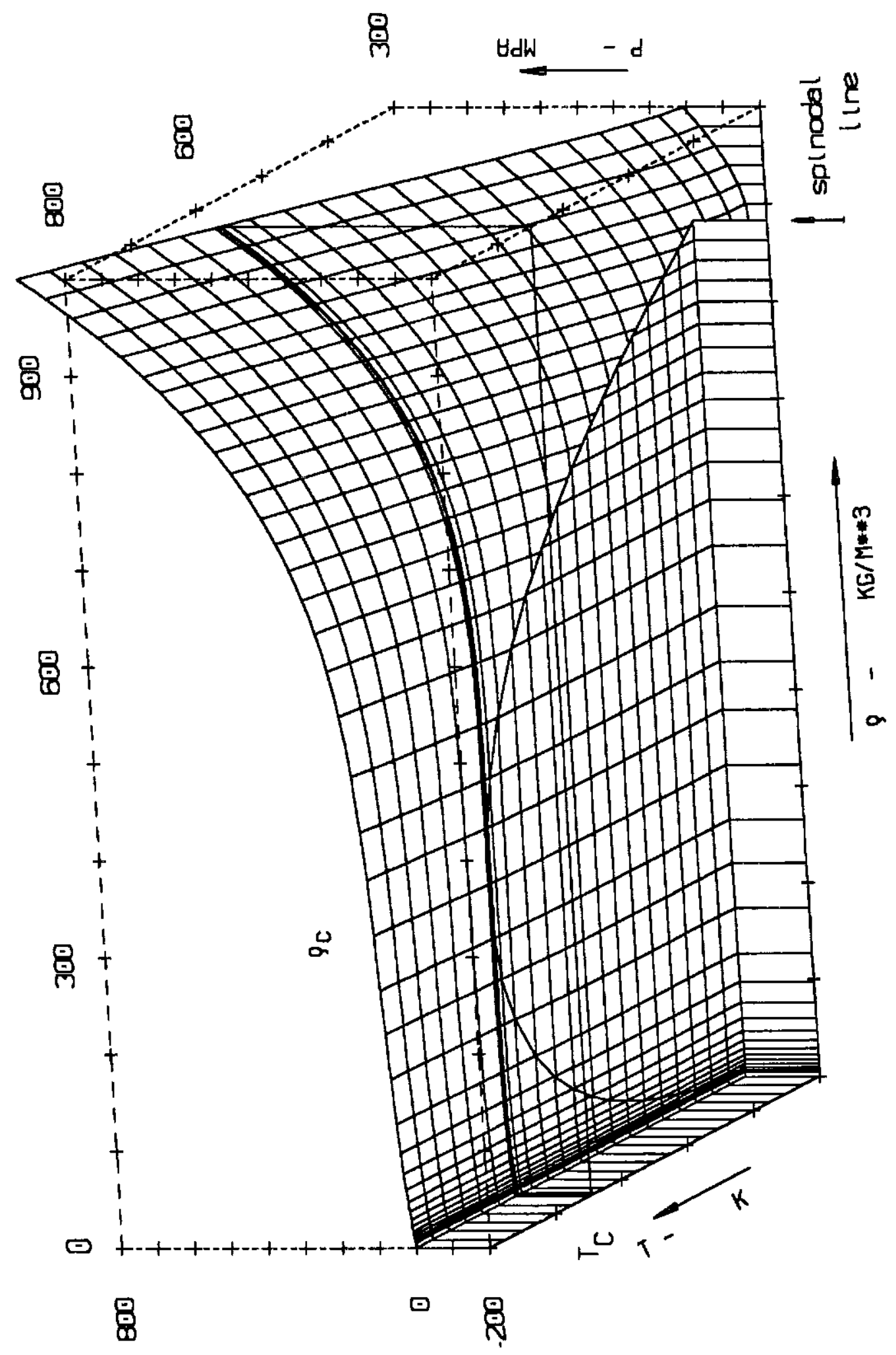

Figure 14. Pressure surface of the water. AQUA 


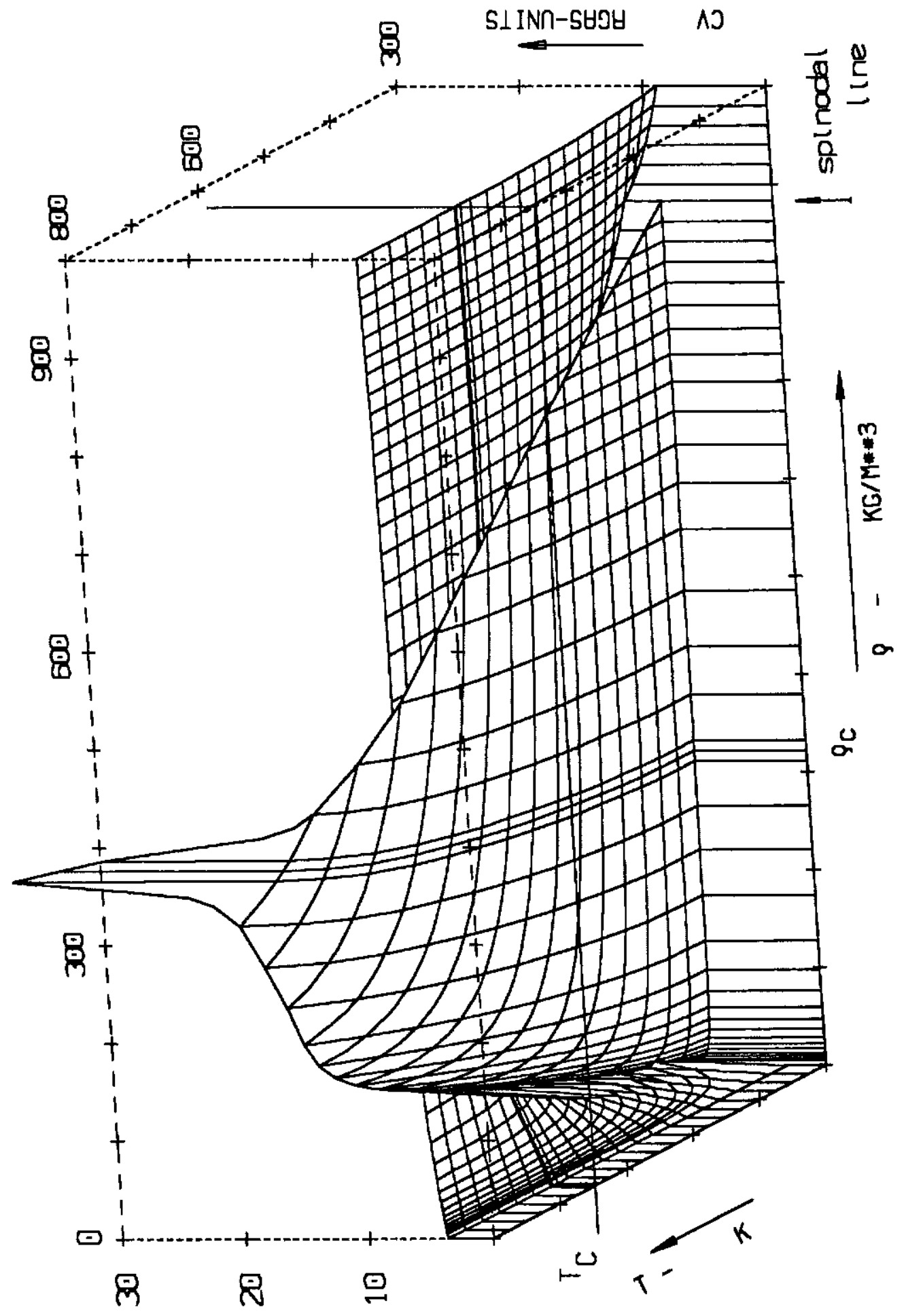

Figure 15. Heat capacity surface of the water. AQUA. View from the cold side. 


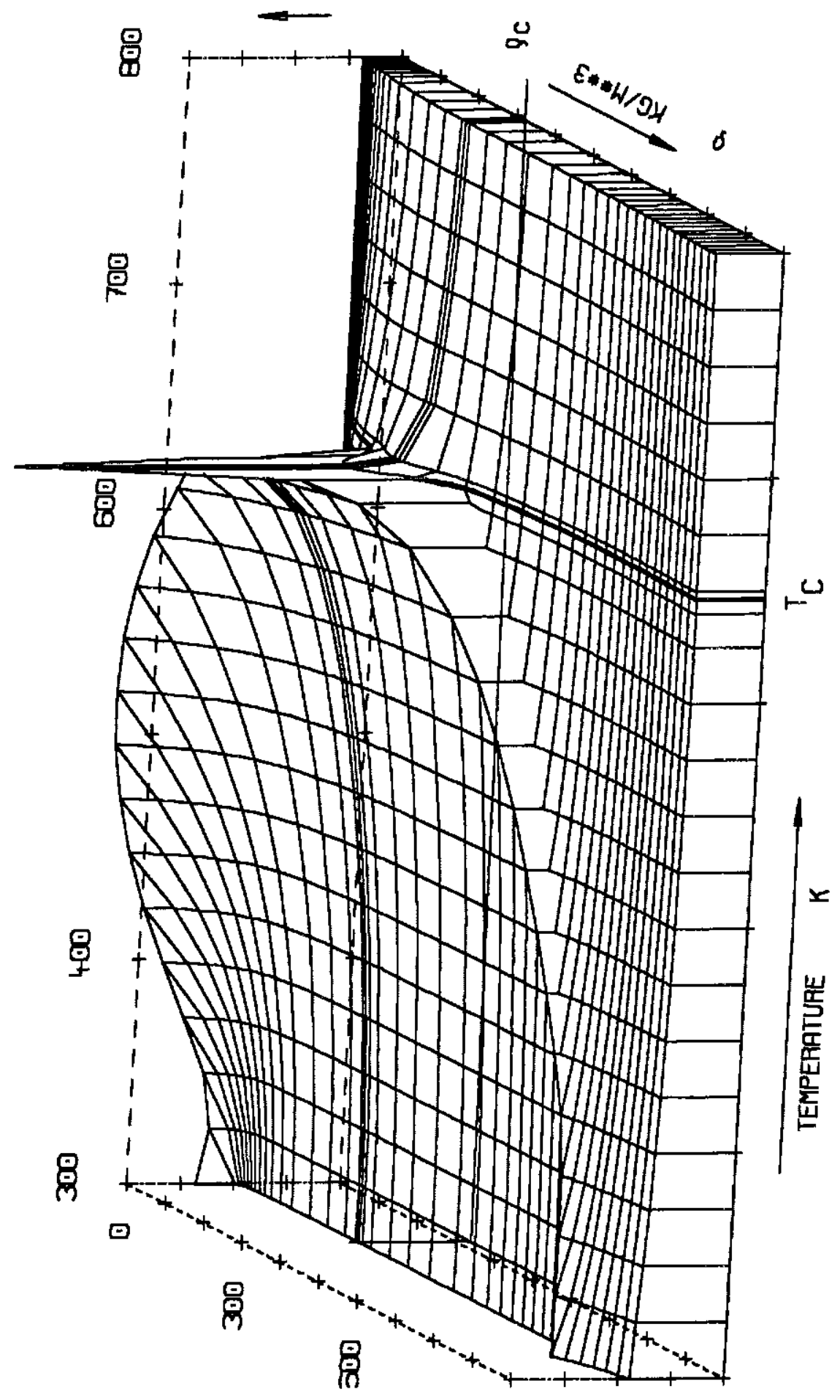

Figure 16. Heat capacity surface of the water. AQUA. View from the liquid side. 


\subsection{Describing the water properties in the saturated states}

In order to be able to calculate the water properties in the region of instability AQUA needs a series of thermal properties of the water in the saturated states ( $\mathrm{s}$. e.g. Eq. [4.18] ). To speed up the calculations AQUA doesn't calculate these properties ( $P^{\times}$, $\rho, \partial P / \partial \rho, \partial P / \partial T, C_{v}$, $\lambda$, etc ) directly, but use pre-defined temperature-functions of the corresponding properties. In constructing these temperature-functions great care was taken

to have negligible deviations to the H.G.K values and

to show the correct behaviour in the vicinity of the critical point.

The remaining part of this chapter describes the temperature-descriptions of these properties of the water in the saturated states.

\subsection{Describing the saturation line of the water}

\section{The saturation pressure}

Haar, Gallagher and Kell describe the vapor pressure of the water ( at temperatures, exceeding $314 \mathrm{~K}$ ) as a function of the scaled temperature

$$
\tau \equiv 1-\frac{T}{T_{c}}
$$

rsp. of the square root of it

$$
w \equiv \sqrt{\tau}
$$

as follows :

$$
\ln P^{x}=\ln P_{c}+\frac{\tau}{1-\tau} \sum_{j=1}^{8} A_{j} \cdot w^{j-1}
$$

In the above Eq. H.G.K. use critical data

$$
T_{c}=647.25 \mathrm{~K} \quad, \quad P_{c}=22.093 \mathrm{MPa}
$$

which differ markedly from their regulary used values Eq. [2.11]

The polynomial coefficients, $A_{i}$ are :

Table 9. The coefficients $A(1)-A(8)$ of the HGK-vapor pressure equation

\begin{tabular}{|c|c|c|c|c|c|}
\hline \multicolumn{5}{|c|}{ Table 9. The coefficients A(1) A(8) of the HGK-vapor pressure equation } \\
\hline 1 & -7.8889166 & 2 & 2.5514255 & 3 & -6.716169 \\
\hline 4 & 33.239495 & 5 & -105.38479 & 6 & 174.35319 \\
\hline 7 & -148.39348 & 8 & 48.631602 & & \\
\hline
\end{tabular}

AQUA uses, instead of the Eq. [5.3] a description, proposed by Wagner and Saul at the conference in Moscow, /14/. The W\&S-equation needs only 6 coefficients and yet repre- 
sent the measured vapor pressure data within their experimental uncertainity ( see Figure 17 ).
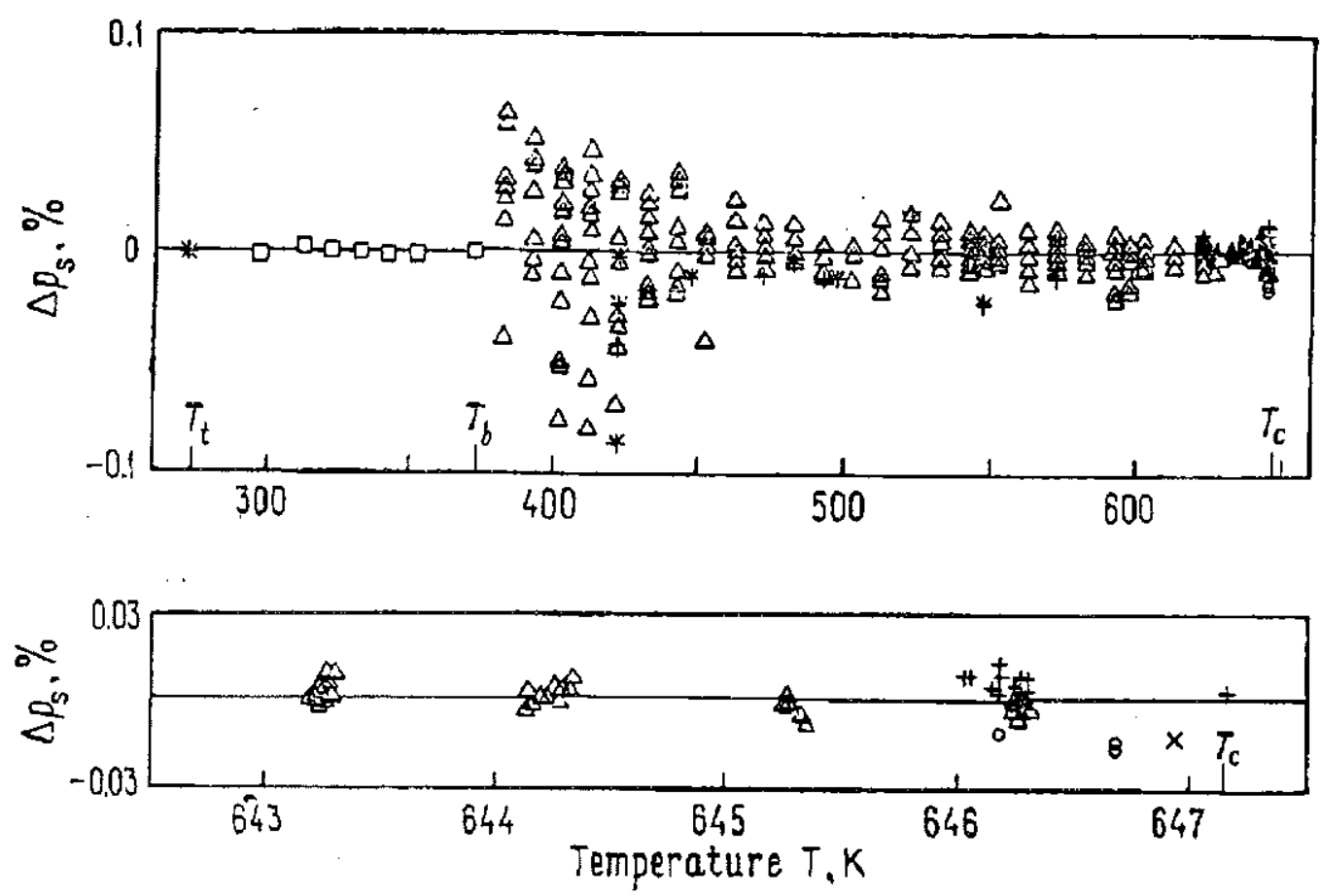

Fig. 1. Rejative deviations $\Delta p_{s}=\left(p_{\text {s. exp }}-p_{s . c a l c}\right)^{\prime} p_{s, \text { exp }}$ of the experimental vapour pressures from values calculated with Eq. (5). $\triangle$ Osborne et al. (14], + Rivkin et al. [16], $\square$ Stimson [13], * Guildner et al. [12], $O$ Hanafusa et al. [17], $X$ Kawai et al. [18], $\Varangle$ Kell et al. [19]

Figure 17. Vapor pressure formula of Wagner and Saul

The W\&S-equation has the same form as the H.G.K. one, Eq. [5.3] ,

$$
\ln P^{\times}=\ln P_{c}+\frac{\tau}{1-\tau} \sum_{j=1}^{13} N_{j} \cdot w^{j-1}
$$

only the critical data and the coefficients differ. They use

$$
T_{\varepsilon}=647.14 \mathrm{~K} \quad, \quad P_{c}=22.064 \mathrm{MPa}
$$

as critical data and

$$
\begin{aligned}
& N_{1}=-7.85823, \quad, \quad N_{2}=1.83991, \quad, \quad N_{5}=-11.7811, \\
& N_{6}=22.6705 \quad, \quad N_{7}=-15.9393 \quad, \quad N_{13}=1.77516,
\end{aligned}
$$

as polynomial-coefficients. In calculating the vapor pressure AQUA uses here also the critical data of Haar, Gallagher and Kell ( Eq. [2.11] ) instead of the data [5.6] .

As well as in the H.G.K.-code, $P^{\times}$of Eq. [5.5] is for AQUA only an approximated pressure. The true vapor pressure is calculated from this first value by correcting the saturated densities till the Eq.s [4.1 - 4.2] are satisfied. 


\section{The saturation line}

The saturated densities are needed not only as limiting borders, but also as properties of their own value. The caclulation of various thermal properties in the region of instability requires mostly the saturated densities and in some cases their temperature derivatives too (s. e.g. Eq. [4.18] ). Consequently one needs not only smooth functions for the saturated densities, but functions with smooth temperature derivatives.

The H.G.K.-code calculates - below $646.3 \mathrm{~K}-\rho^{x}, \rho_{L}$ and $\rho_{V}$ by searching for states $\left(T, \rho_{L}\right)$ resp. (T, $\left.\rho_{V}\right)$ with equal free enthalpy values (Eq.s $[4.1-4.2]$ ). The corresponding equal pressures define then $P^{\times}(T)$. Above $646.3 \mathrm{~K}$ Haar, Gallagher, and Kell use "scaled" equations for the saturated densities :

$$
\begin{aligned}
& \frac{\rho_{L}(T)}{\rho_{c}}=1+2.04077 \cdot \tau^{\beta} \\
& \frac{\rho_{V}(T)}{\rho_{c}}=1-2.04077 \cdot \tau^{\beta}
\end{aligned}
$$

with the critical exponent $\beta=0.325$, without correcting the densities for common free enthalpy.

AQUA describes - as well as the vapor pressure - the saturation line also with the $T_{c}$-related variables $\tau$ and $w$, Eq.s $[5.1],[5.2]$.

Below $620 \mathrm{~K}$ the density of the saturated liquid is described with a polynomial of $\mathrm{w}$,

$$
\rho_{L}(T)=\rho_{c} \cdot \sum_{j=1}^{12} A_{j} \cdot w^{j-1} .
$$

\begin{tabular}{|c|c|c|r|r|r|}
\hline \multicolumn{7}{|c|}{ Table 10. The coefficients $\mathbf{A ( 1 )}-\mathbf{A}(12)$ in the Eq. of the saturated liquid } \\
\hline 1 & 6.072746418 & 2 & -149.9456089 & 3 & 2121.007381 \\
\hline 4 & -17164.83301 & 5 & 90176.84684 & 6 & -323045.6094 \\
\hline 7 & 805443.5472 & 8 & -1398515.305 & 9 & 1658696.365 \\
\hline 10 & -1281195.416 & 11 & 580741.4278 & 12 & -117181.9097 \\
\hline
\end{tabular}

In the case of the saturated vapor instead of the density, the factor of reality is described by a polynomial of $w$ :

$$
\rho_{V}(T)=\frac{P^{\times}(T)}{R_{\text {gas }} \cdot T \cdot Z_{V}(T)} \quad, \quad Z_{V}(T)=\sum_{j=1}^{12} Z_{j} \cdot w^{j-1} .
$$

\begin{tabular}{|c|c|c|c|c|c|}
\hline \multicolumn{7}{|c|}{ Table 11. The coefficients $Z(1) \cdot \mathbf{Z}(12)$ in the Eq. of the saturated vapor } \\
\hline 1 & -1.125999398 & 2 & 42.15284538 & 3 & -538.0831003 \\
\hline 4 & 4150.173161 & 5 & -20809.47751 & 6 & 71295.07069 \\
\hline 7 & -170444.6088 & 8 & 284498.9747 & 9 & -325135.7165 \\
\hline 10 & 242459.309 & 11 & -106255.203 & 12 & 20747.6267 \\
\hline
\end{tabular}


As well for the liquid, as for the vapor the polynomial-coefficients were fitted to properties, calculated by the H.G.K-code. The vapor pressure in Eq. [5.10] was calculated by the W\&S formula.

Above $620 \mathrm{~K}$ AQUA uses practically the same scaled description, as the H.G.K code ( Eq. [5.8] ) only fitting tails had been added:

$$
\begin{gathered}
\rho_{L}(T)=\rho_{c} \cdot\left[1+2.03 \cdot \tau^{\beta}+\tau\left(U_{1}+\tau\left(U_{2}+\tau^{2} U_{4}\right)\right)\right] \\
\rho_{V}(T)=\rho_{c} \cdot\left[1-2.03 \cdot \tau^{\beta}+\tau\left(W_{1}+\tau\left(W_{2}+\tau^{2} W_{4}\right)\right)\right]
\end{gathered} .
$$

The coefficients of the fitting tails

$$
\begin{aligned}
& U_{1}=3.075668853 \quad, \quad U_{2}=-19.58060683 \quad, \quad U_{4}=1383.086689 \\
& W_{1}=1.451962241 \quad, \quad W_{2}=-5.041325559, \quad, \quad W_{4}=611.1810749
\end{aligned}
$$

had ben calculated by demanding a double-smooth connection

$$
f_{-}\left(T_{s}\right)=f_{+}\left(T_{s}\right) \quad, \quad f^{\prime}-\left(T_{s}\right)=f^{\prime}{ }_{+}\left(T_{s}\right) \quad, \quad f^{\prime \prime}\left(T_{s}\right)=f^{\prime \prime}+\left(T_{s}\right)
$$

for them to the low- $T$ formulas at $T_{s}=620 \mathrm{~K}$. ( see Appendix B, "Derivatives of some saturated properties" on page 71 ).

The saturated densities, calculated by the Eq.s [5.9 - 5.11] are again only approximated ones. AQUA corrects them - below $646.0 \mathrm{~K}$ - to fulfil the Eq.s [4.1 - 4.2] ( $\mathrm{s}$. Appendix C, "Adjusting the saturated states" on page 75 ).

\subsection{Describing the spinodals}

\section{Calculating the spinodals of the water.}

The spinodals of the water are essential for the code AQUA : the spinodal densities are needed as domain borders for the calculations in the saturation dome, the spinodal pressures are neded as pressure bounds in converting the pressures to densities.

In order to calculate the densities of the spinodals one has to find the nearest roots of the Eq. [4.3] on the isotherms in the vicinity of the saturated densities. In the codepackage AQUA there is a program HGKSPN wich calculates - using the routines QUADO, MONIKA and SORBET - the densities and pressures of the spinodals of the water.

HGKSPN calculates $\partial P / \partial \rho$ at different densities on an isotherm using the H.G.K.-code.

QUADO selects 3 adjacent densities nearest to the root of Eq. [4.3] and fits a 2 . grade polynomial - $Q_{2}$ - to them.

MONIKA is needed only to ensure, that the densities are properly ordered. QUADO solves the resulting quadratic equation

$$
Q_{2}(\rho)=0
$$

and selects the appropriate root as the first approximation for the spinodal density, $\rho_{s<1}$.

SORBET discards now one of the first 3 density values - the density, with the worst fitting - and replaces it with $\rho_{S L 1}$. These 3 densities are then returned to QUADO and a new root for $\partial P / \partial \rho, \rho_{S L 2}$ will be calculated. The procedure endures, till Eq. [4.3] is fulfilled with sufficient accuracy. 


\section{The spinodal densities}

Figure 18. shows the near-critical part of the calculated spinodal densities. As one can see, above the temperature of $635 \mathrm{~K}$ the spinodal lines get more and more irregular in shape. Above $T=646.3 \mathrm{~K}$ the H.G.K. code prohibites altogether the calculation of the spinodals.

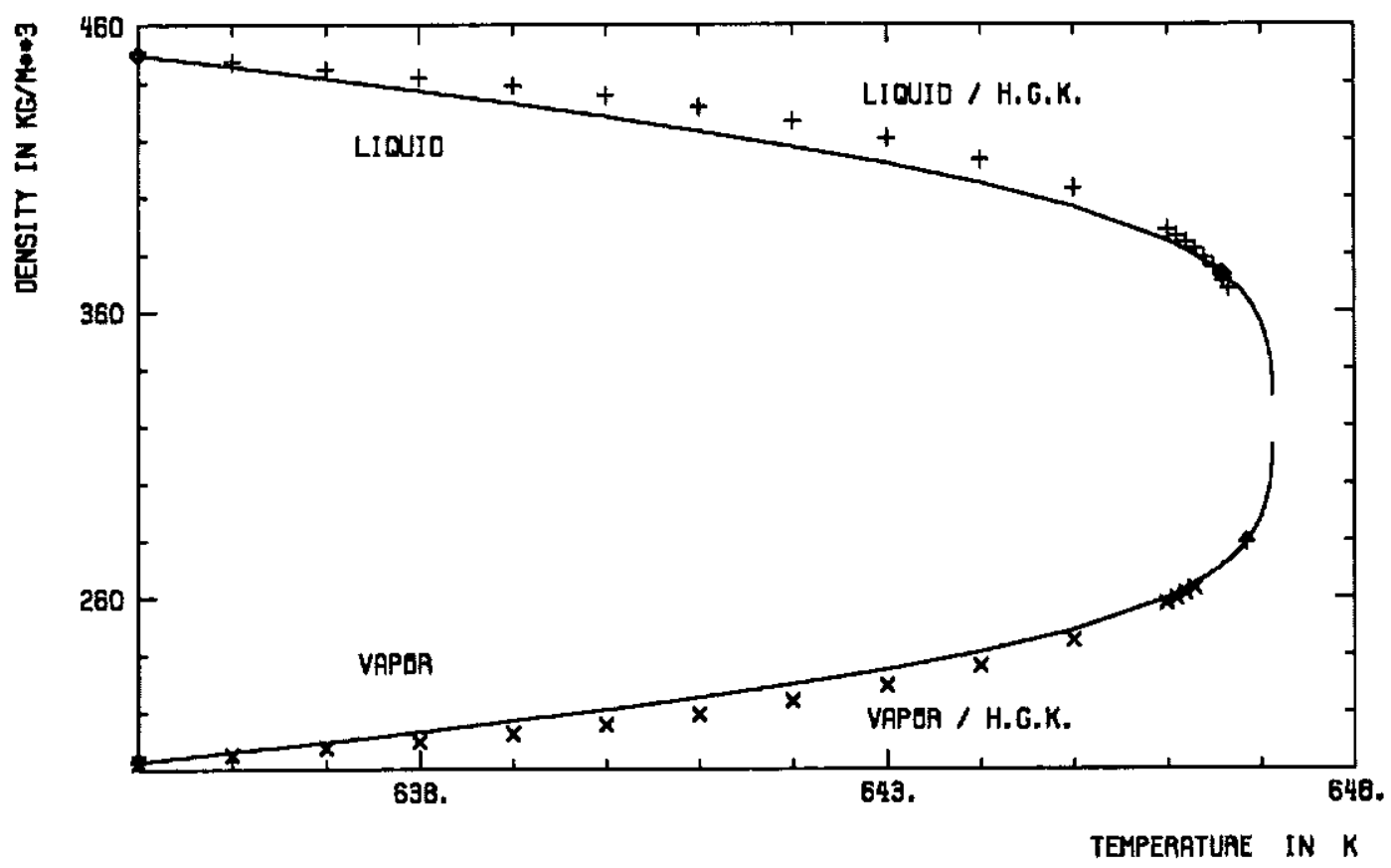

Figure 18. Spinodal densities in the vicinity of the critical point

AQUA describes the spinodal densities - in the same way as the saturated densities - as functions of $w$ resp. $\tau$ (s. Eq. [5.1 - 5.2]).

Below $620 \mathrm{~K}$ the density as well of the liquid, as of the vapor spinodal is approximated with polynomials

$$
\rho_{S L}(T)=\rho_{C} \cdot \sum_{j=1}^{9} A_{j} \cdot w^{j-1} \quad, \quad \rho_{S V}(T)=\rho_{c} \cdot \sum_{j=1}^{7} C_{j} \cdot w^{j-1} .
$$

Table 12, Polynomial coefficients $A(1)-A(9)$ of the density of the liquid spinodal

\begin{tabular}{|c|c|c|r|r|r|}
\hline 1 & 1.911888766 & 2 & -16.54157899 & 3 & 179.7358194 \\
\hline 4 & -940.1374463 & 5 & 2957.964417 & 6 & -5752.429056 \\
\hline 7 & 6772.987553 & 8 & -4428.001759 & 9 & 1234.441322 \\
\hline
\end{tabular}

\begin{tabular}{|c|c|c|c|c|c|}
\hline \multicolumn{5}{|c|}{ Table 13. Polynomial coefficients $\mathbf{C}(\mathbf{1}) \cdot \mathbf{C}(\mathbf{7})$ of the density of the vapor spinodal } \\
\hline 1 & 0.9201508683 & 2 & -2.159701944 & 3 & -0.2932760492 \\
\hline 4 & 6.324940268 & 5 & -10.49597891 & 6 & 8.78261245 \\
\hline 7 & -3.119252324 & & & & \\
\hline
\end{tabular}


The coefficients in Eq. [5.13] were fitted to the liquid resp. vapor densities calculated by HGKSPN.

Above $620 \mathrm{~K}$ the spinodal densities of the H.G.K.-isotherms are not reliable to be used as a fitting source. Instead of using them, a [5.11] - type near-critical extension

$$
\begin{aligned}
& \rho_{S L}(T)=\rho_{c} \cdot\left[1+1.40 \cdot \tau^{\beta}+\tau\left(U_{1}+\tau\left(U_{2}+\tau^{2} U_{4}\right)\right)\right], \\
& \rho_{S V}(T)=\rho_{c} \cdot\left[1-1.40 \cdot \tau^{\beta}+\tau\left(W_{1}+\tau\left(W_{2}+\tau^{2} W_{4}\right)\right)\right]
\end{aligned},
$$

was constructed.

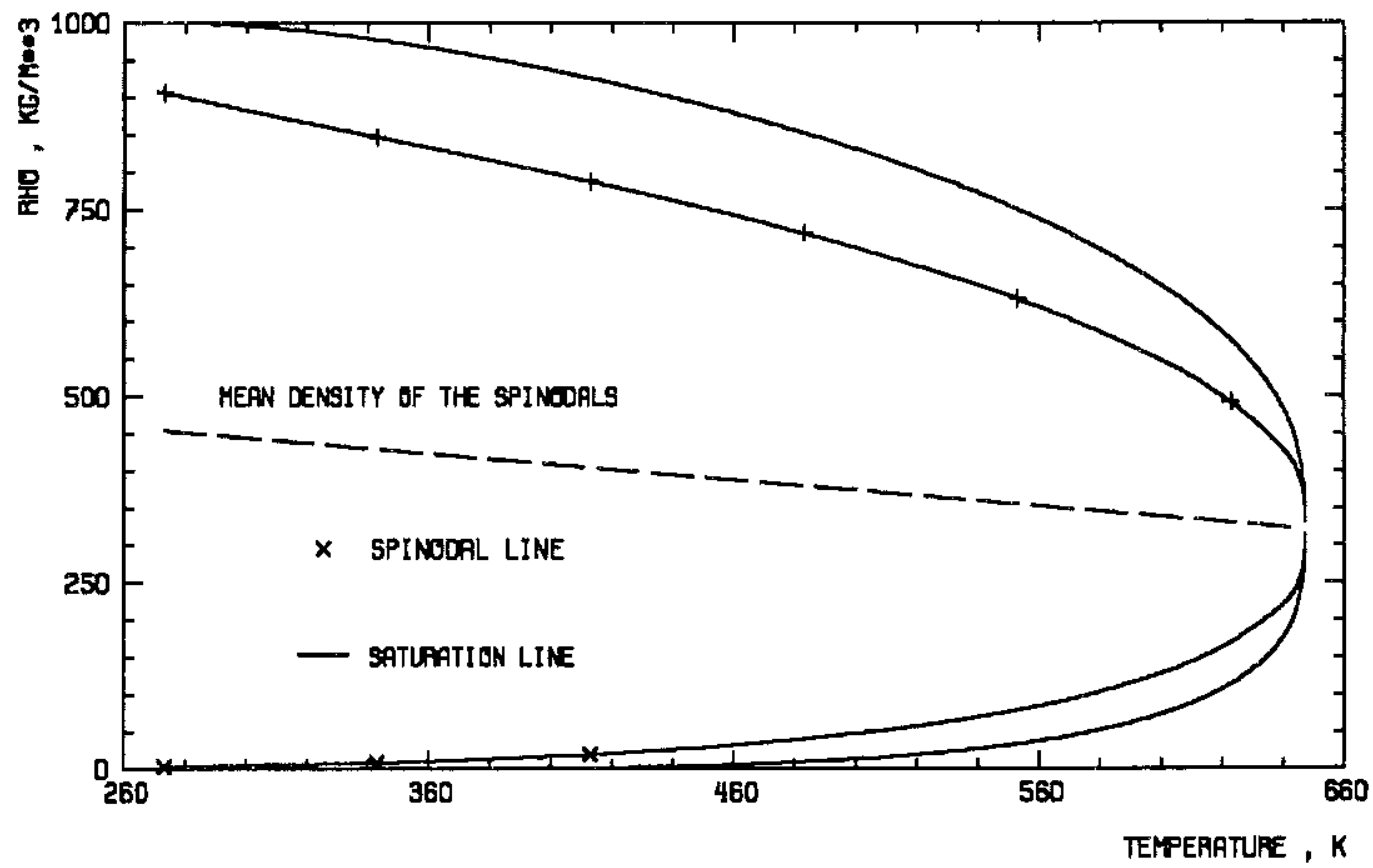

Figure 19. Saturation and spinodal densities of the water

$\rho_{c}$ and $\beta$ in Eq. [5.14] ensure, that for all near-critical isotherms the density-relation

$$
\rho_{V}<\rho_{S V}<\rho_{c}<\rho_{S L}<\rho_{L}
$$

holds. The critical amplitude - 1.4 in Eq. [5.14] - was found by comparing the results of Eq. [5.14] with the H.G.K.-data at temperatures above $640 \mathrm{~K}$. The coefficients of the fitting tails

$$
\begin{aligned}
& U_{1}=0.4871717941, \quad U_{2}=24.26899415, \quad U_{4}=-2461.494028 \\
& W_{1}=1.132819731 \quad, \quad W_{2}=-30.70131059, \quad W_{4}=3324.944936
\end{aligned}
$$

are calculated again - as in the case of the saturated densities - by demanding double smooth connections at $620 \mathrm{~K}$.

Figure 19 displays the saturated and the spinodal densities as functions of the temperature. It is interesting to note that the mean spinodal

$$
\rho_{S M}=\left(\rho_{S L}+\rho_{S V}\right) / 2
$$


is a linear function of the temperature.

\section{The spinodal pressures}

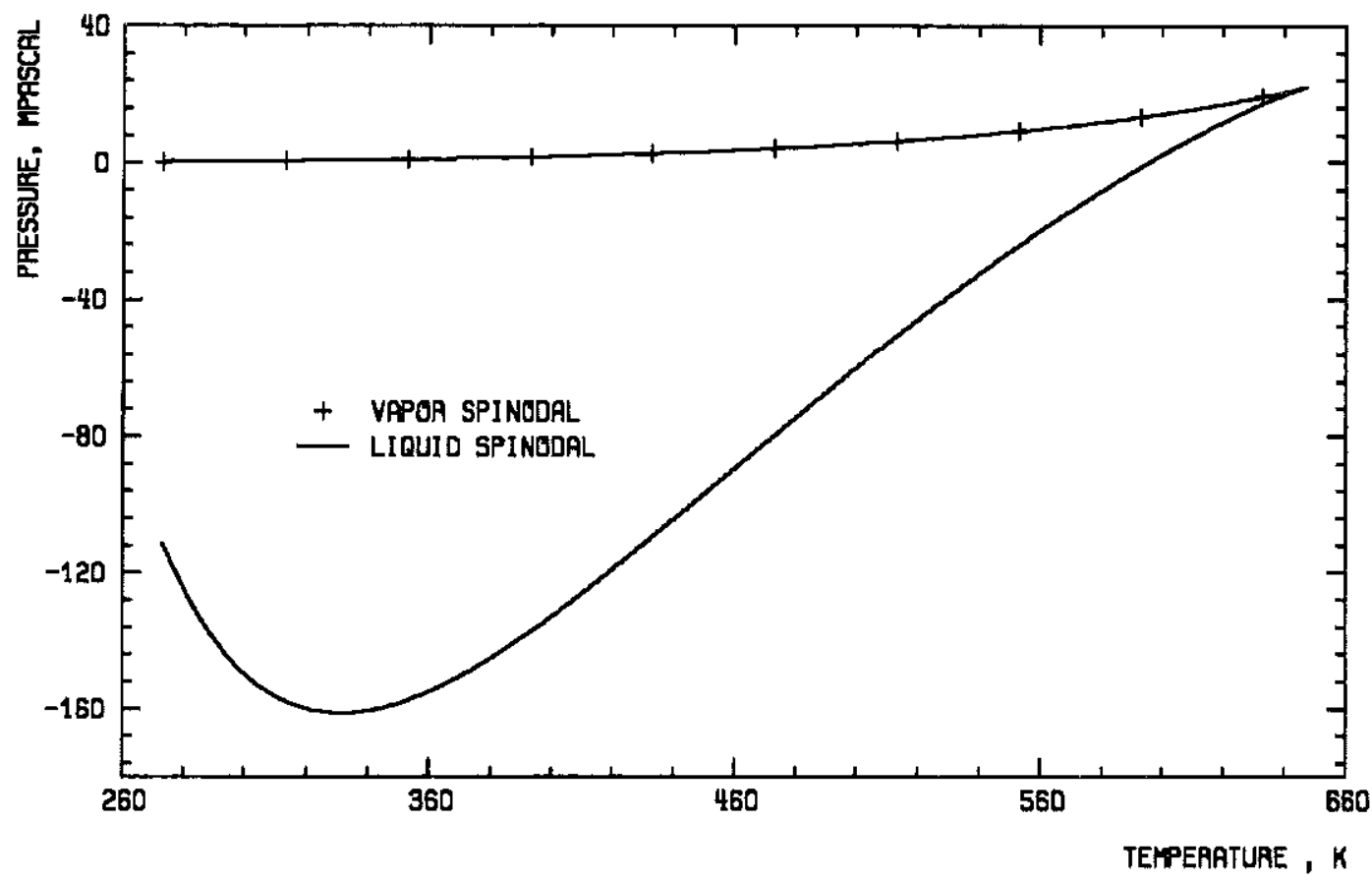

Figure 20. Pressures on the spinodals of the water

In the vicinity of the critical point the spinodal pressures - like the density - are not accessible via the H.G.K.-code. Moreover, at every subcritical T the pressure relation

$$
P_{S L}(T)<P^{\times}(T)<P_{S V}(T)
$$

must hold. To cope with these conditions AQUA approximatates below $620 \mathrm{~K}$ the spinodal pressures - calculated by HGKSPN - with $\tau$ - polynomials and describes - near $T_{\varepsilon}$ their deviations from $P^{\times}$.

Below $620 \mathrm{~K}$ the pressures are described as :

$$
P_{S L}(T)=\sum_{j=1}^{9} A_{j} \cdot \tau^{j-1} \quad, \quad P_{S V}(T)=\sum_{j=1}^{8} C_{j} \cdot \tau^{j-1} .
$$

\begin{tabular}{|c|c|c|c|c|c|}
\hline \multicolumn{6}{|c|}{ Table 14. Polynomial coefficients $\mathbf{A ( 1 )} \cdot \mathbf{A}(9)$ of the pressure of the liquid spinodal } \\
\hline 1 & -0.001387361801 & 2 & 0.1510341901 & 3 & 1.980521347 \\
\hline 4 & 2.921317875 & 5 & -38.3240633 & 6 & 162.2329521 \\
\hline 7 & -384.0027285 & 8 & 479.3961544 & 9 & -264.1248035 \\
\hline
\end{tabular}


Table 15. Polynomial coefficients $\mathrm{C}(1)-\mathrm{C}(8)$ of the pressure of the vapor spinodal

\begin{tabular}{|c|c|c|c|c|c|}
\hline 1 & -0.0007497146775 & 2 & 0.162845372 & 3 & -0.3190428782 \\
\hline 4 & -1.582269493 & 5 & 6.787420254 & 6 & -10.41333815 \\
\hline 7 & 7.599390008 & 8 & -2.285884902 & & \\
\hline
\end{tabular}

Above $620 K$ the descriptions are:

$$
\begin{aligned}
& P_{S L}(T)=P^{\times}(T)-4.98 \cdot 10^{8} \cdot \sum_{j=1}^{3} U_{j} \cdot \tau^{j}, \\
& P_{S V}(T)=P^{\times}(T)+2.00 \cdot 10^{8} \cdot \sum_{j=1}^{3} W_{j} \cdot \tau^{j} .
\end{aligned}
$$

The polynomials in Eq. [5.17] vanish at the critical point as $\tau$. Their coefficients

$$
\begin{aligned}
& U_{1}=0.05235363429, \quad, \quad U_{2}=4.419437236, \quad, \quad U_{3}=-18.86727538 \\
& W_{1}=0.1103469546 \quad, \quad W_{2}=0.913150777, \quad W_{3}=-10.87001272
\end{aligned}
$$

had been gained by using double smooth connections at $620 \mathrm{~K}$.

\subsection{The entropy on the saturation line}

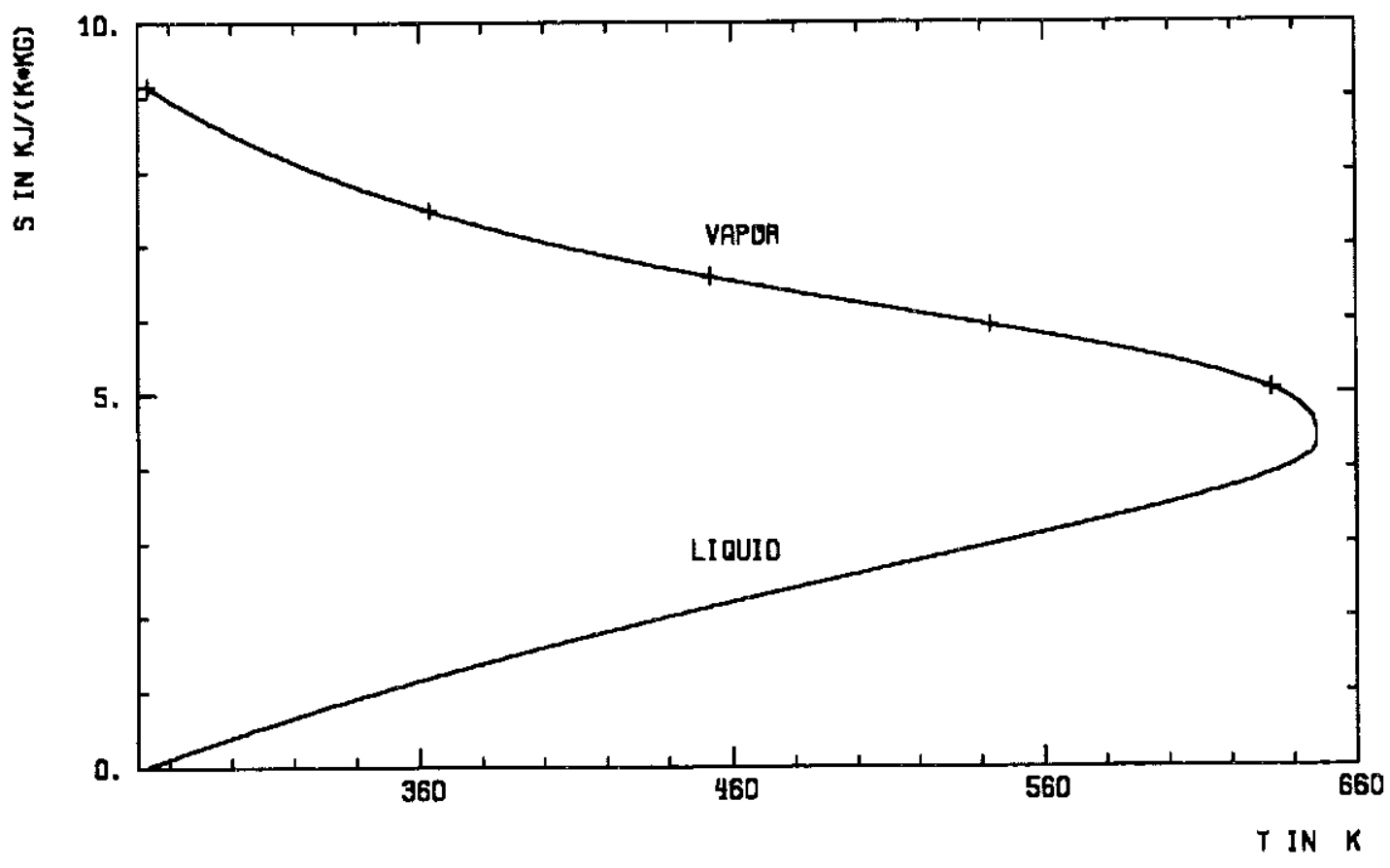

Figure 21. Entropy on the saturation line of the water 
The entropy in the saturated states show a course similar to the course of the saturated densities. Consequently AQUA employs - for the description of the entropy of the saturated liquid - a formula, similar to the one used for the description of the saturated densities.

Below $620 K$ the entropy of the saturated liquid - calculated by the H.G.K. code - is described with a w-polynomial (s. Eq. [5.1 - 5.2])

$$
S_{L}(T)=S_{c} \cdot \sum_{j=1}^{9} A_{j} \cdot w^{j-1}
$$

Table 16. Polynomial coelficients $A(1)-A(9)$ of the entropy of the saturated liquid

\begin{tabular}{|c|c|c|c|c|c|}
\hline 1 & 0.9528621116 & 2 & 0.2725494325 & 3 & -8.457375782 \\
\hline 4 & 44.57631748 & 5 & -150.7441559 & 6 & 311.7914429 \\
\hline 7 & -391.8528748 & 8 & 273.5529633 & 9 & -82.2848053 \\
\hline
\end{tabular}

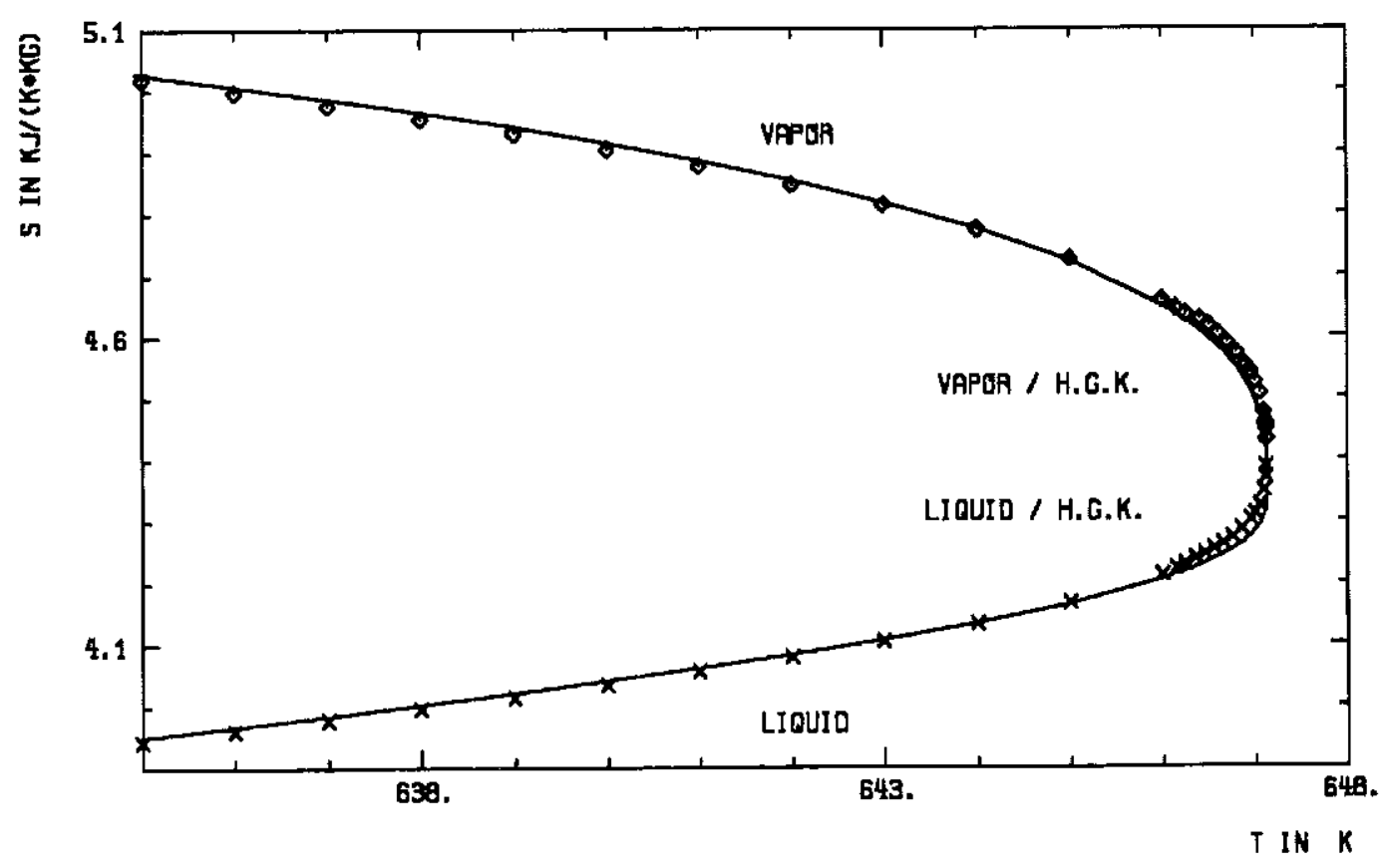

Figure 22. Entropy of the saturated states in the vicinity of $T_{c}$

Above $620 \mathrm{~K}$ the entropy of the liquid is described with a "vapor-like" scaled formula :

$$
S_{L}(T)=S_{c} \cdot\left[1-0.25 \cdot \tau^{\beta}+\tau\left(U_{1}+\tau\left(U_{2}+\tau^{2} U_{4}\right)\right)\right]
$$

The critical entropy and the scaled amplitude

$$
S_{c}=9.43 \cdot R_{\text {gas }} \quad \text { and } \quad B_{s}=0.25
$$

had been determined by fitting as well Eq. [5.19], as the corresponding formula for the entropy of the vapor to the H.G.K.-values above $635 \mathrm{~K}$. The coefficients 


$$
U_{1}=-1.23383958 \quad, \quad U_{2}=-1.656615363 \quad, \quad U_{4}=911.5375812
$$

result from using a double smooth extension to higher temperatures at the switching point.

The entropy on the saturated vapor needs no extra description, it can be calculated from $S_{L}$ by the eq. of Clausius \& Clapeyron

$$
S_{V}=S_{L}+\left(\frac{1}{\rho_{V}}-\frac{1}{\rho_{L}}\right) \cdot \frac{d P^{\times}}{d T}
$$

\subsection{The transport properties on the saturation line}

The following descriptions for the viscosity resp. thermal conductivity in the saturated states were constructed by calculatig the properties on the saturation line with the algorithms, described in 3.0, "Transport properties of the water." on page 9 and approximating these values with adequate functions.

\section{The viscosity}

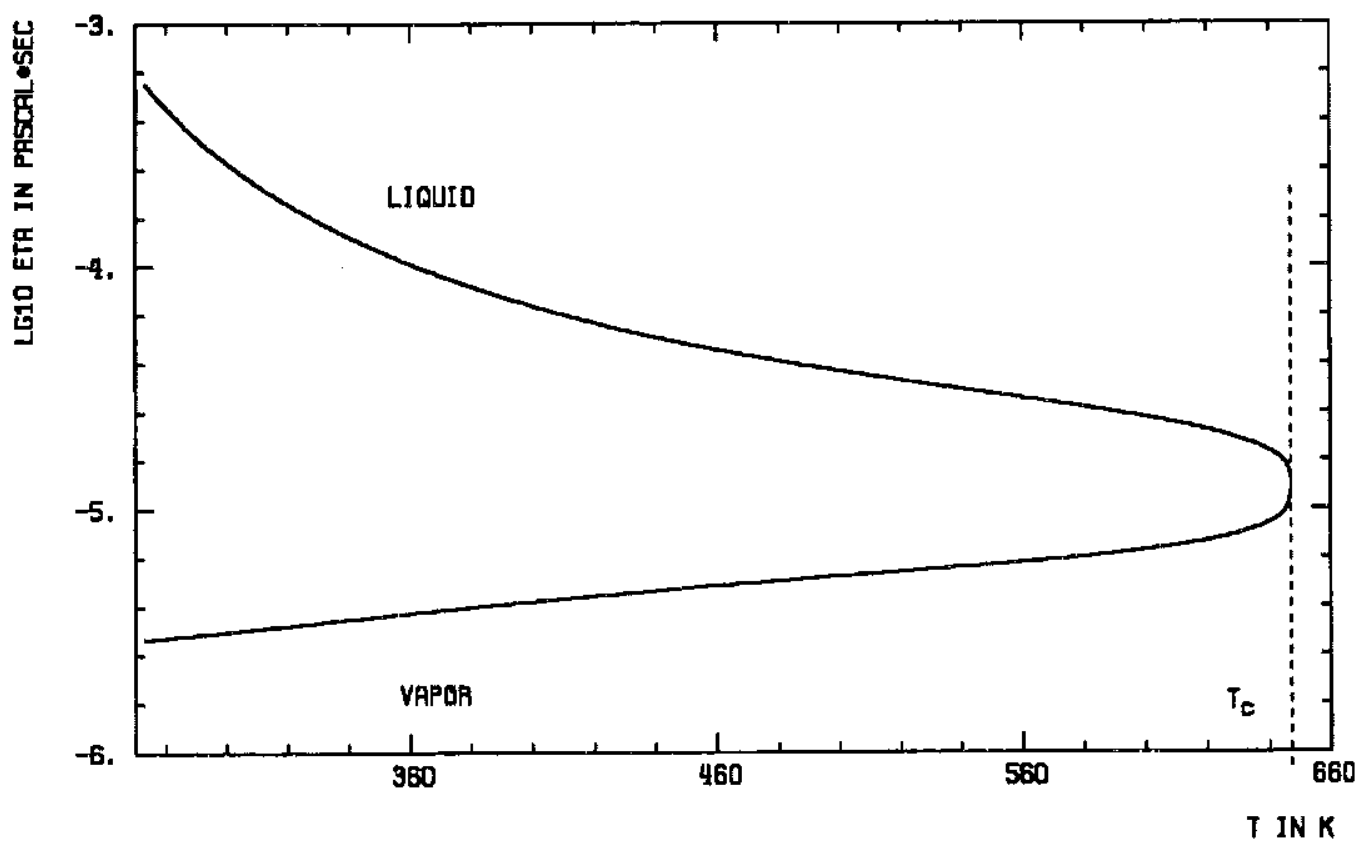

Figure 23. Viscosity of the water in the saturated states

In describing the viscosities in the cold liquid resp. vapor different functions of the critical variable w (Eq. [5.2] ) were used:

$$
\eta_{L}(T)=\frac{\eta_{c}}{\sum_{j=1}^{11} A_{j} \cdot w^{j-1}} \quad, \quad \eta_{V}(T)=\eta_{c} \cdot \sum_{j=1}^{9} c_{j} \cdot w^{j-1}
$$




\begin{tabular}{|c|c|c|c|c|c|}
\hline \multicolumn{6}{|c|}{ Table 17. Polynomial coefficients $\mathbf{A ( 1 )}$ - A(11) of the viscosity in the saturated liquid } \\
\hline 1 & 0.945822019 & 2 & -3.50567042 & 3 & 23.61506749 \\
\hline 4 & -176.2217806 & 5 & 960.5599634 & 6 & -3533.866457 \\
\hline 7 & 8609.716158 & 8 & -13637.7187 & 9 & 13435.90472 \\
\hline 10 & -7453.116048 & 11 & 1776.272412 & & \\
\hline
\end{tabular}

\begin{tabular}{|c|c|c|c|c|c|}
\hline \multicolumn{6}{|c|}{ Table 18. Polynomial coefficients $\mathbf{C}(1) \cdot \mathbf{C}(9)$ of the viscosity in the saturated vapor } \\
\hline 1 & 0.9733280423 & 2 & -4.061585251 & 3 & 20.72025593 \\
\hline 4 & -80.06616536 & 5 & 214.64856 & 6 & -384.6194719 \\
\hline 7 & 433.0818384 & 8 & -278.1018786 & 9 & 78.25010044 \\
\hline
\end{tabular}

In the vicinity of $T_{c}$ density-like formulas were adapted:

$$
\begin{aligned}
& \eta_{L}(T)=\eta_{c} \cdot\left[1+1.50 \cdot \tau^{\beta}+\tau\left(U_{1}+\tau\left(U_{2}+\tau^{2} U_{4}\right)\right)\right] \\
& \eta_{V}(T)=\eta_{c} \cdot\left[1-1.50 \cdot \tau^{\beta}+\tau\left(W_{1}+\tau\left(W_{2}+\tau^{2} W_{4}\right)\right)\right]
\end{aligned}
$$

The polynomial coefficients

$$
\begin{aligned}
& U_{1}=4.669845392 \quad, \quad U_{2}=-19.58930391 \quad, \quad U_{4}=1768.652432 \\
& W_{1}=4.262680597 \quad, \quad W_{2}=-34.89896734 \quad, \quad W_{4}=2452.105565
\end{aligned}
$$

were calculated using the restrictions of double-smooth connections at $620 \mathrm{~K}$ to the "cold" descriptions. By comparing the functions [5.22] with the calculated viscosities above $635 \mathrm{~K}$ the best fitting gives the following critical viscosity :

$$
\eta_{c}=3.95 \cdot 10^{-5} \quad \mathrm{~Pa} \cdot \mathrm{sec}
$$

\section{The thermal conductivity}

AQUA describes the thermal conductivities in the whole T-region as function of $\tau$. Below $620 \mathrm{~K}$ the following polynomials were used:

$$
\lambda_{L}(T)=\sum_{j=1}^{B} A_{j} \cdot \tau^{j-1} \quad, \quad \lambda_{V}(T)=\sum_{j=1}^{9} C_{j} \cdot \tau^{j-1}
$$

Table 19. Coefficients $A(1)-A(8)$ of the thermal conductivity in the saturated liquid

\begin{tabular}{|c|c|c|c|c|c|}
\hline 1 & 0.397252283 & 2 & 1.361430056 & 3 & 0.2886579476 \\
\hline 4 & -1.137153088 & 5 & -75.20016424 & 6 & 333.88123 \\
\hline 7 & -546.0632435 & 8 & 311.575529 & & \\
\hline
\end{tabular}




\begin{tabular}{|c|c|c|c|c|c|}
\hline \multicolumn{6}{|c|}{ Table 20. Coefficients $\mathbf{C ( 1 )}-\mathbf{C}(9)$ of the thermal conductivity in the saturated vapor } \\
\hline 1 & 0.2012600289 & 2 & -2.546881317 & 3 & 19.24073027 \\
\hline 4 & -79.8925815 & 5 & 178.6322576 & 6 & -195.5137779 \\
\hline 7 & 62.06051011 & 8 & 38.86696488 & 9 & -15.11624233 \\
\hline
\end{tabular}

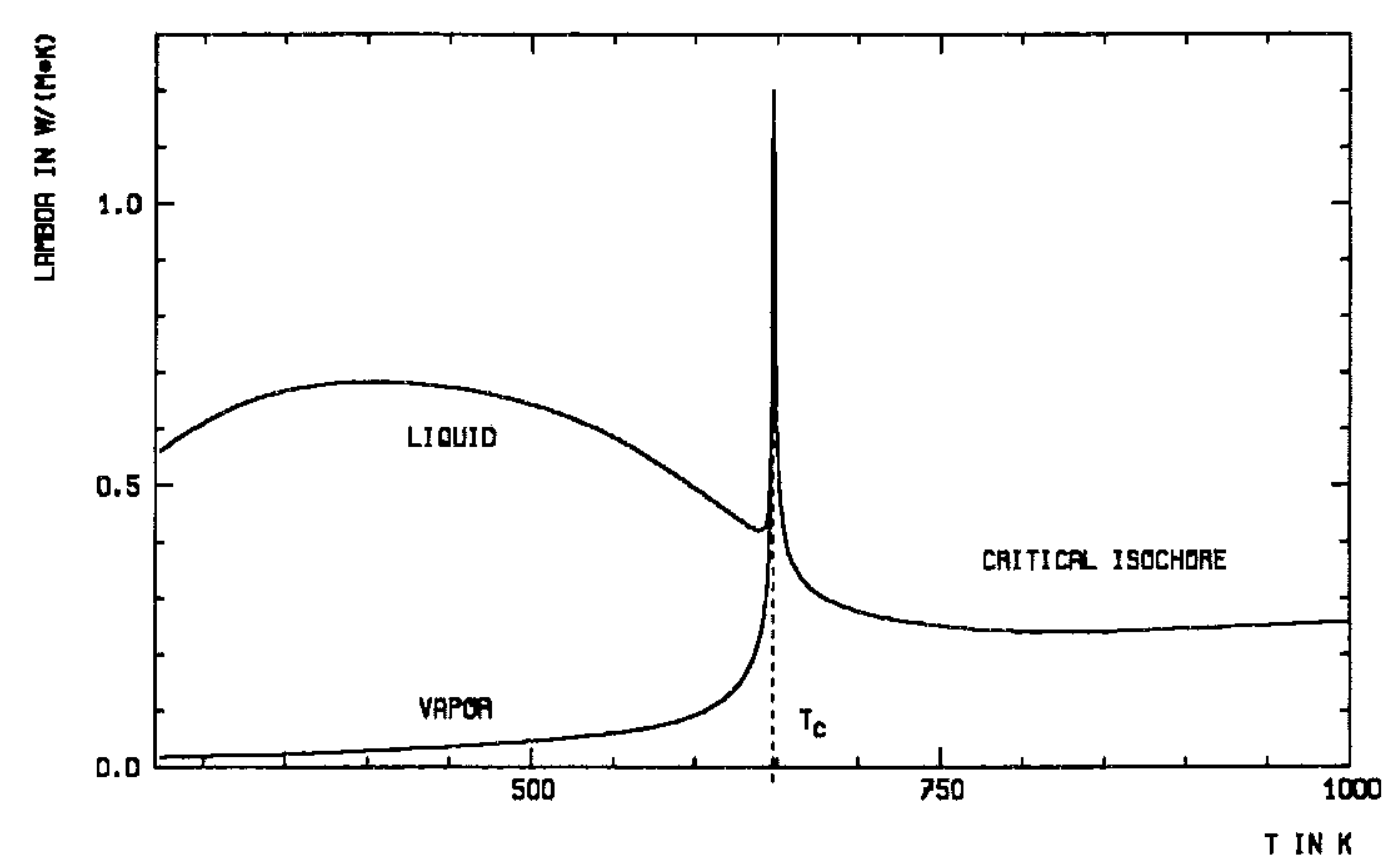

Figure 24. Thermal conductivity of the water as function of the temperature

At the critical point the thermal conductivity approaches infinty as

$$
\lambda \propto \tau^{-0.5}
$$

Consequently above $620 \mathrm{~K}$ the following near-critical descriptions had been applied:

$$
\lambda_{L}(T)=\tau^{-0.5} \cdot \sum_{j=1}^{5} U_{j} \cdot \tau^{j-1} \quad, \quad \lambda_{V}(T)=\tau^{-0.5} \cdot \sum_{j=1}^{5} W_{j} \cdot \tau^{j-1} .
$$

The first coefficients of the appended polynomials are equal:

$$
U_{1}=W_{1}=0.02
$$

For the remaining coefficients the condition of the double smooth continuation at $620 \mathrm{~K}$ gives:

$$
\begin{aligned}
& U_{2}=2.484618723, \quad U_{3}=-31.16080409 \\
& U_{4}=421.0825394 \\
& W_{2}=0.7221916099 \\
& W_{4}=495.59365880
\end{aligned} \quad, \quad \begin{aligned}
& U_{5}=-2390.608760 \\
& W_{3}=-29.169893490
\end{aligned}
$$




\subsection{Other saturated properties}

The following properties are all described in AQUA as functions of the scaled temperature $\tau$, only the form of the functions differ in the cold $(T<620 \mathrm{~K})$ and in the near-critical $(T>620 \mathrm{~K}$ ) part of saturation line. Below $620 \mathrm{~K} \tau$-polynomials were fitted to the property-values calculated with the H.G.K. code. Above $620 \mathrm{~K}$ scaled descriptions ( $\mathrm{s}$. e.g. Eq. [5.30] ) are used. The values of the critical parameters in these formula are gained by fitting the descriptions to the H.G.K.-functions in the region

$$
635 K<T<T_{c} .
$$

The remaining coefficients of the high-T descriptions are defined by demanding a double-smooth connection ( $\mathrm{Eq}$. [5.12] ) for them to the low-T formulas at $T_{s}=620 \mathrm{~K}$.

In all the cases the descriptions had been developed for the reduced properties - $P_{p}^{0}$, $P_{T}^{0}, C_{V}^{0}$ and $G^{0}$ - since AQUA caltulates internally with these functions.

\section{The density derivative of the pressure}

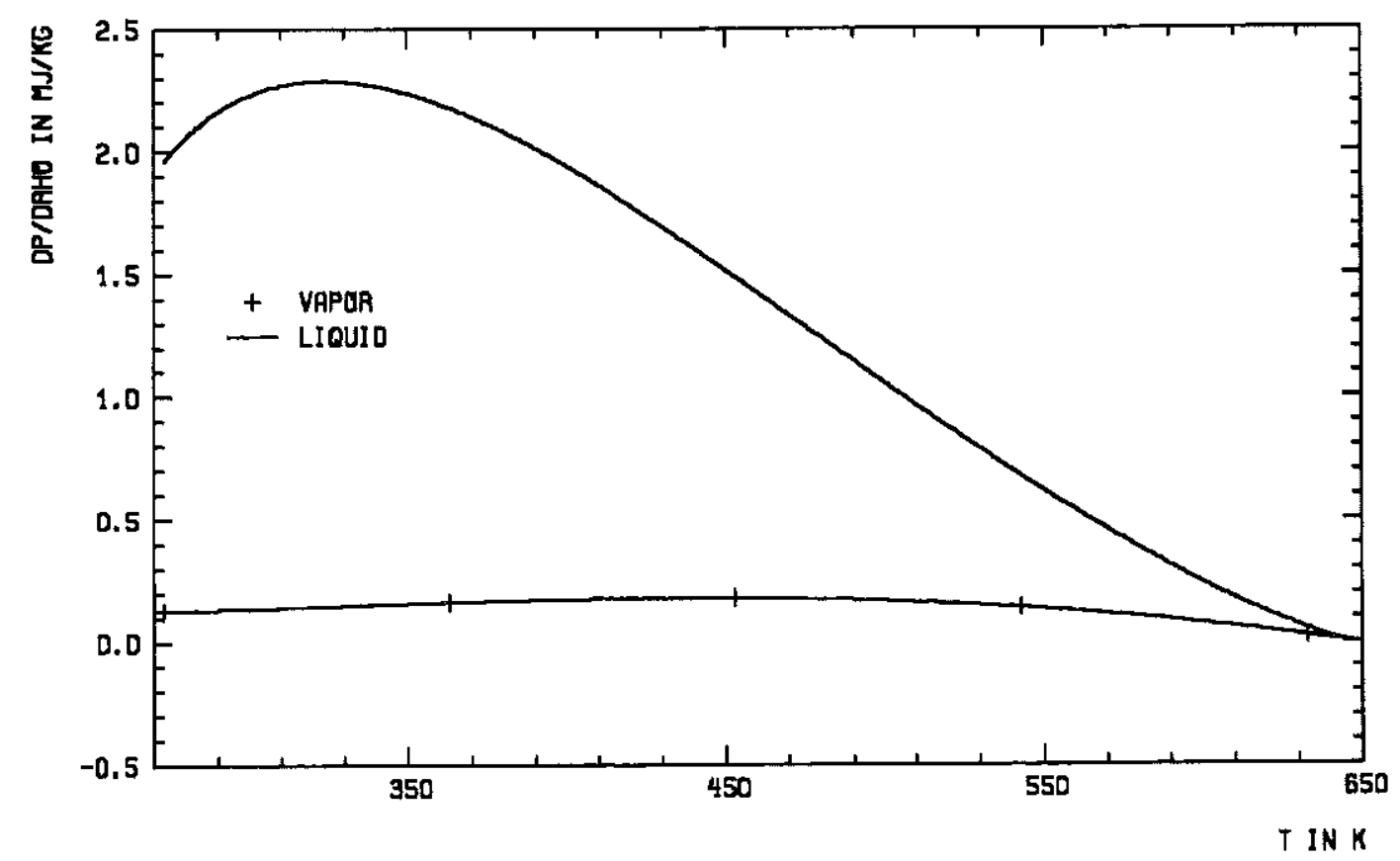

Figure 25. Density derivatives of the pressure in the saturated states

\begin{tabular}{|c|c|c|c|c|c|}
\hline \multicolumn{6}{|c|}{ Table 21. Polynomial coefficients $\mathbf{A}(1)-\mathbf{A}(12)$ of $\partial P / \partial \rho$ in the saturated liquid } \\
\hline 1 & 0.09168326854 & 2 & 0.1410358804 & 3 & 293.745773 \\
\hline 4 & -3694.718543 & 5 & 35315.9487 & 6 & -224505.1913 \\
\hline 7 & 968102.1275 & 8 & -2837321.019 & 9 & 5560661.663 \\
\hline 10 & -6973719.089 & 11 & 5058540.246 & 12 & -1615244.963 \\
\hline
\end{tabular}




\begin{tabular}{|c|c|c|c|c|c|}
\hline \multicolumn{6}{|c|}{ Table 22. Polynomial coefficients $\mathbf{C}(1)-\mathbf{C}(9)$ of $\partial P / \partial \rho$ in the saturated vapor } \\
\hline 1 & 0.001435429119 & 2 & 3.738553917 & 3 & 3.552096947 \\
\hline 4 & -55.88507759 & 5 & 217.5743793 & 6 & -535.2445068 \\
\hline 7 & 812.4224243 & 8 & -670.9285889 & 9 & 229.0827484 \\
\hline
\end{tabular}

Table 21 and Table 22 contain the coefficients of the low temperature description od the density-derivatives for the saturated liquid resp. for the saturated vapor

$$
\frac{\partial P}{\partial \rho_{L}}(T)=R_{\text {gas }} \cdot T \sum_{j=1}^{12} A_{j} \cdot \tau^{j-1} \quad, \quad \frac{\partial P}{\partial \rho_{V}}(T)=R_{\text {gas }} \cdot T \sum_{j=1}^{g} C_{j} \cdot \tau^{j-1}
$$

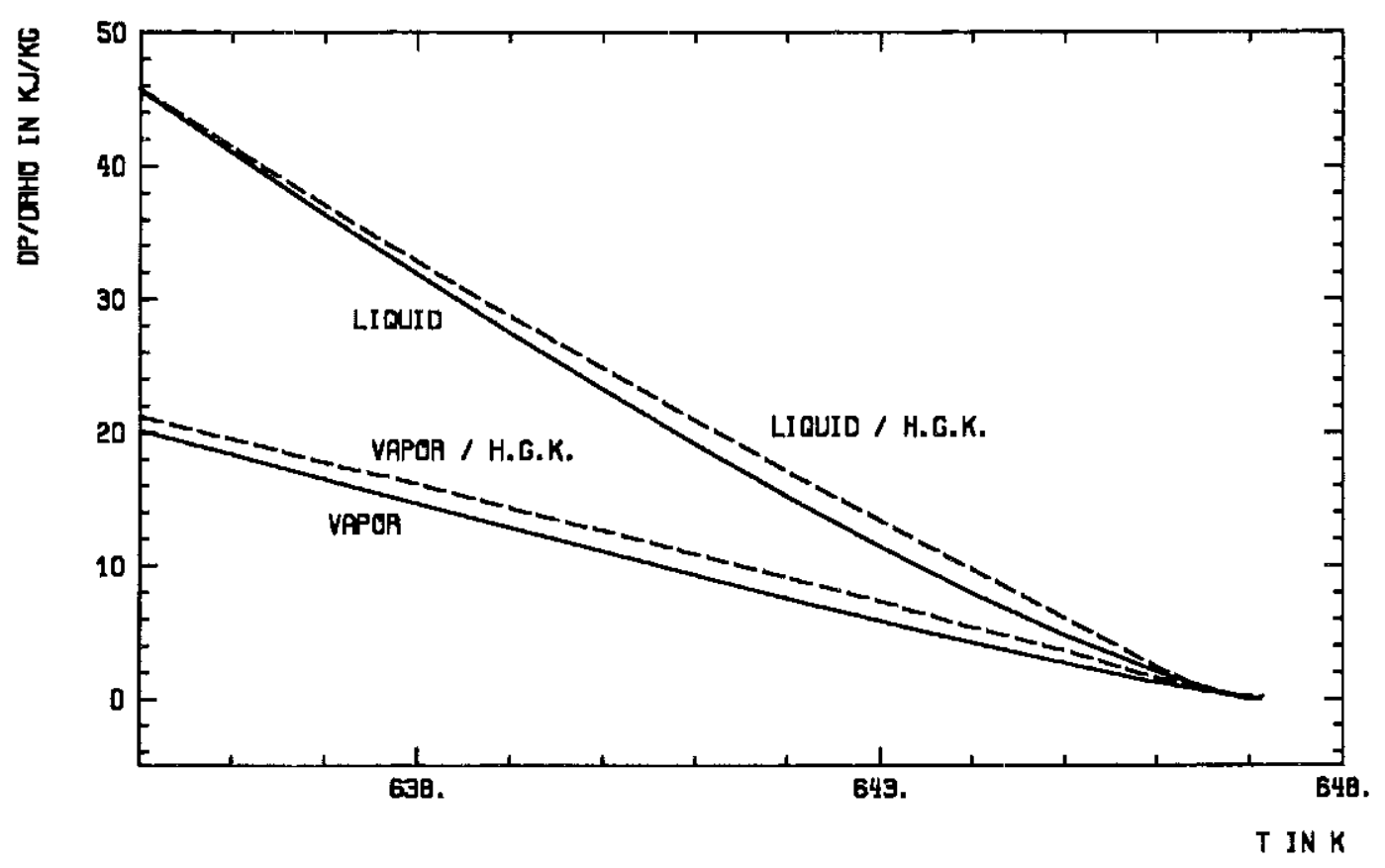

Figure 26. Density derivatives of the pressure in the vicinity of $T_{c}$

At the critical point the density-derivatives vanish as

$$
\frac{\partial P}{\partial \rho_{L}} \propto \rho_{L} \cdot \tau^{\gamma} \quad \text { resp. } \quad \frac{\partial P}{\partial \rho_{V}} \propto \rho_{V} \cdot \tau^{\gamma}
$$

with the critical exponent $\gamma=1.24$ (s. e.g. /17/) so the following near-critical descriptions had been applied:

$$
\begin{aligned}
& \frac{\partial P}{\partial \rho_{L}}(T)=R_{g a s} \cdot T \cdot \frac{\rho_{L}}{\rho_{c}} \cdot \tau^{\gamma} \sum_{j=1}^{4} U_{j} \cdot \tau^{j-1}, \\
& \frac{\partial P}{\partial \rho_{V}}(T)=R_{g a s} \cdot T \cdot \frac{\rho_{V}}{\rho_{c}} \cdot \tau^{\gamma} \sum_{j=1}^{4} W_{j} \cdot \tau^{j-1} .
\end{aligned}
$$

The first coefficients of the polynomials in Eq. [5.30] are the same: 


$$
U_{1}=W_{1}=15
$$

and here are the remaining ones:

$$
\begin{aligned}
& U_{2}=-79.73057836 \quad, \quad U_{3}=-430.1476885, \quad, \quad U_{4}=14139.7632 \\
& W_{2}=369.6750971 \quad, \quad W_{3}=-5110.089071 \quad, \quad W_{4}=46121.0908 \quad .
\end{aligned}
$$

The temperature derivative of the pressure

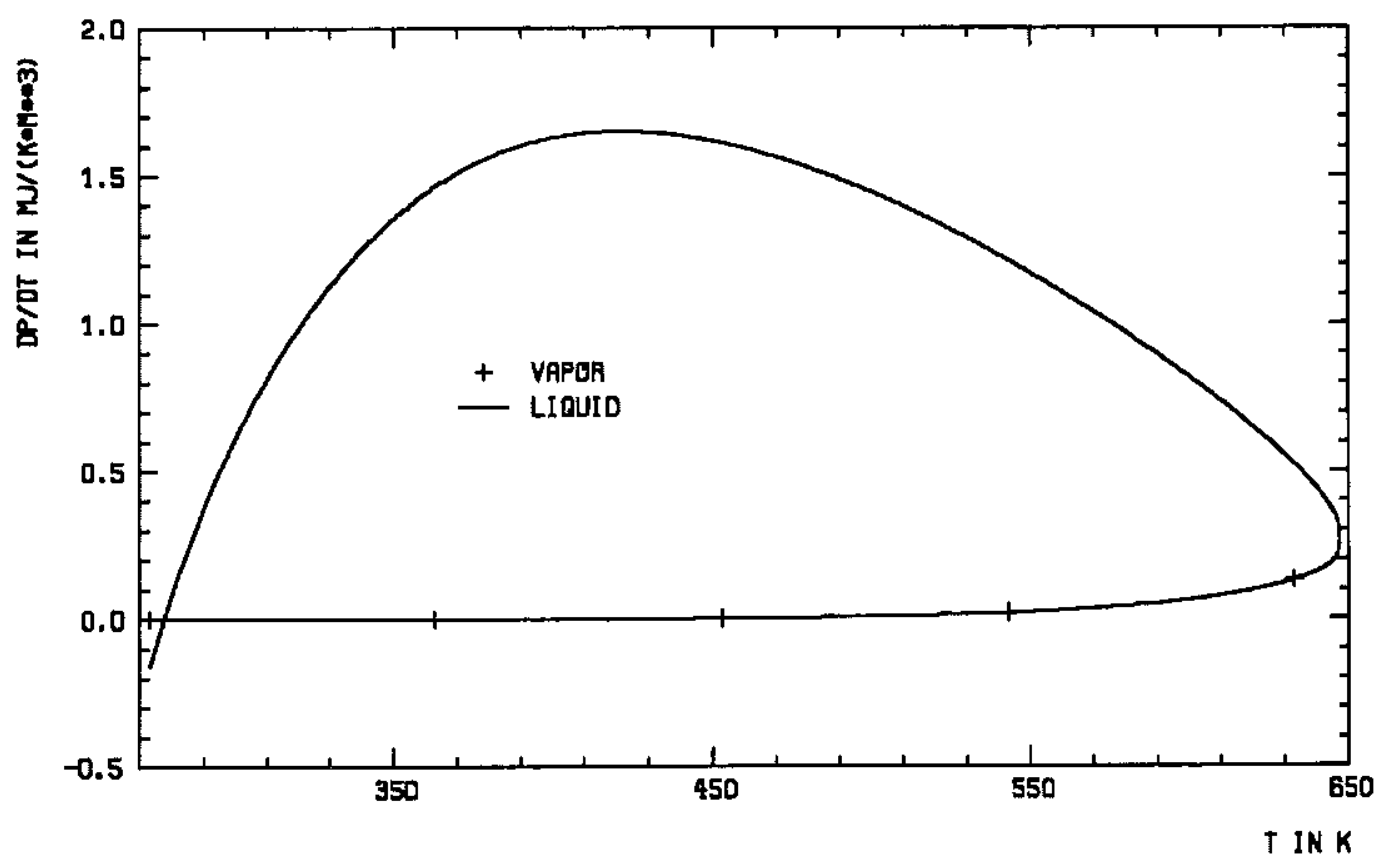

Figure 27. Temperature derivatives of the pressure in the saturated states

The temperature derivatives show quite a regular behaviour at $T_{c}$, so one can use polynomials as well on the cold saturation line as on the near critical one. Below $620 \mathrm{~K}$ the polynomial fittings resulted in

$$
\frac{\partial P}{\partial T_{L}}(T)=R_{\text {gas }} \cdot \rho_{L} \sum_{j=1}^{12} A_{j} \cdot \tau^{j-1} \quad, \quad \frac{\partial P}{\partial T_{V}}(T)=R_{g a s} \cdot \rho_{V} \sum_{j=1}^{10} C_{j} \cdot \tau^{j-1}
$$

\begin{tabular}{|c|c|c|c|c|c|}
\hline \multicolumn{6}{|c|}{ Table 23. Polynomial coefficients $A(1)-A(12)$ of $\partial P / \partial T$ in the saturated liquid } \\
\hline 1 & 1.818884544 & 2 & 16.40737736 & 3 & -65.85455759 \\
\hline 4 & 52.04371914 & 5 & 4031.238729 & 6 & -47257.0313 \\
\hline 7 & 277423.4268 & 8 & -988332.4003 & 9 & 2218919.758 \\
\hline 10 & -3077677.674 & 11 & 2414555.699 & 12 & -821000.2244 \\
\hline
\end{tabular}




\begin{tabular}{|c|c|c|c|c|c|}
\hline \multicolumn{6}{|c|}{ Table 24. Polynomial coefficients $\mathbf{C}(1) \cdot \mathbf{C}(10)$ of $\partial P / \partial T$ in the saturated vapor } \\
\hline 1 & 2.029700729 & 2 & -0.1255470649 & 3 & -61.54407176 \\
\hline 4 & 544.8751175 & 5 & -2848.188899 & 6 & 9708.977783 \\
\hline 7 & -21262.51929 & 8 & 28710.96533 & 9 & -21755.27246 \\
\hline 10 & 7082.224609 & & & & \\
\hline
\end{tabular}

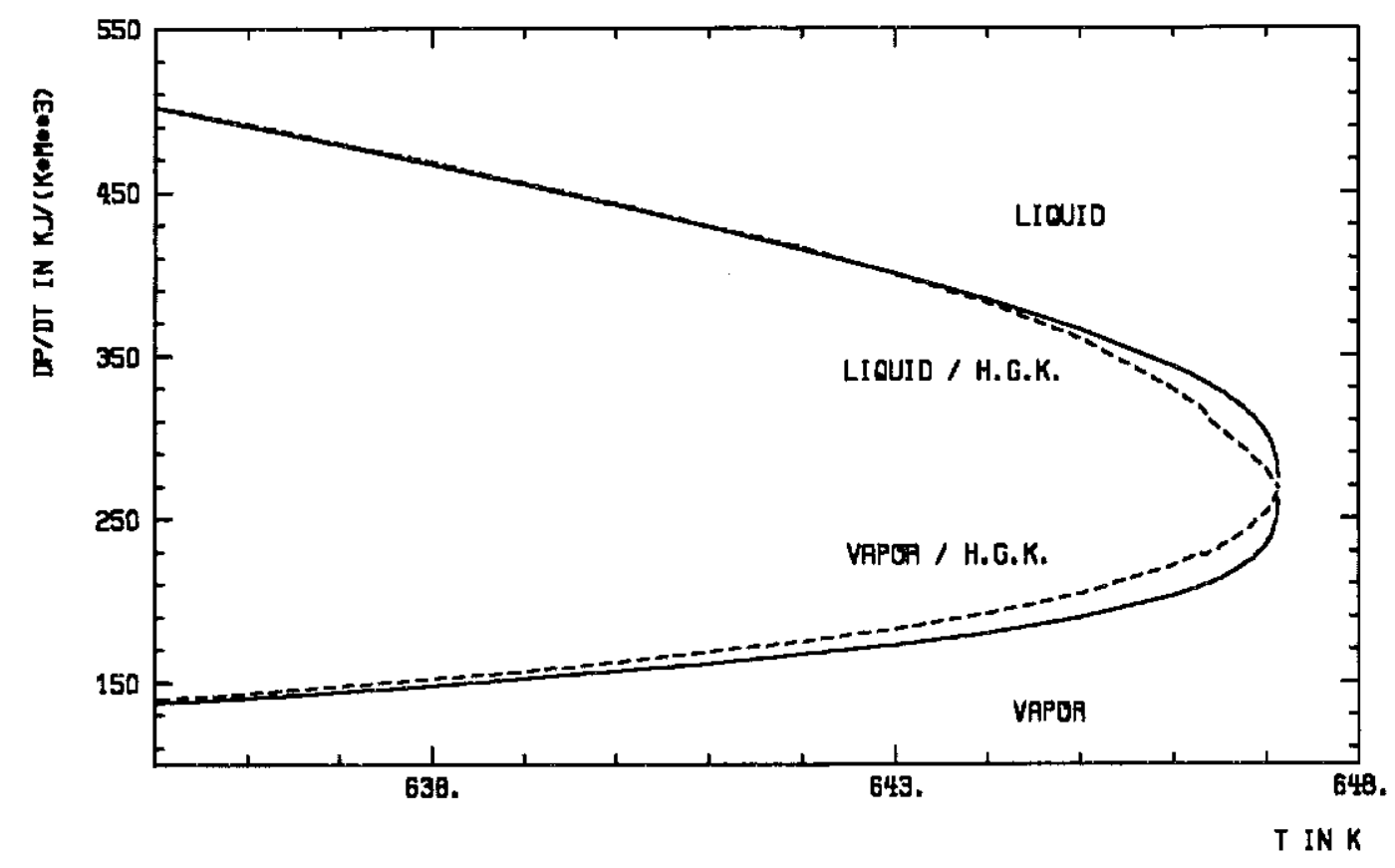

Figure 28. Temperature derivatives of the pressure in the vicinity of $T_{c}$

Above $620 \mathrm{~K}$ the double smooth extension gives

$$
\begin{aligned}
& \frac{\partial P}{\partial T_{L}}(T)=R_{\text {gas }} \cdot \rho_{L} \sum_{j=1}^{4} U_{j} \cdot \tau^{j-1}, \\
& \frac{\partial P}{\partial T_{V}}(T)=R_{\text {gas }} \cdot \rho_{V} \sum_{j=1}^{4} W_{j} \cdot \tau^{j-1} .
\end{aligned}
$$

The first coefficients of the polynomials in Eq. [5.32] must be the same

$$
U_{1}=W_{1}=1.80215732
$$

to fulfil

$$
\frac{\partial P}{\partial T_{V}}\left(T_{c}\right)=\frac{d P^{\times}\left(T_{c}\right)}{d T}=\frac{\partial P}{\partial T_{L}}\left(T_{c}\right)
$$

The remainig ones are: 


$$
\begin{gathered}
U_{2}=17.63135647 \quad, \quad U_{3}=-97.95806903 \quad, \quad U_{4}=451.8053522 \\
W_{2}=16.00172011 \quad, \quad W_{3}=-439.3063303 \quad, \quad W_{4}=3359.729201
\end{gathered}
$$

\section{The heat capacities}

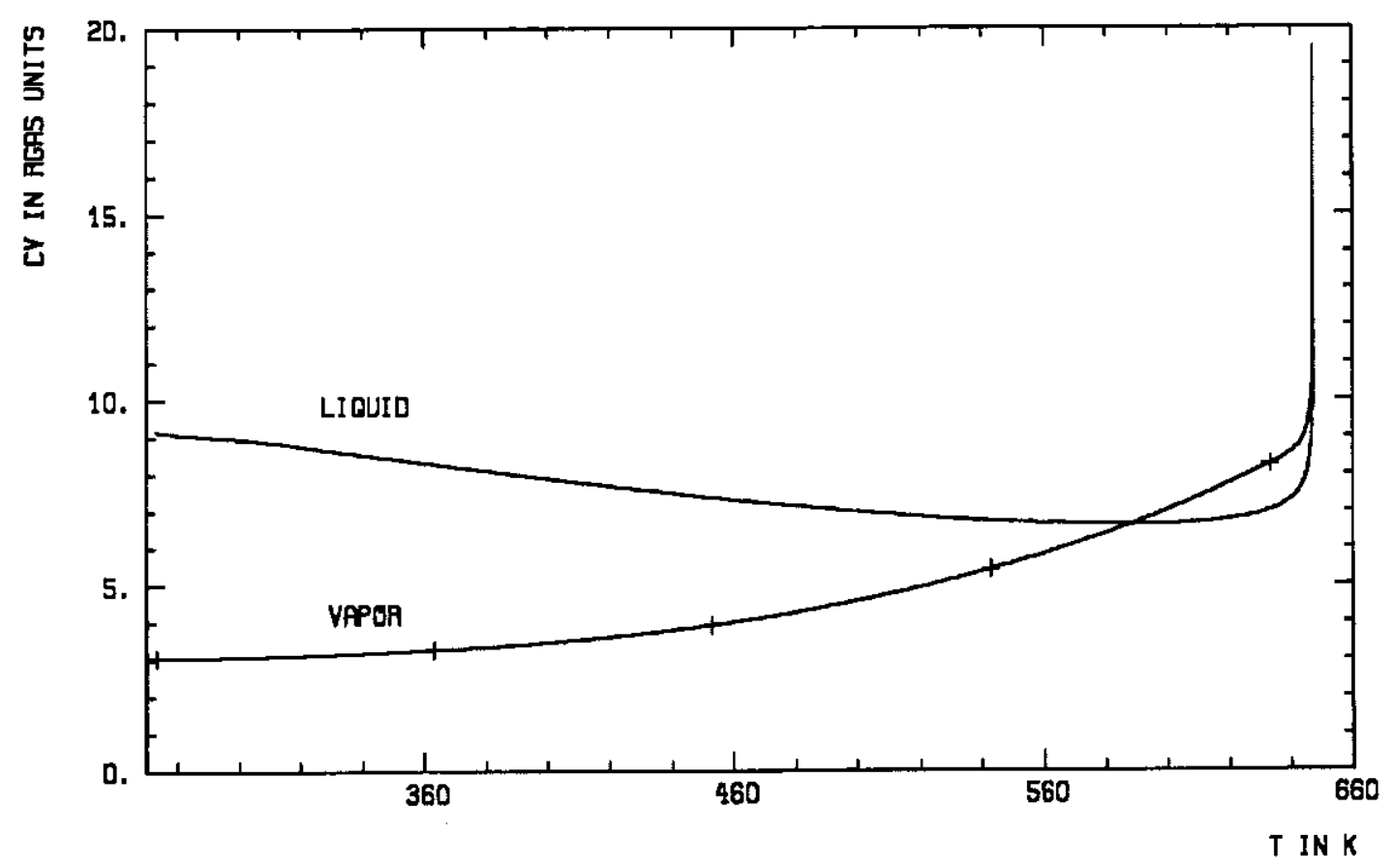

Figure 29. Heat capacities of the water in the saturated states.

AQUA describes the heat capacities in $R_{\text {gas }}$ units. Below $620 \mathrm{~K}$ polynomials were used:

$$
C_{V L}(T)=R_{g a s} \cdot \sum_{j=1}^{12} A_{j} \cdot \tau^{j-1} \quad, \quad C_{V V}(T)=R_{g a s} \cdot \sum_{j=1}^{10} C_{j} \cdot \tau^{j-1}
$$

\begin{tabular}{|c|c|c|c|c|c|}
\hline \multicolumn{6}{|c|}{ Table 25. Polynomial coefficients $\mathbf{A ( 1 )}-\mathbf{A}(12)$ of $C_{V}$ in the saturated liquid } \\
\hline 1 & 7.4305055 & 2 & -24.93618016 & 3 & 195.5654567 \\
\hline 4 & 1986.485797 & 5 & -53305.43411 & 6 & 505697.1723 \\
\hline 7 & -2724774.677 & 8 & 9167737.673 & 9 & -19622033.78 \\
\hline 10 & 25984725.33 & 11 & -19419431.35 & 12 & 6263206.554 \\
\hline
\end{tabular}




\begin{tabular}{|c|c|c|c|c|c|}
\hline \multicolumn{6}{|c|}{ Table 26. Polynomial coefficients $\mathbf{C}(1)-\mathbf{C}(10)$ of $C_{V}$ in the saturated vapor } \\
\hline 1 & 8.956404735 & 2 & -33.97230774 & 3 & 126.5786602 \\
\hline 4 & -513.7462523 & 5 & 1521.138693 & 6 & -2182.266721 \\
\hline 7 & -73.57828067 & 8 & 4483.361889 & 9 & -5407.324042 \\
\hline 10 & 2099.821164 & & & & \\
\hline
\end{tabular}

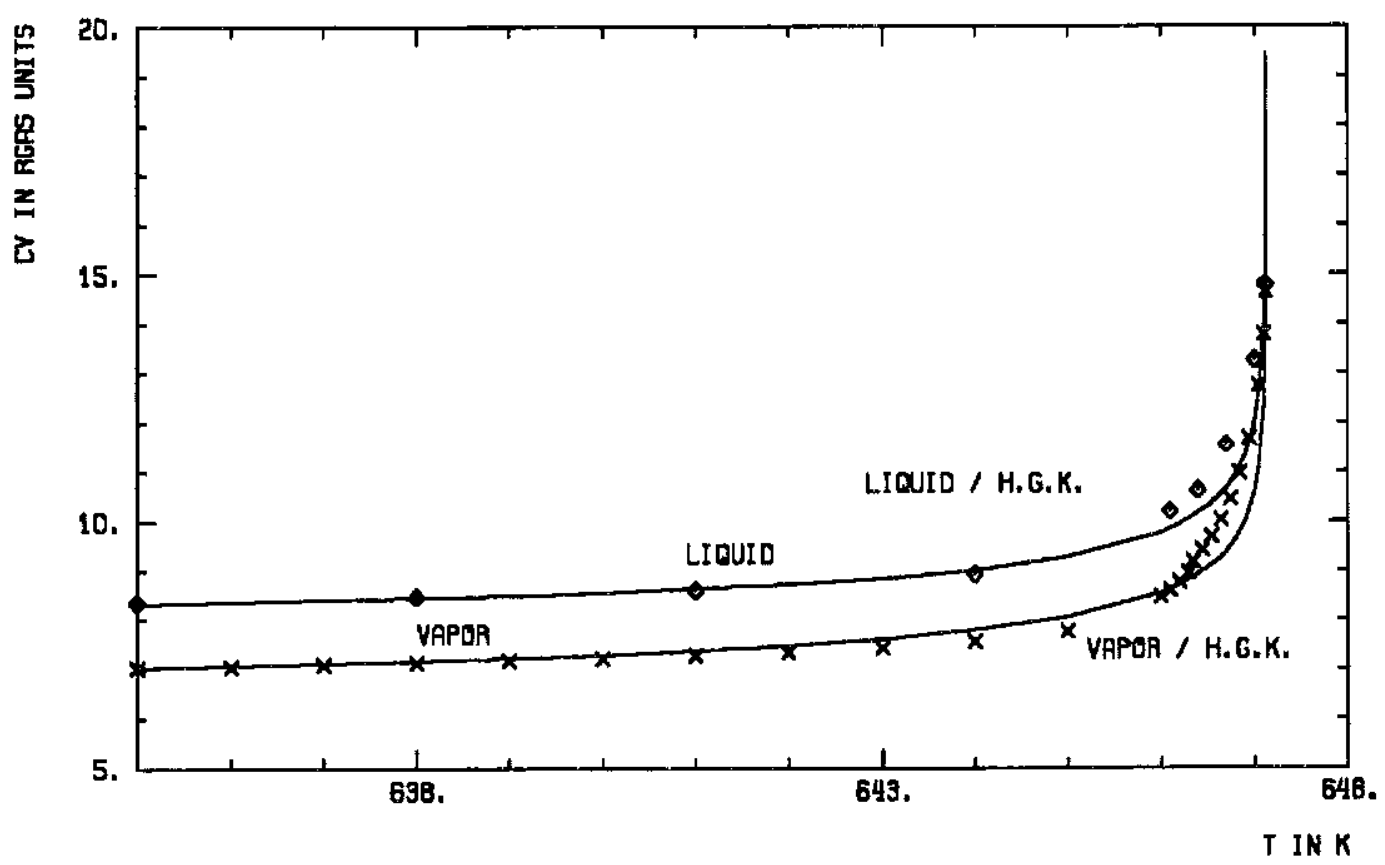

Figure 30. Heat capacities of the water in the vicinity of $T_{c}$

At the critical point the heat capacity approaches infinty as

$$
C_{V} \propto \tau^{\alpha}
$$

with the critical exponent $\alpha=-0.1$ (s. e.g. $/ 17 /$ ). Consequently above $620 \mathrm{~K}$ the following near-critical descriptions had been applied:

$$
C_{V L}(T)=R_{g a s} \cdot \tau^{\alpha} \cdot \sum_{j=1}^{4} U_{j} \cdot \tau^{j-1} \quad, \quad C_{V V}(T)=R_{g a s} \cdot \tau^{\alpha} \cdot \sum_{j=1}^{4} W_{j} \cdot \tau^{j-1} .
$$

The double smooth continuation at $620 \mathrm{~K}$ results in the polynomial-coefficients:

$$
\begin{aligned}
& U_{1}=4.5, \quad U_{2}=15.21452007, \quad U_{3}=-167.2951053, U_{4}=1042.333618, \\
& W_{1}=5.1, W_{2}=42.35451412, W_{3}=-1002.675527, W_{4}=6911.203183 \text {. }
\end{aligned}
$$




\section{The free enthalpy, $G$}

The Gibbs function shows not even a trace of irregularity at $T_{c}$. A single polynomial suffices therefore, to describe it in the whole temperature region:

$$
G_{L}(T)=G_{V}(T)=R_{\text {gas }} \cdot T \sum_{j=1}^{9} A_{j} \cdot \tau^{j-1} .
$$

Table 27. Polynomial coefficients $A(1)-A(9)$ of the free enthalpy of the saturated states

\begin{tabular}{|l|c|c|c|c|c|}
\hline 1 & -2.569516966 & 2 & 5.187876405 & 3 & 0.6408677408 \\
\hline 4 & 1.374106295 & 5 & -18.01831251 & 6 & 68.53337198 \\
\hline 7 & -176.2024879 & 8 & 226.296896 & 9 & -130.4997179 \\
\hline
\end{tabular}

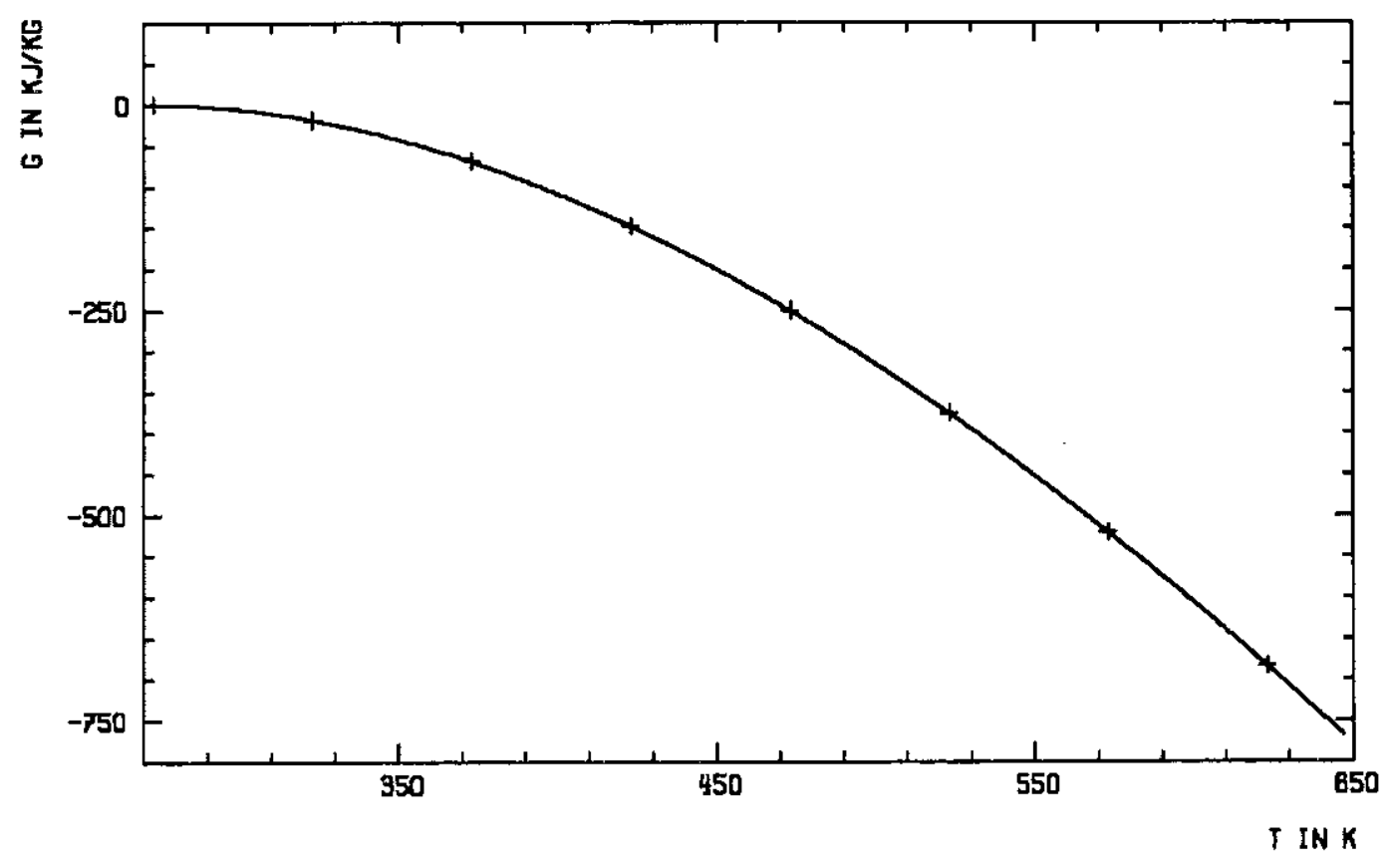

Figure 31. Free enthalpy - $G$ - of the water in the saturated states 


\subsection{Calculating the densities from the pressures}

IVA3 supplies the equation of state with the temperature and the pressure as independent variables, the H.G.K.-routines calculate the thermophysical properties as temperature-density functions. So obviously a procedure is needed to calculate the variable-pair $(T, \rho)$ from the variable-pair $(T, P)$. AQUA uses three routines to do this task : DLFIND seeks $\rho(T, P)$ in the liquid, DVFIND in the vapor, and DGFIND in the supercritical water.

\subsection{Calculating small density changes}

All of these routines

DGFIND(T,P, $\rho, I E C C H)$

$\operatorname{DLFIND}(T, P, \rho, \mathrm{IECCH})$

DVFIND $(T, P, \rho, I E C C H)$

use the same searching-algorithm : beginning with an initial density, $\rho_{0}$ - supplied by the user - a first pressure, $P_{0}$ and $\partial P / \partial \rho$ are calculated, then a corrected density is derived from the difference, $P$ - $P_{0}$ - by Newton's method.

Table 28. Coefficients of $P_{L \max }(\mathrm{T})$.

\begin{tabular}{|c|c|c|c|}
\hline \multicolumn{5}{|c|}{$P_{\text {Lmax }}=A_{0}+A_{1} T^{1}+A_{2} T^{2}+\ldots$} \\
\hline $\mathbf{T}>$ & $\mathbf{0 ~ K}$ & $\mathbf{3 7 3 . 1 5} \mathbf{K}$ & $\mathbf{6 4 7 . 1 2 6 \mathrm { K }}$ \\
\hline$A_{0}$ & $128.0317635 \cdot 10^{9}$ & $1.121372093 \cdot 10^{9}$ & $-731.6836907 \cdot 10^{6}$ \\
\hline$A_{1}$ & $-1.503427271 \cdot 10^{9}$ & $-6.278371391 \cdot 10^{8}$ & $6.597512847 \cdot 10^{6}$ \\
\hline$A_{2}$ & $6.608885188 \cdot 10^{8}$ & $26.44577782 \cdot 10^{3}$ & $-7.08407094 \cdot 10^{3}$ \\
\hline$A_{3}$ & $-12.83080180 \cdot 10^{3}$ & -33.36474460 & 5.764846806 \\
\hline$A_{4}$ & 9.305682808 & $14.81761478 \cdot 10^{-3}$ & $-3.188721412 \cdot 10^{-3}$ \\
\hline$A_{5}$ & & & $1.193485372 \cdot 10^{-6}$ \\
\hline$A_{6}$ & & & $-2.946300976 \cdot 10^{-10}$ \\
\hline$A_{7}$ & & & $4.575561580 \cdot 10^{-14}$ \\
\hline$A_{8}$ & & & $-4.040003535 \cdot 10^{-18}$ \\
\hline$A_{9}$ & & & $1.543953233 \cdot 10^{-22}$ \\
\hline
\end{tabular}

Before beginnig with the iteration, the routines check, if there is a posibility at all to find a density, corresponding to the supplied pressure, $P$ in the given area. To this aim $P$ is compared with a pressure-window,

$$
P_{\min } \leq P \leq P_{\max }
$$

and if $P$ don't fit into it, the routines end with an error message ( for the error handling $s$. Appendix $L$, "Return codes" on page 151). The borders of the pressure-window are

$$
P_{\min }=0, P_{\max }=P_{L \max }(T)
$$

in the supercritical water, 


$$
P_{\min }=0, P_{\max }=P_{S V}(T)
$$

in the vapor, and

$$
P_{\min }=P_{S L}(T) \quad, \quad P_{\max }=P_{L \max }(T)
$$

in the liquid respectively.

$P_{\text {Lmax }}$ in the above eq.s is the pressure at the liquid edge of the validity-domain

$$
P_{L \max }(T)=P\left(T, 1200 \mathrm{~kg} / \mathrm{m}^{3}\right) .
$$

AQUA calculates $P_{L \max }$ with the temperature polynomials given in Table 28 (routine PLMAX). The description is valid in the temperature range

$$
273.15 K \leq T \leq 5000 K \text {. }
$$

The remaining two temperature-functions in Eq. [6.1 - 6.3], $P_{S V}(\mathrm{~T})$ resp. $P_{s L}(\mathrm{~T})$ are the spinodal pressures in the vapor resp. in the liquid, Eq. [5.16 - 5.17]. At least as long the temperatures remain below 635. K. Abowe this point the shape of the H.G.K.-isotherms begins to differ markedly from the shape, one would expect in the neighbourhood of the critical point. As well the pressure, as the density - particularly of the liquid spinodal - differ from the descriptions given in 5.0, "Describing the water properties in the saturated states" on page 27 (compare also Figure 18 on page 31 ). Figure 32 shows a massively enlarged part of the $647 \mathrm{~K}$ isotherm of the water. On this isotherm the liquid spinodal lies in the vapor region already.

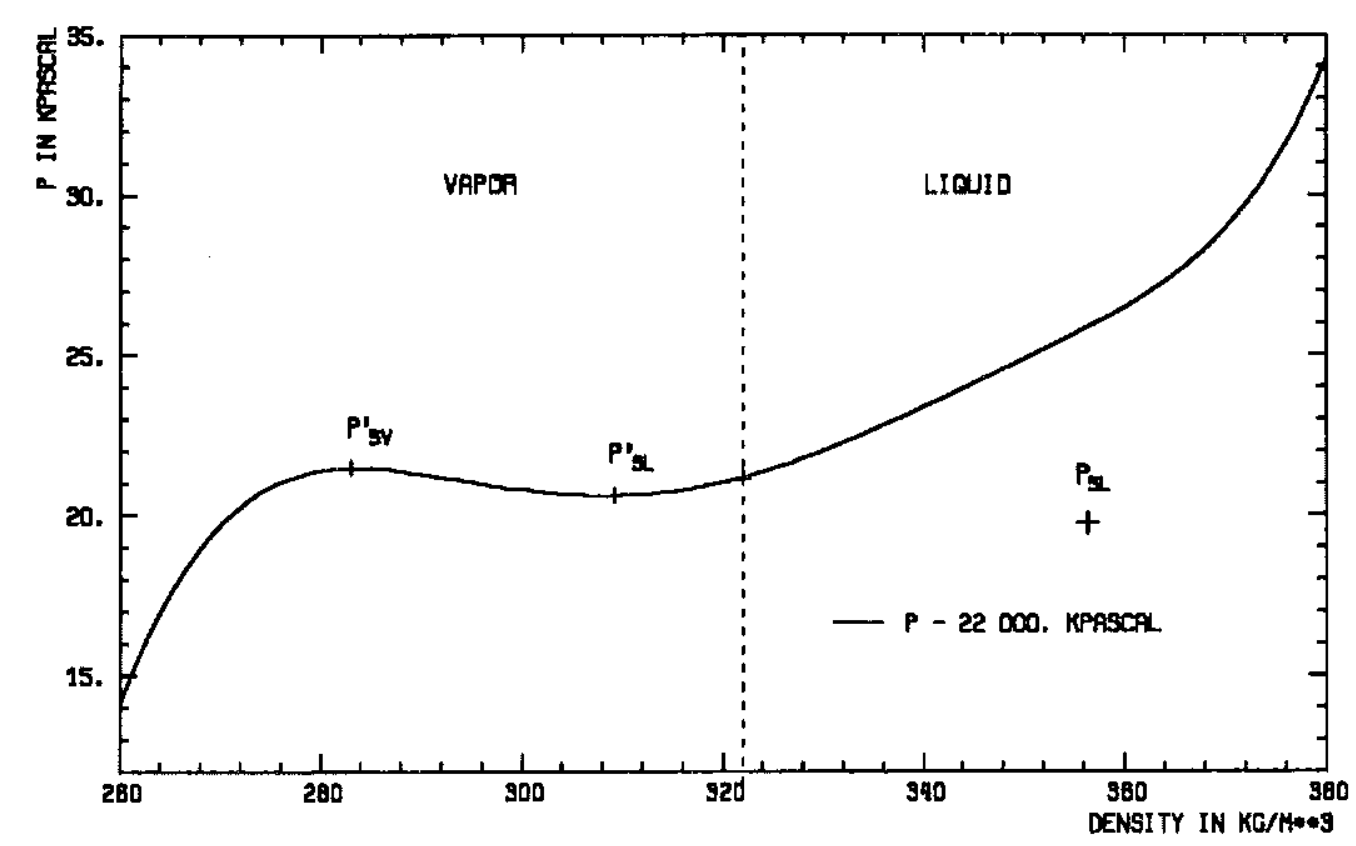

Figure 32. Water pressures on the $647 \mathrm{~K}$ isotherm

AQUA uses additional $\tau$-polynomials to describe the real pressure minima and maxima $P_{s L}^{\prime}, P_{s v}^{\prime}$ in the region above $635 \mathrm{~K}$ : 


$$
\begin{aligned}
& P_{S L}^{\prime}(T)=P_{S L}(T)+\sum_{j=1}^{9} U_{j} \cdot \tau^{j}, \\
& P_{S V}^{\prime}(T)=P_{S V}(T)-\sum_{j=1}^{6} W_{j} \cdot \tau^{j} .
\end{aligned}
$$

with the coefficients

\begin{tabular}{|c|c|c|c|c|c|}
\hline \multicolumn{6}{|c|}{ Table 29. Polynomial coefficients $U(1)-U(9)$ of the correcting term for $P^{\prime} s L$} \\
\hline 1 & 40.49363544 & 2 & $-20.73773694 \cdot 10^{3}$ & 3 & $7.607260219 \cdot 10^{6}$ \\
\hline 4 & $-1.796520658 \cdot 10^{9}$ & 5 & $258.9287847 \cdot 10^{9}$ & 6 & $-22.71838331 \cdot 10^{12}$ \\
\hline 7 & $1.182066587 \cdot 10^{15}$ & 8 & $-33.45912597 \cdot 10^{15}$ & 9 & $396.4473916 \cdot 10^{15}$ \\
\hline
\end{tabular}

resp.

Table 30. Polynomial coefficients $W(1)-W(6)$ of the correcting term for $P^{\prime} s v$

\begin{tabular}{|c|c|c|c|c|c|}
\hline 1 & 17.17830396 & 2 & $-3.434969255 \cdot 10^{3}$ & 3 & $448.7956073 \cdot 10^{3}$ \\
\hline 4 & $-38.08457011 \cdot 10^{6}$ & 5 & $1.646319316 \cdot 10^{9}$ & 6 & $-27.19071374 \cdot 10^{9}$ \\
\hline
\end{tabular}

( routines DILE resp. DIVE).

In a thin region before the critical temperature,

$$
647.0 \mathrm{~K}<T<T_{c}
$$

it can happen, that the liquid pressures of an isotherm remain always above the vapor pressures

$$
P_{S V}^{\prime}<P_{S L}^{\prime}
$$

This would lead to the unacceptable state, that at a distinct ( near critical) temperature there would be a pressure, finding no corresponding density either in the vapor, or in the liquid. To avoid this unphisical state DLFIND checks at near critical temperatures the spinodal pressures and uses the smaller of them as $P_{\min }$ in the window [6.3].

\subsection{Calculating large density changes}

If the supplied density, $\rho_{0}$ differs massively from the final density, $\rho(T, P)$, then in some cases the 19 iteration-steps, allowed in the FIND-routines will not suffice to calculate the final density. The user can circumvent this difficulty by supplying in this case a zero initial density,

$$
\rho_{0}=0
$$

to the FIND-routines. Finding a zero initial density the routines search - after checking the pressure, yet before beginning with the iteration - for an adequate approximated density, which will then serve as an initial density for the iteration with Newton's method. To find this density, the routines use an algorithm, similar to the one, used to calculate the spinodal densities ( page 30 ). 
DVFIND selects three densities with the corresponding pressures

$$
\begin{array}{ccc}
\rho_{1}=0 & , & P_{1}=0 \\
\rho_{2}=\rho_{V} & , & P_{2}=P^{\times} \\
\rho_{3}=\rho_{S V} & , & P_{3}=P_{S V}
\end{array}
$$

and calls the routine DINVA to find a density, corresponding the supplied pressure, $P$ with the help of these points. DINVA supplies the points to the routine QUADO, which constructs from them a polynomial of second grade and solves it for $\rho_{0}(\mathrm{P})$. DINVA then calculates the pressure, $P\left(\rho_{0}\right)$ and checks, if the $\rho_{0}$ is good enough to begin with. If $P$ ( $\left.\rho_{0}\right)$ differs to much from $P$, then DINVA uses SORBET to discard the "worst" of the four points

$$
\rho_{1} \quad, \quad \rho_{2}, \rho_{3}, \rho_{0}
$$

and seeks with the remainig three a better $\rho_{0}$.

DLFIND uses

$$
\begin{aligned}
\rho_{1}=\rho_{S L} & , \quad P_{1}=P_{S L} \\
\rho_{2}=\rho_{L} & , \quad P_{2}=P^{\times} \\
\rho_{3}=1200 \mathrm{~kg} / \mathrm{m}^{3} & , \quad P_{3}=P_{L \max }
\end{aligned}
$$

as pivotal points and calls the routine DINLI to find the density, $\rho_{0}$. DINLI works the same way as DINVA.

DGFIND has a more complicated task to fulfill, as either DVFIND or DLFIND. Since at supercritical temperatures there are no ready-made density-pressure relations to use as the saturation line or the spinodals - some density-pressure relations must be constructed.

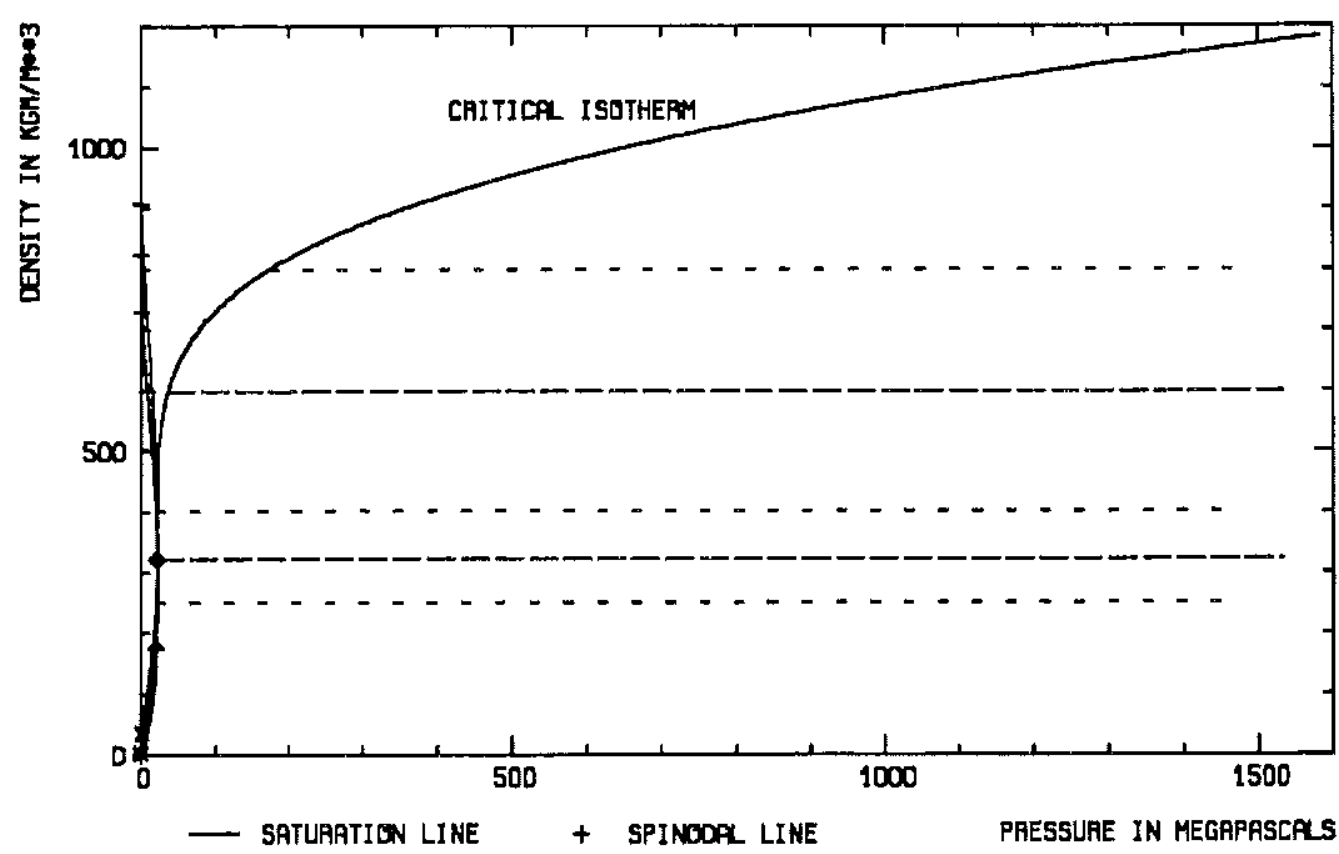

Figure 33. Water. Density-pressure chart 
To this end DGFIND divides the supercritical region in three sub-areas:

$$
\text { "LD": } \quad 0 \leq \rho \leq \rho_{c}
$$

the area of low-densities,

$$
\text { "MD": } \quad \rho_{c} \leq \rho \leq 600 \mathrm{~kg} / \mathrm{m}^{3}
$$

the area of moderate-densities and

$$
\text { "HD" : } \quad 600 \mathrm{~kg} / \mathrm{m}^{3} \leq \rho \leq 1200 \mathrm{~kg} / \mathrm{m}^{3}
$$

the area of high-densities ( $\mathrm{s}$. Figure 33 ). AQUA supplies DGFIND with the following isochoral pressures:

$$
P_{250}(T)=P\left(T, 250 \mathrm{~kg} / \mathrm{m}^{3}\right)
$$

\begin{tabular}{|c|c|c|c|c|c|}
\hline \multicolumn{6}{|c|}{ Table 31. Polynomial coefficients $\mathrm{A}(1)-\mathrm{A}(8)$ of $P_{250}(\mathrm{~T}) . P_{250}=A_{0}+A_{1} \cdot T+A_{2} \cdot T^{2}+\ldots$} \\
\hline 1 & $-161.6042550 \cdot 10^{5}$ & 2 & $370.3861090 \cdot 10^{3}$ & 3 & -183.5936079 \\
\hline 4 & $93.96635527 \cdot 10^{-3}$ & 5 & $-30.07808886 \cdot 10^{-6}$ & 6 & $5.819644183 \cdot 10^{-8}$ \\
\hline 7 & $-619.7247350 \cdot 10^{-15}$ & 8 & $27.81950727 \cdot 10^{-18}$ & & \\
\hline
\end{tabular}

$$
P_{322}(T)=P\left(T, \rho_{c}\right)
$$

\begin{tabular}{|c|c|c|c|c|c|}
\hline \multicolumn{6}{|c|}{ Table 32. Polynomial coefficients $A(1)-A(10)$ of $P_{322}(\mathrm{~T}) . P_{322}=A_{0}+A_{1} \cdot T+A_{2} \cdot T^{2}+\ldots$} \\
\hline 1 & $-115.3411242 \cdot 10^{5}$ & 2 & $-14.61390831 \cdot 10^{3}$ & 3 & 713.8479434 \\
\hline 4 & $-843.0259976 \cdot 10^{-3}$ & 5 & $558.6511529 \cdot 10^{-6}$ & 6 & $-228.9982666 \cdot 10^{-9}$ \\
\hline 7 & $59.25205508 \cdot 10^{-12}$ & 8 & $-9.423230731 \cdot 10^{-15}$ & 9 & $841.0373279 \cdot 10^{-21}$ \\
\hline 10 & $-32.24390358 \cdot 10^{-24}$ & & & & \\
\hline
\end{tabular}

$$
P_{400}(T)=P\left(T, 400 \mathrm{~kg} / \mathrm{m}^{3}\right)
$$

\begin{tabular}{|c|c|c|c|c|c|}
\hline \multicolumn{6}{|c|}{ Table 33. Polynomial coefficients $\mathrm{A}(1) \cdot \mathbf{A}(10)$ of $P_{400}(\mathrm{~T}) . P_{400}=A_{0}+A_{1} \cdot T+A_{2} \cdot T^{2}+\ldots$} \\
\hline 1 & $-48.22391500 \cdot 10^{6}$ & 2 & $-534.0793594 \cdot 10^{3}$ & 3 & $1.893391113 \cdot 10^{3}$ \\
\hline 4 & -2.052518308 & 5 & $1.304520061 \cdot 10^{-3}$ & 6 & $-521.2344512 \cdot 10^{-8}$ \\
\hline 7 & $132.5272444 \cdot 10^{-12}$ & 8 & $-20.80959374 \cdot 10^{-15}$ & 9 & $1.839373352 \cdot 10^{-18}$ \\
\hline 10 & $-69.98460931 \cdot 10^{-24}$ & & & & \\
\hline
\end{tabular}




$$
P_{600}(T)=P\left(T, 600 \mathrm{~kg} / \mathrm{m}^{3}\right)
$$

\begin{tabular}{|c|c|c|c|c|c|}
\hline \multicolumn{6}{|c|}{ Table 34. Polynomial coefficients $\mathbf{A}(1) \cdot \mathbf{A}(10)$ of $P_{800}(\mathrm{~T}) . P_{600}=A_{0}+A_{1} \cdot T+A_{2} \cdot T^{2}+\ldots$} \\
\hline 1 & $-193.5182531 \cdot 10^{5}$ & 2 & $-662.0824295 \cdot 10^{3}$ & 3 & $3.041300733 \cdot 10^{3}$ \\
\hline 4 & -3.331588396 & 5 & $2.091973967 \cdot 10^{-3}$ & 6 & $-822.3881849 \cdot 10^{-9}$ \\
\hline 7 & $205.8600153 \cdot 10^{-12}$ & 8 & $-31.88132588 \cdot 10^{-15}$ & 9 & $2.784677333 \cdot 10^{-18}$ \\
\hline 10 & $-104.8772468 \cdot 10^{-24}$ & & & & \\
\hline
\end{tabular}

$$
\text { and } \quad P_{800}(T)=P\left(T, 800 \mathrm{~kg} / \mathrm{m}^{3}\right)
$$

\begin{tabular}{|c|c|c|c|c|c|}
\hline \multicolumn{6}{|c|}{ Table 35. Polynomial coefficients A(1) $-\mathbf{A}(10)$ of $P_{800}(T) . \quad P_{800}=A_{0}+A_{1} \cdot T+A_{2} \cdot T^{2}+\ldots$} \\
\hline 1 & $-576.9907617 \cdot 10^{6}$ & 2 & $229.0441320 \cdot 10^{3}$ & 3 & $3.275463692 \cdot 10^{3}$ \\
\hline 4 & -4.331244582 & 5 & $3.008662103 \cdot 10^{-3}$ & 6 & $-1.272178994 \cdot 10^{-6}$ \\
\hline 7 & $337.9386420 \cdot 10^{-12}$ & 8 & $-55.07102702 \cdot 10^{-15}$ & 9 & $5.030253110 \cdot 10^{-18}$ \\
\hline 10 & $-197.1414663 \cdot 10^{-24}$ & & & & \\
\hline
\end{tabular}

( routines $\mathrm{P} 250, \mathrm{P} 322, \mathrm{P} 400, \mathrm{P} 600$ and $\mathrm{P} 800$ ). The above polynomials are valid in the temperature range

$$
647.126 K \leq T \leq 5000 K
$$

If now, in the beginnig DGFIND finds a zero for the initial density, then it will compare the supplied pressure with three pressure-windows :

$$
\begin{gathered}
0 \leq P \leq P_{322} \\
P_{322} \leq P \leq P_{600} \quad \text { and } \\
P_{600} \leq P \leq P_{L \max }
\end{gathered}
$$

to decide, in which of the three sub-areas to expect the density. If the pressure $P$ lies in window [6.13] ( sub-area "LD"), then DGFIND selects the following pivotal points

$$
\begin{array}{rll}
\rho_{1}=0 & , & P_{1}=0 \\
\rho_{2}=250 \mathrm{~kg} / \mathrm{m}^{3} & , & P_{2}=P_{250} \\
\rho_{3}=\rho_{c} & , & P_{3}=P_{322}
\end{array}
$$

( $s$. Figure 33 ) and supplies them to the routine DINSU to get the initial density $\rho_{0}$. If $P$ suffices the inequality [6.14] ( sub-area "MD"), then the supplied corner-points will be

$$
\begin{array}{rll}
\rho_{1}=\rho_{c} & , & P_{1}=P_{322} \\
\rho_{2}=400 \mathrm{~kg} / \mathrm{m}^{3} & , & P_{2}=P_{400} \\
\rho_{3}=600 \mathrm{~kg} / \mathrm{m}^{3} & , & P_{3}=P_{400}
\end{array}
$$


and if $P$ lies inside the window [6.15] (sub-area "HD"), then DGFIND uses the points

$$
\begin{array}{ccc}
\rho_{1}=600 \mathrm{~kg} / \mathrm{m}^{3} & , & P_{1}=P_{600} \\
\rho_{2}=800 \mathrm{~kg} / \mathrm{m}^{3} & , & P_{2}=P_{800} \\
\rho_{3}=1200 \mathrm{~kg} / \mathrm{m}^{3} & , & P_{3}=P_{L \max }
\end{array}
$$

to get an initial density, $\rho_{0}$.

DINSU calculates $\rho_{0}$ the same way as DINVA or DINLI. 


\subsection{Using AQUA}

\subsection{The codesystem AQUA}

can be used in different ways :

1. the user can call the interactive procedure WATER, to get the water properties at a given $(T, \rho)$ resp. ( T,P) point displayed on the screen imediately,

2. it is also possible to acquire water properties for a whole string of points, either along a number of isotherms or along a set of isochores in a TSO-session by calling the procedure KAISOT or KAISOK,

3. finally, there are also the routines WASSER, DAMPF, RDRDP, SAETO1 and VD1 which supply the water properties to the code IVA3 and which could be used by other codes too.

\section{SERVUS : auxiliary datasets and routines}

The procedures KAISOT and KAISOK calculate the water properties along a string of density resp. temperature points. To be able to do that, they need

- a SERVUS-dataset to supply a sample isotherm resp. a sample isochore for these routines and to receive the calculated properties,

- some routines from the code SERVUS to read, inspect, handle, sort and store the functions appearing in the procedures.

The code SERVUS (s. /19/) resides in the dataset INR105.SERVUS.LOAD.

The sample functions are either in the dataset INR105.AQUA.DATA or in INR105.AQUAT.DATA. AQUA holds sample isotherms with some 300 density points in the range $\rho<1200 \mathrm{~kg} / \mathrm{m}^{3}$. In AQUAT there are temperature functions with 400 temperature points between the melting and the critical points.

The user can acquire the above datasets by copying and adapting the procedure INR105.SERVUS.CNTL(IEBGENER) to userid.SERVUS.CNTL(IEBGENER) (s. Figure 34 ).

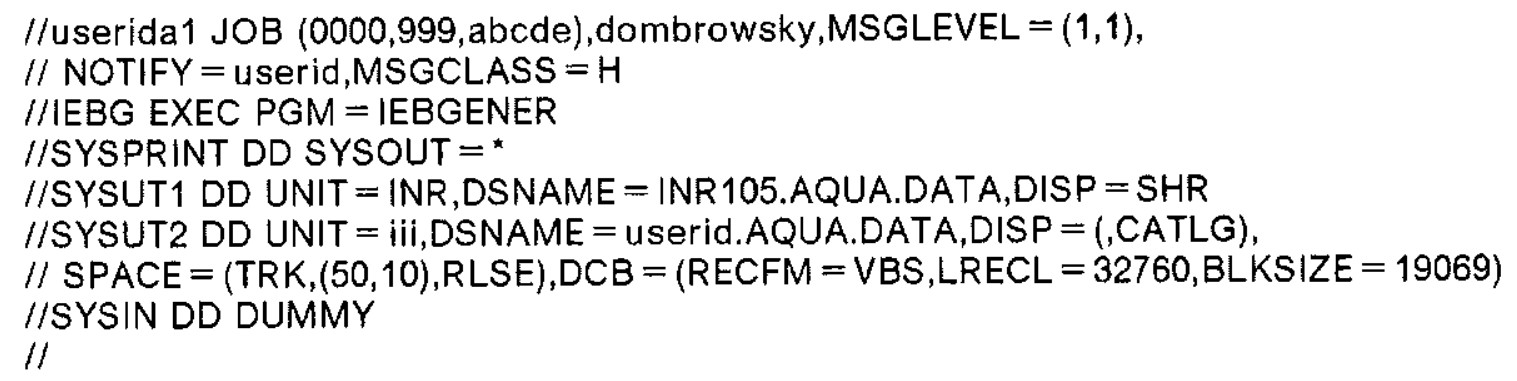

Figure 34. The procedure userid.SERVUS.CNTL(IEBGENER).

The "string"-routines KAISOT and KAISOK need, besides of the SERVUS routines also the AQUA-routines SIGNAT, NAPSZM and MUSTER.

- MUSTER helps in selecting the sample-function in the SERVUS dataset,

- SIGNAT sets the chracteristic numbers and words - needed in registering the function in the dataset - for the properties calculated and

- NUMBER returns the number of day in the year. 


\subsection{WATER}

WATER calculates the water properties either as pressure-temperature or as densitytemperature functions. In the stable and metastable states WATER returns property-values, corresponding to the ones, calculated by the H.G.K.-code. In the region of instability WATER calculates mixed state properties, as described in 4.0, "Thermal properties in the two phase region."

WATER needs the "FIND"-routines for the $(T, P) \Rightarrow(T, \rho)$ conversion and HYDOR to calculate the water properties in the $(\rho, T)$ - dependence ( $\mathbf{s}$. Appendix $D$, "Module trees" on page 77 ).

WATER resides in the datase 'INR 105.KATHER.LOAD' and can be activated by typing simply "WATER".

The following frozen screens exemplify a typical conversation with WATER :

ISPFCOMMAND $===>$

ENTER TSO COMMANO, CLIST, OR REXX EXEC BELOW:

$==>$ WATER

TSO COMMAND PROCESSOR 
ENTER TEMPERATURE $($ IN K ) $/ 373.150 /=: \quad($ STOP WTIH T $=0$ )

00011 ?

373.15

DO YOU WANT THE PROPERTIES AS

$1=$ TEMPERATURE-DENSITY FUNCTIONS

$2=$ TEMPERATURE-PRESSURE FUNCTIONS (STOP WITH 0 )

00014 ?

2

ENTER PRESSURE (II MPASCAL ) / $0.1013250 \quad /=: \quad($ STOP WTIH P $=0$ )

00019 ?

$\theta .101325 \theta$

LIQUID ( 1 ) OR VAPOR ( 2 ) STATE ? $(\theta=$ STOP ) =:

00028 ?

1

$T=373.150$

K

$\mathrm{DP} / \mathrm{DRHO}=2125.38$

$\mathrm{KJ} / \mathrm{KG}$

$C V=3.77087$

$\mathrm{KJ} /(\mathrm{KG} * \mathrm{~K})$

$U=418.958$

$\mathrm{KJ} / \mathrm{KG}$

DU/DRHO $=-0.620588$ $K J * M * * 3 / K G * * 2$

$E T A=0.282103 \mathrm{E}-03$

$\mathrm{KG} / \mathrm{M} / \mathrm{SEC}$

$P R \cdot N R=1.75150$

$R H . V=0.5975324$

$K G / M * \star 3$

RH. $L=958.4467$

$K G / M * * 3$

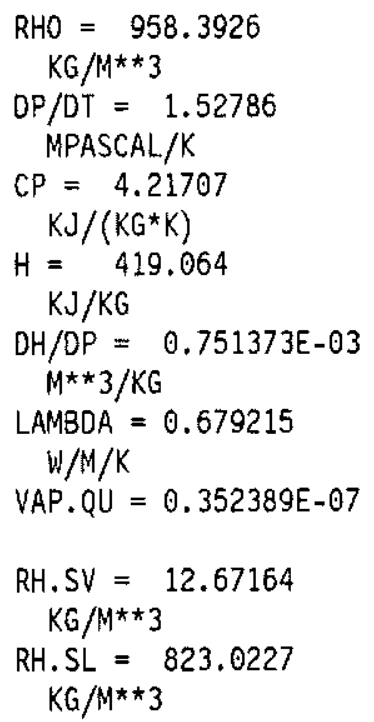

$\mathrm{RHO}=958.3926$

$K G / M * \star 3$

$\mathrm{OP} / \mathrm{DT}=1.52786$

MPASCAL/K

$C P=4.21707$

$\mathrm{KJ} /\left(\mathrm{KG}^{*} \mathrm{~K}\right)$

$H=419.064$

$\mathrm{KJ} / \mathrm{KG}$

$\mathrm{DH} / \mathrm{OP}=0.751373 \mathrm{E}-03$

$M * \star 3 / K G$

LAMBDA $=0.679215$

$W / M / K$

VAP.QU $=0.352389 E-07$

RH.SV $=12.67164$

$K G / M * * 3$

RH.SL $=823.0227$

$K G / M * \star 3$

$P=0.1013458$

MPASCAL

DRHO/DT $=-0.718864$

$\mathrm{KG} /\left(K^{* *} M^{* *} 3\right.$

$S=1.30688$

$\mathrm{KJ} /(\mathrm{KG} * \mathrm{~K})$

$G=-68.5997$

$\mathrm{KJ} / \mathrm{KG}$

VEL. $S=1541.71$

$M / S E C$

SIGMA $=0.589152 \mathrm{E}-01$

$K G / S E C * * 2$

$P S=0.1013127$

MPASCAL

P.SV $=1.21103$

MPASCAL

$P . S L=-149.037$

MPASCAL 
ENTER PRESSURE ( IN MPASCAL ) / $0.1013250 \quad /=: \quad$ (STOP WTIH P $=0$ )

$00019 ?$

$\theta$

DO YOU WANT THE PROPERTIES AS

1 = TEMPERATURE-DENSITY FUNCTIONS

$2=$ TEMPERATURE-PRESSURE FUNCTIONS (STOP WITH O)

00014 ?

$\theta$

ENTER TEMPERATURE $($ IN K ) $/ 373.150 /=: \quad$ (STOP WTIH T $=0$ )

$00011 ?$

$\theta$

\subsection{String-routines}

The routines KAISOT and KAISOK are placed in the dataset 'INR105.AQUA.LOAD'

\section{KAISOT}

KAISOT calculates the water properties as density-temperature functions along isotherms.

KAISOT needs (s. Appendix D, "Module trees" on page 77 ):

- HYDOR for the calculation of the ( $\rho, T)$-properties,

- the AQUA-routines SIGNAT, NAPSZM, MUSTER

- the SERVUS-routines SERDIO, SDEXG8, FENST8, SDING8

- the dataset userid.AQUA.DATA and

- the procedure userid.AQUA.CLIST(KAISOT) (s. Figure 35 ).

ALLOC DA('userid.AQUA.DATA') F(FT15F001) SHR REU

ALLOC DA('userid.AQUA.DATA') F(FT16F001) SHR REU

CALL 'INR 105.AQUA.LOAD(KAISOT)'

FREE DA('userid.AQUA.DATA')

FREE DA('userid.AQUA.DATA')

Figure 35. The procedure userid.AQUA.CLIST(KAISOT)

A sample conversation with KAISOT is something, like this : 
READY

ex aqua(kaisot)

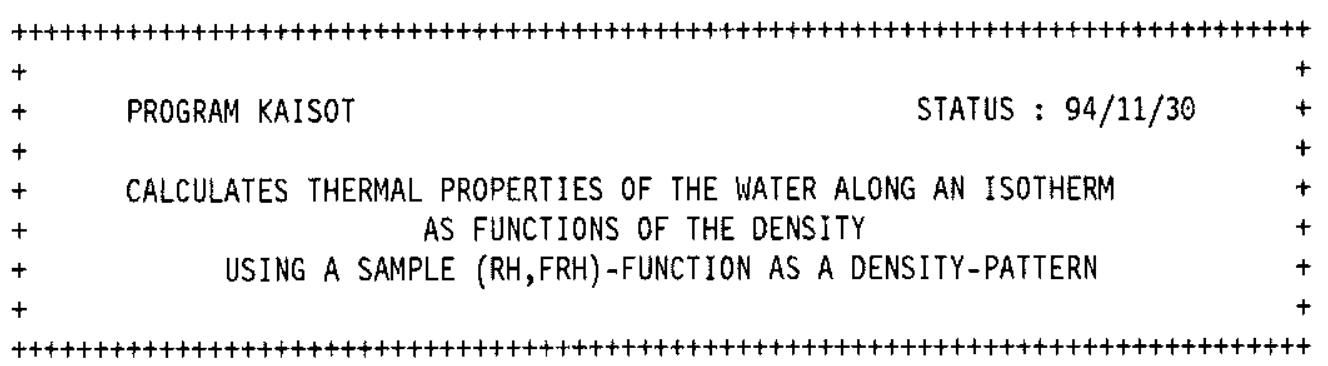

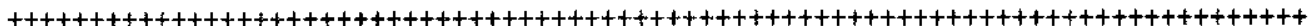

$+$

12.12 .94

LIST OF THE GRAPHS OF THE DATASET

AQUA .DATA +

STORAGE-NORM IS "GRAPHIC8"

$+$

$+$

$+$

DATE OF THE ALLOCATION:

23. 5.91

LAST SCRATCH:

27. 9.94

THE DATASET CONTAINS 275 GRAPHS

TIME: $16 \mathrm{H} 57^{\prime} 11^{\prime \prime}$

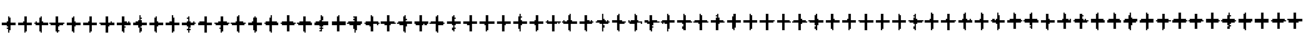

++++++++++++++++++++++++++++++++++++++++++++++++++++++++++++++
+
+
+

ENTER TEMPERATURE OF THE ISOTHERM $=:(\theta=$ END $)$

00016 ?

373.15 
TABLE OF THE PROPERTY-NUMBERS : ( END = 0 )

\begin{tabular}{|c|c|c|c|c|c|c|c|c|}
\hline 1 & 1 & 2 & 3 & 4 & 5 & 6 & 7 & 8 \\
\hline$\theta$ & p* & $p *{ }^{-}$ & DP/DT & $\mathrm{DT} / \mathrm{DP}$ & $T^{*}$ & & & \\
\hline 10 & $\mathrm{RH}$ & $\mathrm{RH}^{-}$ & RH.SP & & $P$ & P.SP & V & $Z$ \\
\hline 20 & P1R & P1T & R1P & R1T & & $\mathrm{CV}$ & $C P$ & \\
\hline 30 & V.S & SIG & & ETA & LAMBDA & PRN & & \\
\hline 40 & A & $G$ & U & $H$ & S & U1R & H1P & \\
\hline $\begin{array}{l}\text { ENTER } \\
00012\end{array}$ & $\begin{array}{l}\text { NUMBER } \\
?\end{array}$ & OF $T$ & E PROPE & RTY / & $0 /=:$ & & & \\
\hline
\end{tabular}

ENTER SERIAL NUMBER OF THE $(T, F T)$ MASTER FUNCTION $=:(0=$ END $)$ 00008 ?

22

\# 22 GRAPH $(1015 / 5000) \quad X:+D E N S I T Y+K G / M * * 3+F:+\quad P . T+P A S C A L+$ $X 1=0.5550 E-03, X(293)=1190 . \quad, 0.0000 E+00<X<1200 . \quad, U=0.10 E+03$ $F 1=128.1, F(293)=0.1283 E+10,-0.6100 E+08<F<0.1300 E+10, U=0.10 E+09$ FUNCTION OK $=:(0=$ YES $\mid g=$ NO $)$ 00012 ?

$\theta$

ENTER BEGIN, END \& INCREMENTUM $(\theta=$ END $) / 1,1000,1 /=:,=:,=$ : 00016 ?

13001

FUNCTION TO 8 E SAVED ? $(0=$ NO $)=$ : 00024 ?

3

$==173$ GRAPH $(26 / 3731) x:+$ OENSITY $+K G / M * * 3+F:+C V . I T H+J / K G / K+$

$X 1=0.5550 E-03, X(293)=1190 . \quad, 0.0000 E+00<X<1200 . \quad, U=0.10 E+03$

$F 1=1428 . \quad, F(293)=3412 . \quad, \quad 1400 . \quad<F<7000 . \quad, U=0.10 E+04$ 
TABLE OF THE PROPERTY-NUMBERS : $($ END $=0)$

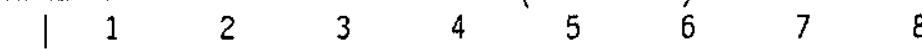

\begin{tabular}{r|cccccccc}
\hline 0 & $P^{*}$ & $P^{*}$ & DP/DT & DT/DP & $T^{*}$ & & & \\
10 & $R H$ & $R^{*}$ & RH.SP & & $P$ & $P . S P$ & $V$ & $Z$ \\
20 & $P 1 R$ & $P 1 T$ & R1P & R1T & & CV & $C P$ & \\
30 & $V . S$ & SIG & & ETA & LAMBDA & PRN & & \\
40 & $A$ & $G$ & $U$ & $H$ & $S$ & U1R & H1P &
\end{tabular}

ENTER NUMBER OF THE PROPERTY / $\theta /=$ :

$00012 ?$

$\theta$

ENTER TEMPERATURE OF THE ISOTHERM $=:(\theta=$ END $)$

$00016 ?$

\section{KAISOK}

KAISOK calculates the water properties as density-temperature functions along isochores.

KAISOK uses, similarly to KAISOT :

- HYDOR for the calculation of the $(\rho, T)$-properties,

- the AQUA-routines SIGNAT, NAPSZM, MUSTER

- the SERVUS-routines SERDIO, SDEXG8, FENST8, SDING8

- the dataset userid.AQUAT.DATA and

- the procedure userid.AQUA.CLIST(KAISOK) (s. Figure 35 ).

ALLOC DA('userid.AQUAT.DATA') F(FT15F001) SHR REU

ALLOC DA('userid.AQUAT.DATA') F(FT16F001) SHR REU

CALL 'INR105.AQUA.LOAD(KAISOK)'

FREE DA('userid.AQUAT.DATA')

FREE DA('userid.AQUAT.DATA')

Figure 36. The procedure userid.AQUA.CLIST(KAISOK)

A dialogue with KAISOK runs in the same way, as one with KAISOT.

READY

ex aqua(kaisok)

etc. 


\subsection{IVA-routines}

A set of the following routines - completed with all the other AQUA-routines needed by them - are deposited in the dataset INR105.IVHZO.FORT.

\section{WASSER}

WASSER calculates thermophysical properties of the liquid water as functions of the temperature and pressure for the codesystem IVA3. WASSER calculates only in the stable and metastable states of the liquid, so the supplied $P$ must be higher as the spinodal-pressure of the liquid. In calling WASSER

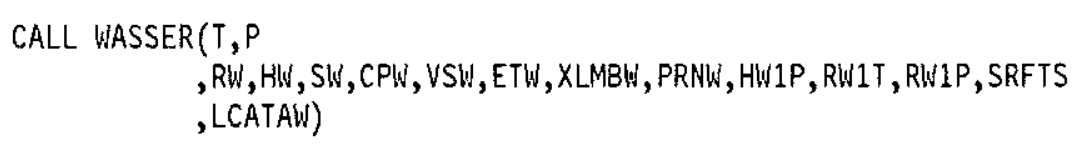

1. T, the temperature and

2. $P$, the pressure

should be supplied. WASSER then returns

3. RW, the density,

4. HW, the specific enthalpy,

5. SW, the specific entropy,

6. CPW, the heat capacity at constant pressure,

7. VSW, the velocity of sound,

8. ETW, the viscosity,

9. XLMBW, the thermal conductivity,

10. PRND, the Prandtl number of the water,

11. HW1P, the pressure derivative of the enthalpy, $\partial H / \partial P$,

12. RW1T, the temperature derivative of the density, $\partial \rho / \partial T$,

13. RW1P, the pressure derivative of the density, $\partial \rho / \partial P$ and

14. SRFTS, the surface tension.

All of the above properties are in SI-units.

LCATAW, a logical variable will be set true. if WASSER falls to find the density $\operatorname{RF}(P, T)$.

\section{DAMPF}

DAMPF calculates thermophysical properties of the vaporized water as functions of the temperature and pressure for the codesystem IVA3. DAMPF calculates only in the stable and mistastable vapor states, so the supplied $P$ must be lower as the spinodal-pressure of the vapor. DAMPF

$$
\begin{aligned}
\text { CALL DAMPF } & (T, P \\
& , \text { RGAS, WGM, RD, HD , SD , CPD, VSD, ETD , XLMBD, PRND, HD1P, RD1T, RDIP } \\
& , \text { LCATAD) }
\end{aligned}
$$

needs initial values for 
1. T, the temperature and

2. $P$, the pressure

and it returns the following properties:

3. RGAS, the gas-law constant of the water,

4. WGM, the molal mass,

5. RD, the density,

6. HD, the specific enthalpy,

7. SD, the specific entropy,

8. CPD, the heat capacity at constant pressure,

9. VSD, the velocity of sound,

10. ETD, the viscosity,

11. XLMBD, the thermal conductivity,

12. PRND, the Prandtl number of the steam

13. HD1P, the pressure derivative of the enthalpy, $\partial H / \partial P$,

14. RD1T, the temperature derivative of the density, $\partial \rho / \partial T$ and

15. RD1P, the pressure derivative of the density, $\partial \rho / \partial P$.

All of the above properties - as in the case of WASSER - are in SI-units.

LCATAD will be again set .true. if DAMPF fails to find the density $\operatorname{RD}(P, T)$.

\section{RDRDP}

RDRDP is an abridged version of DAMPF, only to find the density corresponding to the pressure $P$ and the temperature $T$ in the vapor state for the code IVA3.

CALL RDRDP(T,P, RD, RD1P, LCATAO)

For a given $T$ and $P$ RDRDP returns RD, the density and RD1P, the pressure derivative of the density $(\partial \rho / \partial P)$ of the steam.

\section{SAET01}

$$
\begin{aligned}
\text { CALL SAETO1(T, P } & \\
& \text {,WW, VD, HW, HD, HWO , SW, SD, TSIP, CPW, CPD, ETW, ETD, XLMBW, XLMBD, SRFTS } \\
& \text {,KIND, LCATAS) }
\end{aligned}
$$

SAET01 calculates saturation properties of the water for IVA3 as function of the pressure

$P$ ( If KIND is 1 ) or the temperature T (if KIND equals 0 ).

SAET01 returns - besides of $T$ or $P$ - the following thermophysical properties :

- VW and VD are the specific volume of the liquid resp. of the vapor,

- HW and HD are the corresponding specific enthalpies,

- SW and SD are the specific entropies in the liquid and vapor states,

- $\quad C P W$ and CPD are the corresponding heat capacities at constant pressure,

- ETW and ETD are the viscosities of the liquid resp. of the vapor,

- XLMBW and XLMBD are the corresponding thermal conductivities,

- $\quad$ SRFTS is the surface tension (of the liquid),

- $\quad H W D=H D-H W$ and 
- $\quad T S 1 P=1 / \partial P / \partial T$.

All the properties are again in SI-units.

LCATAS will be set true. if SAET01 fails to find saturated properties ( $i$. e. if TS is supercritical).

Note: There exists also an extended version of the above routine, SAETEX, created as a testing facility for the routine SAETO1. Besides of the properties listed above, SAETEX calculates also the pressure derivatives $d P^{x} / d T, \partial P / \partial T$ and $\partial P / \partial \rho$, the constant volume heat capacities $C_{Y}$ and the sonic velocities.

\section{VD1}

VD1 calculates approximated specific volumes for the saturated vapor, VD in $\mathrm{kg} / \mathrm{m}^{3}-\mathrm{s}$ at the temperature $T$ for the code IVA3.

CALL VD1(T, VD, DUMMY)

For a complete list of available water property procedures see Appendix $M$, "TSO-procedures, calculating thermal properties of the water" on page 153. 


\subsection{References}

11/ V. V. Sychev, Character of the Change of Thermodynamic Quantities on Boundary Curves

High Temperature, Vol. 5, No. 6, p. 1022, 1967.

121 Kh I. Amirkhanov, B. G. Alibekov, B. A. Mursalov, and G. V. Stepanov, Calculation of the Derivatives of Thermal and Caloric Quantities on a Saturation Line

High Temperature, Vol. 10, No. 3, p. 475, 1972.

/3/ V. P. Skripov, Metatstable Liquids, English translation

John Wiley and sons, New York, 1974.

14/ J. V. Sengers, Thermal Conductivity of Steam in the Critical Region, P. 822 in Proceedindgs of the Seventh Symposium on Thermophysical Properties, ASME,

1977.

15/ K.Thurnay, Thermophysical Properties of Sodium in the Liquid and Gaseous States, KFK 2863, Februar 1981.

16/ L. A. Weber, Measurements of the heat capacities $C_{v}$ of dense gaseous and liquid nitrogen and nitrogen trifluoride.

J. Chem. Thermodynamics, Vol. 13, p. 389-403, 1981.

17/ A. M. Sirota, V. I. Latunin, N. E. Nikolaeva, An Experimental Investigation of the Thermal Conductivity Maxima of Water in the Critical Region

Thermal Engineering Vol. 28, No. 4, p. 246, 1981.

18/ K.Thurnay, Evaluation of Thermophysical Properties of Sodium as Surfaces of the Temperature and the Density,

Nucl. Scl. Eng., 82. p. 181, 1982.

19/ C. A. Meyer, R. B. McClintock, G. J. Silvestri, R. C. Spencer, Jr., ASME steam tables : thermodynamic and transport properties of steam comprising tables and charts for steam and water, 5. ed.

American Soc. of Mechanical Engineers, New York, 1983.

/10/ L. Haar, J. S. Gallagher, G. S. Kell, NBS/NRC steam tables : thermodynamic and transport properties and computer programs for vapor and liquid states of water in SI units

Hemisphere Publ. Co., Washington, 1984.

111/ J. V. Sengers and B. Kamgar Parsi, Representative Equations for the Viscosity of Water Substance

J. Phys. Chem. Ref. Data, Vol. 13, No. 1, p. 185, 1984.

112/ H. J. White, Jr., Activities of the International Association for the Properties of Steam Between 1979 and 1984, pp. $31-34$ in

V. V. Sytchev (ed.) The properties of steam

Proc. of the 10th internat. conf., Moscow, USSR, 3 - 7 Sept. 1984.

Moscow: Mir Publishers, London : Plenum Press, 1984.

/13/ L. Haar and J. S. Gallagher, Thermodynamic Values Near the Critical Point of Water, pp. $167-179$ in

V. V. Sytchev (ed.) The properties of steam Proc. of the 10th internat. conf., Moscow, USSR, 3 - 7 Sept. 1984.

Moscow: Mir Publishers, London: Plenum Press, 1984.

114/ W. Wagner and A. Saul, Correlation Equations for the Vapor Pressure and for the Orthobaric Densities of Water Substance, pp. $199-209$ in

V. V. Sytchev (ed.) The properties of steam

Proc. of the 10th internat. conf., Moscow, USSR, 3 - 7 Sept. 1984.

Moscow: Mir Publishers, London : Plenum Press, 1984.

115/ V. P. Skripov, Phase-Change Behaviour of Water in Nonequilibrium Processes, pp. $227-251$ in

V. V. Sytchev (ed.) The properties of steam

Proc. of the 10th internat. conf., Moscow, USSR, 3 - 7 Sept. 1984.

Moscow: Mir Publishers, London : Plenum Press, 1984. 
116/ J. V. Sengers, Transport Properties of Fluids Near Critical Points, pp. $363-389$ in

V. V. Sytchev (ed.) The properties of steam

Proc. of the 10th internat. conf., Moscow, USSR, 3 - 7 Sept. 1984. Moscow: Mir Publishers, London : Plenum Press, 1984.

117/ V. V. Sychev, V. A. Rabinovich, and Yu. E. Sheludyak, Using Differential Thermodynamic Equations at the Critical Point of Pure Materials

High Temperature, Vol. 22, No. 6, p. 829, 1985.

/18/ P. W. Atkins, Physical chemistry, 3. ed.

Oxford University Press, 1986.

/19/ K. Thurnay, SERVUS. Ein System von Dateien und Prozeduren zur Speicherung und Präsentation von Rechenergebnissen, die Funktionen ( einer Variablen ) sind. Version V, April 1989.

Kfk 4587, Juli 1989.

120/ K. Thurnay, SODIUM. A Code for Calculating Thermophysical Properties of the Sodium in the Liquid and Gaseous States.

KfK 4609, September 1989.

121/ N. I. Kolev, IVA3 : Computer Code For Modeling of Transient Three Dimensional Three Phase Flow in Complicated Geometry

$122 /$ V.P. Skripov, Metastable States

Kfk 4950, Dezember 1991

J. Non-Equilib. Thermodyn., Vol. 17, No. 3, p. 193 - 206, 1992.

123/ C. A. Meyer, R. B. McClintock, G. J. Silvestri, R. C. Spencer, Jr., ASME Steam Tables: Thermodynamic and Transport Properties of Steam Comprising Tables and Charts For Steam and Water, 6. ed.

New York, NY : American Soc. of Mechanical Engineers, 1993. 


\section{Appendix A. Some thermal relations}

\section{A.1 The derivatives of the free energy}

In developing the thermal properties of a substance as functions of the temperature and density the appropriate energy property to begin with is the free energy:

$$
A \equiv U-S \cdot T
$$

also known as Helmholtz-function or total work.

Since it holds (s. e. g. /18/)

$$
d U=T \cdot d S-P \cdot d V
$$

one has for $\mathrm{A}$ the following $(\rho, \mathrm{T})$-differential:

$$
d A(\rho, T)=d U-S d T-T d S=-S d T+\frac{\rho}{\rho^{2}} d \rho
$$

The differential [A.3] gives following relations for entropy and pressure :

$$
\begin{aligned}
& S(\rho, T)=-\frac{\partial A}{\partial T}, \\
& P(\rho, T)=\frac{\partial A}{\partial \rho} \rho^{2} .
\end{aligned}
$$

\section{A.2 The enthalpy and its derivatives}

For the enthalpy one can also apply a (d $\rho, \mathrm{dT})$ - expression :

$$
d H(\rho, T)=\frac{\partial H}{\partial T} d T+\frac{\partial H}{\partial \rho} d \rho
$$

The T-derivative in the Eq. [A.6] can be calculeted from the equation

$$
H \equiv U+\frac{P}{\rho}
$$

as

$$
\left.\frac{\partial H}{\partial T}\right|_{\rho}=C_{V}+\frac{1}{\rho} \frac{\partial P}{\partial T}
$$

and the $\rho$-derivative from the equation

$$
H \equiv A+\frac{P}{\rho}+S \cdot T
$$

transformed with the relations [A.4] and [A.5] properly. The result is 


$$
\left.\frac{\partial H}{\partial \rho}\right|_{T}=\frac{1}{\rho}\left(\frac{\partial P}{\partial \rho}-\frac{T}{\rho} \frac{\partial P}{\partial T}\right)
$$

Setting the pressure-differential

$$
d P(\rho, T)=\frac{\partial P}{\partial T} d T+\frac{\partial P}{\partial \rho} d \rho
$$

to zero gives the important relation

$$
\frac{\partial P / \partial T}{\partial P / \partial \rho}=-\left.\frac{\partial \rho}{\partial T}\right|_{P}
$$

Using this relation and the reduced temperature-derivative of the density

$$
\left.\rho_{T}^{o} \equiv \frac{T}{\rho} \frac{\partial \rho}{\partial T}\right|_{P}
$$

allows to describe the density derivative [A.10] in a more simple form

$$
\left.\frac{\partial H}{\partial \rho}\right|_{T}=\frac{1}{\rho} \frac{\partial P}{\partial \rho}\left(1+\rho_{T}^{0}\right)
$$

To develop the derivatives of the $(P, T)$-description the differential $[A .6]$ is to be transformed accordingly. Using a $(P, T)$-differential for the density results in

$$
\begin{aligned}
d H & =\frac{\partial H}{\partial T} d T+\frac{\partial H}{\partial \rho}\left(\frac{\partial \rho}{\partial T} d T+\frac{\partial \rho}{\partial P} d P\right)= \\
& =\left(\left.\frac{\partial H}{\partial T}\right|_{\rho}+\left.\frac{\partial H}{\partial \rho}\right|_{T} \frac{\partial \rho}{\partial T}\right) d T+\left.\frac{\partial H}{\partial \rho}\right|_{T} \frac{\partial \rho}{\partial P} d P
\end{aligned}
$$

Eq. [A.14] combined with Eqs. [A.8], [A.11] and [A.13] results in the following descriptions for the $(P, T)$-derivatives of the enthalpy:

$$
\begin{aligned}
\left.\frac{\partial H}{\partial T}\right|_{P} & \equiv C_{P}(P, T)=\left.\frac{\partial H}{\partial T}\right|_{\rho}+\left.\left.\frac{\partial H}{\partial \rho}\right|_{T} \frac{\partial \rho}{\partial T}\right|_{P}= \\
& =C_{V}(\rho, T)+\frac{T}{\partial P / \partial \rho}\left(\frac{1}{\rho} \frac{\partial P}{\partial T}\right)^{2},
\end{aligned}
$$

respectively

$$
\left.\frac{\partial H}{\partial P}\right|_{T}=\left.\left.\frac{\partial H}{\partial \rho}\right|_{T} \frac{\partial \rho}{\partial P}\right|_{T}=\frac{1}{\rho}\left(1+\rho_{T}^{0}\right)
$$

This last derivative is also known as the 'isothermal factor'

$$
\left.\frac{\partial H}{\partial P}\right|_{T}=V-T \cdot \frac{\partial V}{\partial T}
$$




\section{A.3 The sonic velocity}

is defined as

$$
v_{s}^{2}=\left.\frac{\partial P}{\partial \rho}\right|_{s}
$$

To develop the derivative in the equation above one needs the following differential

$$
d S(\rho, P)=\frac{\partial S}{\partial T}\left(\frac{\partial T}{\partial \rho} d \rho+\frac{\partial T}{\partial P} d P\right)+\frac{\partial S}{\partial \rho} d \rho
$$

Eq. [A.19] can be transformed to

$$
d S(\rho, P)=\frac{\partial S / \partial T}{\partial P / \partial T} d P+\left(\frac{\partial S}{\partial \rho}+\frac{\partial S / \partial T}{\partial \rho / \partial T}\right) d \rho
$$

Setting $d S=0$ in the above equation and using Eq. [A.11] gives

$$
\left.\frac{\partial P}{\partial \rho}\right|_{S}=-\frac{\left(\frac{\partial S}{\partial \rho}+\frac{\partial S / \partial T}{\partial \rho / \partial T}\right)}{\frac{\partial S / \partial T}{\partial P / \partial T}}=\frac{\partial P}{\partial \rho}-\frac{\partial P}{\partial T} \frac{\partial S / \partial \rho}{\partial S / \partial T}
$$

Differentiating the equations Eq. [A.1] respectively Eq. [A.4] result in the entropy-derivatives

$$
\frac{\partial S}{\partial T}=\frac{C_{V}}{T} \quad, \quad \frac{\partial S}{\partial \rho}=-\frac{1}{\rho^{2}} \frac{\partial P}{\partial T}
$$

Setting the above derivatives into the Eq. [A.21] and comparing the result with the Eq. [A.15] ends in

$$
\left.\frac{\partial P}{\partial \rho}\right|_{S}=\frac{\partial P}{\partial \rho}+\frac{T}{C_{V}}\left(\frac{\partial P / \partial T}{\rho}\right)^{2}=\frac{\partial P}{\partial \rho} \frac{C_{P}}{C_{V}} .
$$

Related to the sonic velocity are the adiabatic resp. the isothermal compressibilities :

$$
\begin{gathered}
\kappa_{S}=\frac{1}{\rho \cdot \partial P /\left.\partial \rho\right|_{S}}=\frac{1}{\rho \cdot v_{s}^{2}}, \\
\kappa_{T}=\frac{1}{\rho \cdot \partial P / \partial \rho}=\frac{C_{P}}{C_{V}} \cdot \kappa_{S} .
\end{gathered}
$$




\section{A.4 The Joule Thomson coefficient}

This property is defined as

$$
\text { Joule Thomson coefficient }\left.\equiv \frac{\partial T}{\partial P}\right|_{H}
$$

Using the restraint

$$
d H=\frac{\partial H}{\partial P} d P+\frac{\partial H}{\partial T} d T=0
$$

and the result of Eq. [A.16] one has

$$
\left.\frac{\partial T}{\partial P}\right|_{H}=-\frac{\frac{\partial H}{\partial P}}{\frac{\partial H}{\partial T}}=-\frac{\frac{\partial H}{\partial P}}{C_{P}}=-\frac{1+\rho_{T}^{0}}{\rho \cdot C_{P}} .
$$




\section{Appendix B. Derivatives of some saturated properties}

\section{B.1 Derivatives of the vapor pressure}

Since the derivative of $w$ in the Eq. [5.2] can be expressed as

$$
\frac{d w}{d T}=\frac{-0.5}{T_{c}}\left(1-\frac{1}{T_{c}}\right)^{-0.5}=\frac{-0.5}{W \cdot T_{c}}
$$

it holds for the first T-derivative of the vapor pressure

$$
\begin{gathered}
Q_{1} \equiv \frac{T}{P^{x}} \frac{d P^{\times}}{d T}=T \frac{d \ln P^{x}}{d T}= \\
=-\frac{T_{c}}{T} \cdot \sum_{j=1}^{13} A_{j} \cdot W^{j-1}+\left(\frac{T_{c}}{T}-1\right) \sum_{j=1}^{8} T \cdot \frac{d w}{d T} \cdot(j-1) \cdot A_{j} \cdot W^{j-2}= \\
=-\sum_{j=1}^{8} A_{j} \cdot W^{j-1}\left[\frac{T_{c}}{T}+\frac{j-1}{2}\right] .
\end{gathered}
$$

The derivative of $Q_{1}$ is

$$
\begin{gathered}
Q_{2} \equiv T \frac{d Q_{1}}{d T}= \\
=\sum_{j=1}^{8} A_{j} \cdot W^{j-1}\left[\frac{T_{c}}{T}+\frac{j-1}{2}\left(1+\frac{j+1}{2} \frac{T}{T_{c}-T}\right)\right] .
\end{gathered}
$$

On the other hand one can develop a pressure relation for $Q_{2}$ :

$$
\begin{gathered}
Q_{2} \equiv T \frac{d}{d T}\left[\frac{T}{P^{x}} \frac{d P^{x}}{d T}\right]= \\
\frac{T}{P^{x}} \frac{d P^{x}}{d T}+\frac{T^{2}}{P^{x}} \frac{d^{2} P^{x}}{d T^{2}}-\left[\frac{T}{P^{x}} \frac{d P^{x}}{d T}\right]^{2}= \\
=\frac{T^{2}}{P^{x}} \frac{d^{2} P^{x}}{d T^{2}}+Q_{1}\left(1-Q_{1}\right)
\end{gathered}
$$

Transforming Eq. [B.2] and [B.4] result in the following equations for the temperature derivatives of the vapor pressure:

$$
\begin{gathered}
\frac{d P^{x}}{d T}=\frac{P^{\times}}{T} Q_{1} \quad \text { and } \\
\frac{d^{2} P^{\times}}{d T^{2}}=\frac{P^{\times}}{T^{2}}\left[Q_{2}-Q_{1}\left(1-Q_{1}\right)\right] .
\end{gathered}
$$


To ease the descriptions of the Q-s the coefficients

$$
\begin{gathered}
B_{j} \equiv \frac{j-1}{2} A_{j} \quad \text { and } \\
C_{j} \equiv \frac{j+1}{2} B_{j}
\end{gathered}
$$

will be introduced, resulting in the Q-equations

$$
Q_{1}=-\frac{T_{c}}{T} \sum_{j=1}^{8} A_{j} \cdot w^{j-1}-\sum_{j=1}^{8} B_{j} \cdot w^{j-1}
$$

and

$$
Q_{2}=\frac{T_{c}}{T} \sum_{j=1}^{8} A_{j} \cdot w^{j-1}+\sum_{j=1}^{8} B_{j} \cdot w^{j-1}+\frac{T}{T_{c}-T} \sum_{j=1}^{8} C_{j} \cdot w^{j-1} .
$$

\section{B.2 Derivatives of the saturated densities}

For

the cold water one can develop from Eq. [5.9] with Eq. [B.1] the derivative

$$
\frac{d \rho_{L}}{d T}=-\frac{0.5 \cdot \rho_{c}}{T_{c}} \sum_{j=2}^{12}(j-1) \cdot A_{j} \cdot w^{j-3} .
$$

Correspondingly the second derivative is here

$$
\frac{d^{2} \rho_{L}}{d T^{2}}=\left[\frac{0.5}{T_{c}}\right]^{2} \cdot \rho_{c} \sum_{j=2}^{12}(j-1) \cdot(j-3) \cdot A_{j} \cdot W^{j-5}
$$

To develop the density derivatives for

the cold steam is a bit more complicated, since here is not the density, but the factor of reality given by a polynomial (s. Eq. [5.10]).

From the gas law

$$
P^{\times}=\rho_{V} \cdot R_{\text {gas }} \cdot T \cdot Z_{V}
$$

one has the following relations between the first and second derivatives:

$$
\frac{T}{P^{x}} \frac{d P^{x}}{d T}=1+\frac{T}{\rho_{V}} \frac{d \rho_{V}}{d T}+\frac{T}{Z_{V}} \frac{d Z_{V}}{d T}
$$

and 


$$
\begin{gathered}
\frac{T^{2}}{P^{x}} \frac{d^{2} P^{x}}{d T^{2}}-2 \cdot \frac{T}{P^{x}} \frac{d P^{x}}{d T}+2= \\
=\frac{T^{2}}{\rho_{V}} \frac{d^{2} \rho_{V}}{d T^{2}}+2 \cdot \frac{T}{\rho_{V}} \frac{d \rho_{V}}{d T} \cdot \frac{T}{Z_{V}} \frac{d Z_{V}}{d T}+\frac{T^{2}}{Z_{V}} \frac{d^{2} Z_{V}}{d T^{2}}
\end{gathered}
$$

Since the Z-derivatives are

$$
\begin{aligned}
& \frac{d Z_{V}}{d T}=-\frac{0.5}{T_{c}} \sum_{j=2}^{12}(j-1) \cdot Z_{j} \cdot w^{j-3} \quad \text { and } \\
& \frac{d^{2} Z_{V}}{d T^{2}}=\left[\frac{0.5}{T_{c}}\right]^{2} \sum_{j=2}^{12}(j-1) \cdot(j-3) \cdot Z_{j} \cdot w^{j-5}
\end{aligned}
$$

so the density derivatives in the cold steam can be described as

$$
\begin{gathered}
\frac{d \rho_{V}}{d T}=\frac{\rho_{V}}{T}\left[Q_{1}-1+\frac{0.5 \cdot T}{Z_{V} \cdot T_{c}} \sum_{j=2}^{12}(j-1) \cdot Z_{j} \cdot w^{j-3}\right], \\
\frac{d^{2} \rho_{V}}{d T^{2}}=\frac{\rho_{V}}{T^{2}}\left[Q_{1}^{2}-3 Q_{1}+Q_{2}+2\right]+ \\
+\frac{1}{Z_{V} \cdot T_{c}}\left[\frac{d \rho_{V}}{d T} \sum_{j=2}^{12}(j-1) \cdot Z_{j} \cdot w^{j-3}+\right. \\
\left.\quad-0.25 \frac{\rho_{V}}{T_{c}} \sum_{j=2}^{12}(j-1) \cdot(j-3) \cdot Z_{j} \cdot w^{j-5}\right]
\end{gathered}
$$

In the vicinity of the critical point AQUA describes the densities as

$$
\begin{aligned}
& \rho(T)=\rho_{c} \cdot \omega(\tau) \\
& \omega(\tau) \equiv 1+B \tau^{\beta}+\tau\left[U_{1}+\tau\left(U_{2}+\tau^{2} U_{4}\right)\right]
\end{aligned}
$$

with $B=2.03$ for the liquid and $B=-2.03$ for the vapor. The $\tau$-derivative is

$$
\frac{d \tau}{d T}=-\frac{\rho_{c}}{T_{c}}
$$

so the first density derivatives will be

$$
\frac{d \rho}{d T}=-\frac{\rho_{c}}{T_{c}} \frac{d \omega}{d \tau}=-\frac{\rho_{c} \cdot g}{T_{c}-T}
$$

the function $\mathrm{g}$ being 


$$
g \equiv \tau \frac{d \omega}{d \tau}=B \tau^{\beta} \beta+\tau\left[U_{1}+\tau\left(2 U_{2}+\tau^{2} 4 U_{4}\right)\right]
$$

The second density-derivatives one can develop as

$$
\frac{d^{2} \rho}{d T^{2}}=\frac{\rho_{c}}{T_{c}^{2}} \frac{d^{2} \omega}{d \tau^{2}}=\frac{\rho_{c}}{\left(\tau \cdot T_{c}\right)^{2}}\left[\tau \frac{d g}{d \tau}-g\right]=\frac{\rho_{c} \cdot h}{\left(T_{c}-T\right)^{2}}
$$

with

$$
h \equiv \tau \frac{d g}{d \tau}-g=B \tau^{\beta} \beta(\beta-1)+\tau^{2}\left(2 U_{2}+\tau^{2} 12 U_{4}\right)
$$

Requesting smooth transitions at the switching point for the density and its first and second derivatives leads to the following system of equations for the coefficients $U$ :

$$
\begin{aligned}
& U_{4}=\frac{2(0-g)+h-(1-\beta)(2-\beta) b}{6 \tau^{4}} \\
& U_{2}=-\frac{4(0-g)+h-(1-\beta)(4-\beta) b}{2 \tau^{2}} \\
& U_{1}=\frac{80-5 g+h-(2-\beta)(4-\beta) b}{3 \tau}
\end{aligned}
$$

with the abbreviations

$$
b=B \tau^{\beta} \quad \text { and } \quad 0=\frac{\rho-\rho_{c}}{\rho_{c}}
$$




\section{Appendix C. Adjusting the saturated states}

To be in thermal equilibrium the pressures and the Gibbs-energies of the saturated liquid and the saturated vapor must be in accordance with each other :

$$
G_{L}=G_{V} \quad \text { and } \quad P_{L}=P_{V} \text {. }
$$

For the Gibbs-function

$$
G \equiv A+\frac{P}{\rho}
$$

along an isotherm it holds :

$$
\left.d G\right|_{T}=d \rho \cdot \frac{\partial G}{\partial \rho}
$$

with

$$
\frac{\partial G}{\partial \rho}=\frac{\partial A}{\partial \rho}-\frac{P}{\rho^{2}}+\frac{1}{\rho} \frac{\partial P}{\partial \rho}=\frac{1}{\rho} \frac{\partial P}{\partial \rho}
$$

Suppose the liquid and the vapor state differ from each other by $\Delta P=P_{L}-P_{V}$ and $\Delta G=G_{L}-G_{V}$. To get rid of these differences one needs small changes in the liquid density, $x$ and in the vapor density, $y$.

The density changes, $x$ and $y$ can be calculated as follows : The pressure difference can be transformed to

$$
\Delta P=P_{L}-P^{x}+P^{x}-P_{V}=-\Delta P_{L}+\Delta P_{V}=-x \frac{\partial P}{\partial \rho_{L}}+y \frac{\partial P}{\partial \rho_{V}}
$$

with $\Delta P_{L}=P^{x}-P_{L}$ and $\Delta P_{V}=P^{x}-P_{V}$. Correspondingly one has for the G-s

$$
\Delta G=G_{L}-G^{\times}+G^{x}-G_{V}=-\Delta G_{L}+\Delta G_{V}=-\frac{x}{\rho_{L}} \frac{\partial P}{\partial \rho_{L}}+\frac{y}{\rho_{V}} \frac{\partial P}{\partial \rho_{V}}
$$

The Eqs. [C.5]- [C.6] can be solved for $x$ and $y$ :

$$
\begin{aligned}
& x=\frac{\rho_{L}}{\rho_{L}-\rho_{V}} \cdot \frac{\Delta G \cdot \rho_{V}-\Delta P}{\partial P / \partial \rho_{L}}, \\
& y=\frac{\rho_{V}}{\rho_{L}-\rho_{V}} \cdot \frac{\Delta G \cdot \rho_{L}-\Delta P}{\partial P / \partial \rho_{V}},
\end{aligned}
$$

Using the properties in their reduced forms leads to:

$$
\begin{aligned}
& x=\frac{\rho_{L}}{\rho_{L}-\rho_{V}} \cdot \frac{\rho_{V}\left(\Delta G^{0}+Z_{V}\right)-\rho_{L} \cdot Z_{L}}{\mathrm{PR}^{0}{ }_{L}}, \\
& y=\frac{\rho_{V}}{\rho_{L}-\rho_{V}} \cdot \frac{\rho_{L}\left(\Delta G^{0}-Z_{L}\right)+\rho_{V} \cdot Z_{V}}{\mathrm{PR}^{0}{ }_{V}},
\end{aligned}
$$





\section{D.1 Interactive routines}

WATER

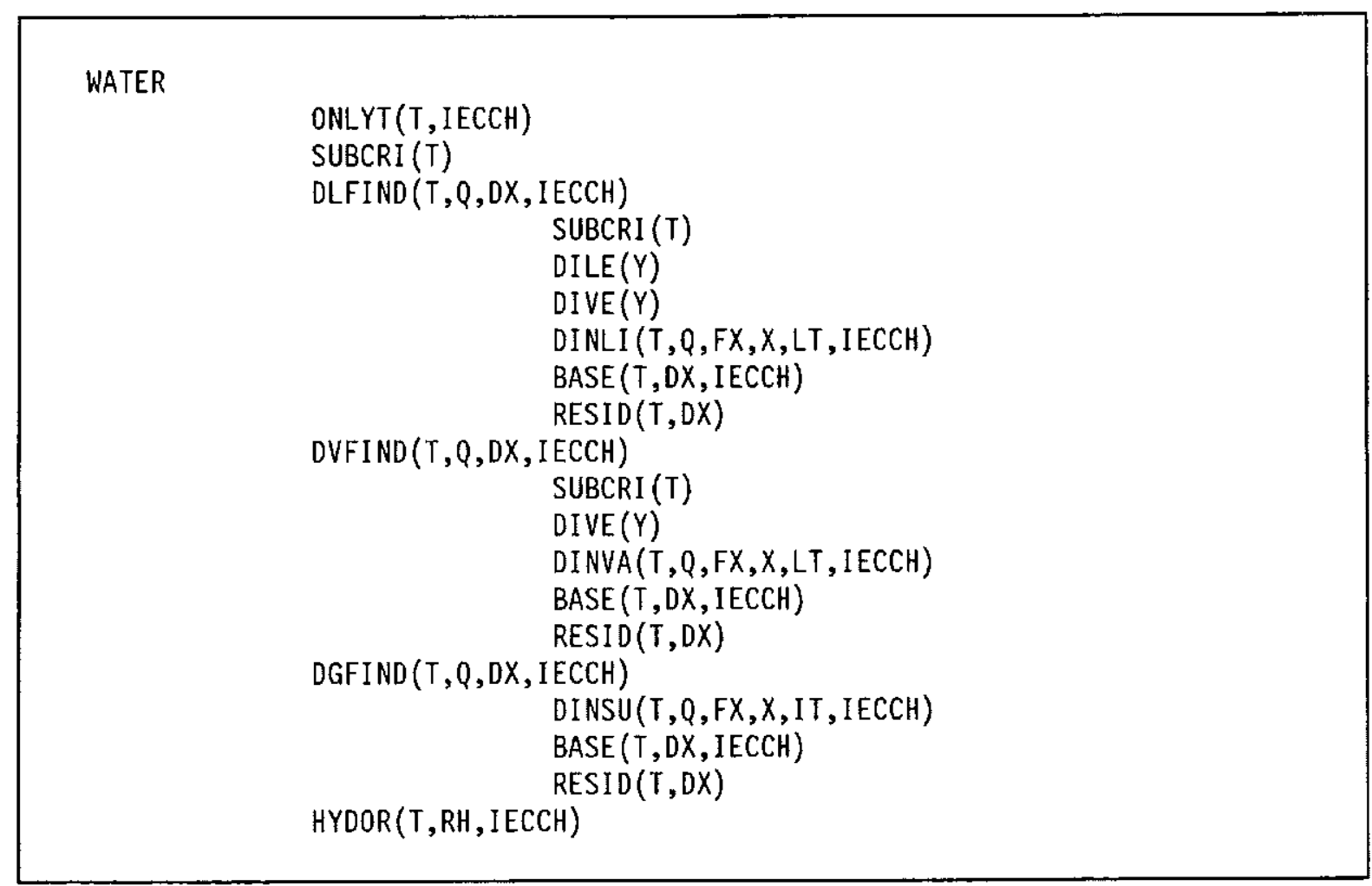

Figure 37. Module tree for the procedure WATER 
KAISOT

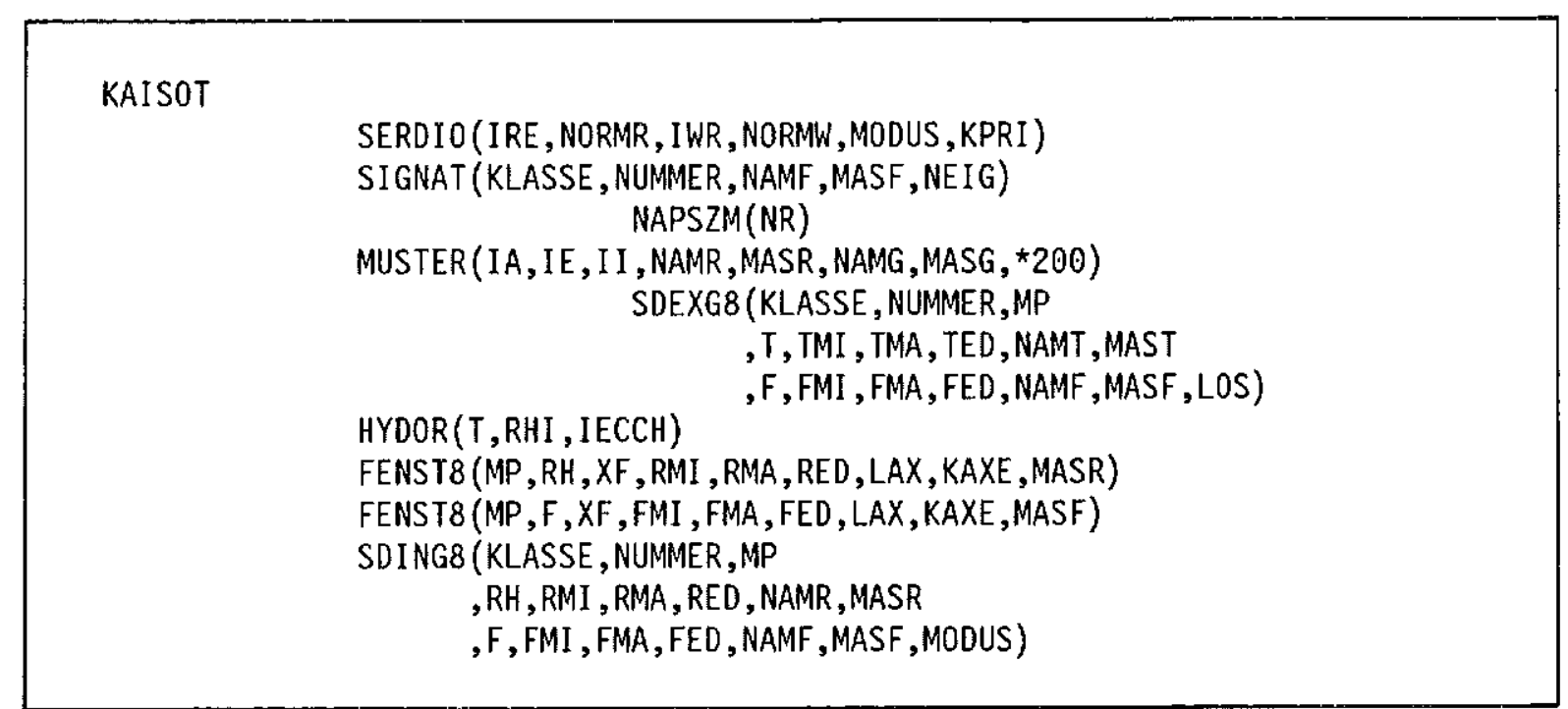

Figure 38. Module tree for the procedure KAISOT

\section{KAISOK}

KAISOK

$$
\begin{aligned}
& \text { SERDI 0 (IRE, NORMR, I WR, NORMW, MODUS, KPRI) } \\
& \text { SI GNAT (KLASSE, NUMMER, NAMF, MASF, NEIG) } \\
& \text { NAPSZM(NR) } \\
& \text { MUSTER(IA , IE, I I , NAMR, MASR, NAMG , MASG , *200) } \\
& \text { SDEXG8 (KLASSE, NUMMER, MP } \\
& \text {, T, TMI , TMA, TED, NAMT, MAST } \\
& \text { HYDOR ( T, RHI , IECCH) } \\
& \text {, F, FMI , FMA, FED, NAMF, MASF, LOS) } \\
& \text { FENST8 (MP, RH, XF, RMI , RMA , RED , LAX, KAXE , MASR) } \\
& \text { FENST8 (MP, F, XF, FMI , FMA, FED, LAX, KAXE, MASF) } \\
& \text { SDING8 (KLASSE, NUMMER, MP } \\
& \text {, RH, RMI , RMA , RED , NAMR , MASR } \\
& \text {, } F \text {, FMI , FMA, FED, NAMF, MASF, MODUS) }
\end{aligned}
$$

Figure 39. Module tree for the procedure KAISOK 


\section{D.2 IVA3-ROUTINES}

\section{WASSER}

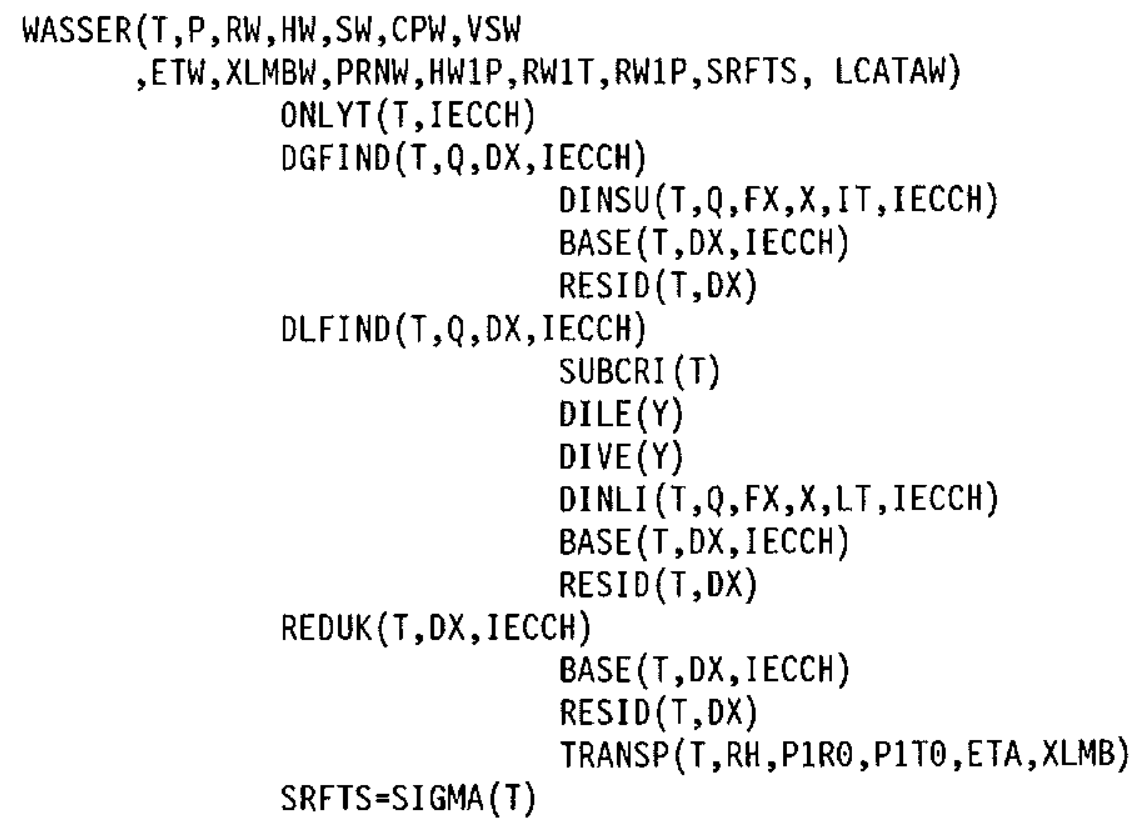

Figure 40. Module tree for the procedure WASSER

\section{DAMPF}

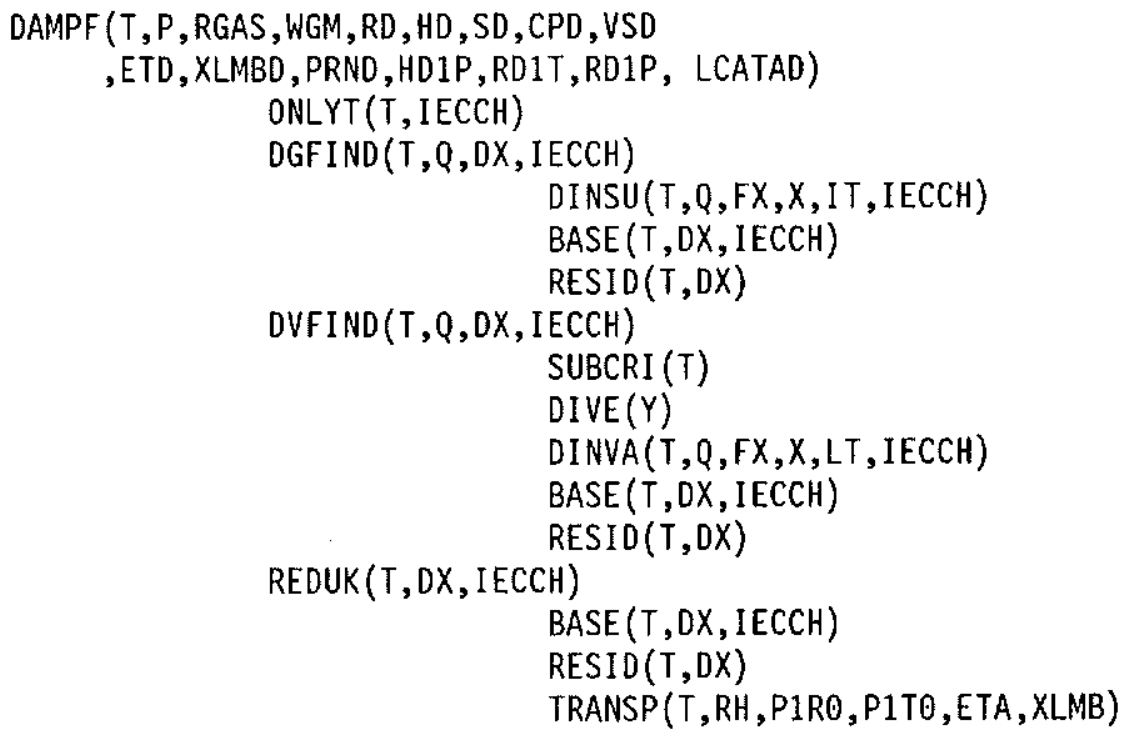

Figure 41. Module tree for the procedure DAMPF 
RDRDP

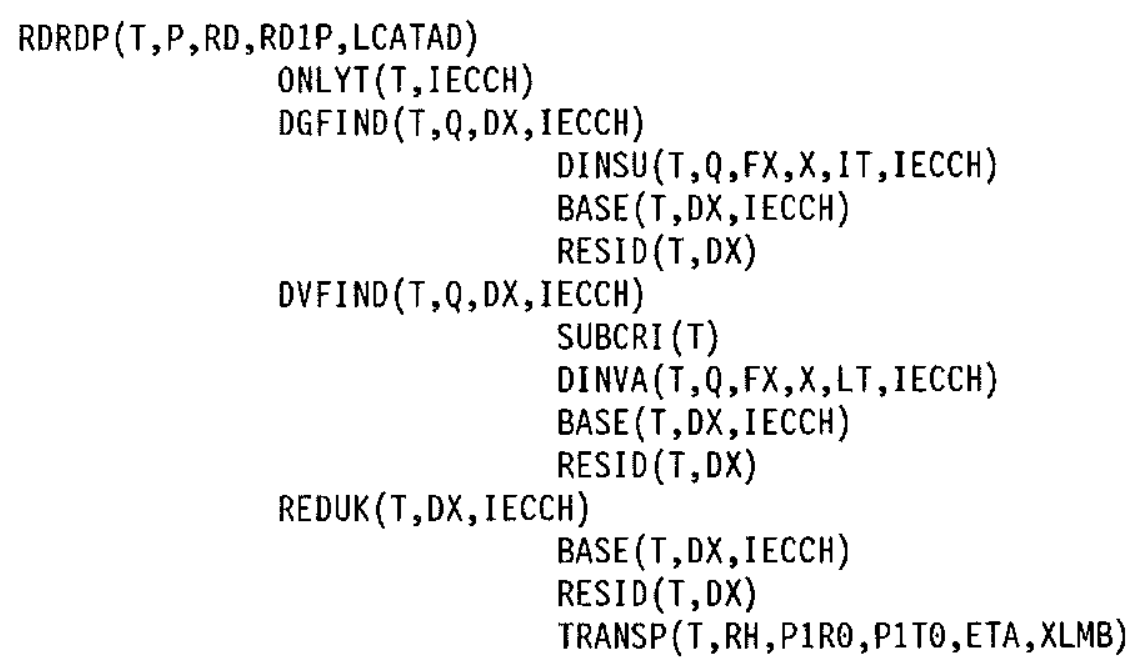

Figure 42. Module tree for the procedure RDRDP

\section{SAET01}

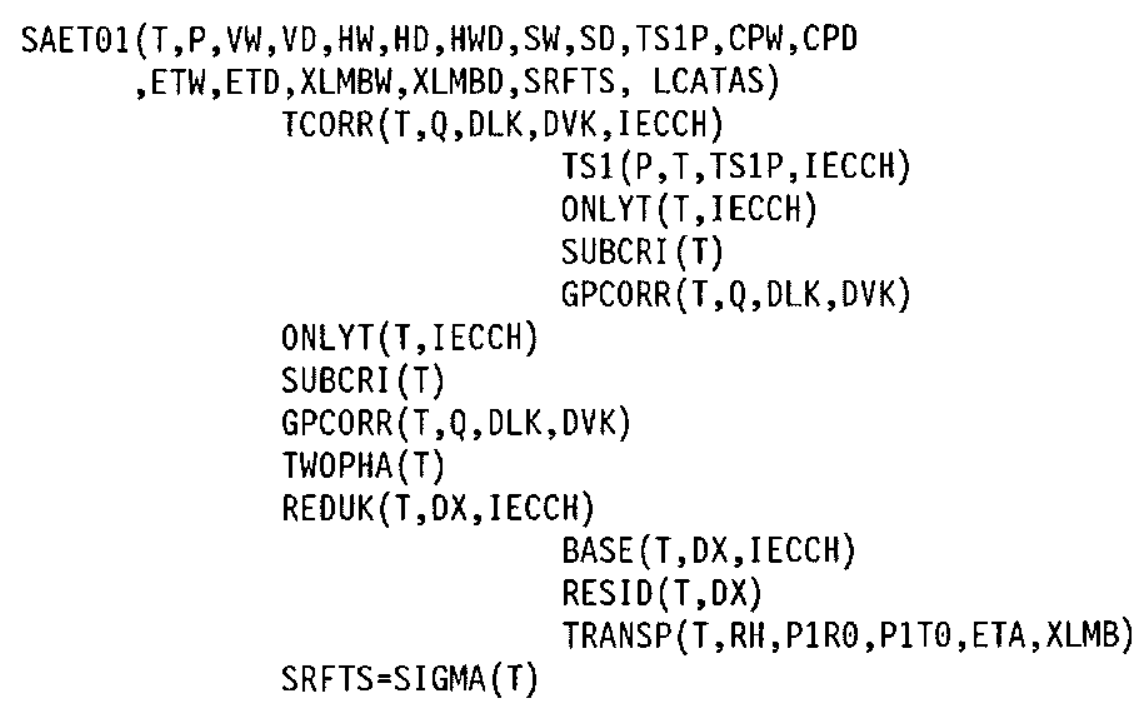

Figure 43. Module tree for the procedure SAET01 


\section{D.3 SUB-ROUTINES}

\section{HYDOR}

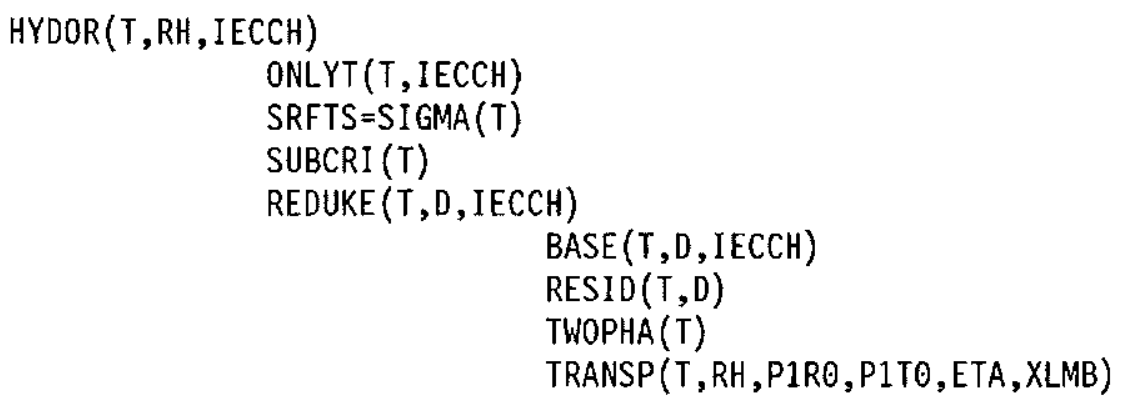

Figure 44, Module tree for the procedure HYDOR

\section{SUBCRI}

$\operatorname{SUBCRI}(\mathrm{T})$

$$
\begin{aligned}
& \text { SSP }(T) \\
& \text { SSRHO(T) } \\
& \text { SPIRHO(T) } \\
& \text { SPIP(T) }
\end{aligned}
$$

Figure 45. Module tree for the procedure SUBCRI

\section{TWOPHA}

TWOPHA $(T)$

$$
\begin{aligned}
& \text { SSCEV (T, CVL, CVV) } \\
& \text { SSPER(T) } \\
& \text { SSPET(T,PTL, PTV) } \\
& \text { SSPET (T,PTL, PTV) } \\
& \text { SSGIS (T, SL, GL) } \\
& \text { SSETA (T, ETL, ETV) } \\
& \text { SSLAM (T, XLL, XLV) }
\end{aligned}
$$

Figure 46. Module tree for the procedure TWOPHA 


\section{GPCORR}

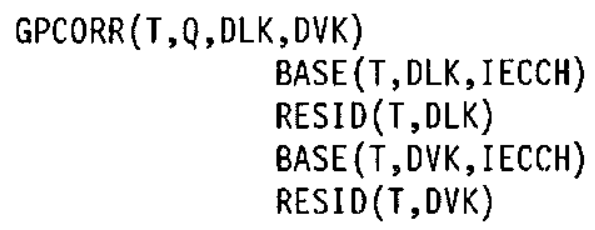

Figure 47. Module tree for the procedure GPCORR

\section{DINSU}

$$
\begin{aligned}
& \operatorname{DINSU}(T, Q, F X, X, I T, I E C C H) \\
&\text { QUADO(FX, } X, Q, D X, J E C C H) \\
&\text { MONIKA(FX, } X, J E C C H) \\
& \text { SORBET }(K I, F X, X, Q, D X) \\
& \text { BASE }(T, D X, I E C C H) \\
& \text { RESID }(T, D X)
\end{aligned}
$$

Figure 48. Module tree for the function DINSU

\section{DINLI}

$$
\begin{aligned}
\text { DINLI }(T, Q, F X, X, I T, I E C C H) \\
\\
\text { QUADO }(F X, X, Q, D X, J E C C H) \\
\text { MONIKA(FX,X,JECCH) } \\
\text { SORBET }(K I, F X, X, Q, D X) \\
\text { BASE }(T, D X, I E C C H) \\
\text { RESID }(T, D X)
\end{aligned}
$$

Figure 49. Module tree for the function DiNLI

\section{DINVA}

$$
\begin{aligned}
& \text { DINVA }(T, Q, F X,X, I T, I E C C H) \\
& \text { QUADO }(F X, X, Q, D X, J E C C H) \\
&\text { MONIKA(FX, } X, J E C C H) \\
& \\
& \text { SORBET }(K I, F X, X, Q, D X) \\
& \\
& \text { BASE }(T, D X, I E C C H) \\
& \text { RESID }(T, D X)
\end{aligned}
$$

Figure 50. Module tree for the function DINVA 


\section{Appendix E. Common blocks}

A substantial part of the data transfer between the moduls of the AQUA code takes place via common blocks. Present appendix serves to describe the most important ones of theese common blocks in an abridged form.

ISATIF/ PS,TPS1T,TTPS2T,DL,DV,RL1TO,RV1TO,RHSL,PSL,RHSV,PSV,SL,GL, PL1R0,PL1T0,CVL,ETL,XLL,PV1R0,PV1T0,CVV,ETV,XLV

carries thermal properties in the saturated and spinodal states, namely

PS, TPS1T, TTPS2T

the vapor pressure and its first and second derivatives,

$S L, G L$

the entropy and the Gibbs-function of the saturated liquid,

DL, DV, RL1T0, RV1T0

the saturated densities with their reduced derivatives,

PL1R0, PV1R0, PL1T0, PV1T0

the density- resp. temperature-derivatives of the pressure in the saturated states,

CVL, CVV, ETL, ETV, XLL, XLV

the constant volume heat capacities, the viscosities and the thermal conductivities in the saturated states,

and the densities and pressures on the liquid and vapor spinodals

RHSL, RHSV, PSL, PSV.

SATIF is supplied with data - under the direction of SUBCRI and TWOPHA - by the moduls SSP, SSRHO, SPIRHO, SSPER and SPIP. SATIF supplies data to the moduls DLFIND, DVFIND, REDUKE, TS1, TCORR, SAET01 and VD1.

IREDUF/ GO,SO,Z,P1TO,P1RO,CVO,CPO,ETA,XLMB,R1T0,CPC,HO,VQ

holds thermal properties of the water, mostly in the reduced form, namely

SO, HO, GO

$z$

the entropy, the enthalpy and the Gibbs-function,

the factor of reality,

CVO, CPO, CPC

the constant volume and constant pressure heat capacities and their ratio,

P1T0, P1R0, R1T0

the density- resp. temperature-derivative of the pressure

and the temperature-derivative of the density,

ETA, XLMB

the viscosity and the thermal conductivity

and the vapor quality

VQ.

REDUF is filled either by REDUK or by REDUKE, and used by the moduls HYDOR, WATER, WASSER, DAMPF and RDRDP.

IHYDUFI S,G,H,H1P,U1R,CV,CP,P,P1T,P1R,R1T,R1P,ETA,XLMB,SRFTS,P1RS, VS,PRN,V,VQ

is needed to supply the thermal properties of the water - calculated by HYDOR to the prorams WATER, KAISOK AND KAISOT. 
The following common blocks

/BASIF/ GB,SB,ZB,PB1TO,PB1RO,CVB

and

IRESEF/ GR,SR,ZR,PR1T0,PR1R0,CVR

carry contributions - in the reduced form - to the thermal properties as calculated by the modul BASE resp. RESID. The properties are :

S, G

the entropy and the Gibbs-function,

Z

the factor of reality,

P1TO, P1R0

the density- resp. temperature-derivative of the pressure, and

CV

the constant volume heat capacity.

BASIF and RESEF are neded by the moduls DGFIND, DLFIND, DVFIND, REDUK, REDUKE and GPCORR.

ITEMPO/ RT,B1,B2,B1T,B2T,B1TT,B2TT,TV,GI,SI,CVI

holds properties calculated in ONLYT, which depend only from the temperature as e.g.

SI, GI, CVI

the entropy, the Gibbs-function and the constant volume heat capacity of the ideal gas.

$R T$ is $R G A S^{*} T$ in $\mathrm{J} / \mathrm{g}$. The remainig properties are needed only in BASE. 


\section{Appendix F. Property routines}

The following routines serve directly to describe some thermal property of the water. The essential ones are basically the same, as the corresponding routines in the H.G.K.code.

\section{F.1 INR105.AQUA.FORT(BLOCK)}

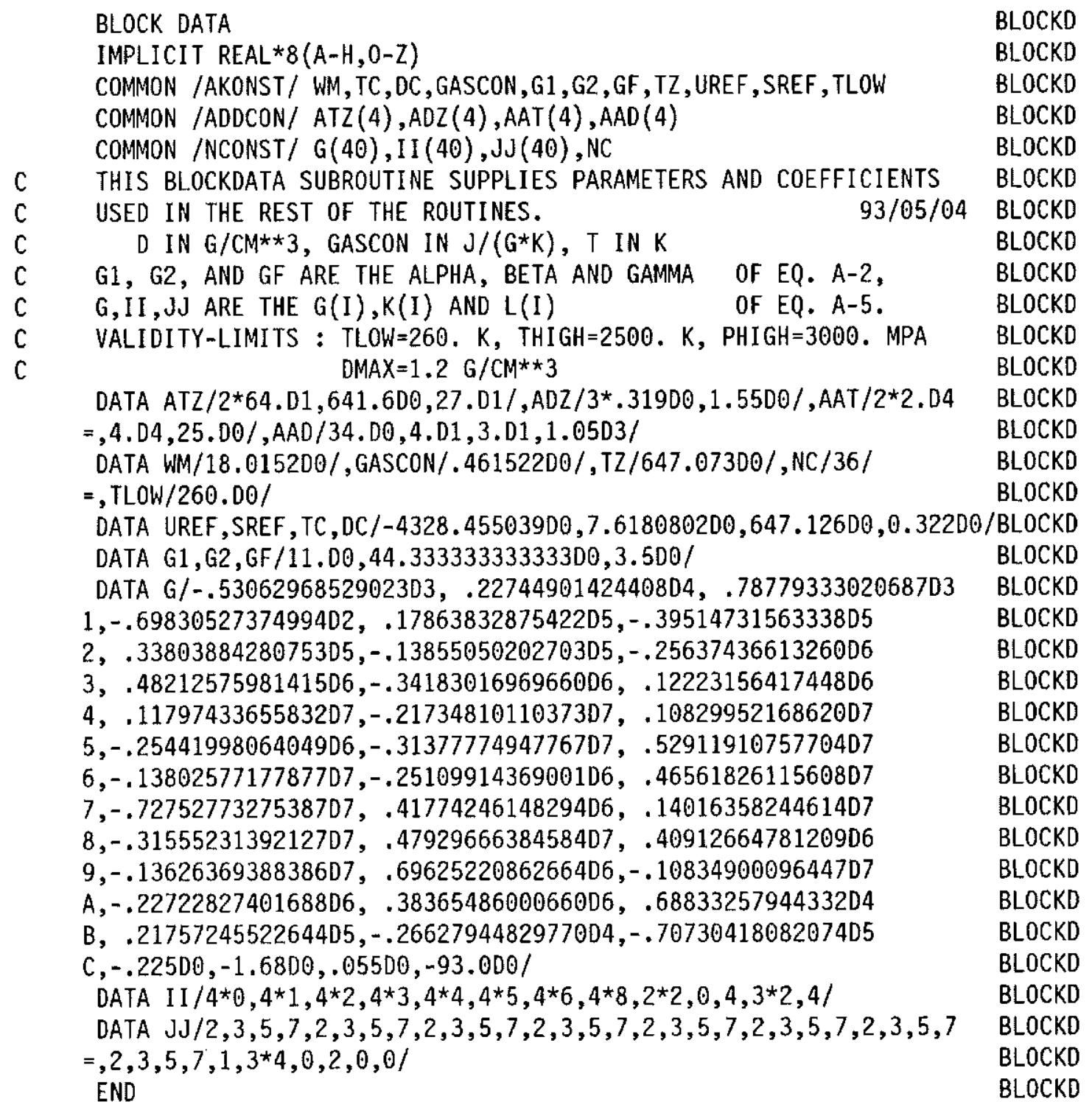




\section{F.2 INR105.AQUA.FORT(ONLYT)}

\begin{tabular}{|c|c|c|}
\hline & SUBROUTINE ONLYT(T, IECCH) & ONLYT \\
\hline C & THIS SUBROUTINE CALCULATES THERMAL PROPERTIES & ONLYT \\
\hline \multirow[t]{14}{*}{ C } & DEPENDING ONLY FROM THE TEMPERATURE & ONLYT \\
\hline & IMPLICIT REAL*8(A-H,0-Z) & ONLYT \\
\hline & COMMON /AKONST/ WM, TC,DC, GASCON,G1,G2,GF, TZ, UREF, SREF, TLOW & ONLYT \\
\hline & COMMON /TEMP0/ CGT,B1,B2,B1T,B2T,B1TT,B2TT,TV,GI,SI,CVI & ONLYT \\
\hline & DIMENSION BP(7), BQ(7), C(18) & ONLYT \\
\hline & DATA BP $/ .747862900,-.354078200,2 * 0.00, .7159876 \mathrm{D}-2,0.00$ & ONLYT \\
\hline & $=,-.35284260-2 /, \mathrm{BQ} / 1.1278334 \mathrm{DO}, 0 . \mathrm{DQ},-.594400100$ & ONLYT \\
\hline & $=,-5.01099600,0.00, .6368425600,0.00 /$ & ONLYT \\
\hline & DATA C/.19730271018D2,.209662681977D2, -.48342945535500 & ONLYT \\
\hline & $=, .60574318924501,22.5602388500,-9.87532442 D 0,-.43135538513 D 1$ & ONLYT \\
\hline & $=, .45815578100,-.47754901883 \mathrm{D}-1, .41238460633 \mathrm{D}-2,-.279290528520-3$ & ONLYT \\
\hline & $=, .14481695261 \mathrm{D}-4,-.56473658748 \mathrm{D}-6, . .16200446 \mathrm{D}-7,-.3303822796 \mathrm{D}-9$ & ONLYT \\
\hline & $=, .451916067368 \mathrm{D}-11,-.370734122708 \mathrm{D}-13, .137546068238 \mathrm{D}-15 /$ & ONLYT \\
\hline & DATA UN/1.DO/ & ONLYT \\
\hline \multirow[t]{5}{*}{ C--- } & 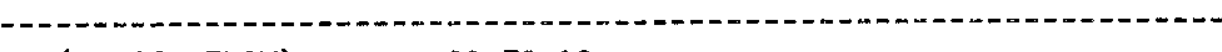 & ONLYT \\
\hline & IF (T . GE. TLOW $) \quad$ G0 T0 10 & ONLYT \\
\hline & WRITE $\left(6,{ }^{\prime}(16 \mathrm{H} \text { TEMPERATURE } \mathrm{T}=, \mathrm{F} 10.4,13 \mathrm{H} \mathrm{K} \text { T00 LOW! } /)^{\prime}\right) \mathrm{T}$ & ONLYT \\
\hline & IECCH $=-4$ & ONLYT \\
\hline & RETURN & ONLYT \\
\hline \multicolumn{2}{|r|}{ 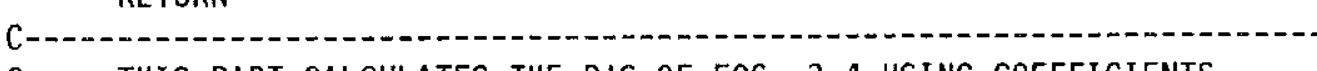 } & ONLYT \\
\hline C & THIS PART CALCULATES THE B'S OF EQS. 3,4 USING COEFFICIENTS & ONLYT \\
\hline C & FROM BLOCKDATA, CALCULATING ALSO THE FIRST AND SECOND DERIVS & ONLYT \\
\hline \multirow{4}{*}{$\begin{array}{l}{ }_{10} \\
{ }_{10}\end{array}$} & W.R. TO TEMP. THE B'S CALCULATED HERE ARE IN CM3/G. & ONLYT \\
\hline & $\mathrm{CGT}=\mathrm{GASCON} * \mathrm{~T}$ & ONLYT \\
\hline & $\mathrm{T} 1=\mathrm{UN} / \mathrm{T}$ & ONLYT \\
\hline & $T V=T Z^{\star} T 1$ & ONLYT \\
\hline \multirow[t]{20}{*}{ C-- - - } & 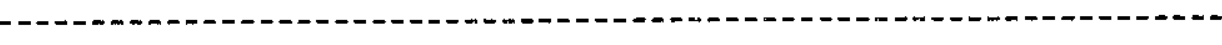 & ONLYT \\
\hline & $\mathrm{B} 1=\mathrm{BP}(7) * \mathrm{TV}$ & ONLYT \\
\hline & $\mathrm{B} 2=\mathrm{BQ}(7) * \mathrm{TV}$ & ONLYT \\
\hline & $\mathrm{B} 1 \mathrm{~T}=\mathrm{B} 1 * 5$ & ONLYT \\
\hline & $\mathrm{B} 2 \mathrm{~T}=\mathrm{B} 2 \star 5$ & ONLYT \\
\hline & $\mathrm{B} 1 \mathrm{TT}=\mathrm{B} 1 \mathrm{~T} * 6$ & ONLYT \\
\hline & $\mathrm{B} 2 \mathrm{TT}=\mathrm{B} 2 \mathrm{~T} * 6$ & ONLYT \\
\hline & D0 $20 \mathrm{I}=1,4$ & ONLYT \\
\hline & $\mathrm{JI}=7-\mathrm{I}$ & ONLYT \\
\hline & $A P=B P(J I)$ & ONLYT \\
\hline & $A Q=B Q(J I)$ & ONLYT \\
\hline & $B 1=(B 1+A P) * T V$ & ONLYT \\
\hline & $B 2=(B 2+A Q) * T V$ & ONLYT \\
\hline & $A P=A P \star(J I-2)$ & ONLYT \\
\hline & $A Q=A Q *(J I-2)$ & ONLYT \\
\hline & $B 1 T=(B 1 T+A P) * T V$ & ONLYT \\
\hline & $B 2 T=(B 2 T+A Q) * T V$ & ONLYT \\
\hline & $A P=A P *(J I-1)$ & ONLYT \\
\hline & $A Q=A Q *(J I-1)$ & ONLYT \\
\hline & $B 1 T T=(B 1 T T+A P) * T V$ & ONLYT \\
\hline \multirow[t]{4}{*}{20} & $B 2 T T=(B 2 T T+A Q) * T V$ & ONLYT \\
\hline & $B 1=B 1-B P(2) * D L 0 G(T V)+B P(1)$ & ONLYT \\
\hline & $\mathrm{B} 2=\mathrm{B} 2+\mathrm{BQ}(1)$ & ONLYT \\
\hline & $\mathrm{B} 1 \mathrm{~T}=(\mathrm{BP}(2)-\mathrm{B} 1 \mathrm{~T}) * \mathrm{~T} 1$ & ONLYT \\
\hline
\end{tabular}




\begin{tabular}{|c|c|c|}
\hline & $\begin{array}{l}B 2 T=-B 2 T * T 1 \\
B 1 T T=(-B P(2)+B 1 T T) * T 1 * T 1 \\
B 2 T T=B 2 T T^{*} T 1^{*} T 1\end{array}$ & $\begin{array}{l}\text { ONLYT } \\
\text { ONLYT } \\
\text { ONLYT }\end{array}$ \\
\hline & 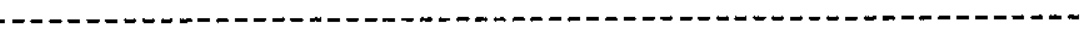 & ONLYT \\
\hline $\mathrm{C}$ & THIS PART CALCULATES THE THERMODYNAMIC PROPERTIES FOR & ONLYT \\
\hline $\mathrm{c}$ & WATER IN THE IDEAL GAS STATE FROM FUNCTION OF H.W. WOOLLEY & ONLYT \\
\hline 50 & $T T=T * 1 . D-2$ & ONLYT \\
\hline & $T T 1=U N / T T$ & ONLYT \\
\hline & $T L=D L O G(T T)$ & ONLYT \\
\hline & $G I=-(C(2)+C(1) * T T 1) * T L$ & ONLYT \\
\hline & $H I=C(2)+C(1) *(U N-T L) * T T 1$ & ONLYT \\
\hline & $C P I=C(2)-C(1) * T T 1$ & ONLYT \\
\hline & D0 $60 \mathrm{~J}=3,18$ & ONLYT \\
\hline & $C I T=C(J) * T T^{*}(J-6)$ & ONLYT \\
\hline & $\mathrm{GI}=\mathrm{GI}-\mathrm{CIT}$ & ONLYT \\
\hline & $H I=H I+(J-6) * C I T$ & ONLYT \\
\hline 60 & $C P I=C P I+(J-5) *(J-6) * C I T$ & ONLYT \\
\hline & $S I=H I-G I$ & ONLYT \\
\hline & $C V I=C P I-U N$ & ONLYT \\
\hline & 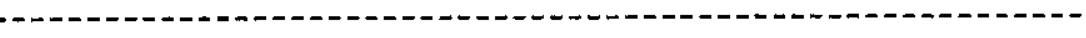 & - ONLYT \\
\hline & RETURN & ONLYT \\
\hline & END & ONLYT \\
\hline
\end{tabular}

\section{F.3 INR105.AQUA.FORT(BASE)}

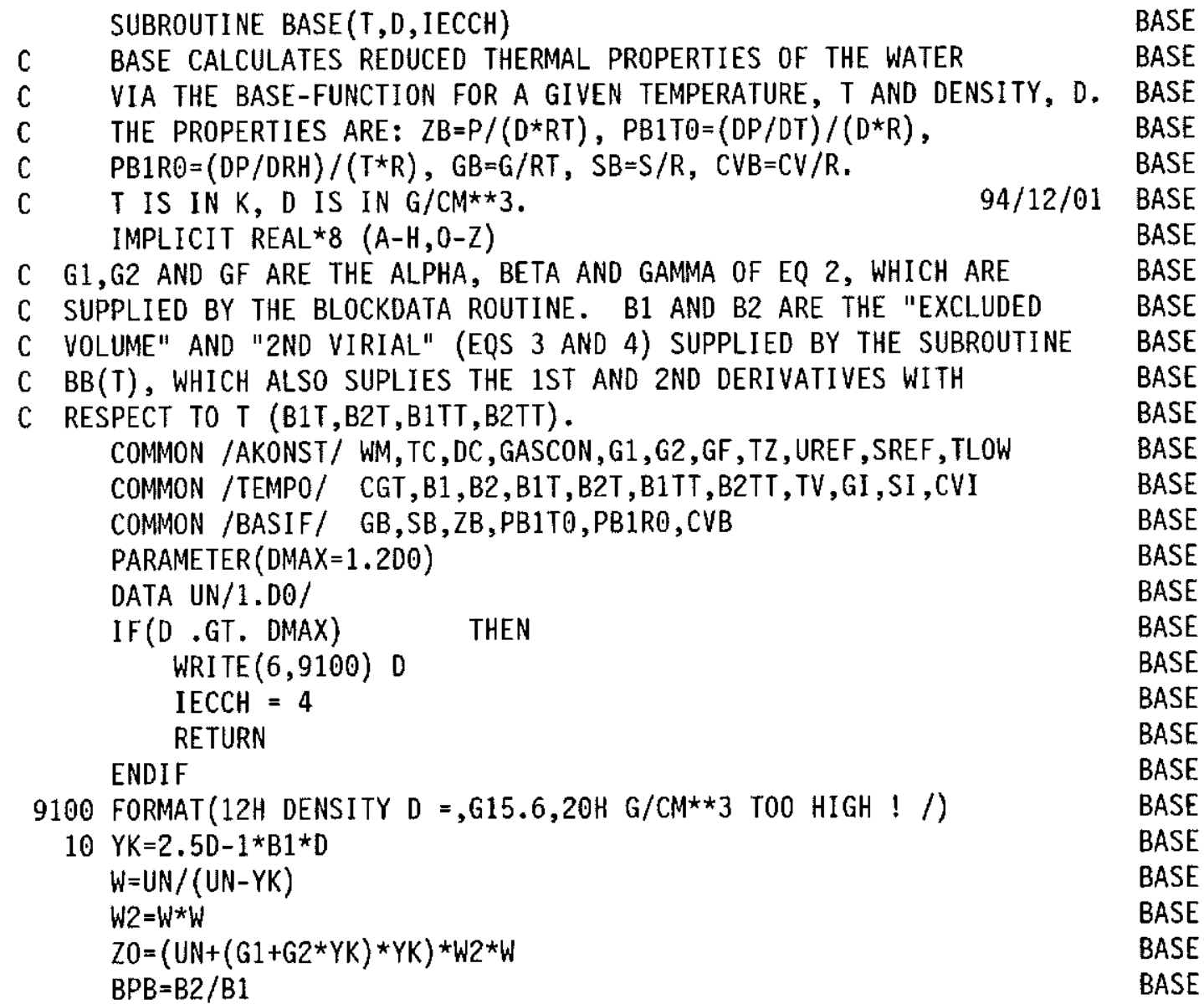




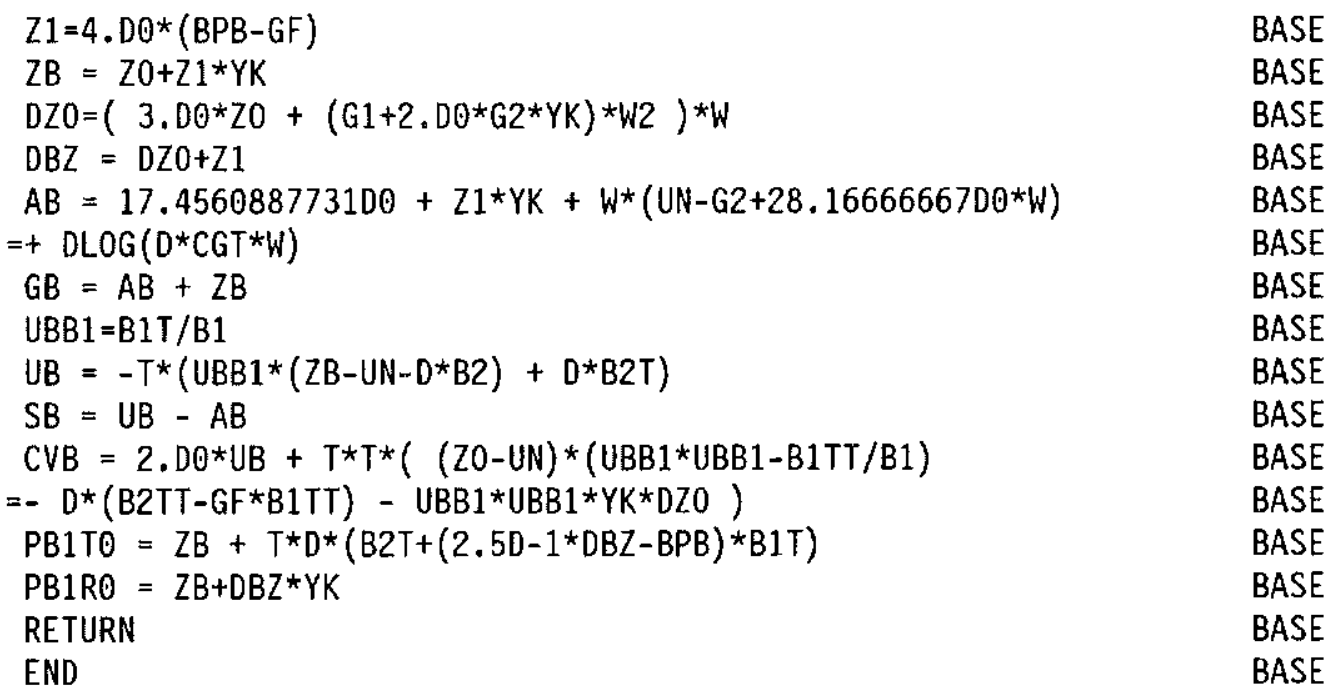

\section{F.4 INR105.AQUA.FORT(RESID)}

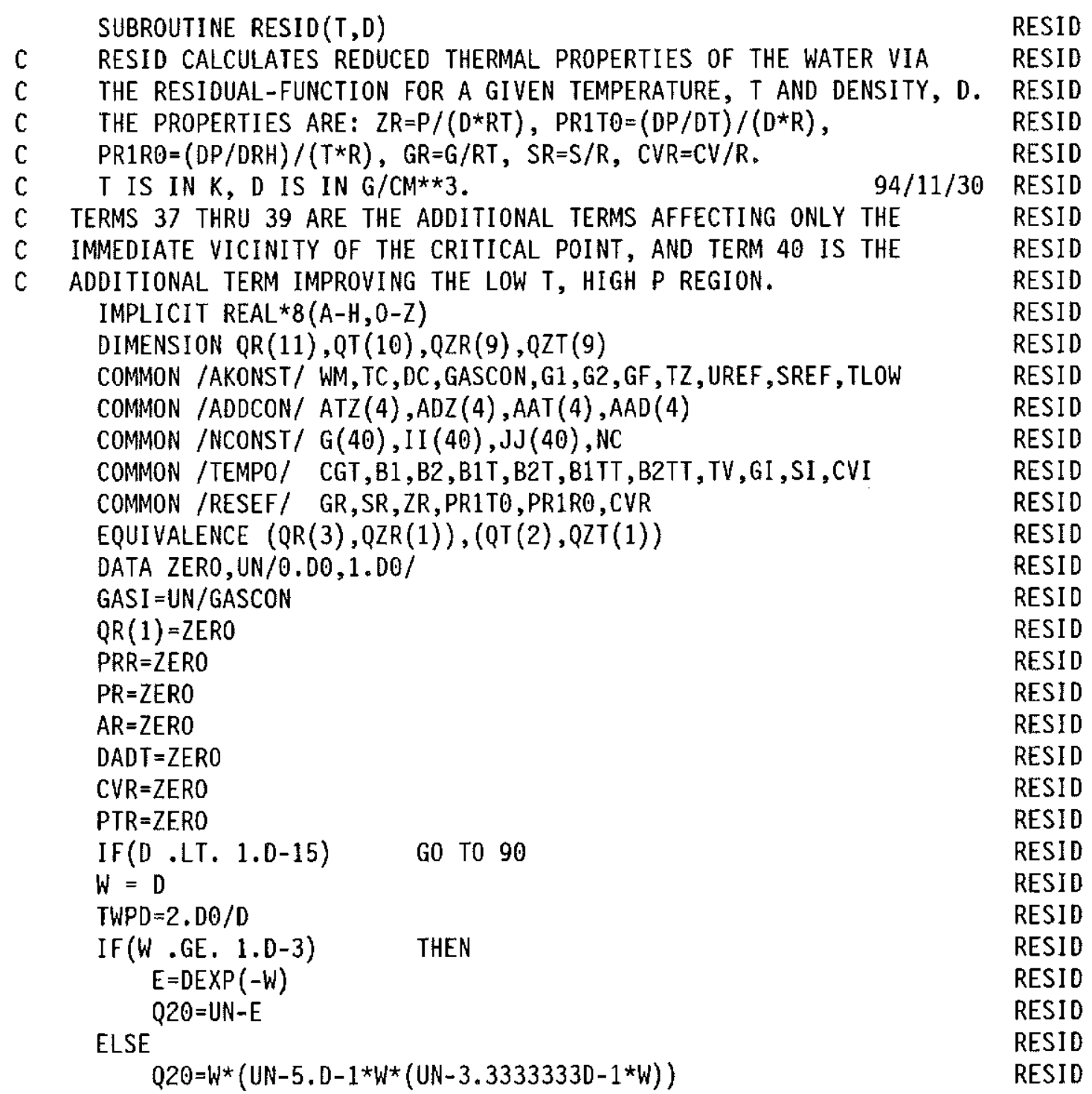


$\begin{array}{ll}E=U N-Q 20 & \text { RESID }\end{array}$

ENDIF $\quad$ RESID

$V E R O=E / 020 \quad$ RESID

$V E R 1 \simeq V E R O * D * D \quad$ RESID

$Q 10=0 * D * E \quad$ RESID

$Q 10 R T=Q 10 * C G T \quad$ RESID

$\mathrm{QR}(2)=Q 10 \quad$ RESID

$Q T(1)=T / T Z \quad$ RESID

DO $11 \mathrm{I}=2,10 \quad$ RESID

IF $(Q R(I)$.LE. 1.E-35) QR(I)=ZERO RESID

$Q R(I+1)=Q R(I) * 020 \quad$ RESID

$11 \mathrm{QT}(\mathrm{I})=\mathrm{QT}(\mathrm{I}-1) * \mathrm{TV} \quad$ RESID

DO $21 \mathrm{I}=1, \mathrm{NC} \quad$ RESID

$K=I I(I)+1 \quad$ RESID

$\mathrm{L}=\mathrm{JJ}(\mathrm{I}) \quad$ RESID

$\mathrm{GPP}=\mathrm{G}(\mathrm{I}) * \mathrm{QZT}(\mathrm{L}) \quad$ RESID

$Q P=G P P * Q Z R(K-1) \quad$ RESID

$P R=P R+Q P \quad$ RESID

$P R R=P R R+Q P *(T W P D-(U N-(K-1) \star V E R O)) \quad$ RESID

$B U A M=K * \operatorname{LOG}(Q 20) \quad$ RESID

IF (BUAM .LE. -35.) AUA=ZERO RESID

IF (BUAM .GT. -35.) AUA=EXP(BUAM) RESID

$A R=A R+G P P * Q Z R(K) /(K * Q 10 R T) \quad$ RESID

$\mathrm{DFDT}=\mathrm{AUA} *(1-\mathrm{L}) * Q Z T(\mathrm{~L}+1) /(\mathrm{TZ} * \mathrm{~K}) \quad$ RESID

$\mathrm{GPDT}=\mathrm{G}(\mathrm{I}) * \mathrm{DFDT} \quad$ RESID

DADT $=$ DADT+GPDT RESID

$D P T=G P D T * K * V E R 1 \quad$ RESID

$P T R=P T R+D P T \quad$ RESID

$D 2 F=L * G P D T * G A S I \quad$ RESID

21 CVR $=$ CVR+D2F RESID

$\mathrm{QP}=$ ZERO $\quad$ RESID

Q2A $=$ ZERO $\quad$ RESID

DO $31 \mathrm{~J}=37,40 \quad$ RESID

$\operatorname{IF}(\mathrm{G}(\mathrm{J}) \cdot \mathrm{EQ} \cdot \mathrm{ZERO}) \quad$ GO TO 31

$K=I I(J) \quad$ RESID

$K M=J J(J) \quad$ RESID

$D D Z=A D Z(J-36) \quad$ RESID

DDZI $=U N / D D Z \quad$ RESID

$D E L=D * D D Z 1-U N \quad$ RESID

IF (DABS (DEL) .LT. 1.D-10) DEL=1.D-10 RESID

$E X 1=-A A D(J-36) * D E L * * K \quad$ RESID

IF (EX1 .GT. $-170 . D 0) \quad D E X=D E X P(E X 1) * D E L * \star K M \quad$ RESID

IF (EX1 .LE. $-170 . D 0) \quad$ DEX $=$ ZERO RESID

ATT $=\operatorname{AAT}(\mathrm{J}-36) \quad$ RESID

TX1 $=U N / A T Z(\mathrm{~J}-36) \quad$ RESID

$T A=T * T \times 1 \quad$ RESID

$T A U=T A-U N \quad$ RESID

$E X 2=-A T T * T A U * T A U \quad$ RESID

IF $(E X 1+E X 2$.GT. $-170 . D 0)$ THEN RESID

$T E X=D E X P(E X 2) \quad$ RESID

$010=0 E X * T E X \quad$ RESID

IF (DABS $(Q 10) \cdot L T, 1 . D-14) \quad Q 10=Z$ ZERO RESID

ELSE

$Q 10=$ ZERO

RESID

RESID

GO TO 31

RESID 


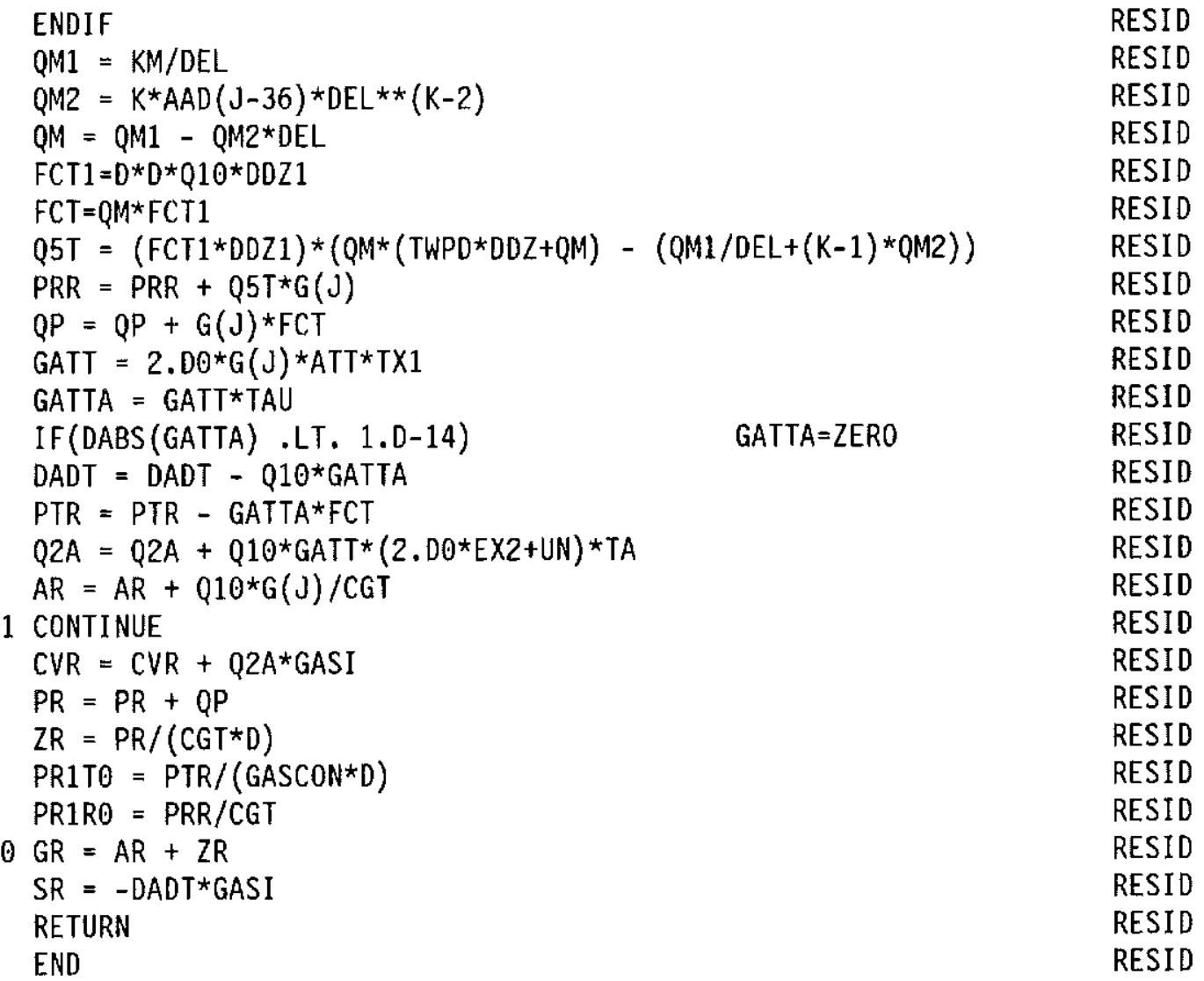

\section{F.5 INR105.AQUA.FORT(SIGMA)}

FUNCTION SIGMA(T) SIGMA

C CALCULATES THE SURFACE TENSION OF THE WATER IN N/M 94/12/07 SIGMA IMPLICIT REAL*8(A-H, O-Z)

SIGMA

PARAMETER $(T C=647.126 \mathrm{DO}, \mathrm{BG}=0.2358 \mathrm{DO}, \mathrm{BK}=-0.625 \mathrm{D0}, \mathrm{AMU}=1.256 \mathrm{D0}) \quad$ SI GMA

$Y=(T C-T) / T C$

SI GMA

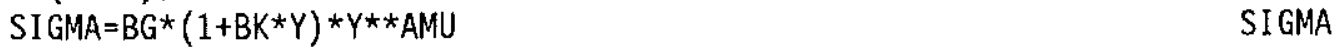

RETURN SIGMA

END SIGMA

\section{F.6 INR105.AQUA.FORT(TRANSP)}

\begin{tabular}{|c|c|c|}
\hline & SUBROUTINE TRANSP(T,RH,P1RO,P1TO,ETA,XLMB) & TRANSP \\
\hline $\mathrm{C}$ & TRANSP CALCULATES THE TRANSPORT PROPERTIES & TRANSP \\
\hline $\mathrm{c}$ & VISCOSITY ( ETA ) AND THERMAL CONDUCTIVITY ( XLMB ) & TRAN \\
\hline 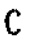 & AS FUNCTIONS OF THE TEMPERATURE ( $\mathrm{T}$ ) AND THE DENSITY ( RH ). & IRAN \\
\hline & ALL THE PROPERTIES ARE IN IN S.I. UNITS . & RAN \\
\hline C & 'TRANSP' NEEDS ALSO THE REDUCED PRESSURE DERIVATIVES & IRAN \\
\hline C & $P 1 R O=D P /(R G A S * T * D R H O)$ AND $P 1 T 0=D P /(R G A S * R H 0 * D T)$ & RAI \\
\hline C & FOR CALCULATING THE NONREGULAR PART OF THE & RAN \\
\hline & THERMAL CONDUCTIVITY ( DELLAM ) & \\
\hline & IMPLICIT REAL*8 $(A-H, 0-Z)$ & \\
\hline & DIMENSION EO (4), XO(4), BE $(6,5), B X(5,6)$ & \\
\hline & PARAMETER $(T C=647.126 \mathrm{D} 0, \mathrm{RGAS}=4.615220+$ & \\
\hline
\end{tabular}


DATA RZ0,TZ0,PZ0/317.763D+0,647.1260+0,22.1150+6/

TRANSP

$=, C C, 0 M E G A, A C, B C / 3.7711 D-8,0.4678 D+0,18.66 D+0,1.0 D+0 /$

TRANSP

DATA EO/1.81583D-2,1.77624D-2,1.05287D-2, $-0.36744 \mathrm{D}-2 /$

TRANSP

DATA X0/2.02223D+0,1.411166D+1,5.25597D+0,-2.01870D+0/

TRANSP

DATA BE/5.01938D-1,1.62888D-1,-1.30356D-1,9.079190-1,-5.51119D-1

TRANSP

$=, 1.46543 \mathrm{D}-1,2.35622 \mathrm{D}-1,7.89393 \mathrm{D}-1,6.73665 \mathrm{D}-1,1.207552 \mathrm{D}-0$

TRANSP

$=, 6.70665 \mathrm{D}-2,-8.43370 \mathrm{D}-2,-2.74637 \mathrm{D}-1,-7.43539 \mathrm{D}-1,-9.59456 \mathrm{D}-1$

TRANSP

$=,-6.87343 \mathrm{D}-1,-4.97089 \mathrm{D}-1,1.95286 \mathrm{D}-1,1.45831 \mathrm{D}-1,2.63129 \mathrm{D}-1$

TRANSP

$=, 3.472470-1,2.134860-1,1.007540-1,-3.29320 D-2,-2.70448 D-2$

TRANSP

$=,-2.53093 \mathrm{D}-2,-2.67758 \mathrm{D}-2,-8.22904 \mathrm{D}-2,6.02253 \mathrm{D}-2,-2.02595 \mathrm{D}-2 /$

TRANSP

DATA BX/1.32930460D-0,1.70183630-0,5.2246158D-0,8.7127675D-0

$=,-1.8525990-0,-4.04524370-1,-2.21568450-0,-1.01241110+1$

TRANSP

$=,-9.5000611 \mathrm{D}-0,9.340469 \mathrm{D}-1,2.440949 \mathrm{D}-1,1.65110570-0,4.9874687 \mathrm{D}-0$

TRANSP

$=, 4.3786606 \mathrm{D}-0,0 . \mathrm{D}-0,1.8660751 \mathrm{D}-2,-7.6736002 \mathrm{D}-1,-2.72976940-1$

TRANSP

$=,-9.1783782 \mathrm{D}-1,0 . \mathrm{D}-0,-1.2961068 \mathrm{D}-1,3.7283344 \mathrm{D}-1,-4.3083393 \mathrm{D}-1$

TRANSP

$=, 0.0-0,0 . D-0,4.4809953 D-2,-1.120316 \mathrm{D}-1,1.3333849 \mathrm{D}-1,0 . \mathrm{D}-0,0 . \mathrm{D}-0 /$

TRANSP

C

THE IDEAL TEMPERATURE

TRANSP

$T I D=P Z O /(R Z 0 * R G A S)$

$T R=T / T I D$

C REDUCED VARIABLES

$T T=T / T Z 0$

$T 1=1 . D 0 / T T$

$\mathrm{T} 2=\mathrm{SQRT}(\mathrm{TT})$

$T 3=T 1-1 . D-\theta$

$T 4=T T-1 . D-0$

TRANSP

TRANSP

TRANSP

TRANSP

TRANSP

TRANSP

TRANSP

TRANSP

TRANSP

$R R=R H / R Z O$

TRANSP

$R 2=S Q R T(R R)$

TRANSP

$R 3=R R-1 . D-0$

C VISCOSITY

$E N=E O(1)+T 1 *(E O(2)+T 1 *(E O(3)+T 1 * E O(4)))$

TRANSP

TRANSP

TRANSP

TRANSP

$E S U=0 . D 0$

TRANSP

DO $110 \mathrm{~J}=6,1,-1$

TRANSP

$B E J=B E(J, 1)+R 3^{\star}(B E(J, 2)+R 3 *(B E(J, 3)+R 3 *(B E(J, 4)+R 3 * B E(J, 5))))$

110 ESU $=\mathrm{T} 3 * \mathrm{ESU}+\mathrm{BEJ}$

$E T A=E T A 0 \star E X P(R R \star E S U)$

C THERMAL CONDUCTIVITY

$X N=X O(1)+T 1 *(X 0(2)+T 1 *(X 0(3)+T 1 * X \theta(4)))$

$X L A O=T 2 / X N$

$E X U=0.00$

D0 $210 \mathrm{I}=5,1,-1$

$B X I=B X(1,1)+R 3 *(B X(I, 2)+R 3 *(B X(1,3)$

$\left.\left.=+R 3^{*}\left(B X(I, 4)+R 3^{*}\left(B X(I, 5)+R 3^{*} B X(I, 6)\right)\right)\right)\right)$

$210 E X U=T 3^{*} E X U+B X I$

$Q \times Q=R R^{\star} E X U$

$X L M B=X L A 0 * E X P(R R * E X U)$

C NONREGULAR PART OF THE THERMAL CONDUCTIVITY

TRANSP

TRANSP

TRANSP

TRANSP

TRANSP

TRANSP

TRANSP

TRANSP

TRANSP

TRANSP

TRANSP

TRANSP

TRANSP

TRANSP

TRANSP

TRANSP

230 IF (P1RO .NE. O.DO $) \quad C H I T=R R /(T R * P 1 R O)$

IF (P1RO .EQ. O.DO $\quad$ CHIT $=1 . D 40$

$F I 0=A B S$ (CHIT)

IF (FI0 .EQ. O.DO $) \quad F I 0=1 . D-6$

TRANSP

TRANSP

TRANSP

TRANSP

CHITE $=$ FIO $* *$ OMEGA

TRANSP

C DAMPNG FUNCTION OF SENGERS, J. V., 10TH INT. CONF. ON STEAM

TRANSP 


\section{F.7 INR105.AQUA.FORT(SSP)}

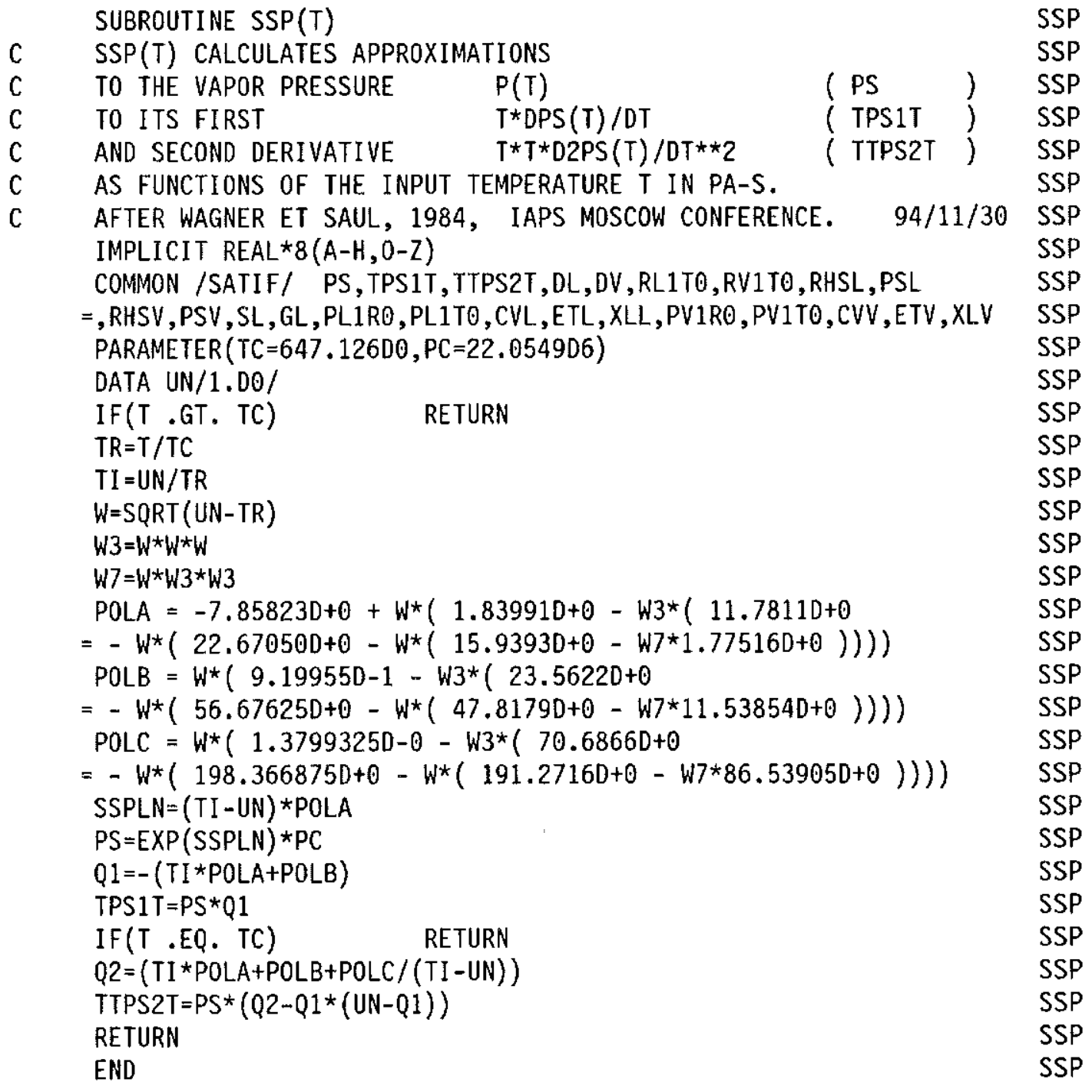




\section{F.8 INR105.AQUA.FORT(TS1)}

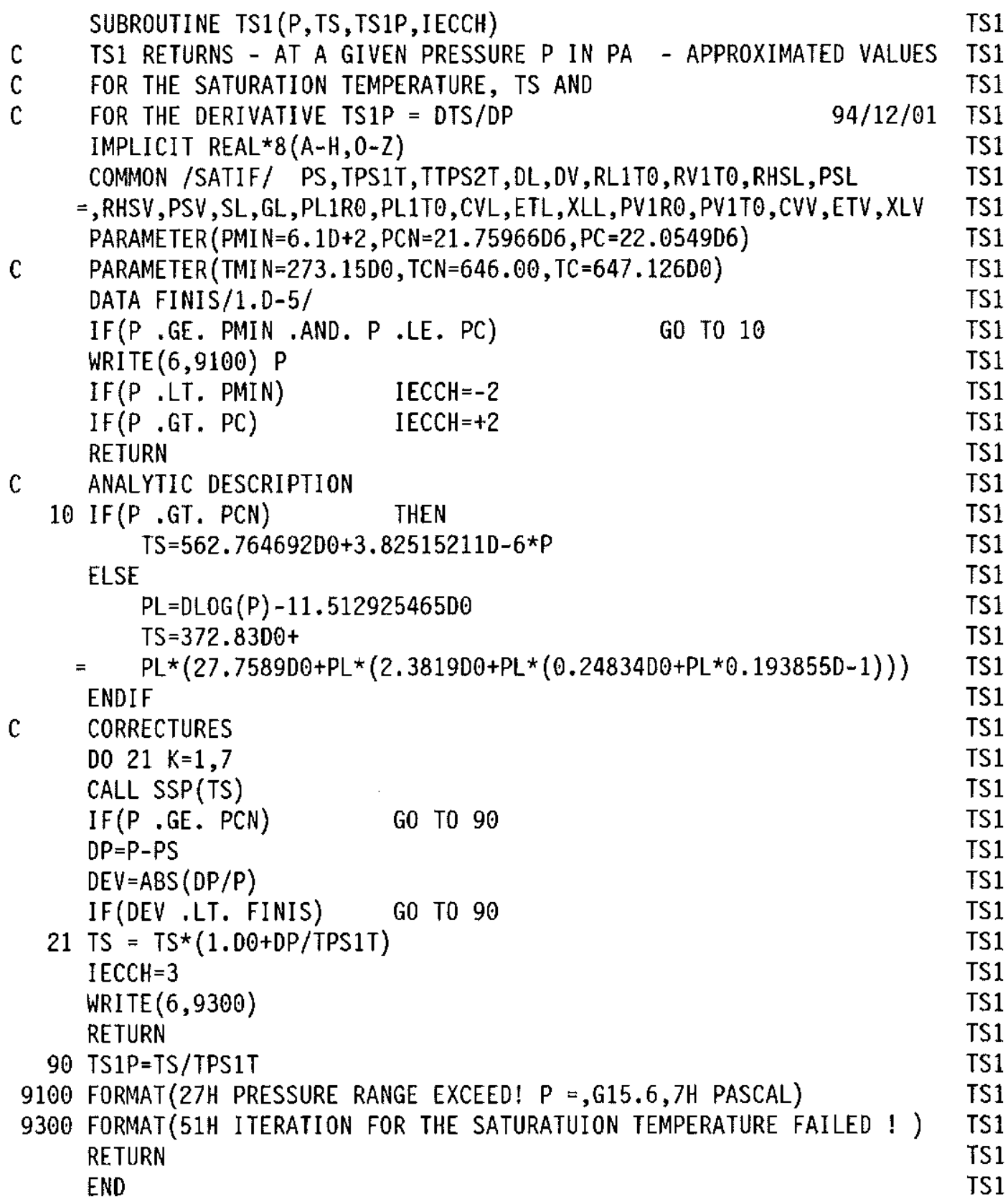

\section{F.9 INR105.AQUA.FORT(SSRHO)}

SUBROUTINE SSRHO(T) SSRHO

SSRHO RETURNS APPROXIMATED VALUES OF THE DENSITIES OF SSRHO

THE SATURATED LIQUID ( DL ) AND THE SATURATED VAPOR ( DV ) SSRHO

- IN G/CM**3! - AS FUNCTIONS OF THE TEMPERATURE ( $T$ ). SSRHO

SSRHO CALCULATES ALSO THE REDUCED DENSITY DERIVATIVES SSRHO

RL1TO $=T /$ RHL $*$ DRHL. $/$ DT AND RV1TO $=T /$ RHV * DRHV $/ D T .94 / 12 / 01 \quad$ SSRHO

IMPLICIT REAL*8(A-H,O-Z)

DIMENSION PUL(12), DPUL(12), PUV (12), DPUV (12)

SSRHO

SSRHO 
COMMON /SATIF/ PS, TPS1T,TTPS2T,DL,DV, RL1TO, RV1TO, RHSL,PSL

$\approx$, RHSV , PSV ,SL, GL, PL1RO, PL1T0, CVL, ETL, XLL, PV1RO,PV1TO, CVV, ETV, XLV

SSRHO

PARAMETER $(T C=647.12600, D C=0.322 D 0, R G A S=4.61522 D+2)$

SSRHO

PARAMETER $(B R=2.0300, B E T=0.32500)$

DATA PUL/ $6.072746418 D+0,-149.94560890+0,2.121007381 D+3$

SSRHO

$=,-17.164833010+3,90.17684684 D+3,-323.0456094 D+3,805.4435472 D+3$

SSRHO

$=,-1.398515305 \mathrm{D}+6,1.658696365 \mathrm{D}+6,-1.281195416 \mathrm{D}+6,580.7414278 \mathrm{D}+3$

SSRHO

$=,-117.1819097 \mathrm{D}+3 /$

DATA DPUL/ $0.0 \mathrm{D}+0,-74.97280445 \mathrm{D}+0,2.121007381 \mathrm{D}+3$

SSRHO

$=,-25.747249515 \mathrm{D}+3,180.35369368 \mathrm{D}+3,-807.6140235 \mathrm{D}+3$

SSRHO

SSRHO

$=, 2.41633064160+6,-4.8948035675 D+6,6.634785460+6$

SSRHO

$=,-5.765379372 \mathrm{D}+6,2.9037071390+6,-644.50050335 \mathrm{D}+3 /$

SSRHO

SSRHO

DATA PUV $/-1.125999398 \mathrm{D}+0,42.15284538 \mathrm{D}+0,-538.0831003 \mathrm{D}+0$

SSRHO

$=, 4.150173161 \mathrm{D}+3,-20.80947751 \mathrm{D}+3,71.29507069 \mathrm{D}+3,-170.4446088 \mathrm{D}+3 \quad$ SSRHO

$=, 284.4989747 D+3,-325.1357165 D+3,242.4593090 D+3,-106.2552030 D+3 \quad$ SSRHO

$=, 20.74762670 D+3 /$

SSRHO

DATA DPUV $/ 0.0 \mathrm{D}+0,21.07642269 \mathrm{D}+0,-538.0831003 \mathrm{D}+0,6.225259741 \mathrm{D}+3 \quad$ SSRHO

$=,-41.61895501 \mathrm{D}+3,178.2376767 \mathrm{D}+3,-511.3338264 \mathrm{D}+3,995.7464115 \mathrm{D}+3 \quad$ SSRHO

$=,-1.300542866 \mathrm{D}+6,1.091066891 \mathrm{D}+6,-531.2760148 \mathrm{D}+3,114.1119469 \mathrm{D}+3 /$ SSRHO

IF (T . GE. TC) THEN

$D L=D C$

SSRHO

$D V=D C$

SSRHO

SSRHO

RETURN

SSRHO

ENDIF

$Y=(T C-T) / T C$

$\mathrm{CHI}=\mathrm{T} /(\mathrm{T}-\mathrm{TC})$

IF(T .LE. 620.00)

THEN

SSRHO

SSRHO

SSRHO

SSRHO

SSRHO

SSRHO

$W=S Q R T(Y)$

OML = PUL(12)

SSRHO

TDOML = DPUL(12)

SSRHO

$Z V=\operatorname{PUV}(12)$

TDZV $=$ DPUV (12)

SSRHO

SSRHO

DO $31 K=11,1,-1$

SSRHO

TDOML $=$ TDOML $* W+D P U L(K)$

SSRHO

TDZV $=T D Z V * W+D P U V(K) \quad$ SSRHO

$O M L=O M L W^{*}+\mathrm{PUL}(K)$

SSRHO

31. $\quad Z V=Z V * W+P U V(K)$

SSRHO

DLOML $=\mathrm{TDOML} / \mathrm{OML}$.

SSRHO

$O V=P S * 1 . D-3 /(R G A S * T * Z V)$

SSRHO

$D L Z V=C H I * T D Z V / Z V$

SSRHO

RV1TO $=$ TPS1T/PS -1. DO -DLZV $\quad$ SSRH0

ELSE

C NEAR CRITICAL TEMPERATURES

SSRHO

SSRHO

$B E G=B R * Y \star * B E T$

SSRHO

$E B=B E G * B E T$

SSRHO

$A L=Y *(3.0756688530-0-Y *(19.58060683 D-0-Y * Y * 1.3830866890+3))$ SSRH0

$O M L=1.00+B E G+A L$

SSRHO

$D A L=A L-Y * Y *(19.580606830-0-Y * Y * 4.149260067 D+3) \quad$ SSRH0

$D L O M L=(E B+D A L) / O M L \quad$ SSRHO

$A V=Y *(1.451962241 D-0-Y *(5.041325559 D-0-Y * Y * 611.1810749 D-0))$ SSRHO

$O M V=1 . D O-B E G+A V$

SSRHO

$D A V=A V-Y * Y *(5.0413255590-0-Y * Y * 1.833543225 D+3) \quad$ SSRHO

$D V=O M V * D C$

SSRHO

RV1TO $=C H I *(-E B+O A V) / O M V$

SSRHO 
ENDIF

SSRHO

$D L=O M L * D C$

SSRHO

RL1TO = DLOML*CHI

SSRHO

RETURN

SSRHO

END

SSRHO

\section{F.10 INR105.AQUA.FORT(SPIRHO)}

SUBROUTINE SPIRHO(T)

SPIRHO

C SPIRHO RETURNS - FOR A GIVEN TEMPEREATURE T - APPROXIMATED VALUES OF THE DENSITY OF THE LIQUID SPINODAL ( RHSL ) AND

SPIRHO

C OF THE VAPOR SPINODAL (RHSV) IN KG/M**3.

IMPLICIT REAL*8(A-H,O-Z)

94/12/01 SPIRHO

DIMENSION PUL $(9)$, PUV (9)

COMMON /SATIF/ PS, TPS1T, TTPS2T, DL, DV, RL1TO, RV1TO, RHSL, PSL

SPIRHO

SPIRHO

SPIRHO

$=$, RHSV ,PSV, SL, GL , PL1RO, PL1T0,CVL, ETL, XLL, PV1RO, PV1TO, CVV , ETV, XLV

PARAMETER $(T C=647.12600, R H C=322 . D 0, R G A S=4.61522 D+2)$

SPIRHO

PARAMETER $(B S P=1.4000, \mathrm{BET}=0.32500)$

SPIRHO

DATA PUL/1.911888766D+0, $-16.541578990+0,179.7358194 \mathrm{D}+0$

SPIRHO

$=,-940.1374463 D+0,2.957964417 D+3,-5.7524290560+3,6.772987553 D+3$

SPIRHO

$=,-4.4280017590+3,1.234441322 D+3 /$

DATA PUV $/ 0.92015086830-0,-2.1597019440-0,-0.2932760492 D-0$

SPIRHO

SPIRHO

SPIRHO

$=, 6.324940268 \mathrm{D}-0,-10.49597891 \mathrm{D}-0,8.782612450-0,-3.119252324 \mathrm{D}-0 \quad$ SPIRHO

$=, 0.00,0.00 /$

IF $(T . G E, T C)$

SPIRHO

RHSL $=$ RHC

SPIRHO

RHSV $=$ RHC

SPIRHO

RETURN

SPIRHO

ENDIF

SPIRHO

SPIRHO

SPIRHO

$Y=(T C-T) / T C$

THEN

SPIRHO

LOW TEMPERATURES

SPIRHO

$W=\operatorname{SQRT}(Y)$

$O M L=P U L(9)$

OMV $=$ PUV $(9)$

SPIRHO

SPIRHO

SPIRHO

D0 $31 \mathrm{I}=8,1,-1$

SPIRHO

$O M L=O M L * W+P U L(I)$

SPIRHO

$O M V=O M V * W+P U V(I)$

SPIRHO

ELSE

C NEAR CRITICAL TEMPERATURES

SPIRHO

SPIRHO

$A L=Y *(487.17179410-3+Y *(24.26899415 D-\theta-Y * \gamma * 2.461494028 D+3))$ SPIRHO

$O M L=1.00+B S P * \gamma * * B E T+A L$

SPIRHO

$A V=Y^{*}(1.1328197310-0-Y *(30.70131059 D-0-Y * \gamma * 3.3249449360+3))$ SPIRH0

$O M V=1.00-B S P \star Y \star \star B E T+A V$

SPIRHO

ENDIF

SPIRHO

SPIRHO

RHSL $=O M L * R H C$

SPIRHO

RHSV $=0 M V * R H C$

SPIRHO

RETURN

SPIRHO 


\section{F.11 INR105.AQUA.FORT(SPIP)}

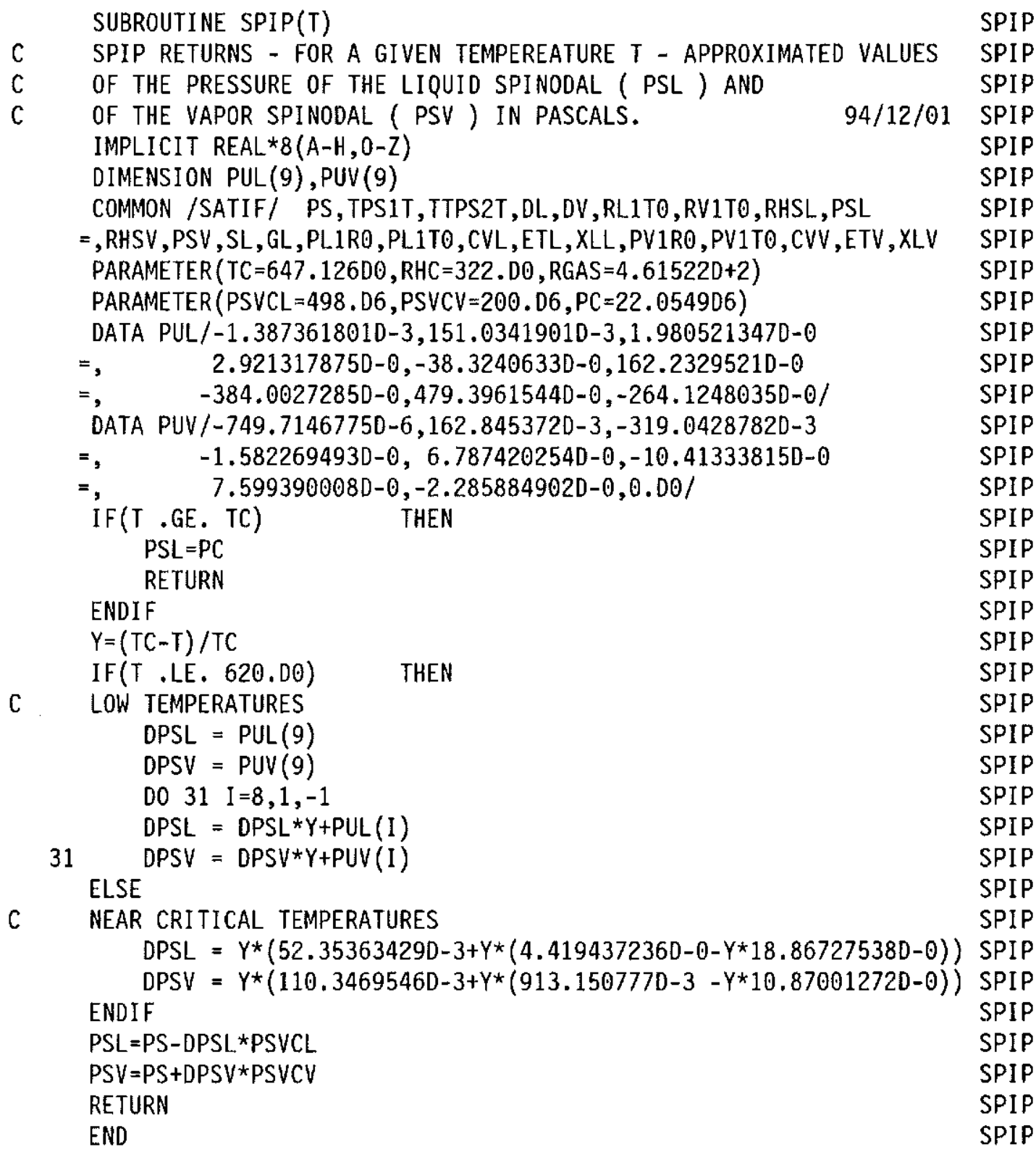

\section{F.12 INR105.AQUA.FORT(SSPER)}

SUBROUTINE SSPER(T) SSPER

C SSPER RETURNS - FOR A GIVEN TEMPERATURE T -

C APPROXIMATED DENSITY DERIVATIVES OF THE PRESSURE

C IN THE SATURATED STATES - IN REDUCED FORM . 94/12/01 SSPER

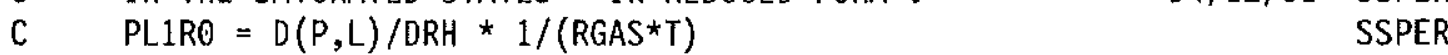

C PV1RO $=D(P, V) / D R H * 1 /($ RGAS $* T) \quad$ SSPER

IMPLICIT REAL*8(A-H, O-Z) SSPER

DIMENSION PUL (12), PUV(12) SSPER

COMMON /SATIF/ PS, TPS1T, TTPS2T,DL, DV, RL1TO,RV1TO, RHSL, PSL SSPER

$=$, RHSV, PSV ,SL, GL, PL1RO, PL1TO, CVL, ETL, XLL, PV1RO,PV1TO, CVV, ETV, XLV SSPER 
PARAMETER $(T C=647.126 D 0, D C=322 . D-3, P R O C=15 . D 0, G A M=1.24 D 0) \quad$ SSPER

DATA PUL/91.68326854D-3,141.0358804D-3,293.745773D- $\theta$ SSPER

$=,-3.694718543 \mathrm{D}+3,35.3159487 \mathrm{D}+3,-224.5051913 \mathrm{D}+3,968.1021275 \mathrm{D}+3$ SSPER

$=,-2.8373210190+6,5.560661663 \mathrm{D}+6,-6.973719089 \mathrm{D}+6,5.058540246 \mathrm{D}+6$ SSPER

$=,-1.6152449630+6 /$

DATA PUV $/ 1.4354291190-3,3.738553917 D-0,3.552096947 D-\theta \quad$ SSPER

$=,-55.885077590-0,217.57437930-0,-535.2445068 D-0,812.42242430-0 \quad$ SSPER

$=,-670.92858890-0,229.08274840-0,0.00,0.00,0.00 / \quad$ SSPER

IF (T .GE. TC) THEN SSPER

SSPRHL $=0$. DO $\quad$ SSPER

RETURN SSPER

ENDIF SSPER

$Y=(T C-T) / T C \quad$ SSPER

IF(T . LE. 620.D0) THEN SSPER

C LOW TEMPERATURES SSPER

PLIRO = PUL(12) SSPER

PV1RO = PUV(12) SSPER

D0 $31 \mathrm{I}=11,1,-1 \quad$ SSPER

PL1RO $=$ PL1RO $* Y+P U L(I) \quad$ SSPER

$31 \quad P V 1 R 0=P V 1 R 0 * Y+P U V(I) \quad$ SSPER

ELSE $\quad$ SSPER

C NEAR CRITICAL. TEMPERATURES SSPER

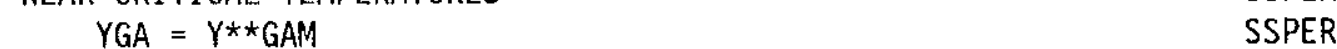

$F I L=P R O C \quad$ SSPER

$=-Y^{\star}\left(79.73057836 D-0+Y^{*}(430.14768850-0-Y * 14139.7632 D+0)\right) \quad$ SSPER

FIV $=$ PROC $\quad$ SSPER

$=\quad+Y^{*}\left(369.67509710-0-Y^{*}(5110.089071 D-0-Y * 46121.0908 D-0)\right) \quad$ SSPER

PLIRO $=(D L / D C) * F I L * Y G A \quad$ SSPER

PV1RO $=(D V / D C)^{\star F I V * Y G A}$ SSPER

RETURN $\quad$ SSPER

END SSPER

\section{F.13 INR105.AQUA.FORT(SSPET)}

SUBROUTINE SSPET(T,PL1TO,PV1TO) SSPET

$\begin{array}{lll}c & \text { SSPET RETURNS - FOR A GIVEN TEMPERATURE T - } & \text { SSPET } \\ c & \text { APPROXIMATED TEMPERATURE DERIVATIVES OF THE PRESSURE } & \text { SSPET }\end{array}$

C IN THE SATURATED STATES - IN REDUCED FORM . 94/12/01 SSPET

C PL1TO $=D(P, L) / D T * 1 /(R G A S * R H, L) \quad$ SSPET

C PVITO $=D(P, V) / D T * 1 /\left(R_{G A S * R H, V)}\right.$ SSPET

IMPLICIT REAL*8(A-H,O-Z) SSPET

DIMENSION PUL(12), PUV(12) SSPET

PARAMETER $(T C=647.12600$, PTOC $=1.80215732 \mathrm{D}-0) \quad$ SSPET

DATA PUL $/ 1.8188845440-0,16.407377360-0,-65.854557590-0 \quad$ SSPET

$=, 52.043719140-0,4.031238729 \mathrm{D}+3,-47.2570313 \mathrm{D}+3,277.4234268 \mathrm{D}+3 \quad$ SSPET

$=,-988.3324003 D+3,2.218919758 D+6,-3.077677674 D+6,2.414555699 D+6 \quad$ SSPET

$=,-821.0002244 D+3 /$

DATA PUV $/ 2.0297007290-0,-125.5470649 D-3,-61.54407176 \mathrm{D}-0$

SSPET

$=, 544.8751175 \mathrm{D}-0,-2.848188899 \mathrm{D}+3,9.708977783 \mathrm{D}+3,-21.26251929 \mathrm{D}+3$ SSPET

$=28.710965330+3,-21.755272460+3,7.0822246090+3,0.00,0.00 /$ SSPET

IF (T . GE. TC ) THEN SSPET

$\begin{array}{ll}\text { PL1TO }=\text { PTOC } & \text { SSPET }\end{array}$ 


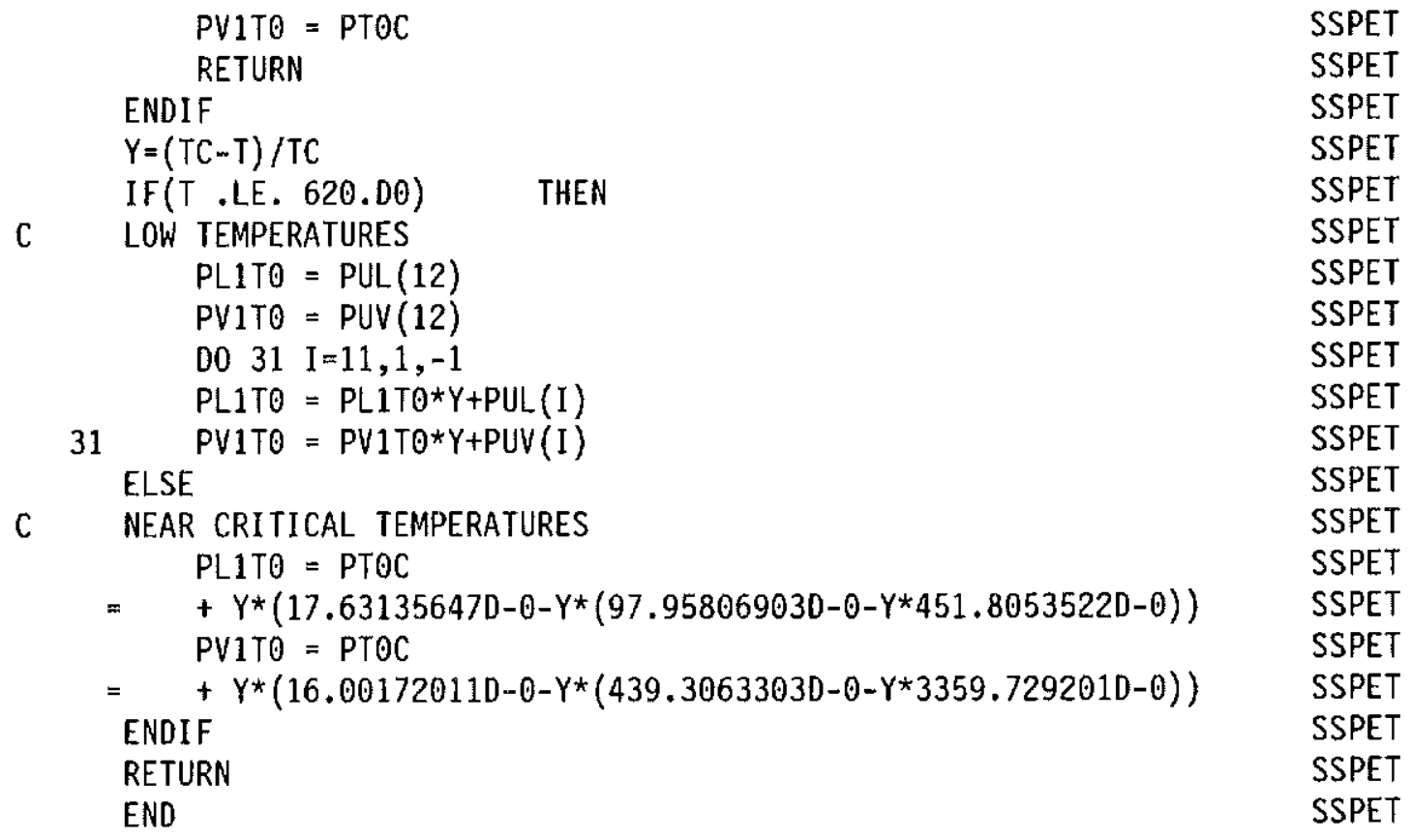

\section{F.14 INR105.AQUA.FORT(SSCEV)}

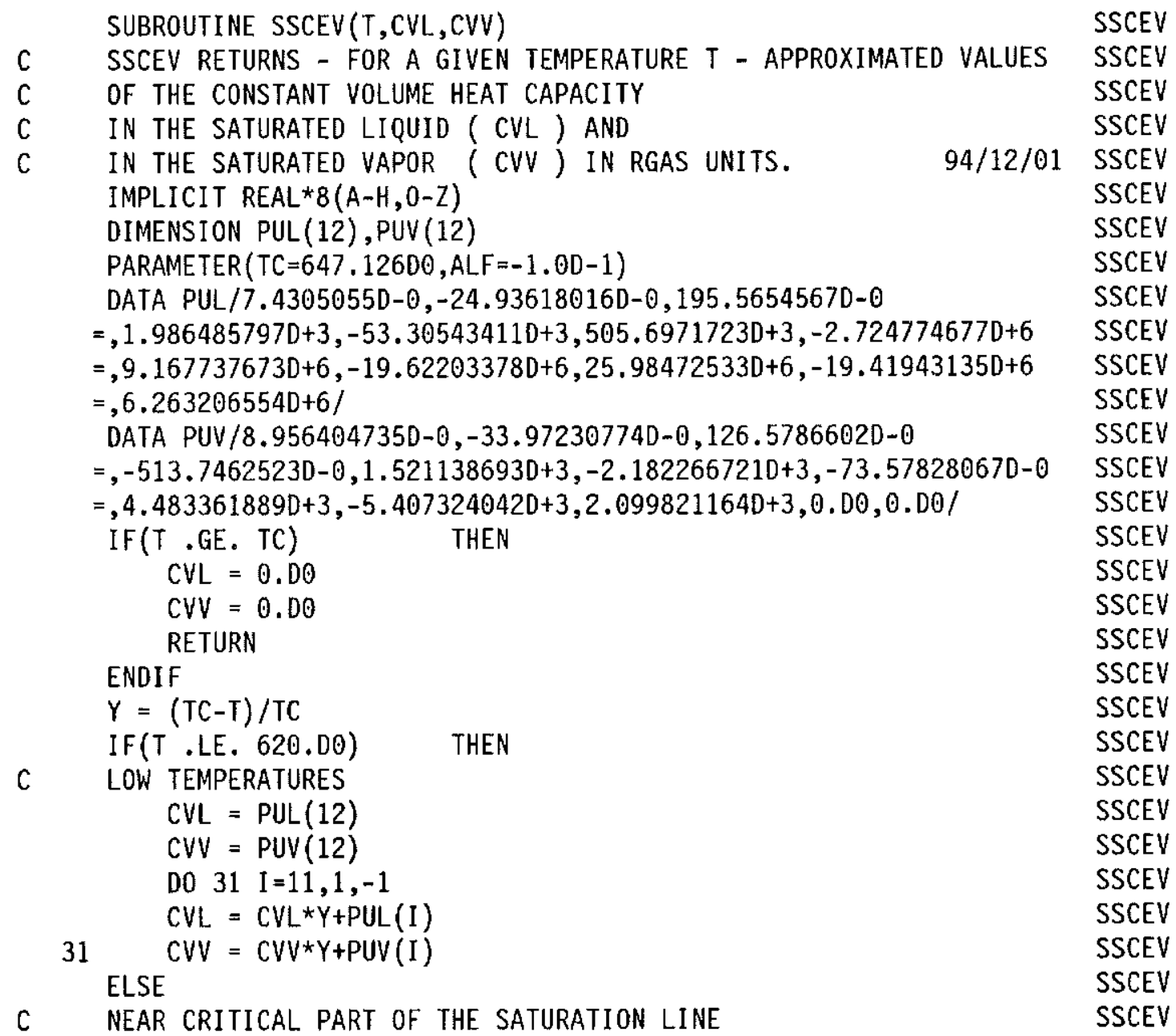




\begin{tabular}{|c|c|c|}
\hline & & SSCEY \\
\hline PSIL & $=4.50-0+$ & SSCEV \\
\hline 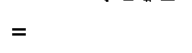 & $Y^{\star}(15.21452007 D-0-Y \star(167.2951053 D-0-Y \star 1.042333618 D+3))$ & SSCEV \\
\hline PSIV & $=5.10-0+$ & SSCEV \\
\hline (20 & $Y^{*}\left(42.35451412 D-0-Y *\left(1.002675527 D+3-Y^{*} 6.9112031830+3\right)\right)$ & SSCEV \\
\hline$C V L=$ & $=P S I L * B E G$ & SSCEV \\
\hline CVV $=$ & $=P S I V * B E G$ & SSCEV \\
\hline ENDIF & & SSCEV \\
\hline RETURN & & SSCEV \\
\hline END & & SSCEV \\
\hline
\end{tabular}

\section{F.15 INR105.AQUA.FORT(SSG/S)}

SUBROUTINE SSGIS(T,SL,GL) SSGIS

C SSGIS RETURNS APPROXIMATED VALUES FOR THE ENTROPY AND FOR SSGIS

C THE GIBBS-FUNCTIOM OF THE SATURATED LIQUID SSGIS

C AS FUNCTIONS OF THE INPUT TEMPERATURE T. SSGIS

c $\mathrm{SL}=$ S.LIQUID/RGAS, GL = G.LIQUID/(RGAS*T)

IMPLICIT REAL*8 (A-H, O-Z)

SSGIS

DIMENSION PSL.(9), PGL(9) SSGIS

PARAMETER $(T C=647.126 \mathrm{DO}, \mathrm{SC}=9.430 \mathrm{D} 0, \mathrm{BR}=0.25 \mathrm{D} 0, \mathrm{BET}=0.325 \mathrm{D0}) \quad$ SSGIS

DATA PSL/952.8621116D-3,272.5494325D-3,-8.457375782D-0 SSGIS

$=, 44.57631748 D-\theta,-150.74415590-0,311.7914429 D-\theta,-391.8528748 D-\theta \quad$ SSGIS

$=, 273.5529633 \mathrm{D}-0,-82.2848053 \mathrm{D}-0 / \mathrm{O}$ SSGIS

DATA PGL/ $-2.569516966 \mathrm{D}-0,5.187876405 \mathrm{D}-0,640.8677408 \mathrm{D}-3 \quad$ SSGIS

$=, 1.374106295 \mathrm{D}-0,-18.01831251 \mathrm{D}-0,68.53337198 \mathrm{D}-0,-176.20248790-0 \quad$ SSGIS

$=, 226.296896 \mathrm{D}-0,-130.4997179 \mathrm{D}-0 / \mathrm{O}$ SSGIS

IF (T , GE. TC) THEN SSGIS

$S L=0.00 \quad$ SSGIS

$\mathrm{GL}=0.00 \quad$ SSGIS

RETURN SSGIS

ENDIF SSGIS

$Y=(T C-T) / T C \quad$ SSGIS

C ENTROPY $S S G I S$

IF (T .LE. 620.DO) THEN SSGIS

C LOW TEMPERATURES SSGIS

$W=\operatorname{SQRT}(Y) \quad$ SSGIS

OMV $=$ PSL $(9) \quad$ SSGIS

DO $31 \mathrm{~K}=8,1,-1 \quad$ SSGIS

$31 \quad O M V=O M V * W+P S L(K) \quad$ SSGIS

ELSE $\quad$ SSGIS

C NEAR CRITICAL TEMPERATURES SSGIS

$B E G=B R * Y * * B E T \quad$ SSGIS

$A V=-Y *(1.23383958 D-0+Y *(1.656615363 D-0-Y * Y * 911.5375812 D-0))$ SSGIS

$O M V=1.00-B E G+A V \quad$ SSGIS

ENDIF SSGIS

$S L=O M V * S C \quad$ SSGIS

C GIBBS-FUNCTION SSGIS

$\mathrm{GL}=\mathrm{PGL}(9) \quad$ SSGIS

D0 $71 K=8,1,-1 \quad$ SSGIS

$71 \mathrm{GL}=\mathrm{GL} * Y+P G L(K) \quad$ SSGIS

RETURN $\quad$ SSGIS

END SSGIS 


\section{F.16 INR105.AQUA.FORT(SSETA)}

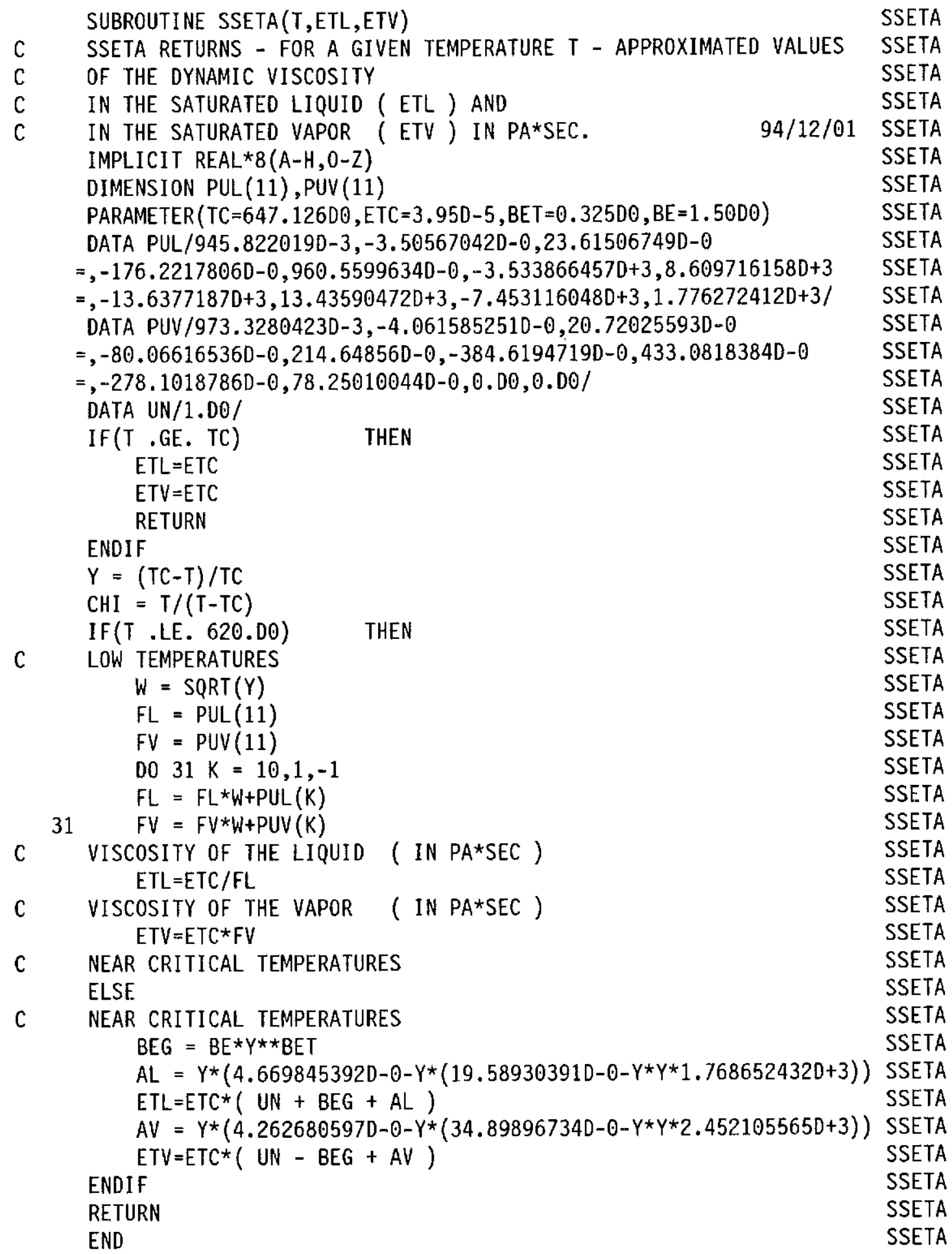




\section{F.17 INR105.AQUA.FORT(SSLAM)}

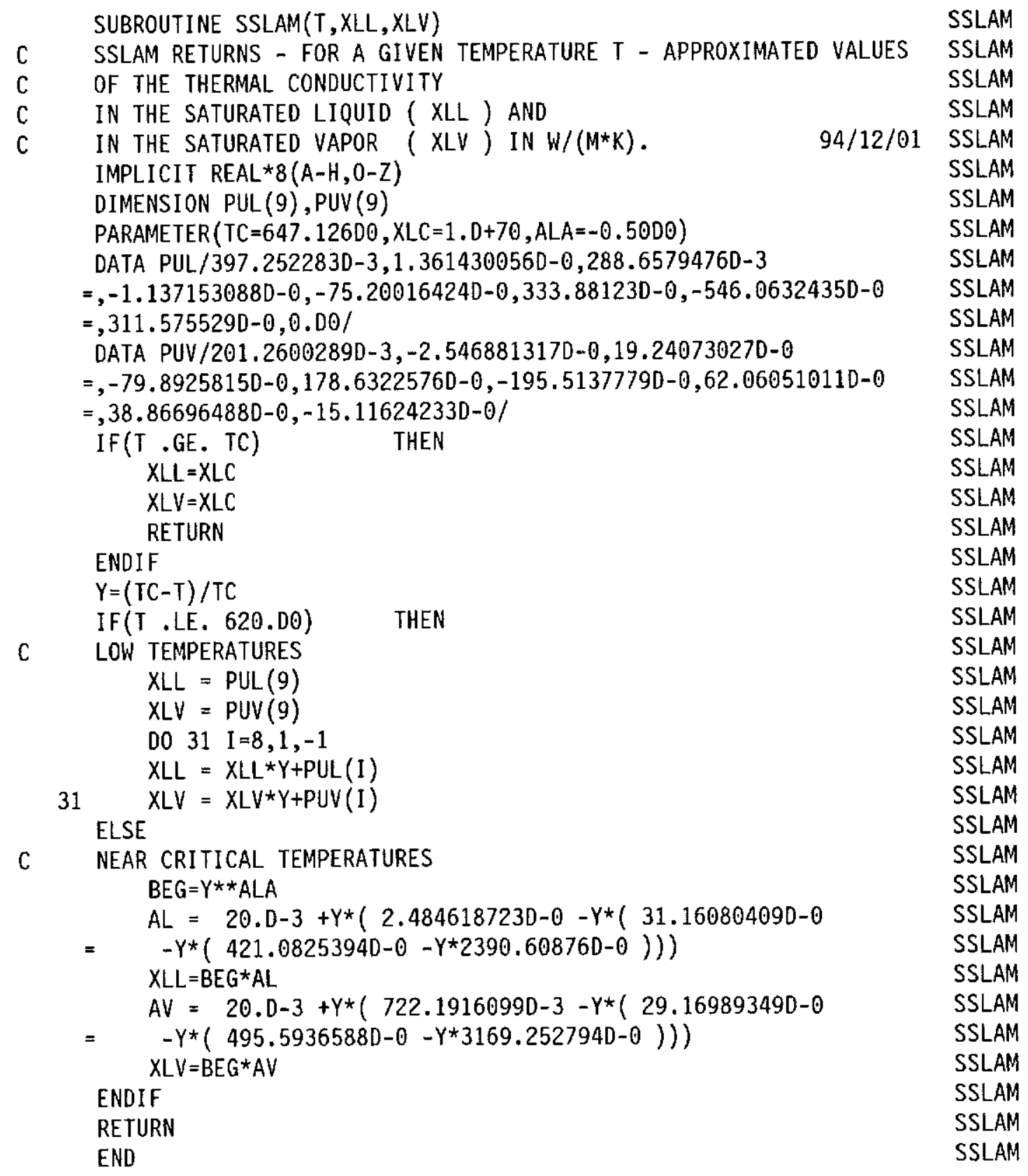

\section{F.18 INR105.AQUA.FORT(DILE)}

FUNCTION DILE(Y) DILE

C RETURNS AN ADDITIVE TERM FOR PSL(T) TO DESCRIBE THE PRESSURE DILE

C OF THE LIQUID SPINODAL ON A HGK-ISOTHERM.

C DILE IS A FUNCTION OF THE SCALED TEMPERATURE $Y=1-T / T C$ DILE

DILE $=\left(40.49363544 D+0-Y^{*}\left(20.73773694 D+3-Y^{*}(7.607260219 D+6 \quad\right.\right.$ DILE

$=-Y^{*}\left(1.796520658 D+9-Y^{*}(258.928784714 D+9-Y *(22.71838331 D+12 \quad\right.$ DILE

$=-Y *\left(1.182066587 D+15-Y^{*}(33.45912597 D+15-Y * 396.4473916 D+15 \quad\right.$ DILE

$=())()))) * Y \quad$ DILE 


\section{F.19 INR105.AQUA.FORT(DIVE)}

FUNCTION DIVE(Y) DIVE

C RETURNS AN ADDITIVE TERM FOR PSV(T) TO DESCRIBE THE PRESSURE DIVE

C OF THE VAPOR SPINODAL ON A HGK-ISOTHERM.

$C$ DIVE IS A FUNCTION OF THE SCALED TEMPERATURE $Y=1-T / T C$ DIVE DIVE $=Y^{*}(17.178303960+0-Y *(3.4349692550+3 \quad$ DIVE

$=-Y *(448.795607300 \mathrm{D}+3-Y *(3.808457011 \mathrm{D}+7-Y *(1.646319316 \mathrm{D}+9 \quad$ DIVE

$=-Y * 2.7190713740+10)))))$ DIVE RETURN DIVE

END DIVE

\section{F.20 INR105.AQUA.FORT(PLMAX)}

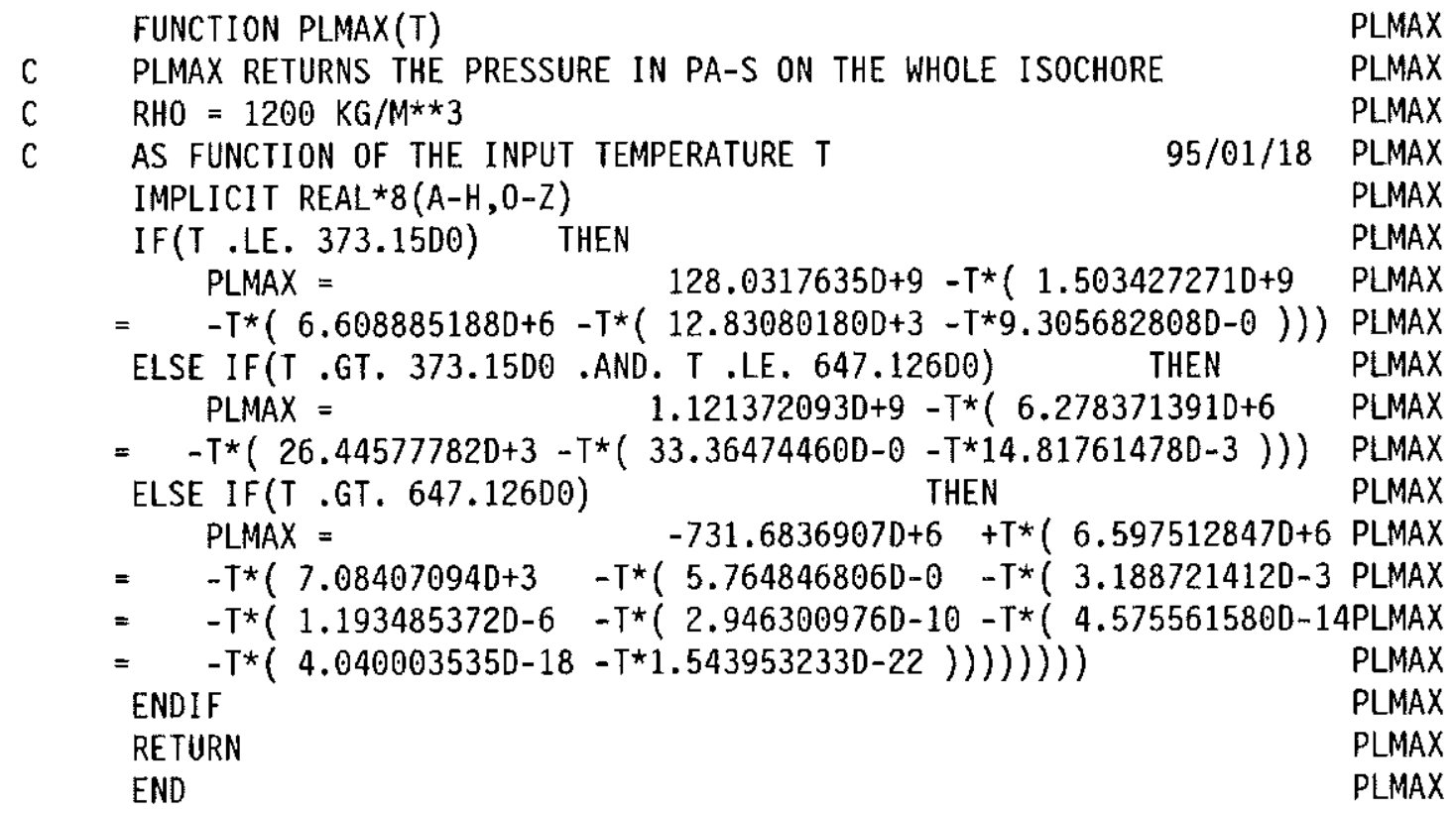

\section{F.21 INR105.AQUA.FORT(P1200)}

FUNCTION P800(T) $\quad P 800$

C P800 RETURNS THE PRESSURE IN PA-S ON THE SUPERCRITICAL PART P800

C OF THE ISOCHORE RHO $=800 \mathrm{KG} / \mathrm{M} * * 3 \quad P 800$

C AS FUNCTION OF THE INPUT TEMPERATURE T $\quad 95 / 01 / 18$ P800

$\mathrm{P} 800=\quad-576.9907617 \mathrm{D}+6+\mathrm{T}^{*}(229.0441320 \mathrm{D}+3 \quad \mathrm{P} 800$

$=+T^{*}(3.275463692 D+3-T *(4.331244582 D-0-T *(3.008662103 D-3 \quad P 800$

$=-T^{*}\left(1.2721789940-6-T^{*}\left(337.938642 D-12-T^{*}(55.071027020-15 \quad\right.\right.$ P800

$=-T *(5.030253110-18-T * 197.14146630-24)))))))) \quad$ P800

RETURN $\quad P 800$

$\begin{array}{lr}\text { END } & \text { P800 }\end{array}$ 


\section{F.22 INR105.AQUA.FORT(P600)}

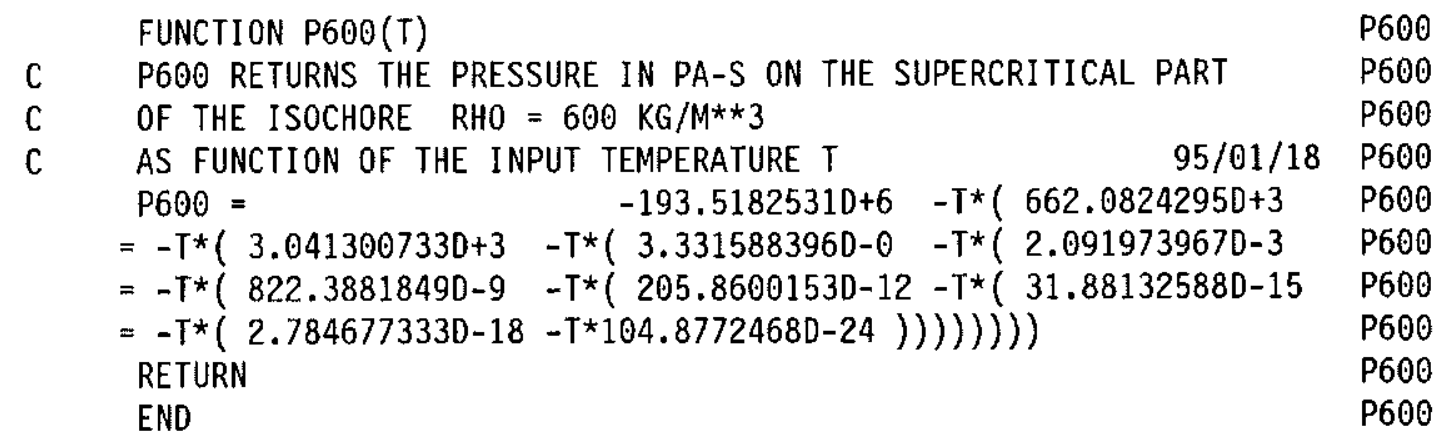

\section{F.23 INR105.AQUA.FORT(P400)}

FUNCTION P400(T) P400

C P400 RETURNS THE PRESSURE IN PA-S ON THE SUPERCRITICAL PART P400

C OF THE ISOCHORE RHO $=400 \mathrm{KG} / \mathrm{M}^{* * 3} 3400$

C AS FUNCTION OF THE INPUT TEMPERATURE T $\quad 95 / 01 / 18$ P400

$\mathrm{P} 400=\quad-48.22391500 \mathrm{D}+6 \quad-T^{*}(534.0793594 \mathrm{D}+3 \quad \mathrm{P} 400$

$=-T^{*}\left(1.893391113 \mathrm{D}+3 \quad-T^{*}(2.052518308 \mathrm{D}-0 \quad-T *(1.304520061 \mathrm{D}-3 \quad \mathrm{P} 400\right.$

$=-T^{*}\left(521.2344512 \mathrm{D}-9 \quad-T^{*}\left(132.5272444 \mathrm{D}-12-T^{*}(20.80959374 \mathrm{D}-15 \quad P 400\right.\right.$

$\left.\left.\left.\left.\left.\left.\left.=-T^{\star}\left(1.839373352 \mathrm{D}-18-T^{\star} 69.98460931 \mathrm{D}-24\right)\right)\right)\right)\right)\right)\right)\right) \quad$ P400 RETURN $\quad$ P400

$\begin{array}{ll}\text { END } & \text { P400 }\end{array}$

\section{F.24 INR105.AQUA.FORT(P322)}

FUNCTION P322(T)

C P322 RETURNS THE PRESSURE IN PA-S ON THE SUPERCRITICAL PART P322

C OF THE CRITICAL ISOCHORE

$\begin{array}{lll}\text { C AS FUNCTION OF THE INPUT TEMPERATURE T } & 95 / 01 / 18 & \text { P322 }\end{array}$

$\mathrm{P} 322=\quad-115.3411242 \mathrm{D}+6-T^{*}(14.61390831 \mathrm{D}+3 \quad \mathrm{P} 322$

$=-T *(713.84794340-0)-T *\left(843.0259976 \mathrm{D}-3 \quad-T^{*}(558.65115290-6 \quad\right.$ P322

$=-T^{*}(228.9982666 \mathrm{D}-9)-T *\left(59.25205508 \mathrm{D}-12-T^{*}(9.423230731 \mathrm{D}-15 \quad\right.$ P322

$=-T *(841.0373279 \mathrm{D}-21-T * 32.24390358 \mathrm{D}-24 \quad J))))))) \quad$ P322

RETURN $\quad$ P322

END $\quad$ P322 


\section{F.25 INR105.AQUA.FORT(P250)}

C P250 RETURNS THE PRESSURE IN PA-S ON THE SUPERCRITICAL PART P250

C OF THE ISOCHORE RHO $=250 \mathrm{KG} / \mathrm{M} * \star 3 \quad$ P250

C AS FUNCTION OF THE INPUT TEMPERATURE T $\quad 95 / 01 / 18$ P250

$P 250=-161.6042550+6+T *(370.3861090 D+3-T *(183.59360790+0 \quad P 250$

$=-T *(93.96635527 \mathrm{D}-3-T *(30.07808886 \mathrm{D}-6-T *(5.819644183 \mathrm{D}-9 \quad P 250$

$=-T *(619.7247350-15-T * 27.819507270-18)))))) \quad$ P250

$\begin{array}{ll}\text { RETURN } & \text { P250 }\end{array}$

END $\quad$ P250 


\section{Appendix G. Secondary routines}

The following routines either organize the calculation of the thermal properties of the water, or help to find a density to a given pressure.

\section{G.1 INR105.AQUA.FORT(DGFIND)}

\begin{tabular}{|c|c|c|c|}
\hline & SUBROUTINE DGFIND(T,Q,DX,IECCH) & & DGFIND \\
\hline C & DGFIND SEEKS A DENSITY DX (G/CM**3) & & DGFIND \\
\hline C & CORRESPONDING TO THE PRESSURE Q(MPA) AND & & DGFIND \\
\hline \multirow[t]{8}{*}{ C } & TO THE - SUPERCRITICAL - TEMPERATURE T (K). & $94 / 12 / 06$ & DGFIND \\
\hline & IMPLICIT REAL*8(A-H,0-Z) & & DGFIND \\
\hline & COMMON /TEMPO/ RT, B1,B2,B1T,B2T,B1TT,B2TT,TV,GI,SI, CVI & & DGFIND \\
\hline & COMMON /BASIF/ GB,SB,ZB,PB1TO,PB1RO,CVB & & DGFIND \\
\hline & COMMON /RESEF/ GR,SR,ZR,PR1TO,PR1RO,CVR & & DGFIND \\
\hline & $R E A L * 8 \quad F X(3), X(3)$ & & DGFIND \\
\hline & $\operatorname{PARAMETER}(D C=0.322 D 0$, DMAX $=1.200, \mathrm{FINIS}=5.0-5)$ & & DGFIND \\
\hline & DATA PF $/ 1 . D-6 /$, ZERO $/ 0.00 /$ & & DGFIND \\
\hline \multirow[t]{6}{*}{ C } & RANGE CONTROL & & DGFIND \\
\hline & $Q S M A X=P L M A X(T) \star P F$ & & DGFIND \\
\hline & $\operatorname{IF}(Q . G T . Q S M A X)$ & & DGFIND \\
\hline & IF (IECCH.NE. $\theta)$ & & DGFIND \\
\hline & $Q S M I N=P 600(T) * P F$ & & DGFIND \\
\hline & $\operatorname{IF}(Q . L T \cdot Q S M I N)$ & & DGFIND \\
\hline \multirow{7}{*}{${ }^{C}{ }_{100}$} & REGION OF HIGH DENSITIES & & DGFIND \\
\hline & $X(3)=D M A X$ & & DGFIND \\
\hline & $X(1)=0.600$ & & DGFIND \\
\hline & $x(2)=0.80 \mathrm{D} 0$ & & DGFIND \\
\hline & $F X(2)=P 800(T) * P F$ & & DGFIND \\
\hline & $S A M=2 . D-1$ & & DGFIND \\
\hline & G0T0 600 & & DGFIND \\
\hline \multirow{10}{*}{${ }_{200}$} & REGION OF MODERATE DENSITIES & & DGFIND \\
\hline & $x(3)=0.600$ & & DGFIND \\
\hline & $X(1)=O C$ & & DGFIND \\
\hline & QSMAX $=$ QSMIN & & DGF IND \\
\hline & $Q S M I N=P 322(T) * P F$ & & DGFIND \\
\hline & IF $(Q \cdot L T, Q S M I N)$ & & DGFIND \\
\hline & $x(2)=0.4000$ & & DGFIND \\
\hline & $F X(2)=P 400(T) * P F$ & & DGFIND \\
\hline & $S A M=1 \cdot D-1$ & & DGFIND \\
\hline & GOTO 600 & & DGFIND \\
\hline \multirow{10}{*}{${ }^{C} 300$} & REGION OF LOW DENSITIES & & DGFIND \\
\hline & $X(3)=D C$ & & DGFIND \\
\hline & $X(1)=$ ZER0 & & DGFIND \\
\hline & QSMAX $=Q S M I N$ & & DGFIND \\
\hline & QSMIN=ZERO & & DGFIND \\
\hline & $\operatorname{IF}(Q \cdot L T \cdot Q S M I N)$ & & DGFIND \\
\hline & IF (IECCH .NE. 0) & & DGFIND \\
\hline & $x(2)=0.2500$ & & DGFIND \\
\hline & $F X(2)=P 250(T) * P F$ & & DGFIND \\
\hline & $S A M=5.0-2$ & & DGFIND \\
\hline 600 & $F X(1)=Q S M I N$ & & DGFIND \\
\hline
\end{tabular}




\begin{tabular}{|c|c|c|c|}
\hline \multirow{4}{*}{$\begin{array}{l}c \\
c\end{array}$} & \multicolumn{2}{|c|}{$F X(3)=Q S M A X$} & DGFIND \\
\hline & \multicolumn{2}{|c|}{ WRITE $(6,4400)$ QSMIN, QSMAX, SAM } & DGFIND \\
\hline & \multicolumn{2}{|c|}{ FIRST DENSITY APPROXIMATIONS } & DGFIND \\
\hline & \multicolumn{2}{|c|}{$\mathrm{LI}=1$} & DGFIND \\
\hline \multirow[t]{3}{*}{ c } & \multicolumn{2}{|l|}{ WRITE $(6,6660)$} & DGFIND \\
\hline & IF (DX .LE. ZERO) & $D X=D I N S U(T, Q, F X, X, L I, I E C C H)$ & DGFIND \\
\hline & IF (IECCH . NE. O O) & RETURN & DGFIND \\
\hline C & \multicolumn{2}{|c|}{ REFINED DENSITY APPROXIMATIONS IN THE MANNER OF MR. I. NEWTON } & DGFIND \\
\hline $\mathrm{c}$ & \multicolumn{2}{|c|}{$\operatorname{WRITE}\left(6,{ }^{\prime}()^{\prime}\right)$} & DGFIND \\
\hline C & \multicolumn{2}{|l|}{ ITERATING } & DGFIND \\
\hline & \multirow{2}{*}{\multicolumn{2}{|c|}{$\begin{array}{l}\mathrm{LF}=\mathrm{LI}+19 \\
0071=L I F\end{array}$}} & DGFIND \\
\hline & & & DGFIND \\
\hline & \multicolumn{2}{|l|}{ IF (DX .GT. DMAX) } & DGFIND \\
\hline \multicolumn{3}{|c|}{$D X=D M A X$} & DGFIND \\
\hline & \multicolumn{2}{|l|}{$\mathrm{IECCH}=2$} & DGFIND \\
\hline & \multicolumn{2}{|l|}{ ENDIF } & DGFIND \\
\hline & IF (DX .LE. ZERO) & $D X=Q / R T$ & DGFIND \\
\hline & \multicolumn{2}{|l|}{ CALL BASE $(T, D X, I E C C H)$} & DGFIND \\
\hline & \multicolumn{2}{|l|}{ CALL RESID $(T, D X)$} & DGFIND \\
\hline & \multicolumn{2}{|l|}{$Z P=Z B+Z R$} & DGFIND \\
\hline & \multicolumn{2}{|l|}{$Q A X=Z P * D X * R T$} & DGFIND \\
\hline & \multicolumn{2}{|l|}{$D E L Q=Q-Q A X$} & DGFIND \\
\hline & \multicolumn{3}{|l|}{$E P S=A B S(D E L Q / Q)$} \\
\hline & \multirow{2}{*}{\multicolumn{2}{|c|}{$\begin{array}{l}\text { IF(EPS .LT. FINIS) } \\
\text { IECCH }=0\end{array}$}} & DGFIND \\
\hline & & & DGFIND \\
\hline & \multicolumn{2}{|l|}{ RETURN } & DGFIND \\
\hline & ENDIF & & DGFIND \\
\hline & IF (IECCH.NE. O ) & GOTO 900 & DGFIND \\
\hline & $P 1 R O=P B 1 R \theta+P R 1 R O$ & & DGFIND \\
\hline & $D Q D=P 1 R 0 * R T$ & & DGFIND \\
\hline & $D E L R=D E L Q / D Q D$ & & DGFIND \\
\hline c & WRITE $(6,6666) \quad L, D X, C$ & AX,DELQ,FINIS,DELR & DGFIND \\
\hline & IF(DELR .GT. ZERO) & $D E L R=M I N(D E L R, S A M)$ & DGFIND \\
\hline & IF (DELR .LT. ZERO) & $D E L R=M A X(D E L R,-S A M)$ & DGFIND \\
\hline & $D X=D X+D E L R$ & & DGFIND \\
\hline 71 & CONTINUE & & DGFIND \\
\hline & IECCH $=3$ & & DGFIND \\
\hline & WRITE $(6,9000)$ & & DGFIND \\
\hline & RETURN & & DGFIND \\
\hline 900 & IF (IECCH .GT. O) & WRITE $(6,9100) Q$ & DGFIND \\
\hline & IF (IECCH . LT. O $)$ & WRI TE $(6,9300) \quad Q$ & OGFIND \\
\hline & RETURN & & DGFIND \\
\hline C4400 & FORMAT $(8 H$ QSMIN $=, F 1$ & $9,2 X, 7$ HQSMAX $=, F 14.9,2 X, 5$ HSAM $=, 2 X, F 7.3)$ & DGFIND \\
\hline C6660 & FORMAT (3H L, $5 X, 2 H D X$ & $2 \mathrm{XX}, 3 \mathrm{HQAX}, 13 \mathrm{X}, 4 \mathrm{HDELQ}, 11 \mathrm{X}, 3 \mathrm{HQGR}, 7 \mathrm{X}, 4 \mathrm{HDELR})$ & DGFIND \\
\hline C6666 & FORMAT $(I 3, F 13.9, G 18 . S$ & $, G 15.6, F 9.5, F 13.9)$ & DGFIND \\
\hline 9000 & FORMAT $(41 \mathrm{H}$ ITERATION & EOR THE DENSITY VALUE FAILED！） & DGFIND \\
\hline 9100 & FORMAT (13H PRESSURE & $=$, G15.7,16H MPA .T00 HIGH ! & DGFIND \\
\hline 9300 & FORMAT(13H PRESSURE & $=$, G15.7,16H MPA T00 LOW ! & DGFIND \\
\hline & & & DGFIND \\
\hline
\end{tabular}




\section{G.2 INR105.AQUA.FORT(DLFIND)}

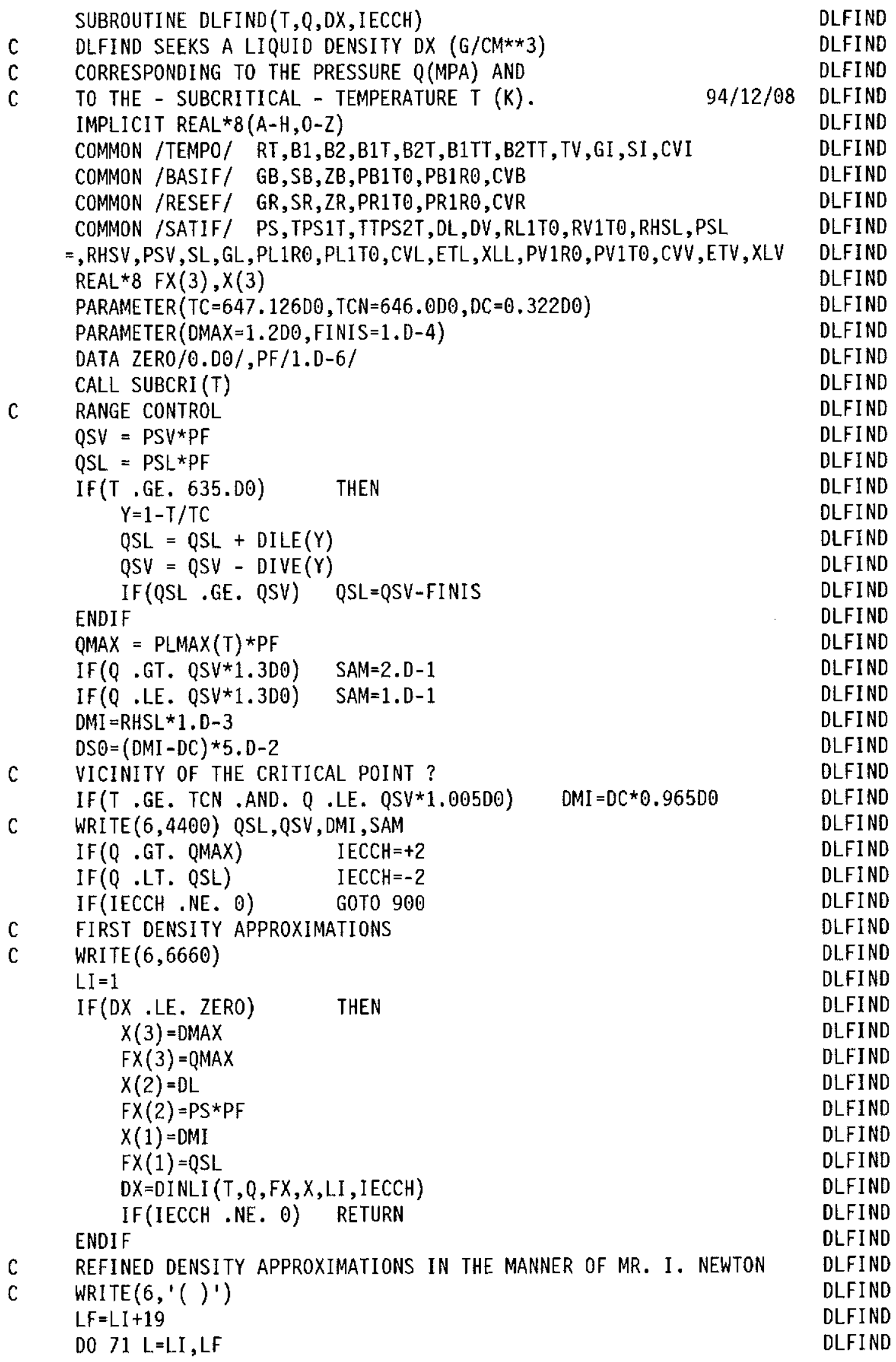




\begin{tabular}{|c|c|c|c|}
\hline & $\begin{array}{c}\text { IF (DX .GT. DMAX) } \\
D X=D M A X\end{array}$ & THEN & $\begin{array}{l}\text { DLFINU } \\
\text { DLFIND }\end{array}$ \\
\hline & $\mathrm{IECCH}=2$ & & DLFIND \\
\hline & ENDIF & & DLFIND \\
\hline & IF (DX.LT. DMI $)$ & $D X=D M I$ & DLFIND \\
\hline & CALL BASE $(T, D X, I E C C H)$ & & DLFIND \\
\hline & CALL RESID $(T, D X)$ & & DLFIND \\
\hline & $Z P=Z B+Z R$ & & DLFIND \\
\hline & $Q A X=Z P * D X * R T$ & & DLFIND \\
\hline & $D E L Q=Q-Q A X$ & & DLFIND \\
\hline & $E P S=A B S(D E L Q)$ & & DLFIND \\
\hline & IF (EPS .LT. FINIS) & THEN & DLFIND \\
\hline & $\mathrm{IECCH}=0$ & & DLFIND \\
\hline & RETURN & & DLFIND \\
\hline & ENDIF & & DLFIND \\
\hline & IF (IECCH .GT. 0) & GO TO 900 & DLFIND \\
\hline & $P 1 R 0=P B 1 R 0+P R 1 R 0$ & & DLFIND \\
\hline & $D Q D=P 1 R \theta * R T$ & & DLFIND \\
\hline & IF (DQD .LE. ZERO) & THEN & DLFIND \\
\hline & $D X=D X+D S \theta$ & & DLFIND \\
\hline & G0 TO 71 & & DLFIND \\
\hline & ENDIF & & DLFIND \\
\hline & $D E L R=D E L Q / D Q D$ & & DLFIND \\
\hline C & WRITE $(6,6666) \quad L, D X, Q A X$ & ,DELQ,FINIS,DELR & DLFIND \\
\hline & IF (ABS (DELR) .LT. 1.D- & 6) THEN & DLFIND \\
\hline & $\mathrm{IECCH}=0$ & & DLFIND \\
\hline & RETURN & & DLFIND \\
\hline & ENDIF & & DLFIND \\
\hline & IF (DELR . GT. ZERO) & DELR=MIN (DELR,SAM) & DLFIND \\
\hline & IF (DELR .LT. ZERO) & $D E L R=\operatorname{MAX}(D E L . R,-S A M)$ & DLFIND \\
\hline & $D X=D X+D E L R$ & & DLFIND \\
\hline 71 & CONTINUE & & DLFIND \\
\hline & $\mathrm{IECCH}=3$ & & DLFIND \\
\hline 800 & WRITE $(6,9000)$ & & DLFIND \\
\hline & RETURN & & DLFIND \\
\hline 900 & IF (IECCH .GT. 0$)$ & WRITE $(6,9100) \quad Q$ & DLFIND \\
\hline & IF (IECCH .LT. O) & $\operatorname{WRITE}(6,9300) \quad Q$ & DLFIND \\
\hline & RETURN & & DLFIND \\
\hline C4400 & FORMAT $(7 \mathrm{H} \quad$ QSPL $=, F 14.9$ & $, 3 X, 6$ HQSPV $=, F 14.9,3 X, 5$ HDMI $=, 3 X, F 10.6,3 X$ & DLFIND \\
\hline & $=, 5$ HSAM $=, F 7.3)$ & & DLFIND \\
\hline C6660 & FORMAT $(3 \mathrm{H} \quad \mathrm{L}, 5 \mathrm{X}, 2 \mathrm{HDX}, 1$ & $2 X, 3$ HQAX, 13X,4HDELQ $, 11 X, 3$ HQGR, 7X,4HDELR) & DLFIND \\
\hline C6666 & FORMAT $(\mathrm{I} 3, \mathrm{~F} 13.9, \mathrm{G18.9}$, & $\mathrm{G} 15.6, \mathrm{~F} 9.5, \mathrm{~F} 13.9)$ & DLFIND \\
\hline 9000 & FORMAT (41H ITERATION F & OR THE DENSITY VALUE FAILED !) & DLFIND \\
\hline 9100 & FORMAT(13H PRESSURE $P$ & $=$, G15.7,16H MPA T00 HIGH $! \quad j$ & DLFIND \\
\hline 9300 & FORMAT(13H PRESSURE $P$ & $=$, G15.7,16H MPA TOO LOW ! & DLFIND \\
\hline & END & & DLFIND \\
\hline
\end{tabular}




\section{G.3 INR105.AQUA.FORT(DVFIND)}

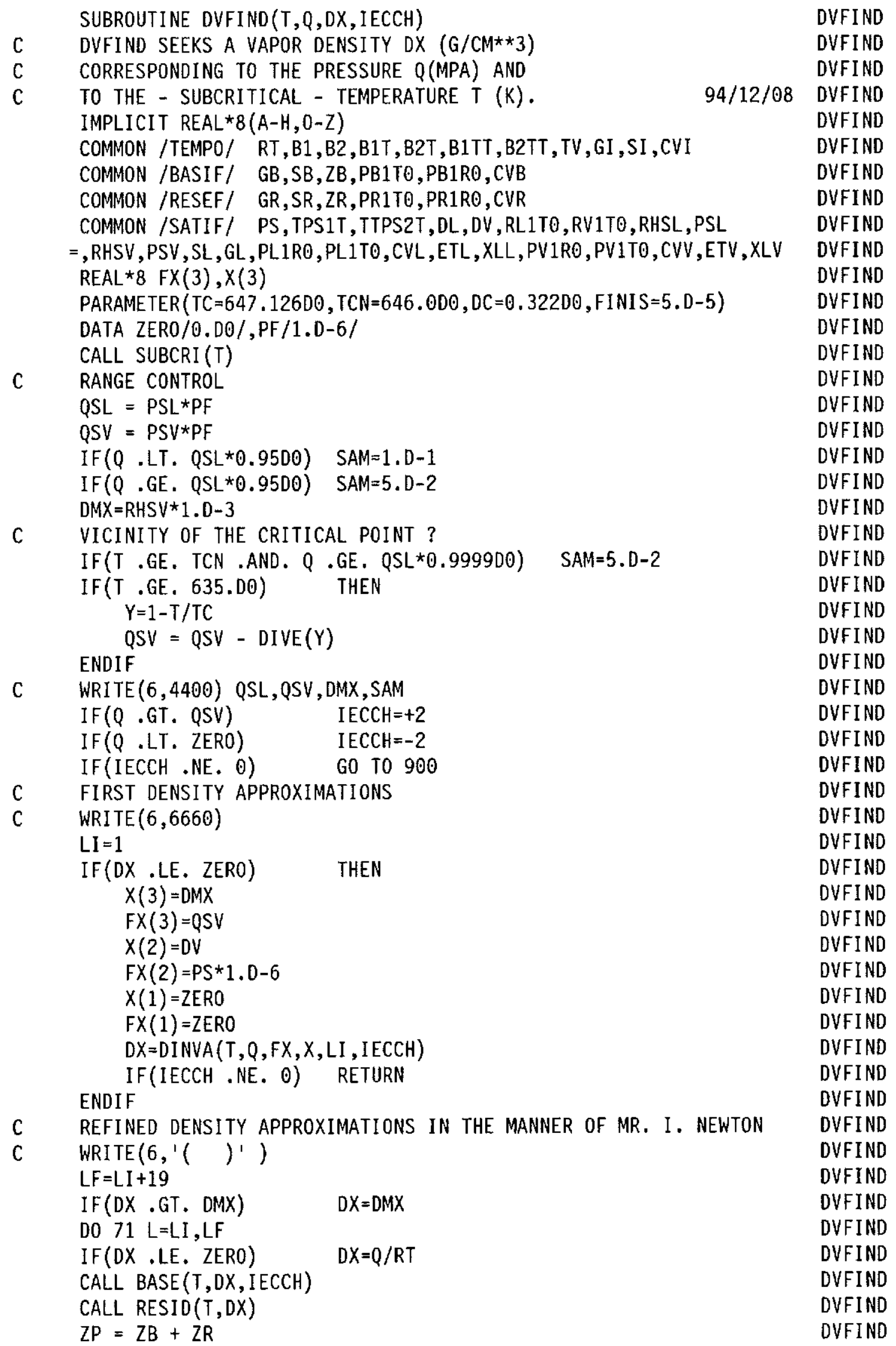




\begin{tabular}{|c|c|c|c|}
\hline & $Q A X=Z P * D X * R T$ & & DVFIND \\
\hline & $D E L Q=Q-Q A X$ & & DVFIND \\
\hline & $E P S=A B S(D E L Q / Q)$ & & DVFIND \\
\hline & IF(EPS .LT. FINIS) & THEN & DVFIND \\
\hline & IECCH $=0$ & & DVFIND \\
\hline & RETURN & & DVFIND \\
\hline & ENDIF & & DVFIND \\
\hline & IF (IECCH .NE. O) & GO T0 900 & DVFIND \\
\hline & $P 1 R \theta=P B 1 R 0+P R 1 R 0$ & & DVFIND \\
\hline & $\mathrm{DQD}=\mathrm{P} 1 \mathrm{R} \theta * \mathrm{RT}$ & & DVFIND \\
\hline & IF (DQD .LE. ZERO) & THEN & DVFIND \\
\hline & $\operatorname{IF}(L \cdot E Q, L I)$ & THEN & DVFIND \\
\hline & $D X=D M X$ & & DVFIND \\
\hline & ELSE & & DVFIND \\
\hline & $0 X=D V * 0.900$ & & OVFIND \\
\hline & ENDIF & & DVFIND \\
\hline & $\begin{array}{lll}\text { GO } & \text { T0 } & 71\end{array}$ & & DVFIND \\
\hline & ENDIF & & DVFIND \\
\hline & $\mathrm{DELR}=\mathrm{DELQ} / \mathrm{DQD}$ & & DVFIND \\
\hline c & WRITE $(6,6666) \quad L, D X, Q A$ & ,DELQ,FINIS,DELR & DVFIND \\
\hline & IF (DELR .GT. ZERO) & $D E L R=M I N(D E L R, S A M)$ & DVFIND \\
\hline & IF (DELR . LT. ZERO) & DELR $=$ MAX (DELR, - SAM $)$ & DVFIND \\
\hline & $D X=D X+D E L R$ & & DVFIND \\
\hline & $\operatorname{IF}(D X . G T, D M X)$ & THEN & DVFIND \\
\hline & $\mathrm{DX}=\mathrm{DMX}$ & & DVFIND \\
\hline & IECCH $=+2$ & & DVFIND \\
\hline & ENDIF & & DVFIND \\
\hline 71 & CONTINUE & & DVFIND \\
\hline & $\mathrm{IECCH}=3$ & & DVFIND \\
\hline & WRITE $(6,9000)$ & & OVFIND \\
\hline & RETURN & & DVFIND \\
\hline 900 & IF (IECCH .GT. 0) & WRITE $(6,9100) \quad Q$ & DVFIND \\
\hline & IF(IECCH .LT. O) & WRITE $(6,9300) Q$ & DVFIND \\
\hline & RETURN & & DVFIND \\
\hline C4400 & FORMAT $(7 H$ QSPL $=, F 14$. & $, 3 X, 6 H Q S P V=, F 14.9,3 X, 5 H D M X=, 3 X, F 10.6,3 X$ & DVFIND \\
\hline & $=, 5 \mathrm{HSAM}=, \mathrm{F} 7.3)$ & & DVFIND \\
\hline C6660 & FORMAT (3H L, 5X,2HDX, & $2 X, 3 H Q A X, 13 X, 4 H D E L Q, 11 X, 3 H Q G R, 7 X, 4 H D E L R)$ & DVFIND \\
\hline C6666 & FORMAT $(\mathrm{I} 3, \mathrm{~F} 13.9, \mathrm{G} 18.9$ & $G 15.6, F 9.5, F 13.9)$ & DVFIND \\
\hline 9000 & FORMAT (41H ITERATION & OR THE DENSITY VALUE FAILED ! ) & DVFIND \\
\hline 9100 & FORMAT (13H PRESSURE $P$ & $=$, G15.7,16H MPA TO0 HIGH ! ) & DVFIND \\
\hline 9300 & FORMAT (13H PRESSURE $P$ & $=$, G15.7,16H MPA T00 LOW ! ） & DVFIND \\
\hline & END & & DVFIND \\
\hline
\end{tabular}

\section{G.4 INR105.AQUA.FORT(DINSU)}

FUNCTION DINSU(T, Q FX, X, IT, IECCH) DINSU

C DINSU IS AN INITAL DENSITY FOR THE ROUTINE DSFIND. DINSU

C DINSU IS THE ROOT OF A 2. GRADE EQUATION Q.IS(DX) $-Q=0 . \quad$ DINSU

C PRESSURES ARE IN MPA-S, DENSITIES IN G/CM**3-S. 93/09/03 DINSU IMPLICIT REAL*8 $(A-H, 0-Z) \quad$ DINSU

COMMON /TEMP0/ RT,B1,B2,B1T,B2T,B1TT,B2TT,TV,GI,SI,CVI DINSU

COMMON /BASIF/ GB,SB,ZB,PTOB,PROB,CVB DINSU

COMMON /RESEF/ GR,SR,ZR,PTOR,PROR,CVR DINSU 


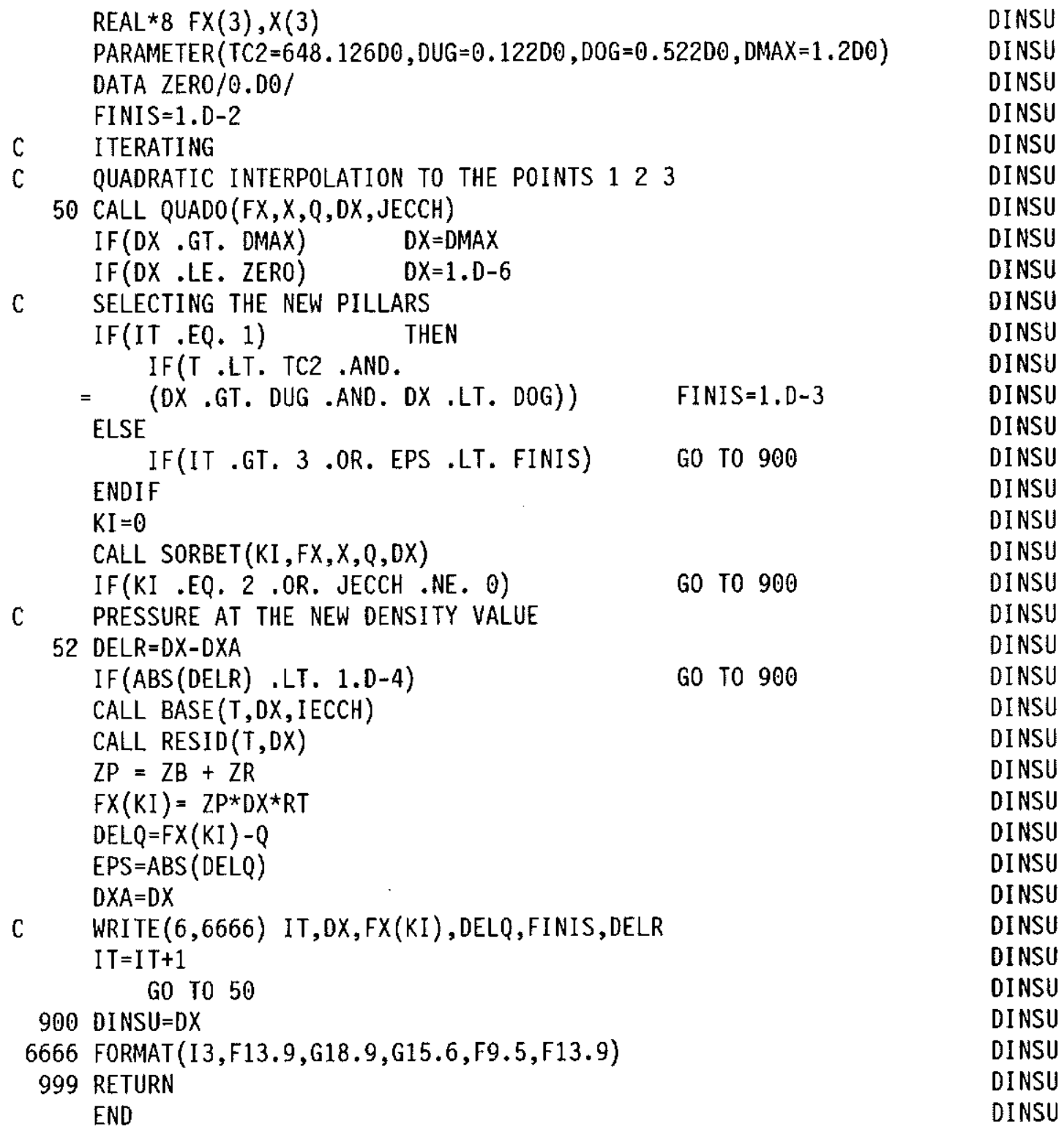

\section{G.5 INR105.AQUA.FORT(DINLI)}

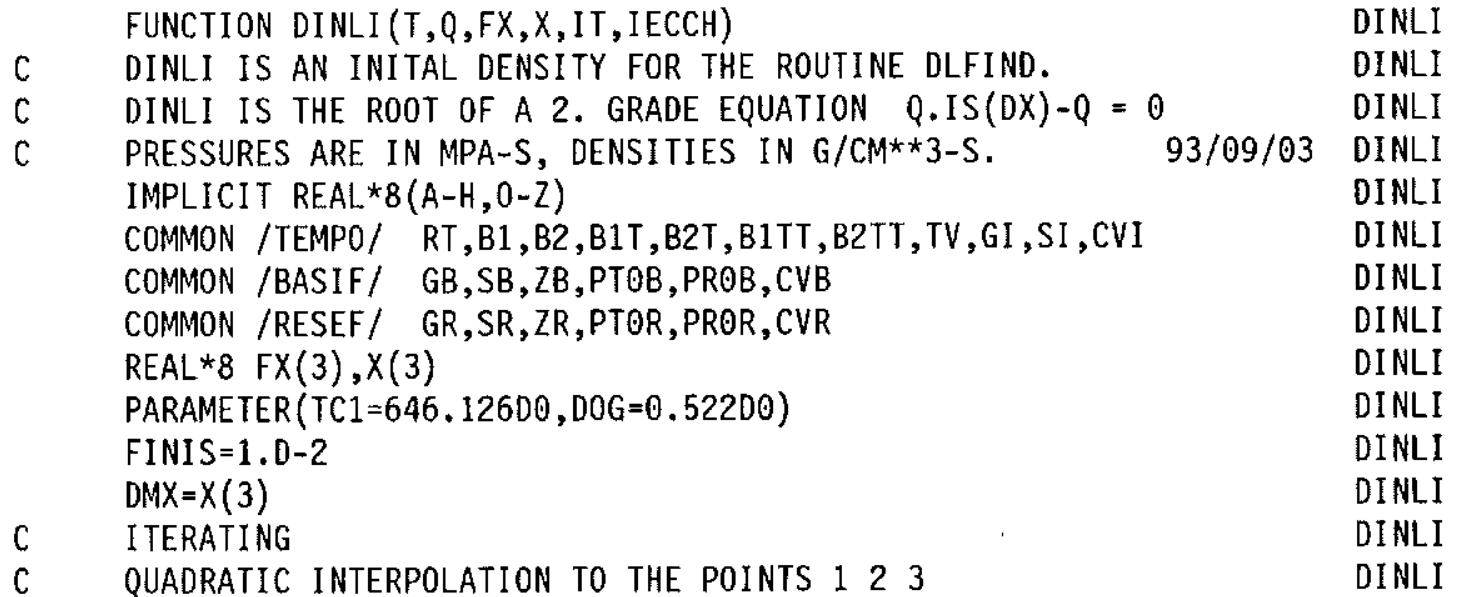


50 CALL QUADO (FX, X, Q, DX, JECCH)

IF (DX .GT. DMX) DX $=D M X$

DINLI

C

SELECTING THE NEW PILLARS

DINLI

IF(IT .EQ. 1) THEN

DINLI IF (T .GT. TC1) THEN

$\mathrm{KI}=1$

DINLI

IF (DX .LT. DOG)

FINIS $=1 . D-3$

DINLI

ELSE $\mathrm{KI}=0$

DINLI

ENDIF

ENDIF

CALL SORBET (KI, FX, X, Q, DX)

IF(KI .EQ. 2 .OR. JECCH . NE. O)

G0 T0 900

DINLI

IF (IT .LE. 1)

G0 T0 52

DINLI

IF(IT .GT. 3 .OR. EPS .LT. FINIS)

C PRESSURE AT THE NEW DENSITY VALUE

DINLI

DINLI

OINLI

DINLI

$52 D E L R=D X-D X A$

IF (ABS (DELR) .LT. 1.D-4)

CALL BASE ( $T, D X, I E C C H)$

CALL RESID(T,DX)

$Z P=Z B+Z R$

GO TO 900

DINLI

$F X(K I)=Z P * D X * R T$

DINLI

DINLI

DINLI

DINLI

GO TO 900

DINLI

DINLI

DINLI

DINLI

DINLI

$D E L Q=F X(K I)-Q$

DINL.I

$E P S=A B S(D E L Q)$

DINLI

DXA $=D X$

C WRITE $(6,6666)$ IT, DX, FX(KI), DELQ, FINIS, DELR

DINLI

DINLI

$\mathrm{IT}=\mathrm{IT}+1$ GO TO 50

DINLI

DINLI

900 DINLI $=D X$

DINLI

DINLI

DINLI

RETURN

DINLI

\section{G.6 INR105.AQUA.FORT(DINVA)}

FUNCTION DINVA (T,Q,FX,X,IT, IECCH)

DINVA

C DINVA IS AN INITAL DENSITY FOR THE ROUTINE DVFIND.

DINVA

C DINVA IS THE ROOT OF A 2. GRADE EQUATION Q.IS(DX)-Q $=0$.

C PRESSURES ARE IN MPA-S, DENSITIES IN G/CM**3-S.

DINVA

IMPLICIT REAL*8(A-H,O-Z)

COMMON /TEMP0/ RT, B1,B2,B1T,B2T, B1TT, B2TT, TV, GI, SI, CVI

$93 / 09 / 17$

DINVA

DINVA

COMMON /BASIF/ GB,SB,ZB,PTOB,PROB,CVB

DINVA

COMMON /RESEF/ GR,SR, ZR, PTOR,PROR, CVR

DINVA

REAL $\star 8$ FX (3), X(3)

DINVA

PARAMETER $($ TC $1=646.12600, D U G=0.122 D 0)$

DINVA

FINIS $=1 . D-2$

DINVA

DINVA

C ITERATING

C QUADRATIC INTERPOLATION TO THE POINTS 123

DINVA

50 CALL QUADO (FX, X,Q,DX,JECCH)

DINVA

IF (DX . LT. O.DO) DX $=1 . D-6$

DINVA

DINVA

C SELECTING THE NEW PILLARS

DINVA

IF (IT .EQ. 1) THEN

DINVA

IF(T .GT. TC1) THEN

DINVA 


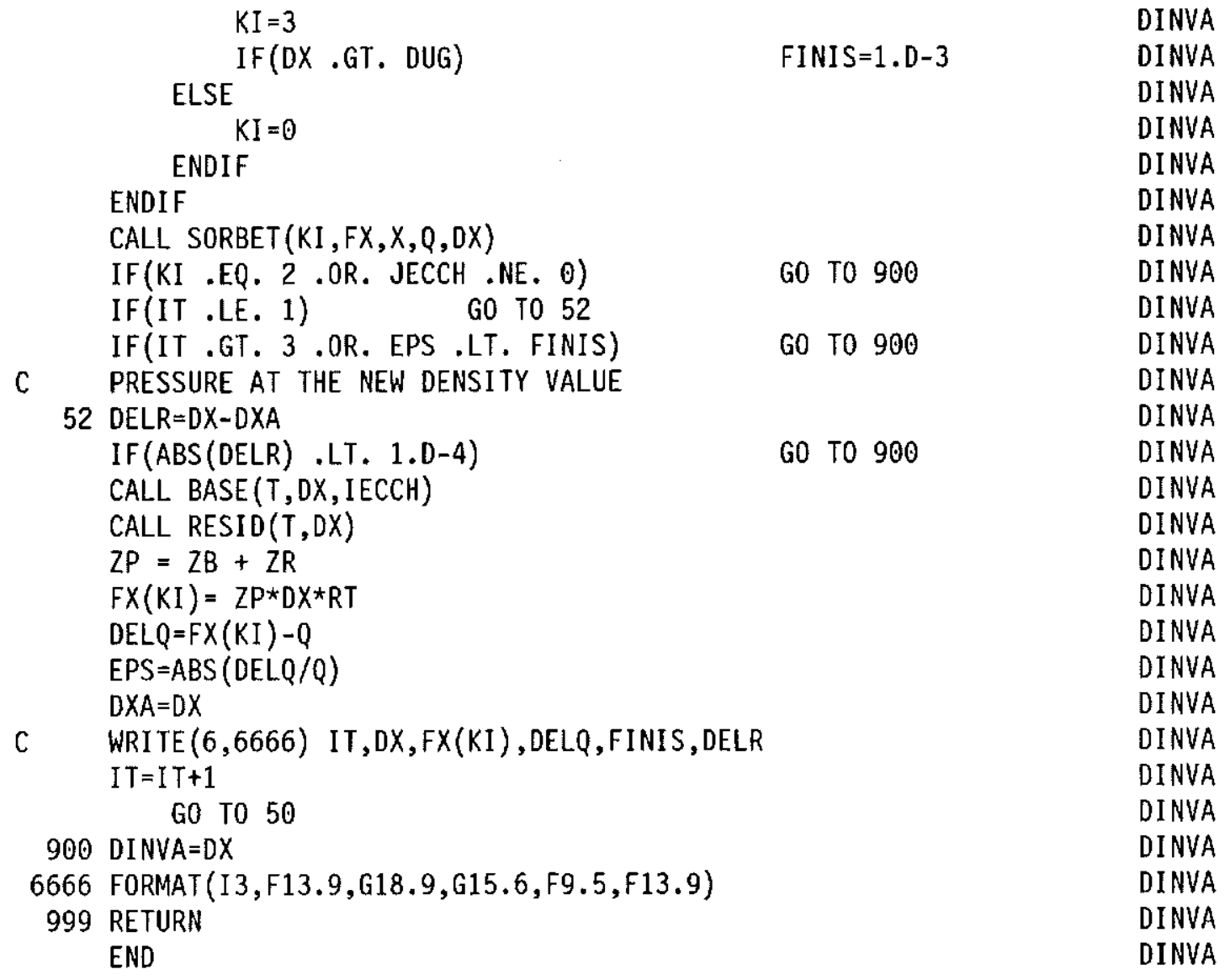

\section{G.7 INR105.AQUA.FORT(QUADO)}

\begin{tabular}{|c|c|c|c|c|}
\hline & SUBROUTINE QUADO(FX,X,F & $X S, X S, J E C C H)$ & & QUADO \\
\hline C & SEARCHES AN XS WITH THE & PROPERTY FX(XS) $=$ FXS & $93 / 09 / 07$ & QUADO \\
\hline c & BY FITTING A QUADRATIC & POLYNOMIAL TO THE POINTS FX(1). & $\mathrm{FX}(3)$ & QUADO \\
\hline & IMPLICIT REAL $* 8(\mathrm{~A}-\mathrm{H}, \mathrm{O}-\mathrm{Z}$ & & & QUADO \\
\hline & $R E A L \star 8 F X(3), X(3), F Y(3)$ & & & QUADO \\
\hline & DATA ZERO,UN/0.00,1.00/ & & & QUADO \\
\hline & CALL MONIKA(FX,X,JECCH) & & & QUADO \\
\hline & IF (JECCH .NE, O) & RETURN & & QUADO \\
\hline & $A=Z E R 0$ & & & QUADO \\
\hline & $B=Z E R 0$ & & & QUADO \\
\hline & $C=Z E R 0$ & & & QUADO \\
\hline & $\mathrm{IECCH}=0$ & & & QUADO \\
\hline C & THE COEFFICIENTS OF THE & POLYNOMIAL & & QUADO \\
\hline & $D 021 \mathrm{~K}=1,3$ & & & QUADO \\
\hline 21 & $F Y(K)=F X(K)-F X S$ & & & QUADO \\
\hline & $D 031 \quad I=1,3$ & & & QUADO \\
\hline & $J=I+1$ & & & QUADO \\
\hline & IF (J .GT. 3) & $J=J-3$ & & QUAD0 \\
\hline & $X D=X(J)-X(I)$ & & & QUADO \\
\hline & $\mathrm{K}=\mathrm{J}+1$ & & & QUAD0 \\
\hline & $\operatorname{IF}(K . G T .3)$ & $K=K-3$ & & QUADO \\
\hline & $Y X D=F Y(K) * X D$ & & & QUADO \\
\hline & $Y X 2=-Y X D^{*}(X(\mathrm{~J}$ & & & QUAD \\
\hline
\end{tabular}


$Y X 3=Y X D \star X(J) \star X(I)$

QUADO

$A=A+Y X D$

QUADO

$B=B+Y X 2$

QUADO

$C=C+Y X 3$

QUADO

QUADO

31 CONTINUE

QUADO

QUADO

QUADO

$B /(A+A)$

$U S=U N-C /\left(A^{*} X G^{\star} \times G\right)$

IF(US .LE. ZERO) THEN

QUADO

$X S=X G$

RETURN

QUADO

QUADO

ENDIF

QUADO

QUADO

QUADO

QUADO

$X A=X G^{\star}(U N+W)$

QUADO

THE APPROPRIATE ROOT

$80 X M=(X(1)+X(2)+X(3)) / 3.00$

QUADO

$X S=X A$

$I F(A B S(X B-X M) \quad . L T . A B S(X A-X M))$

$X S=X B$

QUADO

RETURN

QUADO

END

QUADO

QUADO

\section{G.8 INR105.AQUA.FORT(MONIKA)}

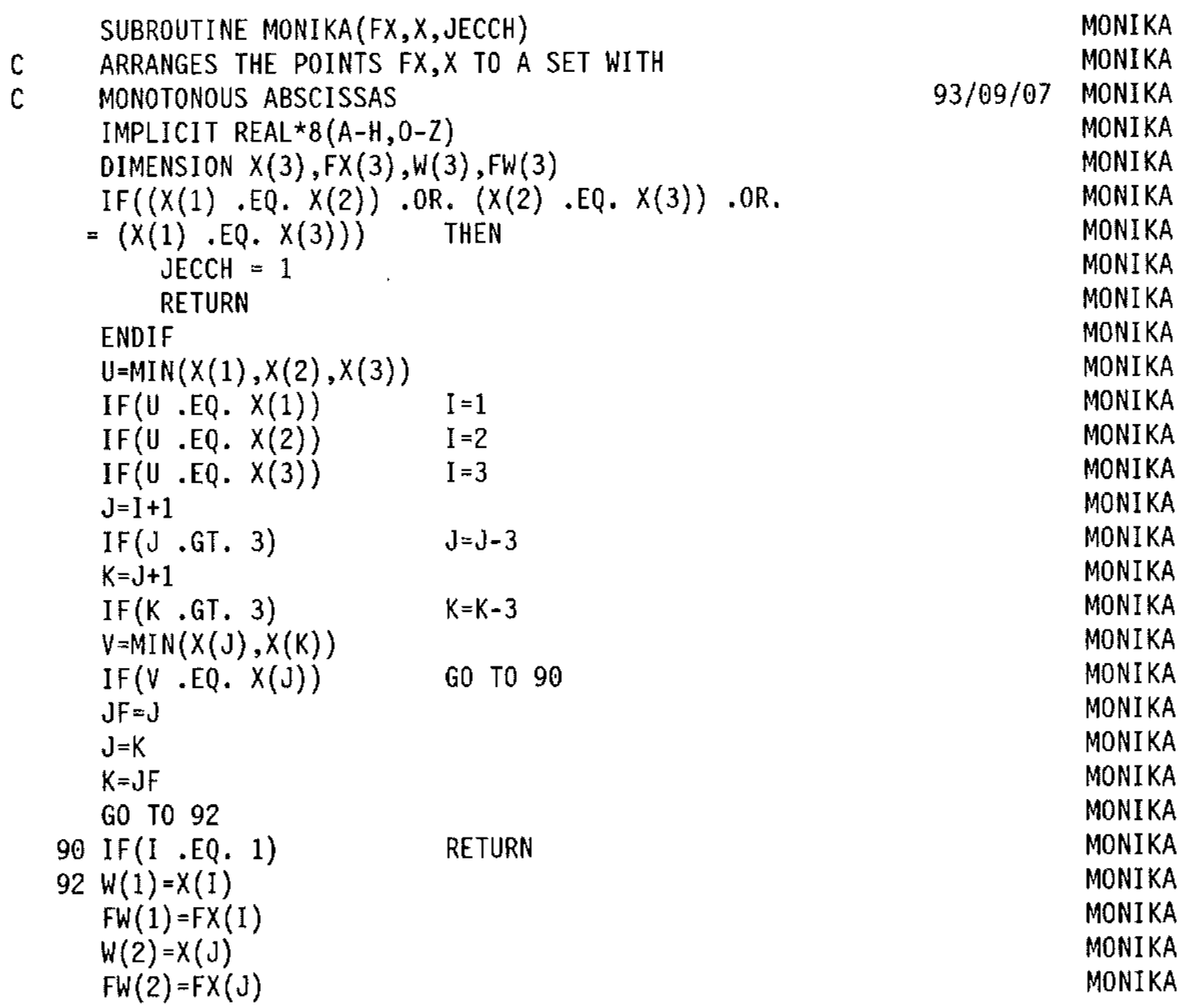


$W(3)=X(K) \quad$ MONIKA

$\mathrm{FW}(3)=F X(K) \quad$ MONIKA

DO $91 \mathrm{~N}=1,3 \quad$ MONIKA

$X(N)=W(N) \quad$ MONIKA

$91 \mathrm{FX}(\mathrm{N})=\mathrm{FW}(\mathrm{N}) \quad$ MONIKA

END MONIKA

\section{G.9 INR105.AQUA.FORT(SORBET)}

SUBROUTINE SORBET (KI, FX, X,FXS,XS) SORBET

C REPLACES ONE OF THE BOUNDARY POINTS $X(1)$ OR X(3) WITH XS. SORBET

C NORMALLY THE POINT WITH THE LARGER (FXS-FX) WILL BE REPLACED. SORBET

C IF 2 OF THE 3 POINTS ARE VERY NEAR TO EACH OTHER SORBET

C $(X(K) / X(L)<1.05)$, THEN AT FIRST ONE OF THESE POINTS WELL BE SORBET

C REPLACED. 93/07/09 SORBET

IMPLICIT REAL*8(A-H,O-Z) SORBET

DIMENSION $X(3), F X(3) \quad$ SORBET

C

$\begin{array}{lll}I F(K I . N E .0) & \text { GO TO } 10 & \text { SORBET }\end{array}$

SORBET

$D 3=A B S(F X(3)-F X S) \quad$ SORBET

$D 1=A B S(F X(1)-F X S) \quad$ SORBET

IF(D3 .GT. D1) KI $=3 \quad$ SORBET

C SORTING

SORBET

C FIRST POINT DISCARDED

10 IF (KI .EQ. 3) GO TO 50 SORBET

IF (XS .GT. X(2)) GO TO $20 \quad$ SORBET

$X(K I)=X S \quad$ SORBET

$F X(K I)=F X S \quad$ SORBET

GO TO $90 \quad$ SORBET

$20 \times(1)=X(2) \quad$ SORBET

$F X(1)=F X(2) \quad$ SORBET

IF(XS .GT. X(3)) GO TO $30 \quad$ SORBET

$\mathrm{KI}=2 \quad$ SORBET

$X(K I)=X S \quad$ SORBET

$F X(K I)=F X S \quad$ SORBET

GO TO 90 SORBET

$30 \times(2)=X(3) \quad$ SORBET

$F X(2)=F X(3) \quad$ SORBET

$\mathrm{KI}=3 \quad$ SORBET

$X(K I)=X S \quad$ SORBET

$F X(K I)=F X S \quad$ SORBET

GO TO 90 SORBET

C LAST POINT DISCARDED SORBET

$50 \mathrm{IF}(\mathrm{XS} . \mathrm{LT} . \mathrm{X}(2)) \quad$ GO TO $60 \quad$ SORBET

SORBET

$F X(K I)=F X S \quad$ SORBET

GO TO $90 \quad$ SORBET

$60 \times(3)=X(2) \quad$ SORBET

$F X(3)=F X(2) \quad$ SORBET

IF (XS .LT. X(1)) GO TO $70 \quad$ SORBET

$\mathrm{KI}=2 \quad$ SORBET

$X(K I)=X S \quad$ SORBET 
$F X(K I)=F X S$

SORBET

GO TO 90

SORBET

$70 x(2)=x(1)$

SORBET

$F X(2)=F X(1)$

SORBET

$\mathrm{KI}=1$

SORBET

$X(K I)=X S$

SORBET

$F X(K I)=F X S$

SORBET

90 RETURN

SORBET

END

\section{G.10 INR105.AQUA.FORT(TCORR)}

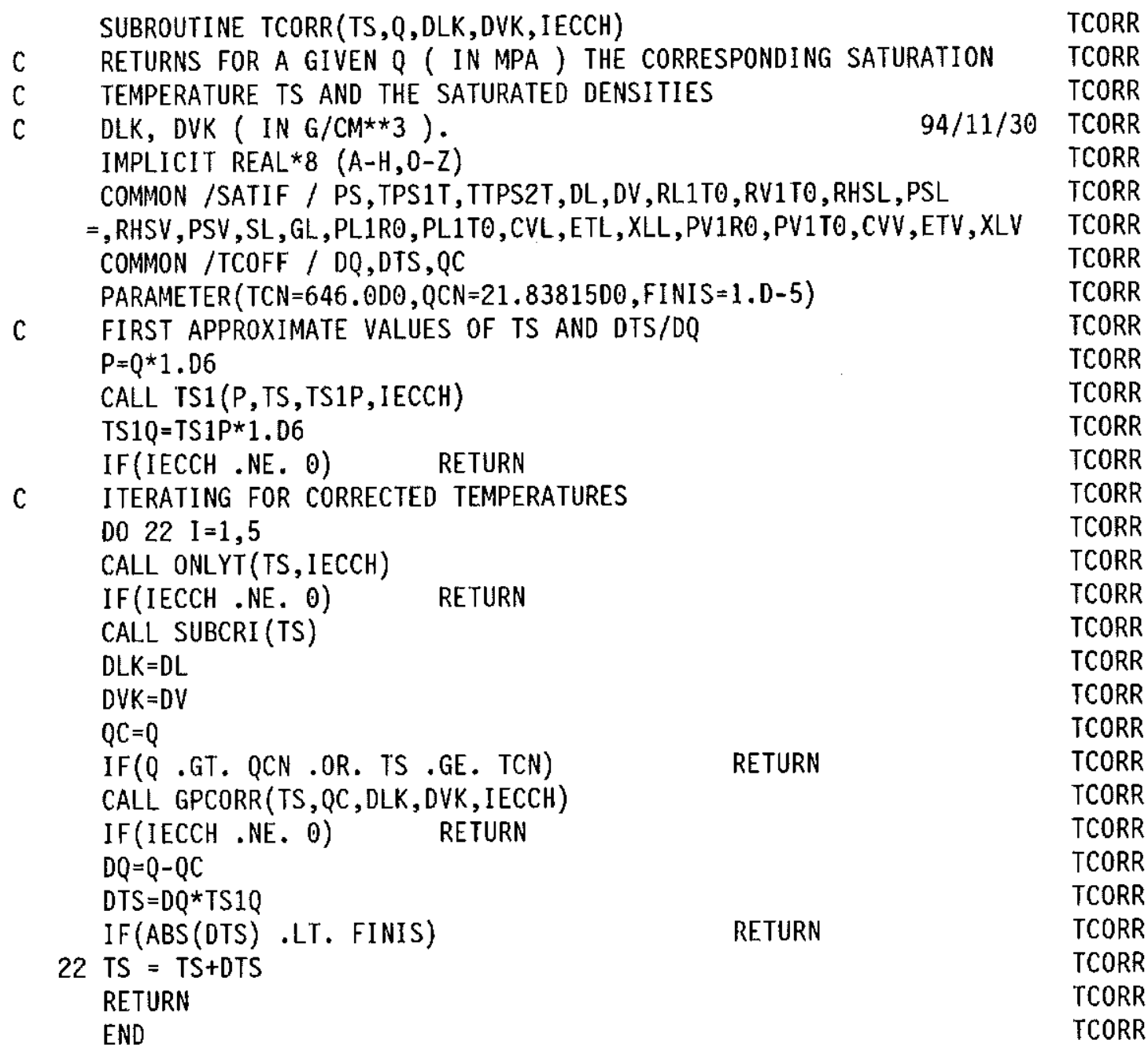

\section{G.11 INR105.AQUA.FORT(GPCORR)}

SUBROUTINE GPCORR(T, Q, DLK, DVK, IECCH)

C RETURNS FOR A GIVEN T THE SATURATED PRESSURE Q (IN MPA)

C AND THE SATURATED DENSITIES DLK, DVK ( IN G/CM**3)

C CORRECTED FOR $G, L=G, V$ AND $Q, L=Q, V \quad 94 / 11 / 30$ IMPLICIT REAL*8(A-H,O-Z)

COMMON /TEMP0/ RT, B1, B2, B1T, B2T, B1TT, B2TT, TV, GI , SI , CVI

GPCORR

GPCORR

GPCORR

GPCORR

GPCORR

GPCORR 
COMMON /BASIF/ GB,SB,ZB,PB1TO,PB1RO,CVB

GPCORR

COMMON /RESEF/ GR,SR,ZR,PR1TO,PR1RO,CVR

GPCORR

COMMON /GPCOF/ ZL, ZV,GL,GV

GPCORR

PARAMETER $($ TCN $=646.000$, FINIS $=1 . D-7)$

GPCORR

D0 $55 \mathrm{~K}=1,10$

GPCORR

GPCORR

SATURATED LIQUID STATE

GPCORR

CALL BASE ( $T, D L K, I E C C H)$

GPCORR

CALL RESID $(T, D L K)$

$Z L=Z B+Z R$

GPCORR

$\mathrm{GL}=\mathrm{GB}+\mathrm{GR}$

GPCORR

PROL = PB1RO+PR1RO

GPCORR

C SATURATED VAPOR STATE

GPCORR

CALL BASE(T,DVK, IECCH)

GPCORR

CALL RESID(T,DVK)

GPCORR

$Z V=Z B+Z R$

GPCORR

$G V=G B+G R$

GPCORR

$P R O V=P B 1 R O+P R 1 R O$

$Q=R T *(Z V * D V K+Z L * D L K) * 5.0-1$

IF (T .GE. TCN) RETURN

GPCORR

GPCORR

GPCORR

C DEVIATIONS AND CORRECTIONS

GPCORR

$D D=D L K-D V K$

GPCORR

$D E L G=G L-G V$

GPCORR

$C L=D V K *(D E L G+Z V)-D L K * Z L$

GPCORR

$C V=D L K *(D E L G-Z L)+D V K * Z V$

GPCORR

$C X L=C L * D L K /(D D * P R O L)$

GPCORR

$C X V=C V * D V K /(D D * P R O V)$

$\operatorname{IF}(A B S(C X L)$.LT. FINIS)

GPCORR

$D L K=D L K+C X L$

RETURN

GPCORR

GPCORR

GPCORR

55 DVK $=D V K+C X V$

GPCORR

RETURN

GPCORR

\section{G.12INR105.AQUA.FORT(SUBCRI)}

SUBROUTINE SUBCRI (T)

SUBCRI

SUBCRI

SUBCRI

OF THE PRESSURES IN THE SATURATED STATES

DL DV $G / C M * * 3 \quad$ SUBCRI

PS TPS1T TTPS2T PASCAL SUBCRI

AS WELL AS THE DENSITIES AND PRESSURES OF THE SPINODALS SUBCRI

RHSL RHSV $K G / M * * 3 \quad$ SUBCRI

PSL PSV PASCAL SUBCRI

AS FUNCTIONS OF THE TEMPERATURE T. 94/12/01 SUBCRI

IMPLICIT REAL*8(A-H, O-Z) SUBCRI

COMMON /SATIF/ PS,TPS1T, TTPS2T, DL, DV, RL1TO, RV1TO, RHSL, PSL SUBCRI

$=$, RHSV ,PSV , SL, GL , PL1RO, PL1TO, CVL, ETL, XLL, PV1RO,PV1TO, CVV ,ETV , XLV SUBCRI

C--.-APPROXIMATION TO THE VAPOR PRESSURE --...-...... SUBCRI

CALL SSP(T) SUBCRI

C-..-APPROXIMATIONS TO THE SATURATED DENSITIES-.................... SUBCRI

CALL SSRHO(T) SUBCRI

C----APPROXIMATIONS TO THE-.............. SUBCRI

C----DENSITIES AND PRESSURES ON THE LIQUID AND VAPOR SPINODAL--.---.- SUBCRI

CALL SPIRHO(T) SUBCRI 
CALL SPIP(T)

SUBCRI

C-1

END $\quad$ SUBCRI

\section{G.13 INR105.AQUA.FORT(TWOPHA)}

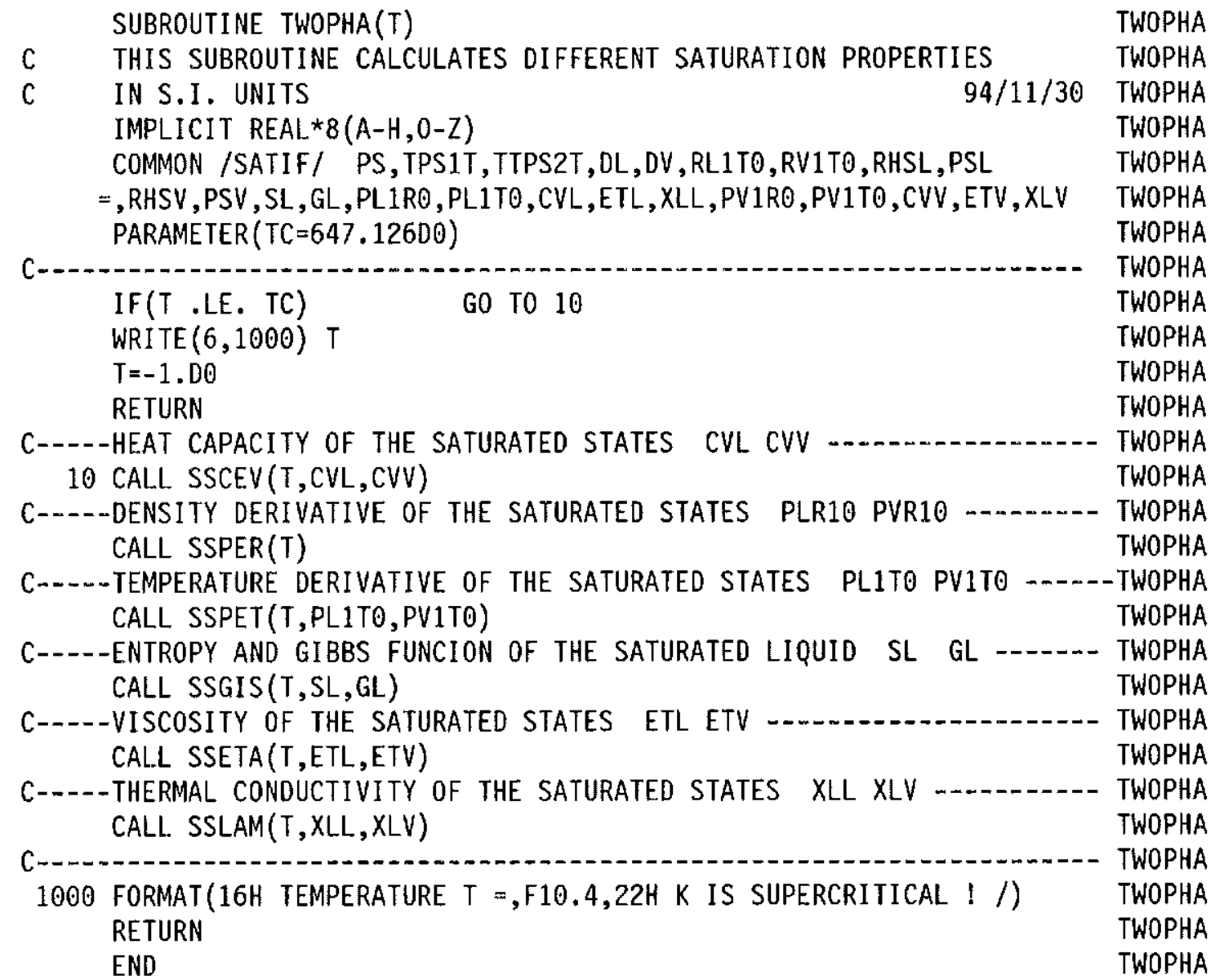

\section{G.14 INR105.AQUA.FORT(REDUK)}

SUBROUTINE REDUK(T,D,IECCH) REDUK

C CALCULATES THERMAL PROPERTIES OF THE WATER REDUK

C IN REDUCED ( DIMENSIONLESS ) UNITS REDUK

C IN THE LIQUID, VAPOR AND GAS STATES REDUK

C D : DENSITY IN G/CM**3, RH : IN KG/M**3

C R1TO : REDUCED DENSITY DERIVATIVE $=(T / R H) *(D R H / D T) \quad$ REDUK

C P1TO, P1RO : REDUCED DERIVATIVES OF THE PRESSURE REDUK

C HO , SO : REDUCED ENTHALPY RESP. ENTROPY, CPC : CP/CV REDUK

C ETA, XLMB : VISCOSITY RESP. THERMAL CONDUCTIVITY REDUK IMPLICIT REAL*8(A-H,O-Z) REDUK COMMON /AKONST/ WM, TC,DC, GASCON,G1,G2,GF, TZ, UREF, SREF, TLOW REDUK COMMON /TEMPO/ RT,B1,B2,B1T,B2T,B1TT,B2TT,TV,GI,SI,CVI REDUK COMMON /BASIF/ GB,SB,ZB,PB1TO,PB1RO,CVB REDUK COMMON /RESEF/ GR,SR,ZR,PR1TO,PR1RO,CVR REDUK 


\begin{tabular}{|c|c|c|}
\hline & $\begin{array}{l}\text { COMMON /REDUF / GO,SO,Z,P1TO,P1RO, CVO,CP } \\
\text { PARAMETER }(\text { RGAS }=4.61522 D+2) \\
\text { DATA FNI } / 1 . D+70 /\end{array}$ & $\begin{array}{l}\text { REDUK } \\
\text { REDUK } \\
\text { REDUK }\end{array}$ \\
\hline C--- & CALL BASE (T D IECCH) & $\begin{array}{l}\text { REDUK } \\
\text { REDUK }\end{array}$ \\
\hline & IF(IECCH.NE. O) & REDUK \\
\hline & CALL RESIO $(T, D)$ & REDUK \\
\hline 200 & $Z=Z B+Z R$ & REDU \\
\hline & P1TO $=$ PR1TO + PB1TO & REDUK \\
\hline & $P 1 R 0=P R 1 R 0+P B 1 R O$ & REDUK \\
\hline & $S O=S B+S R+S I-S R E F$ & REDUK \\
\hline & $G \theta=G B+G R+G I-1 . D O-U R E F / T+S R E F$ & REDUK \\
\hline & $C V O=C V B+C V R+C V I$ & REDL \\
\hline & IF (P1RO .EQ. O.DO) THEN & REDUK \\
\hline & R1T0 $=-F N I$ & REDUK \\
\hline & $C P O=F N I$ & REDUK \\
\hline & $C P C=F N I$ & REDU \\
\hline & ELSE & REDL \\
\hline & $R 1 T 0=-P 1 T \theta / P 1 R 0$ & REDL \\
\hline & $C P O=C V O-P 1 T O * R 1 T O$ & REDU \\
\hline & $C P C=C P O / C V O$ & REDL \\
\hline & ENDIF & REDU \\
\hline 900 & $H O=S O+G O$ & REDUK \\
\hline & $R H=D * 1.03$ & REDUK \\
\hline & CALL TRANSP(T,RH,P1RO,P1TO,ETA, XLMB) & EDUK \\
\hline & RETURN & REDUK \\
\hline & END & REDI \\
\hline
\end{tabular}

\section{G.15 INR105.AQUA.FORT(REDUKE)}

SUBROUTINE REDUKE(T,D,IECCH) REDUKE

C CALCULATES THERMAL PROPERTIES OF THE WATER REDUKE

C IN REDUCED ( DIMENSIONLESS ) UNITS REDUKE

C D : DENSITY IN G/CM**3, RH : IN KG/M**3 94/12/08 REDUKE

C R1TO : REDUCED DENSITY DERIVATIVE $=(T /$ RHO $) \star(D R O / D T) \quad$ REDUKE

C P1TO, P1RO : REDUCED DERIVATIVES OF THE PRESSURE REDUKE

C HO, SO : REDUCED ENTHALPY RESP. ENTROPY, CPC : CP/CV REDUKE

C ETA, XLMB : VISCOSITY RESP. THERMAL CONDUCTIVITY REDUKE

C VQ : VAPOR QUALITY REDUKE

IMPLICIT REAL*8(A-H,O-Z) REDUKE

COMMON /AKONST/ WM, TC, DC, GASCON, G1, G2, GF, TZ, UREF, SREF, TLOW REDUKE

COMMON /TEMPO/ RT,B1,B2,B1T,B2T,B1TT,B2TT,TV,GI,SI,CVI REDUKE

COMMON /BASIF/ GB,SB,ZB,PB1TO,PB1RO,CVB REDUKE

COMMON /RESEF/ GR,SR,ZR,PR1TO,PR1RO,CVR REDUKE

COMMON /REDUF/ GO,SO,Z,P1TO,P1RO,CVO,CPO,ETA, XLMB, R1TO,CPC, HO, VQ REDUKE

COMMON /SATIF/ PS, TPS1T, TTPS2T,DL, DV, RL1TO, RV1TO, RHSL, PSL REDUKE

$=$, RHSV, PSV, SL, GL, PL1RO,PL1TO, CVL, ETL, XLL, PV1RO, PV1TO, CVV, ETV, XLV REDUKE

PARAMETER (RGAS $=4.615220+2)$ REDUKE

DATA ZERO $/ 0 . D 0 /$, FNI $/ 1.0+70 /$, UN $/ 1 . D 0 /$ REDUKE

CALL BASE $(T, D, I E C C H) \quad$ REDUKE 


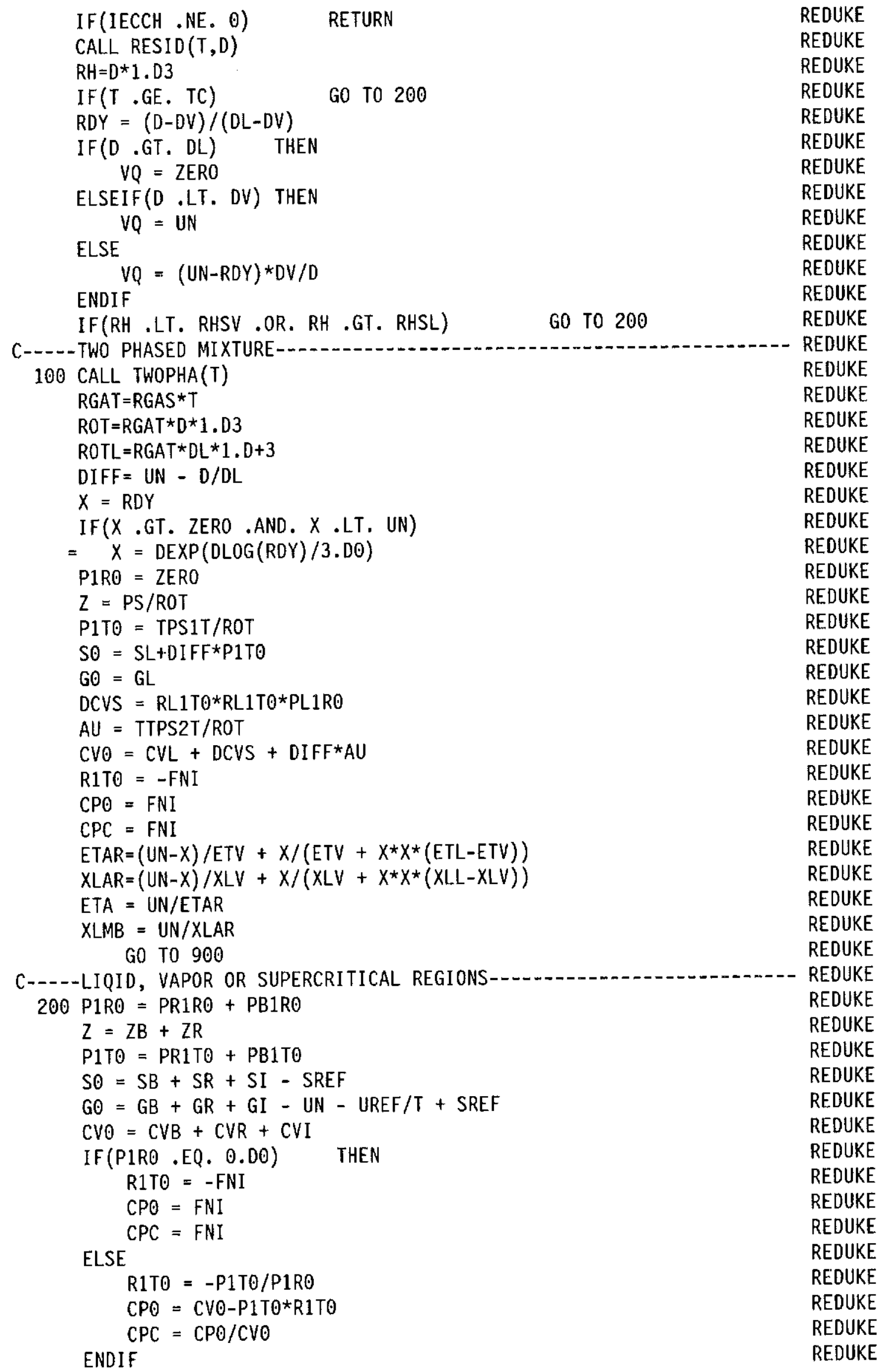




\begin{tabular}{lr} 
CALL TRANSP(T, RH,P1RO,P1TO, ETA, XLMB) & REDUKE \\
REDUKE \\
$900 H O=S O+G O$ & REDUKE \\
\hline & REDUKE \\
RETURN & REDUKE \\
END & REDUKE
\end{tabular}

\section{G.16 INR105.AQUA.FORT(HYDOR)}

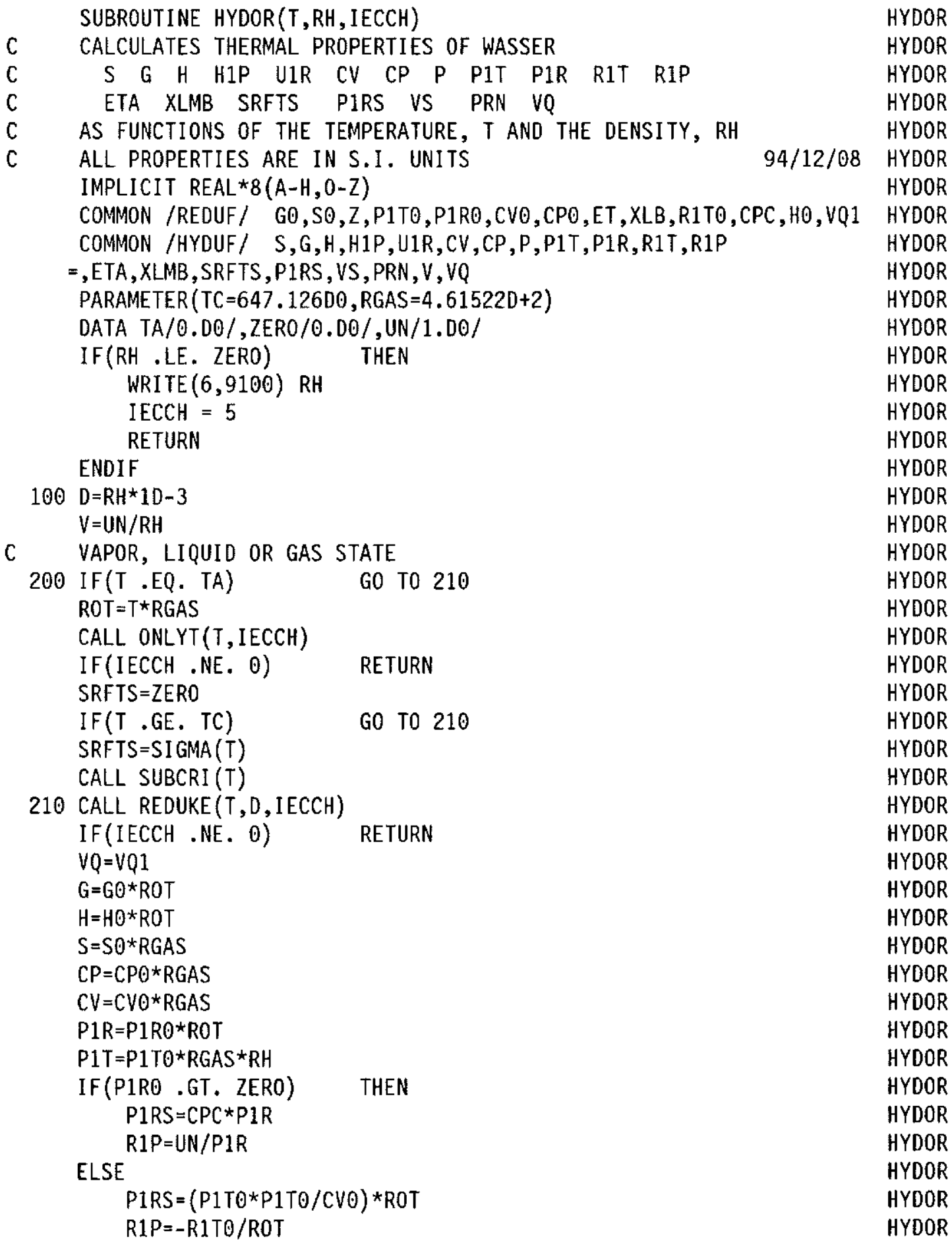


ENDIF

$U 1 R=(Z-P 1 T 0) * V * R O T$

$H 1 P=(U N+R 1 T O) * V$

$R 1 T=(R H / T) * R 1 T O$

$V S=S Q R T(P 1 R S)$

$P=Z \star R 0 T * R H$

$E T A=E T$

$X L M B=X L B$

$P R N=C P \star E T A / X L M B$

$999 \mathrm{TA}=\mathrm{T}$

RETURN

9100 FORMAT (13H DENSITY RH $=, \mathrm{G} 15.6,20 \mathrm{H} \mathrm{KG} / \mathrm{M}^{\star *} 3$ TO0 LOW $! /$ ) END
HYDOR

HYDOR

HYDOR

HYDOR

HYDOR

HYDOR

HYDOR

HYDOR

HYDOR

HYDOR

HYDOR

HYDOR

HYDOR 
The following pages list the programs, which are needed directly by the users to calculate the water properties.

\section{H.1 INR105.AQUA.FORT(WATER)}

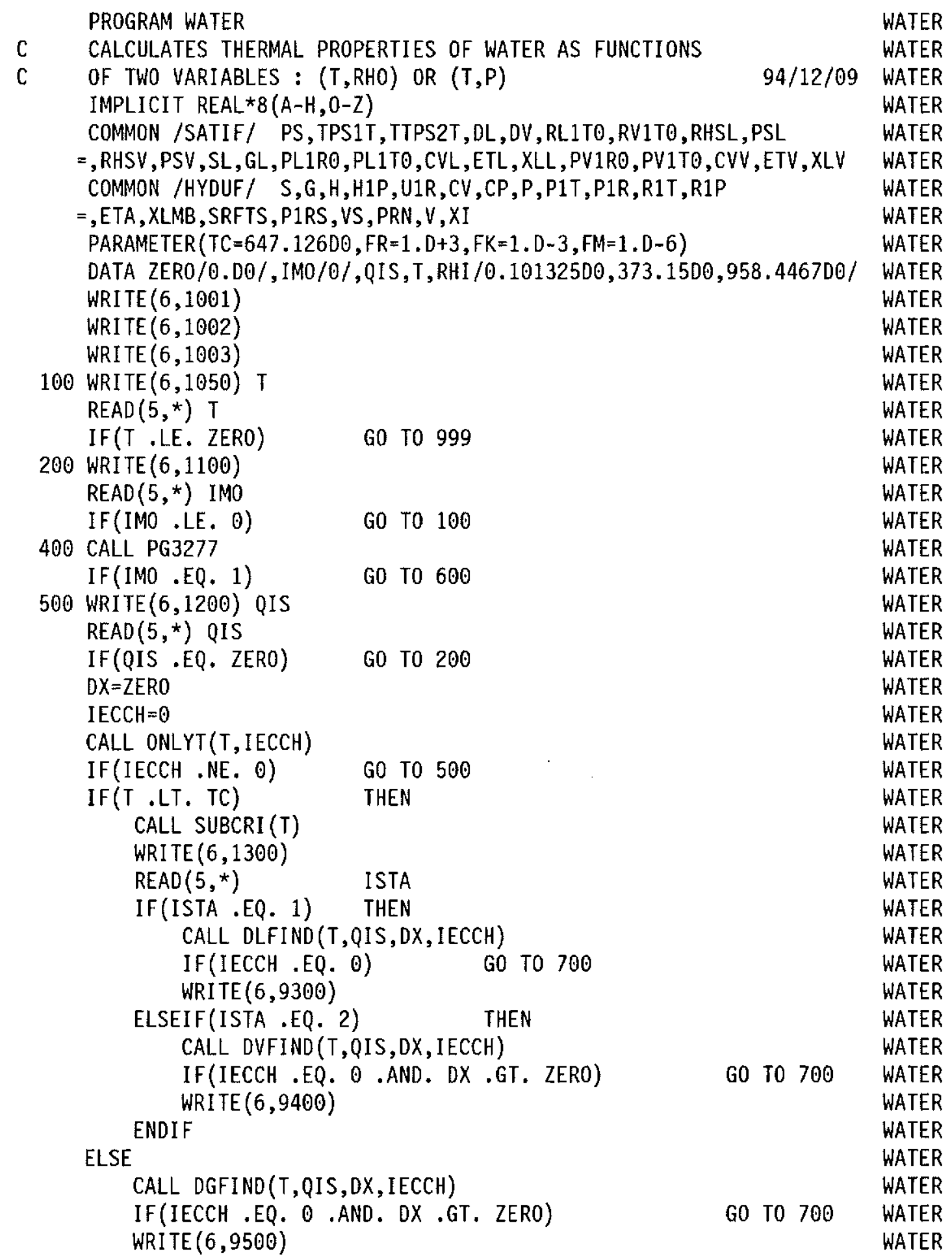


ENDIF

WATER

G0 TO 500

600 WRITE $(6,1400)$ RHI

$\operatorname{READ}(5, *)$ RHI

IF(RHI .LE. ZERO) GO TO 200

GO TO 800

IF (RHI .GT. ZERO)

$700 \mathrm{RHI}=\mathrm{DX} * \mathrm{FR}$

WATER

WATER

WATER

WATER

WATER

WATER

WATER

WATER

CALL HYDOR(T, RHI, IECCH)

IF(IECCH . NE. O) GO TO 300

WATER

$A=G-P / R H I$

WATER

$\mathrm{U}=\mathrm{H}-\mathrm{P} / \mathrm{RHI}$

WRITE $(6,1610) T, R H I, P \star F M$

WATER

IF(P1R . NE. ZER0) THEN

WATER

WRITE $(6,1620) P 1 R^{\star} F K, P 1 T * F M, R 1 T$

WATER

WRITE $(6,1630) \quad C V * F K, C P * F K, S^{\star} F K$

WATER

WRITE $(6,1640) U \star F K, H^{\star} F K, G * F K$

WATER

WRITE $(6,1650)$ U1R ${ }^{\star} F K, H 1 P, V S$

WATER

EL.SE

WRITE $(6,1622) \quad P 1 R * F K, P 1 T \star F M$

WRITE $(6,1632) \quad C V * F K, S \star F K$

WRITE $(6,1640) \quad U * F K, H * F K, G * F K$

WRITE $(6,1652) \cup I R \star F K, V S$

ENDIF

IF (T . LE. TC ) THEN

IF(XI .LT. 1.D0) WRITE $(6,1660)$ ETA,XLMB,SRFTS WATER

IF (XI .GE. 1.D0) WRITE $(6,1662)$ ETA, XLMB WATER

IF (P1R . NE. ZER0) WRITE $(6,1670)$ PRN,XI,PS*FM WATER

IF $(P 1 R$.EQ. ZER0) WRITE $(6,1674) X I, P S * F M \quad$ WATER

ELSE

WRITE $(6,1662)$ ETA, XLMB

WATER

WATER

WRITE $(6,1672)$ PRN

WATER

ENDIF

IF (T . LE. TC) THEN

WRITE $(6,1680) \quad D V * F R, R H S V, P S{ }^{*} F M \quad$ WATER

ENDIF

WRITE $(6,1682) \quad D L * F R, R H S L, P S L * F M$

WATER

WATER

WATER

WATER

GO TO 400

WATER

1001 FORMAT $(/ 2 \mathrm{H}+, 39(2 \mathrm{H}++) / 2 \mathrm{H}+, 77 \mathrm{X}, 1 \mathrm{H}+/ 2 \mathrm{H}+, 5 \mathrm{X}, 1 \mathrm{HW}, 5 \mathrm{X}, 1 \mathrm{HW}, 5 \mathrm{X}, 1 \mathrm{HA}, 5 \mathrm{X}$

$=, 7(1 \mathrm{HT}), 2 \mathrm{X}, 7(1 \mathrm{HE}), 2 \mathrm{X}, 6(1 \mathrm{HR}), 9 \mathrm{X}, 17 \mathrm{HSTATUS}: 94 / 12 / 09,4 \mathrm{X}, 1 \mathrm{H}+/ 2 \mathrm{H}+$

WATER

$=, 5 X, 1 \mathrm{HW}, 5 \mathrm{X}, 1 \mathrm{HW}, 4 \mathrm{X}, 3(1 \mathrm{HA}), 4 \mathrm{X}, 7(1 \mathrm{HT}), 2 \mathrm{X}, 7(1 \mathrm{HE}), 2 \mathrm{X}, 7(1 \mathrm{HR}), 29 \mathrm{X}, 1 \mathrm{H}+$ WATER

$=/ 2 \mathrm{H}+, 5 \mathrm{X}, 1 \mathrm{HW}, 5 \mathrm{X}, 1 \mathrm{HW}, 3 \mathrm{X}, 5 \mathrm{HAA} A \mathrm{AA}, 6 \mathrm{X}, 1 \mathrm{HT}, 5 \mathrm{X}, 1 \mathrm{HE}, 6 \mathrm{X}, 2 \mathrm{X}, 1 \mathrm{HR}, 5 \mathrm{X}, 1 \mathrm{HR}, 29 \mathrm{X}$ WATER

$=, 1 \mathrm{H}+/ 2 \mathrm{H}+, 5 \mathrm{X}, 7 \mathrm{HW} W \mathrm{~W}, 2 \mathrm{X}, 7 \mathrm{HAA}$ AA, 5X,1HT,5X,5HE EEE,4X,1HR, $1 \mathrm{X}$ WATER

$=, 5(1 H R), 29 X, 1 H+/ 2 H+, 5 X, 7 H W$ WWW W, 2X,1HA, 5X,1HA, 5X,1HT, 5X, 5HE EEE WATER

$=, 4 X, 1 H R, 1 X, 4(1 H R), 30 X, 1 H+/ 2 H+, 5 X, 7 H W W W W W W, 2 X, 7 H A$ AAA A, 5X,1HT WATER

$=, 5 X, 1 H E, 8 X, 5 H R \quad R R, 31 X, 1 H+/ 2 H+, 5 X, 7 H W W$ WW, $2 X, 7 H A$ AAA A, 5X,1HT WATER

$=, 5 X, 7(1 \mathrm{HE}), 2 \mathrm{X}, 6 \mathrm{HR} \quad \mathrm{RR}, 30 \mathrm{X}, 1 \mathrm{H}+/ 2 \mathrm{H}+, 5 \mathrm{X}, 1 \mathrm{HW}, 5 \mathrm{X}, 1 \mathrm{HW}, 2 \mathrm{X}, 1 \mathrm{HA}, 5 \mathrm{X}$ WATER

$=, 1 \mathrm{HA}, 5 \mathrm{X}, 1 \mathrm{HT}, 5 \mathrm{X}, 7(1 \mathrm{HE}), 2 \mathrm{X}, 1 \mathrm{HR}, 4 \mathrm{X}, 2 \mathrm{HRR}, 29 \mathrm{X}, 1 \mathrm{H}+)$ WATER

1002 FORMAT $(2 \mathrm{H}+, 77 \mathrm{X}, 1 \mathrm{H}+/ 2 \mathrm{H}+, 14 \mathrm{X}$

$=, 48$ HWATER CALCULATES THERMAL PROPERTIES OF THE WATER, 15X,1H+

$=/ 2 \mathrm{H}+, 19 \mathrm{X}, 39 \mathrm{HIN}$ THE LIQUID, VAPOR AND GASEOUS STATES, 19X, $1 \mathrm{H}+$

WATER

$=/ 2 \mathrm{H}+, 15 \mathrm{X}, 46 \mathrm{HEITHER}$ AS FUNCTIONS OF TEMPERATURE AND DENSITY, $16 \mathrm{X}$

WATER

WATER

$=, 1 \mathrm{H}+/ 2 \mathrm{H}+, 16 \mathrm{X}, 44 \mathrm{HOR}$ AS FUNCTIONS OF TEMPERATURE AND PRESSURE.

WATER

$=, 17 \mathrm{X}, 1 \mathrm{H}+$ )

WATER

WATER 
1003 FORMAT $(2 \mathrm{H}+, 77 \mathrm{X}, 1 \mathrm{H}+/ 2 \mathrm{H}+, 14 \mathrm{X}$

WATER

$=, 49 H T H E$ PROPERTIES CALCULATED ARE THE FOLLOWING ONES:

WATER

$=, 14 \mathrm{X}, 1 \mathrm{H}+/ 2 \mathrm{H}+, 77 \mathrm{X}, 1 \mathrm{H}+/ 2 \mathrm{H}+, 5 \mathrm{X}, 3 \mathrm{HT}=, 12 \mathrm{H}$ TEMPERATURE, $11 \mathrm{X}, 3 \mathrm{HP}=$

WATER

$=, 9 \mathrm{H}$ PRESSURE, $15 \mathrm{X}, 5 \mathrm{HRHO}=, 8 \mathrm{H}$ DENSITY, $6 \mathrm{X}, 1 \mathrm{H}+/ 2 \mathrm{H}+, 5 \mathrm{X}$

$=, 46 \mathrm{HCV} / \mathrm{CP}=$ ISOBARIC / ISOCHORIC HEAT CAPACITIES, 7X

$=, 11 \mathrm{HS}=$ ENTROPY $, 8 \mathrm{X}, 1 \mathrm{H}+/ 2 \mathrm{H}+, 5 \mathrm{X}, 18 \mathrm{HG}=\mathrm{GIBBS}$ FUNCTION, $8 \mathrm{X}$

WATER

WATER

$=, 10 H U=$ ENERGY $, 17 X, 12 \mathrm{HH}=$ ENTHALPY $, 7 X, 1 \mathrm{H}+/ 2 \mathrm{H}+, 5 \mathrm{X}$

$=, 22 H V E L . S=$ SONIC VELOCITY, $4 X, 23$ HSIGMA = SURFACE TENSION, $4 X$

WATER

WATER

$=, 15 H E T A=V I S C O S I T Y, 4 X, 1 H+/ 2 H+, 5 X$

$=, 29 H L A M B D A=$ THERMAL CONDUCTIVITY, 12X,22HPR. NR = PRANDTL NUMBER

$=, 9 X, 1 \mathrm{H}+/ 2 \mathrm{H}+, 5 \mathrm{X}, 20 \mathrm{HVAP} . \mathrm{QU}=\mathrm{M} \cdot \mathrm{VAP} / \mathrm{M} \cdot \mathrm{TOT}, 52 \mathrm{X}, 1 \mathrm{H}+$

$=/ 2 \mathrm{H}+, 77 \mathrm{X}, 1 \mathrm{H}+/ 2 \mathrm{H}+, 28 \mathrm{X}, 21 \mathrm{HFOR}$ MORE INFORMATION, $5 \mathrm{H} \Rightarrow$

$=, 19 H K$. THURNAY, T: $2477,4 \mathrm{X}, 1 \mathrm{H}+/ 2 \mathrm{H}+, 39(2 \mathrm{H}++) / / / \mathrm{l}$

1050 FORMAT (//29H ENTER TEMPERATURE ( IN K ) /,F10.3

$=, 31 \mathrm{H} /=: \quad($ STOP WTIH T $=0)$ )

1100 FORMAT( $/ 30 \mathrm{H}$ DO YOU WANT THE PROPERTIES AS

$=/ 5 X, 35 \mathrm{H} 1=$ TEMPERATURE-DENSITY FUNCTIONS

$=/ 5 X, 35 \mathrm{H} 2=$ TEMPERATURE-PRESSURE FUNCTIONS

$=, 15 X, 15 \mathrm{H}(\mathrm{STOP}$ WITH 0$)$ )

1200 FORMAT (//33H ENTER PRESSURE ( IN MPASCAL ) /,615.7

$=, 28 \mathrm{H} /=: \quad($ STOP WTIH $P=0) \quad$

1300 FORMAT (/36H LIQUID ( 1 ) OR VAPOR ( 2 ) STATE ?

$=, 17 \mathrm{H}(\theta=$ STOP $)=:$ )

1400 FORMAT $(/ / 31 \mathrm{H}$ ENTER DENSITY ( IN KG/M**3) $/$, G15.7

$=, 28 \mathrm{H} /=: \quad($ STOP WTIH RHO $=0))$

$1610 \mathrm{FORMAT}(/ / 4 \mathrm{H} \mathrm{T}=, \mathrm{F} 10.3,13 \mathrm{X}, 5 \mathrm{HRHO}=, \mathrm{G} 14.7,8 \mathrm{X}, 3 \mathrm{HP}=, \mathrm{G} 15.7$

$=/ 2 X, 2 \mathrm{H} \mathrm{K}, 25 \mathrm{X}, 7 \mathrm{HKG} / \mathrm{M} * * 3,20 \mathrm{X}, 7 \mathrm{HMPASCAL})$

1620 FORMAT (10H DP $/$ DRHO $=$, G13.6,4X,7HDP $/ D T=, G 13.6,7 X, 9 H D R H O / D T=$

$=, \mathrm{G} 14.6 / 2 \mathrm{X}, 6 \mathrm{H} \mathrm{KJ} / \mathrm{KG}, 21 \mathrm{X}, 9 \mathrm{HMPASCAL} / \mathrm{K}, 18 \mathrm{X}, 10 \mathrm{HKG} /(\mathrm{K} * \mathrm{M} * * 3)$

1622 FORMAT (1OH DP $/$ DRHO $=$, G13.6, 4X,7HDP $/ D T=, G 13.6,7 X, 9 H D R H O / D T=$

$=, 6 \mathrm{H}-\mathrm{INF} . / 2 \mathrm{X}, 6 \mathrm{H} \mathrm{KJ} / \mathrm{KG}, 21 \mathrm{X}, 9 \mathrm{HMPASCAL} / \mathrm{K}, 17 \mathrm{X}, 9 \mathrm{HKG} / \mathrm{M} \star * 3 / \mathrm{K})$

1630 FORMAT ( $5 \mathrm{H}$ CV $=, G 13.6,9 \mathrm{X}, 4 \mathrm{HCP}=, \mathrm{G} 13.6,10 \mathrm{X}, 3 \mathrm{HS}=, \mathrm{G} 14.6$

$=/ 3 \mathrm{X}, 9 \mathrm{HKJ} /(\mathrm{KG} \star \mathrm{K}), 17 \mathrm{X}, 9 \mathrm{HKJ} /(\mathrm{KG} \star \mathrm{K}), 18 \mathrm{X}, 9 \mathrm{HKJ} /(\mathrm{KG} \star \mathrm{K}))$

1632 FORMAT ( $5 \mathrm{H} \mathrm{CV}=, \mathrm{G} 13.6,9 \mathrm{X}, 4 \mathrm{HCP}=, 5 \mathrm{H}$ INF.,18X,3HS $=, \mathrm{G} 14.6$

$=/ 3 \mathrm{X}, 9 \mathrm{HKJ} /(\mathrm{KG} \star \mathrm{K}), 17 \mathrm{X}, 9 \mathrm{HKJ} /(\mathrm{KG} \star \mathrm{K}), 18 \mathrm{X}, 9 \mathrm{HKJ} /(\mathrm{KG} \star \mathrm{K}))$

1640 FORMAT ( $4 \mathrm{H} \mathrm{U}=, \mathrm{G} 14.6,9 \mathrm{X}, 3 \mathrm{HH}=, \mathrm{G} 14.6,10 \mathrm{X}, 3 \mathrm{HG}=, \mathrm{G} 14.6$

$=/ 2 X, 6 \mathrm{H} \mathrm{KJ} / \mathrm{KG}, 21 \mathrm{X}, 5 \mathrm{HKJ} / \mathrm{KG}, 22 \mathrm{X}, 5 \mathrm{HKJ} / \mathrm{KG})$

1650 FORMAT (1OH DU/DRHO $=$, G14.6, $3 X, 7 H D H / D P=, G 14.6,6 X$

$=$, 7HVEL.S $\left.=, G 13.6 / 2 X, 14 \mathrm{H} \mathrm{KJ} * M^{*} * 3 / \mathrm{KG} * \star 2,13 X, 7 \mathrm{HM} * \star 3 / \mathrm{KG}, 20 X, 5 \mathrm{HM} / \mathrm{SEC}\right)$

1652 FORMAT ( $10 \mathrm{H}$ DU/DRHO $=, \mathrm{G} 14.6,3 \mathrm{X}, 7 \mathrm{HDH} / \mathrm{DP}=, 6 \mathrm{H}-\mathrm{INF} ., 14 \mathrm{X}$

$=$, $7 \mathrm{HVEL} . \mathrm{S}=, \mathrm{G} 13.6 / 2 \mathrm{X}, 14 \mathrm{H} \mathrm{KJ} * \mathrm{M} * \star 3 / \mathrm{KG} * \star 2,13 \mathrm{X}, 7 \mathrm{HM} * \star 3 / \mathrm{KG}, 20 \mathrm{X}, 5 \mathrm{HM} / \mathrm{SEC})$

1660 FORMAT $(6 \mathrm{H}$ ETA $=, \mathrm{G} 13.6,8 \mathrm{X}, 8 \mathrm{HLAMBDA}=, \mathrm{G} 13.6,6 \mathrm{X}$

$=, 7 \mathrm{HSIGMA}=, \mathrm{G} 13.6 / 2 \mathrm{X}, 9 \mathrm{H} \mathrm{KG} / \mathrm{M} / \mathrm{SEC}, 18 \mathrm{X}, 5 \mathrm{HW} / \mathrm{M} / \mathrm{K}, 22 \mathrm{X}, 9 \mathrm{HKG} / \mathrm{SEC} \star \star 2)$

1662 FORMAT $(6 \mathrm{H}$ ETA $=, \mathrm{G} 13.6,8 \mathrm{X}, 8 \mathrm{HLAMBDA}=, \mathrm{G} 13.6$

$=/ 2 X, 9 \mathrm{H} \mathrm{KG} / \mathrm{M} / \mathrm{SEC}, 18 X, 5 \mathrm{HW} / \mathrm{M} / \mathrm{K})$

1670 FORMAT $(8 \mathrm{H}$ PR.NR $=$, G13.6, $6 \mathrm{X}, 8 \mathrm{HVAP} . \mathrm{QU}=, \mathrm{G} 13.6,6 \mathrm{X}, 4 \mathrm{HPS}=, \mathrm{G} 14.7$

$=/ 56 \times$, 7 HMPASCAL )

1672 FORMAT (8H PR.NR $=, 613.6 /$ )

1674 FORMAT (8H PR.NR $=, 6 \mathrm{H}-\mathrm{INF} ., 13 \mathrm{X}, 8 \mathrm{HVAP} . \mathrm{QU}=, \mathrm{G13} .6,6 \mathrm{X}, 4 \mathrm{HPS}=, \mathrm{G} 14.7$ $=/ 56 X, 7 H M P A S C A L)$

1680 FORMAT(7H RH.V = G14.7,6X,7HRH.SV $=$, G14.7,6X,6HP.SV $=$

$=, G 13.6 / 2 X, 8 \mathrm{H} \mathrm{KG} / \mathrm{M} * * 3,19 X, 7 \mathrm{HKG} / \mathrm{M} * * 3,20 X, 7 \mathrm{HMPASCAL})$

WATER

WATER

WATER

WATER

WATER

WATER

WATER

WATER

WATER

WATER

WATER

WATER

WATER

WATER

WATER

WATER

WATER

WATER

WATER

WATER

WATER

WATER

WATER

WATER

WATER

WATER

WATER

WATER

WATER

WATER

WATER

WATER

WATER

WATER

WATER

WATER

WATER

WATER

WATER

WATER

WATER

WATER

WATER

WATER

WATER

WATER

WATER

$\left.=, \mathrm{G} 13.6 / 2 \mathrm{X}, 8 \mathrm{H} \mathrm{KG} / \mathrm{M} * * 3,19 \mathrm{X}, 7 \mathrm{HKG} / \mathrm{M}^{\star *} 3,20 \mathrm{X}, 7 \mathrm{HMPASCAL}\right)$

WATER 
9300 FORMAT(/35H NO LIQUID STATE AT THIS PRESSURE ! )

WATER

9400 FORMAT (/35H NO VAPOR STATE AT THIS PRESSURE ! )

WATER

9500 FORMAT(/42H NO SUPERCRITICAL STATE AT THIS PRESSURE ! )

WATER

999 STOP

END

WATER

WATER

\section{H.2 INR105.AQUA.FORT(KAISOT)}

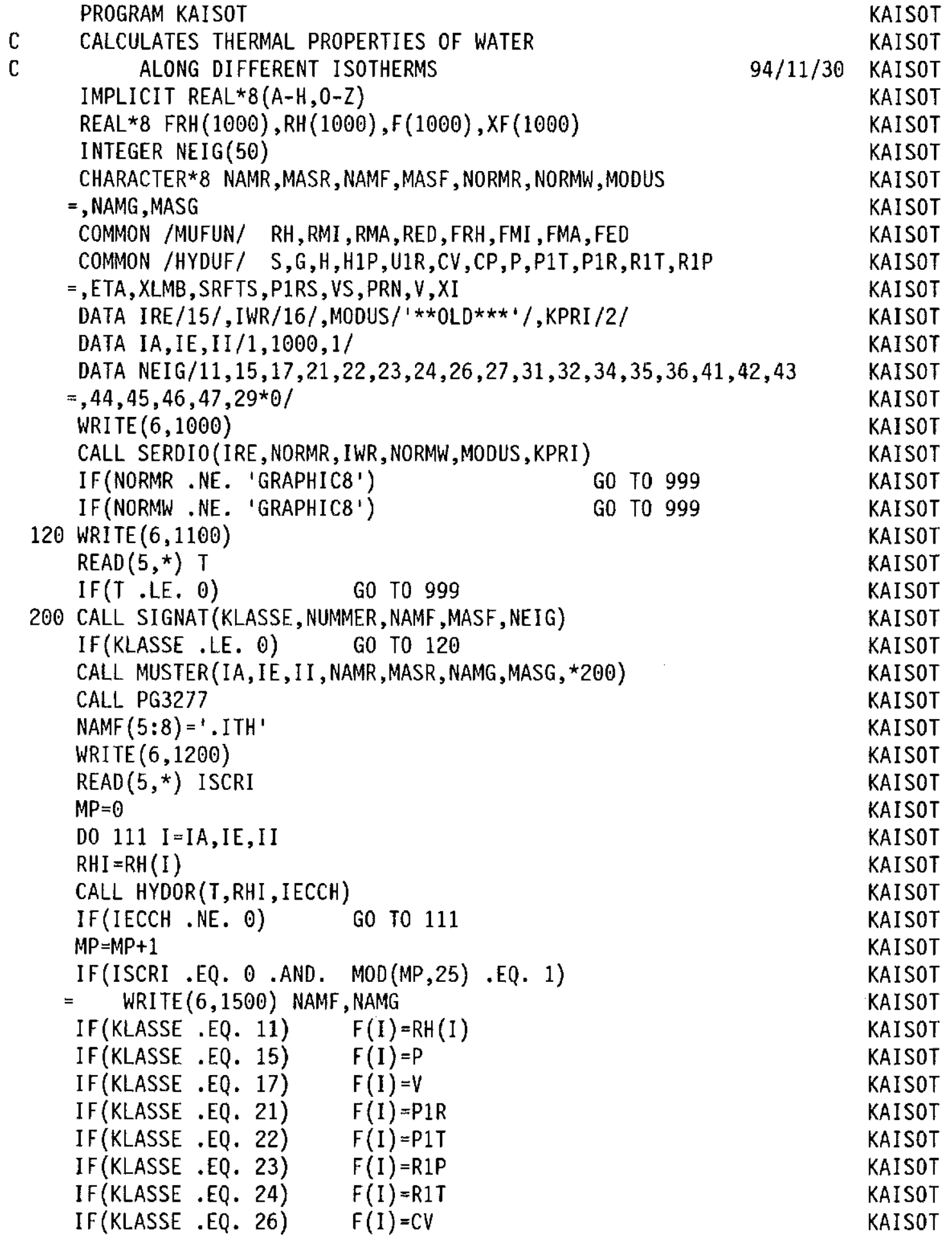




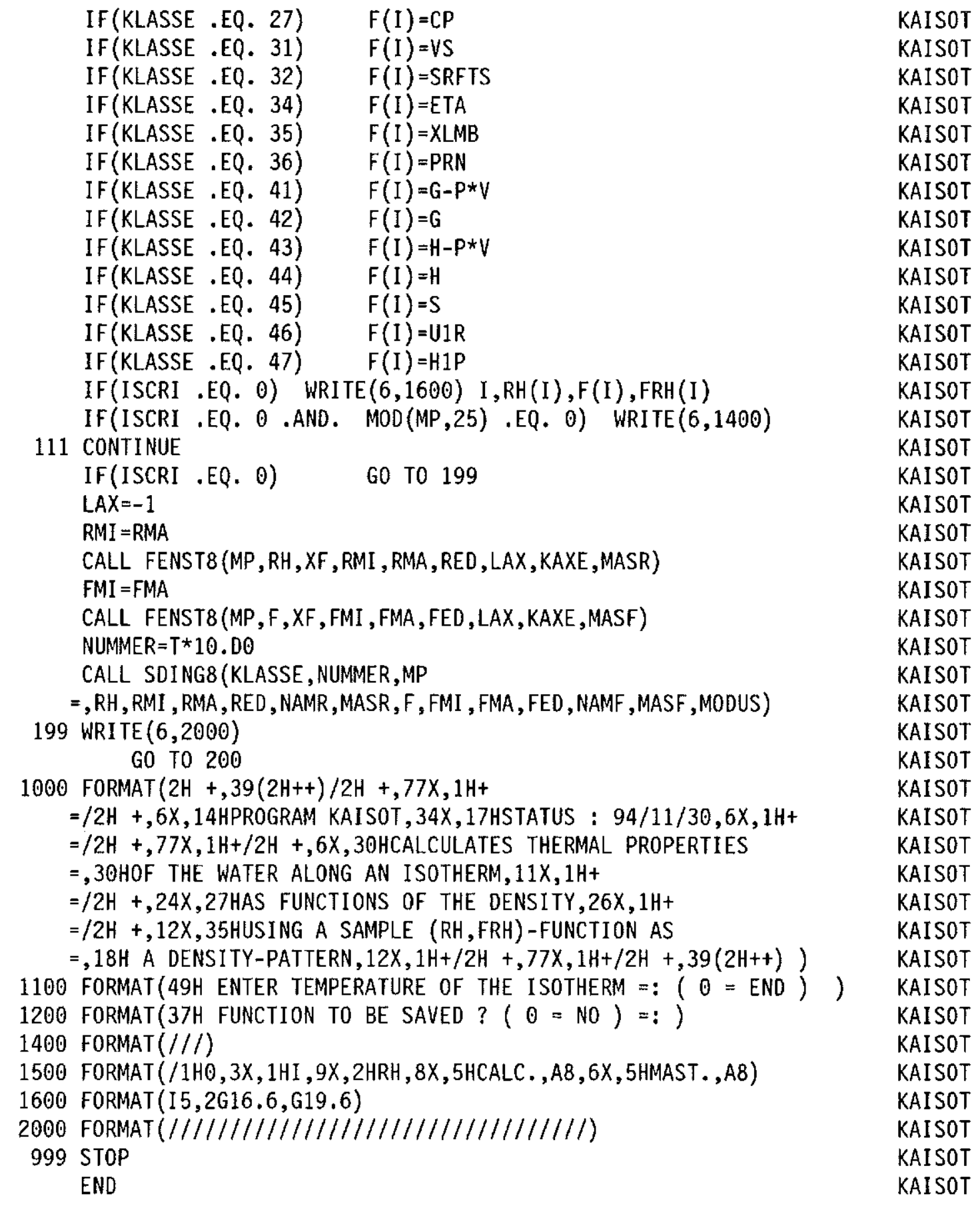

\section{H.3 INR105.AQUA.FORT(KAISOK)}

PROGRAM KAISOK

KAISOK

C CALCULATES THERMAL PROPERTIES OF WATER

KAISOK

C ALONG OIFFERENT ISOCHORES

IMPLICIT REAL*8 $(\mathrm{A}-\mathrm{H}, 0-\mathrm{Z})$

REAL*8 FX(1000), X(1000), $F(1000), X F(1000)$

KAISOK

INTEGER NEIG(50)

CHARACTER $^{*} 8$ NAMX, MASX, NAMF, MASF, NORMR, NORMW, MODUS

KAISOK

KAISOK

KAISOK

$=$, NAMG

KAISOK

KAISOK 
COMMON /MUFUN/ X,XMI, XMA, XED, FX, FMI, FMA, FED KAISOK

COMMON /HYDUF/ S, G,H,H1P,U1R,CV,CP,P,P1T,P1R,R1T,R1P KAISOT

$=, E T A, X L M B$, SRFTS, P1RS, VS , PRN, V, XI

DATA IRE $/ 15 /$, IWR $/ 16 /$, MODUS $/{ }^{* *}$ OLD $* * * 1 /$, KPRI $/ 2 /$

KAISOT

DATA IA, IE, II $/ 1,1000,1 /$

DATA NEIG/11,15,17,21,22,23,24,26,27, 31, 32, 34, 35, 36, 41, 42, 43

KAISOK

KAISOK

$=, 44,45,46,47,29 * 0 /$

KAISOT

KAISOT

WRITE $(6,1000)$

KAISOK

CALL SERDIO(IRE, NORMR, IWR, NORMW, MODUS, KPRI)

IF (NORMR .NE. 'GRAPHIC8')

G0 T0 999

IF (NORMW .NE. 'GRAPHIC8')

G0 T0 999

120 WRITE $(6,1100)$

$\operatorname{READ}(5, *)$ RHI

IF (RHI . LE. O)

GO TO 999

200 CALL SIGNAT (KLASSE, NUMMY, NAMF, MASF, NEIG)

KAISOK

KAISOK

KAISOK

KAISOK

KAISOK

KAISOK

KAISOK

IF(KLASSE . LE. O) GO TO 120

CALL MUSTER(IA, IE, I I , NAMX, MASX, NAMG , MASF * 200 )

KAISOK

CALL PG3277

$\operatorname{NAMF}(5: 8)={ }^{\prime} . \mathrm{ICH}^{\prime}$

WRITE $(6,1200)$

$\operatorname{READ}(5, *)$ ISCRI

$M P=0$

D0 $111 \mathrm{I}=\mathrm{IA}, \mathrm{IE}, \mathrm{II}$

KAISOK

KAISOK

KAISOK

KAISOK

KAISOK

KAISOK

KAISOK

$T=X(I)$

KAISOK

CALL HYDOR(T, RHI, IECCH)

IF(IECCH .NE. 0) GO TO 111

KAISOK

$M P=M P+1$

IF(ISCRI .EQ. 0 .ANO. MOD(MP,25) .EQ. 1)

KAISOK

KAISOK

$=\quad$ WRITE $(6,1500)$ NAMF, NAMG

IF (KLASSE .EQ. 15) $\quad F(I)=P$

IF (KLASSE .EQ. 17) $\quad F(I)=V$

IF(KLASSE .EQ. 21) $\quad F(I)=P 1 R$

KAISOK

KAISOK

KAISOK

KAISOK

KAISOK

IF (KLASSE .EQ. 22) $\quad F(I)=P 1 T$

KAISOK

IF (KLASSE .EQ. 23) $\quad F(I)=R 1 P$

KAISOK

IF (KLASSE .EQ. 24) $\quad F(I)=R 1 T$

KAISOK

IF (KLASSE .EQ. 26) $\quad F(I)=C V$

IF (KL_ASSE .EQ . 27) $\quad F(I)=C P$

KAISOK

KAISOK

IF (KLASSE .EQ. 31) $\quad F(I)=V S$

KAISOK

IF (KLASSE .EQ. 32) $\quad F(I)=$ SRFTS

KAISOK

IF (KLASSE .EQ. 34) $\quad F(I)=E T A$

KAISOK

IF (KLASSE .EQ. 35) $\quad F(I)=X L M B$

KAISOK

IF (KLASSE .EQ. 36) $\quad F(I)=P R N$

KAISOK

IF (KLASSE .EQ. 41) $\quad F(I)=G-P * V$

KAISOT

IF (KLASSE .EQ. 42) $\quad F(I)=G$

IF (KLASSE .EQ. 43) $\quad F(I)=H-P * V$

KAISOK

KAISOT

IF (KLASSE .EQ. 44) $\quad F(I)=H$

KAISOK

IF (KLASSE .EQ. 45) $\quad F(I)=S$

KAISOK

IF (KLASSE .EQ. 46) $\quad F(I)=U 1 R$

KAISOT

IF (KLASSE .EQ. 47) $\quad F(I)=H 1 P$

KAISOK

IF(ISCRI .EQ. 0$)$ WRITE $(6,1600)$ I , T,F(I), FX(I)

KAISOK

IF(ISCRI .EQ. 0 .AND. MOD(MP, 25) .EQ. O) WRITE $(6,1400)$

KAISOK

KAISOK

KAISOK

IF(ISCRI .EQ . O) GO TO 199

KAISOK

$X M I=X M A$

KAISOK 
CALL FENST8 (MP, X,XF, XMI , XMA, XED,LAX,KAXE,MASR) KAISOK

$F M I=F M A \quad$ KAISOK

CALL FENST8(MP, $F, X F, F M I, F M A, F E D, L A X, K A X E, M A S F) \quad$ KAISOK

NUMMER $=$ RHI

CALL SDING8 (KLASSE, NUMMER,MP

$=, X, X M I, X M A, X E D, N A M X, M A S X, F, F M I, F M A, F E D, N A M F, M A S F, M O D U S) \quad$ KAISOK

199 WRITE $(6,2000)$

GO TO 200

KAISOK

KAISOK

KAISOK

1000 FORMAT $(2 \mathrm{H}+, 39(2 \mathrm{H}++) / 2 \mathrm{H}+, 77 \mathrm{X}, 1 \mathrm{H}+$

KAISOK

$=/ 2 \mathrm{H}+, 6 \mathrm{X}, 14 \mathrm{HPROGRAM}$ KAISOK,34X,17HSTATUS : $94 / 11 / 30,6 \mathrm{X}, 1 \mathrm{H}+$

KAISOK

$=/ 2 \mathrm{H}+, 77 \mathrm{X}, 1 \mathrm{H}+/ 2 \mathrm{H}+, 6 \mathrm{X}, 30 \mathrm{HCALCULATES}$ THERMAL PROPERTIES

KAISOK

$=, 30 H O F$ THE WATER ALONG AN ISOCHORE, $11 X, 1 \mathrm{H}+$

KAISOK

$=/ 2 \mathrm{H}+, 23 \mathrm{X}, 31 \mathrm{HAS}$ FUNCTIONS OF THE TEMPERATURE, $23 \mathrm{X}, 1 \mathrm{H}+$

KAISOK

$=22 \mathrm{H}$ A TEMPERATURE-PATTERN $10 \mathrm{X}, 1 \mathrm{H}+12 \mathrm{H}+, 77 \mathrm{X}, 1 \mathrm{H}+12$

KAISOK

1100 FORMAT(1H1/45H ENTER DENSITY OF THE ISOCHORE $=:(0=$ END $)$ ) KAISOK

1200 FORMAT (37H FUNCTION TO BE SAVED ? $(\theta=$ NO $)=:$ ) KAISOK

1400 FORMAT $(/ / /) \quad$ KAISOK

1500 FORMAT ( $/ 1 H 0,3 X, 1 H I, 5 X, 1 H T, 8 X, 5 H C A L C ., A 8,6 X, 5 H M A S T ., A 8) \quad$ KAISOK

1600 FORMAT (I5, F10.3, G16.6,G19.6)

$2000 \operatorname{FORMAT}(/ / / / / / / / / / / / / / / / / / / / / / / / / / / / / / /)$

KAISOK

KAISOK

KAISOK

END

KAISOK

Note: The routine PG3277 in the above programs serves only to clear the screen for a new batch of output and can be omitted, or replaced with an alternative routine. 
The following programs serve to calculate different water properties using the H.G.K.-routines and the IAPS-82 equations (3.0, "Transport properties of the water." on page 9 ).

\section{I.1 INR105.AQUA.FORT(HGKSPN)}

\begin{tabular}{|c|c|c|}
\hline & PROGRAM HGKSPN & HGKSPN \\
\hline C & CALCULATES THE SPINODALS OF THE WATER & HGKSPN \\
\hline \multirow[t]{16}{*}{ C } & USING THE HGK-CODE & HGKSPN \\
\hline & IMPLICIT REAL*8(A-H,0-Z) & HGKSPN \\
\hline & $R E A L * 8 \quad P(1000), F(1000), R(1000), W(1000)$ & HGKSPN \\
\hline & $R E A L * 8 \quad Y(3), F Y(3)$ & HGKSPN \\
\hline & CHARACTER $\star 8$ NORMR, NORMW, MODUS & HGKSPN \\
\hline & $=$, NAMW , MASW, NAMR, MASR, NAMP, MASP & HGKSPN \\
\hline & COMMON /MUFUN/ W, WMI, WMA, WED ,F, FMI, FMA, FED & HGKSPN \\
\hline & COMMON /REDUF/ GO,SO,Z,P1TO,P1RO,CVO,CPO,ETA,XLMB, R1TO,CPC, HO & HGKSPN \\
\hline & COMMON /SATIF/ PS,TPS1T,TTPS2T,DL,DV,RL1TO,RV1T0,RHSL,PSL. & HGKSPN \\
\hline & $=$, RHSV, PSV ,SL, GL, PL1RO,PL1TO,CVL,ETL, XLL, PV1RO,PV1TO,CVV, EV, XLV & HGKSPN \\
\hline & PARAMETER $(T C=647.126 \mathrm{DO}, \mathrm{RHC}=0.322 \mathrm{D} 3, \mathrm{RGAS}=4.61522 \mathrm{D}+2, \mathrm{TCN}=646.3 \mathrm{DO})$ & HGKSPN \\
\hline & DATA IRE $/ 15 /$, IWR $/ 16 /$, MODUS $/ 1 * \star 0 L D * \star \star 1 /$, KPRI $/ 2 /$ & HGKSPN \\
\hline & DATA IA, IE, II $/ 1,1000,1 /, \mathrm{IP} / 0 /$ & HGKSPN \\
\hline & DATA ITE $/ 10 /$, ZERO $/ 0 . D 0 /$, PRMO/1.D-10/,RHMAX/1.2D3/ & HGKSPN \\
\hline & DATA NAMW/' T $1 /$ & HGKSPN \\
\hline & $K \quad$ ', 'KG/M**3',' PASCAL'/ & HGKSPN \\
\hline \multirow{12}{*}{106} & 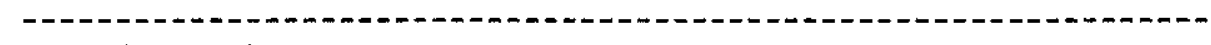 & HGKSPN \\
\hline & WRITE $(6,1000)$ & HGKSPN \\
\hline & CALL SERDI0(IRE,NORMR,IWR,NORMW,MODUS,KPRI) & HGKSPN \\
\hline & IF(NORMR .NE. 'GRAPHIC8' .OR. NORMW .NE. 'GRAPHIC8') G0 T0 999 & HGKSPN \\
\hline & WRITE $(6,1100)$ IP & HGKSPN \\
\hline & $\operatorname{READ}(5, *)$ IP & HGKSPN \\
\hline & $\operatorname{IPP}=\operatorname{MIN}(\mathrm{IPP}, 2)$ & HGKSPN \\
\hline & IF (IP .LE. 0) & HGKSPN \\
\hline & CALL MUSTER(I A, IE, I I , NAMT, MAST, NAMP, MASP, * 100 ) & HGKSPN \\
\hline & CALL PG3277 & HGKSPN \\
\hline & WRITE $(6,1200)$ & HGKSPN \\
\hline & $\operatorname{READ}\left(5,{ }^{*}\right)$ ISCRI & HGKSPN \\
\hline \multirow[t]{4}{*}{ C } & DENSITY ITERATION FOR THE "DP/DRH $=0 "$ POINT & HGKSPN \\
\hline & $M P=0$ & HGKSPN \\
\hline & D0 $211 \mathrm{~J}=\mathrm{IA}, \mathrm{IE}, \mathrm{II}$ & HGKSPN \\
\hline & $T=W(J)$ & HGKSPN \\
\hline \multirow[t]{10}{*}{ C } & IF (T .GT. TCN $)$ & HGKSPN \\
\hline & CALL ONLYT (T, IECCH) & HGKSPN \\
\hline & CALL SUBCRI (T) & HGKSPN \\
\hline & RED $=2.0-2 \star R H C$ & HGKSPN \\
\hline & IF (IP .EQ. 1) & HGKSPN \\
\hline & $N A M R='$ RHSL. HGK' & HGKSPN \\
\hline & NAMP = 'PSPL. HGK' & HGKSPN \\
\hline & $\mathrm{RHL}=\mathrm{DL} * 1 . \mathrm{D} 3$ & HGKSPN \\
\hline & RHI $=M I N(1.25 D 0 * R H L, R H M A X)$ & HGKSPN \\
\hline & RED $=A B S(R E D)$ & HGKSPN \\
\hline
\end{tabular}




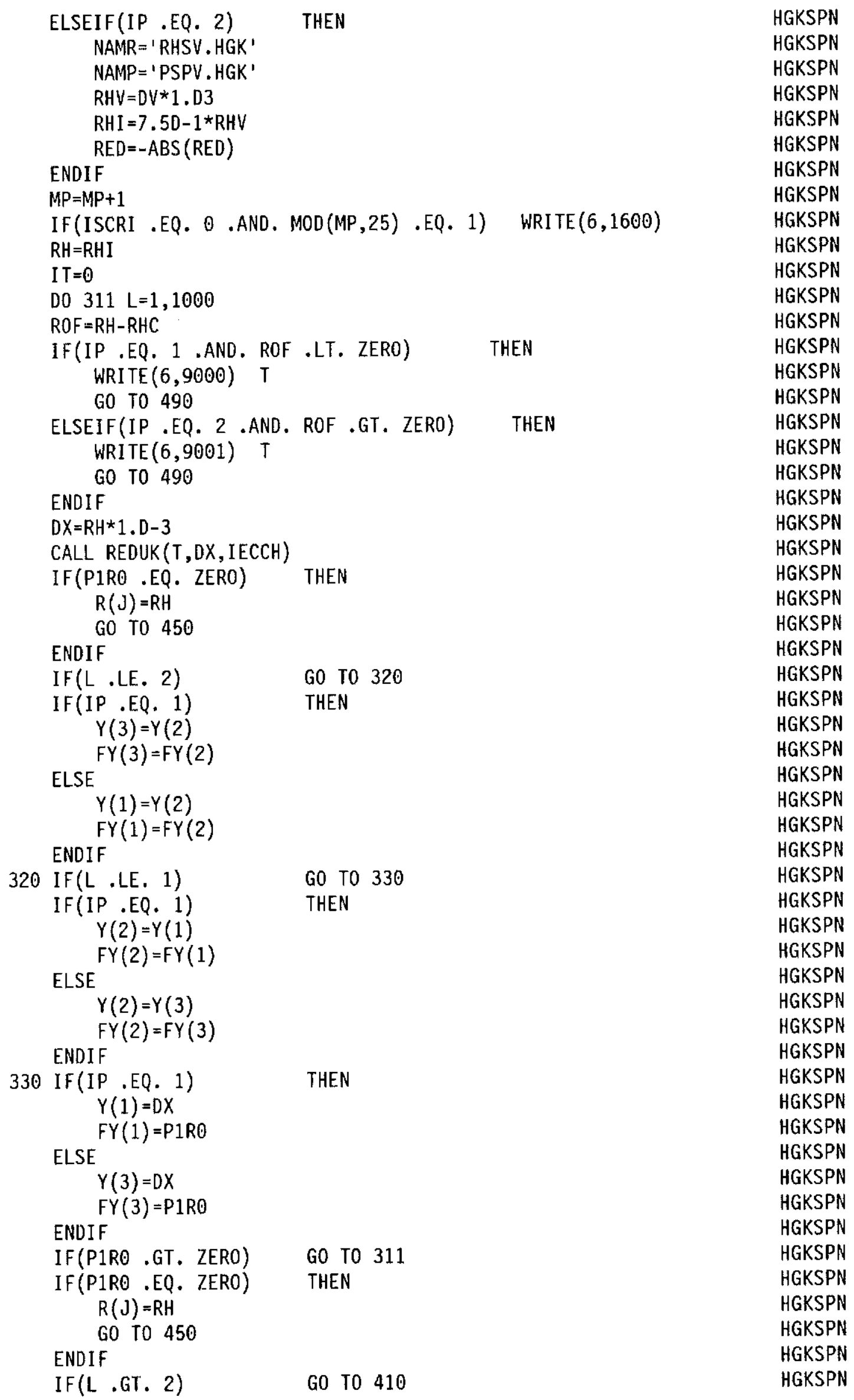




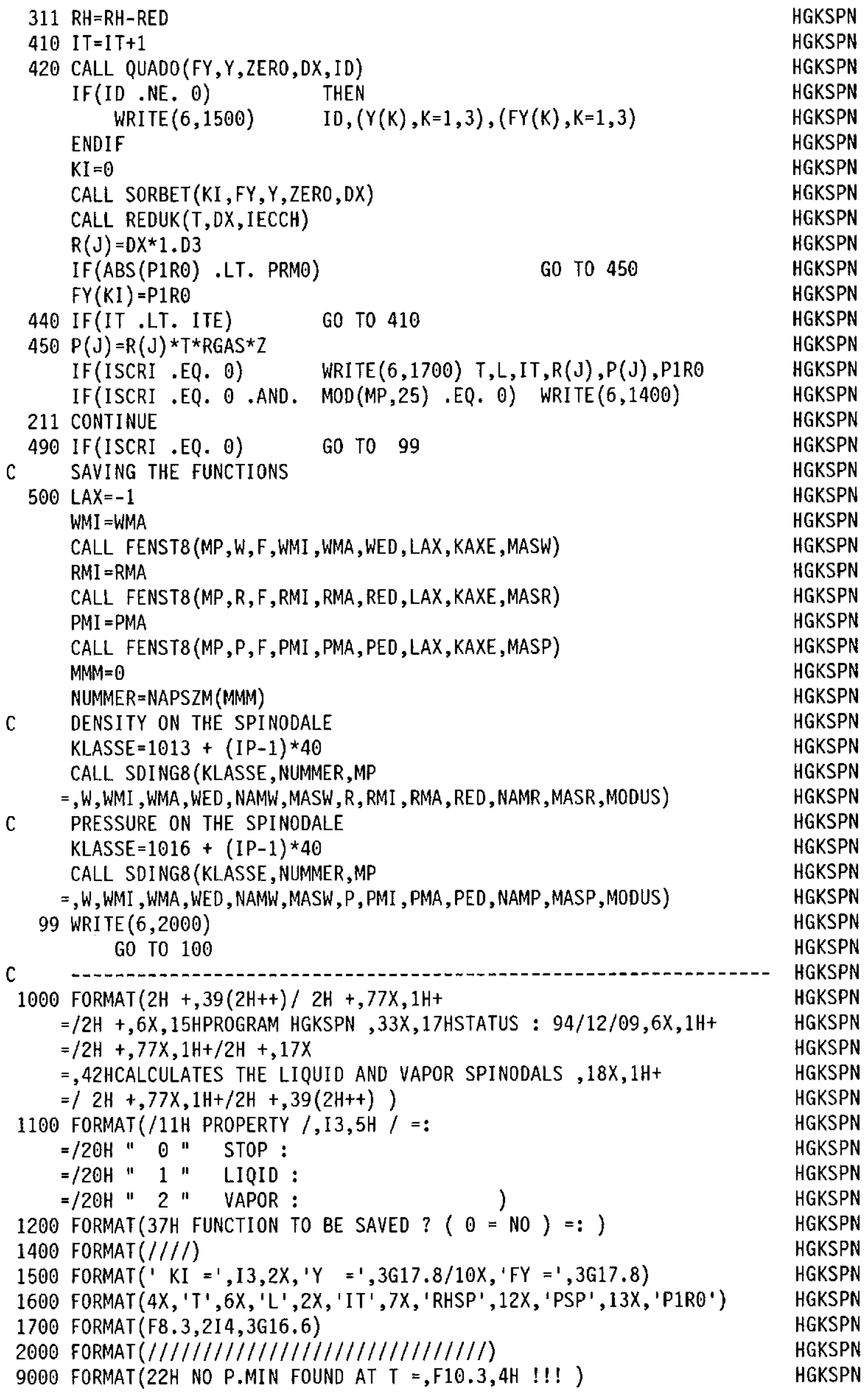




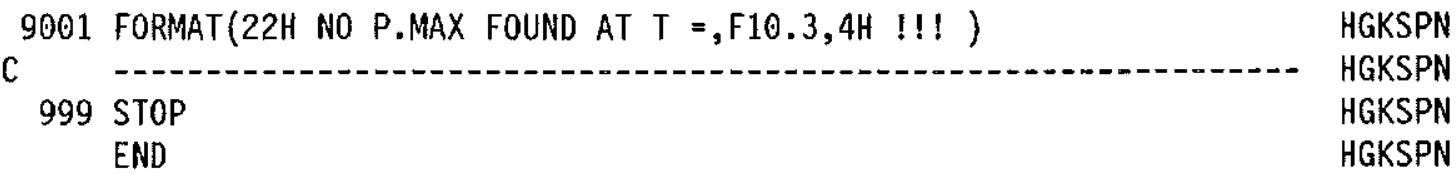

\section{I.2 INR105.AQUA.FORT(HGKSAT)}

\begin{tabular}{|c|c|c|}
\hline & PROGRAM HGKSAT & HGKSAT \\
\hline C & CALCULATES SATURATED PROPERTIES OF THE WATER & HGKSAT \\
\hline \multirow[t]{15}{*}{ C } & USING THE HGK-CODE & HGKSAT \\
\hline & IMPLICIT REAL*8(A-H,O-Z) & HGKSAT \\
\hline & INTEGER NEIG(50) & HGKSAT \\
\hline & REAL*8 X(1000), TS $(1000), F L(1000), F V(1000), X F(1000), F X(1000)$ & HGKSAT \\
\hline & CHARACTER $* 8$ NAMT, MAST, NAMF, MASF, NORMR, NORMW, MODUS, NAMP, MASP, NAMV & HGKSAT \\
\hline & COMMON /MUFUN/ X,XMI, XMA, XED, FX,FMI,FMA, FED & HGKSAT \\
\hline & COMMON /ACONST/WM, GASCON, TZ,AA,ZB,DZB, YB, UREF, SREF & HGKSAT \\
\hline & COMMON /FCTS/ AD, GD,SD,UD, HD,CVD,CPD,DPDT,DVDT, CJTT, CJTH,Z,DPDD & HGKSAT \\
\hline & DATA IRE $/ 15 /$, IWR $/ 16 /$, MODUS $/ 1 * * 0 L D * \star * 1 /, \mathrm{KPRI} / 2 /, \mathrm{IA}, \mathrm{IE}, \mathrm{II} / 1,1000,1 /$ & HGKSAT \\
\hline & $=$, TAUS $/ 1.03 /$ & HGKSAT \\
\hline & DATA NEIG $/ 1,11,15,21,22,26,27,42,44,45,40 * 0 /$ & HGKSAT \\
\hline & WRITE $(6,1000)$ & HGKSAT \\
\hline & CALL SERDIO(IRE, NORMR, IWR, NORMW, MODUS, KPRI) & HGKSAT \\
\hline & IF(NORMR .NE. 'GRAPHIC8') $\quad$ GO TO 999 & HGKSAT \\
\hline & IF (NORMW . NE. 'GRAPHIC8') & HGKSAT \\
\hline \multirow[t]{3}{*}{100} & WRITE $(6,1100)$ & HGKSAT \\
\hline & $\operatorname{READ}(5, *)$ NEP & HGKSAT \\
\hline & IF (NEP .LE. 0) & HGKSAT \\
\hline \multirow[t]{3}{*}{200} & CALL SIGNAT (KLASSE, NUMMER, NAMF, MASF, NEIG) & HGKSAT \\
\hline & IF(KLASSE .LE. 0) G0 TO 100 & HGKSAT \\
\hline & CALL MUSTER(IA, IE, II , NAMT, MAST, NAMP, MASP, *200) & HGKSAT \\
\hline \multirow[t]{23}{*}{220} & CALL PG3277 & HGKSAT \\
\hline & WRITE $(6,1200)$ & HGKSAT \\
\hline & $\operatorname{READ}(5, *)$ ISCRI & HGKSAT \\
\hline & $\operatorname{NAMF}(5: 8)={ }^{\prime}-\mathrm{HGK}^{\prime}$ & HGKSAT \\
\hline & NAMV $=$ NAMF & HGKSAT \\
\hline & $M P=0$ & HGKSAT \\
\hline & $J=0$ & HGKSAT \\
\hline & $D L=1.00$ & HGKSAT \\
\hline & $D V=5.0-3$ & HGKSAT \\
\hline & RGAS $=$ GASCON*TAUS & HGKSAT \\
\hline & DO 111 I=IA, IE, I I & HGKSAT \\
\hline & $J=J+1$ & HGKSAT \\
\hline & IF(ISCRI .EQ. 0 .AND. $\operatorname{MOD}(J, 25)$.EQ. 1) & HGKSAT \\
\hline & $=\quad$ WRITE $(6,1500)$ NAMF, NAMV & HGKSAT \\
\hline & $T=x(I)$ & HGKSAT \\
\hline & $T S(j)=T$ & HGKSAT \\
\hline & CALL PCORR $(T, P, D L, D V)$ & HGKSAT \\
\hline & IF(KLASSE .EQ. 1) & HGKSAT \\
\hline & $F L(J)=P * 1 . D+6$ & HGKSAT \\
\hline & $F V(J)=P S(T) \star 1 . D 6$ & HGKSAT \\
\hline & GO TO 110 & HGKSAT \\
\hline & ENDIF & HGKSAT \\
\hline & IF (KLASSE & HGKSAT \\
\hline
\end{tabular}




\begin{tabular}{|c|c|c|}
\hline $\mathrm{FL}(\mathrm{J})=\mathrm{DL} *$ TAUS & & HGKSAT \\
\hline$F V(J)=D V *$ TAUS & & HGKSAT \\
\hline GO TO 110 & & HGKSAT \\
\hline ENDIF & & HGKSAT \\
\hline ROT $=$ RGAS*T & & HGKSAT \\
\hline$Z D U M=B A S E(D L, T)$ & & HGKSAT \\
\hline CALL $Q Q(T, D L)$ & & HGKSAT \\
\hline CALL THERM(DL, T) & & HGKSAT \\
\hline IF (KLASSE .EQ. 15) & $F L(J)=Z * R 0 T * D L * T A U S$ & HGKSAT \\
\hline IF (KLASSE .EQ. 21) & $F L(\mathrm{~J})=D P D 0^{*}$ TAUS & HGKSAT \\
\hline IF(KLASSE .EQ. 22) & $\mathrm{FL}(\mathrm{J})=\mathrm{DPDT} * 1 . \mathrm{D} 6$ & HGKSAT \\
\hline IF(KLASSE .EQ. 26) & $\mathrm{FL}(\mathrm{J})=\mathrm{CVD}$ *RGAS & HGKSAT \\
\hline IF(KLASSE .EQ. 27) & $F L(J)=C P D * R G A S$ & HGKSAT \\
\hline IF(KLASSE .EQ. 42) & $\mathrm{FL}(\mathrm{J})=\mathrm{GO} * \mathrm{R} 0 T$ & HGKSAT \\
\hline IF (KLASSE .EQ. 44) & $F L(J)=H D * R O T$ & HGKSAT \\
\hline IF(KLASSE .EQ. 45) & $F L(d)=S D * R G A S$ & HGKSAT \\
\hline$Z D U M=B A S E(D V, T)$ & & HGKSAT \\
\hline CALL $Q Q(T, D V)$ & & HGKSAT \\
\hline CALL THERM(DV,T) & & HGKSAT \\
\hline IF (KLASSE .EQ. 15) & $F V(J)=Z * R O T * D V *$ TAUS & HGKSAT \\
\hline IF(KLASSE .EQ. 21) & $\mathrm{FV}(\mathrm{J})=\mathrm{DPDD} *$ TAUS & HGKSAT \\
\hline IF (KLASSE .EQ. 22) & $\mathrm{FV}(\mathrm{J})=0 \mathrm{PD} \top^{\star} 1.06$ & HGKSAT \\
\hline IF(KLASSE .EQ. 26) & $F V(J)=C V D \star R G A S$ & HGKSAT \\
\hline IF(KLASSE .EQ. 27) & $F V(J)=C P D \star R G A S$ & HGKSAT \\
\hline IF (KLASSE .EQ. 42) & $\mathrm{FV}(\mathrm{J})=\mathrm{GD} * \mathrm{R} 0 \mathrm{~T}$ & HGKSAT \\
\hline IF(KLASSE .EQ. 44) & $F V(J)=H D * R 0 T$ & HGKSAT \\
\hline IF(KLASSE .EQ. 45) & $F V(J)=S D * R G A S$ & HGKSAT \\
\hline 0 IF(ISCRI .EQ. O) WRI & $\operatorname{TE}(6,1700) \mathrm{J}, \mathrm{T}, \mathrm{FX}(\mathrm{I}), \mathrm{FL}(\mathrm{J}), \mathrm{FV}(\mathrm{J})$ & HGKSAT \\
\hline IF (ISCRI .EQ. 0 .AND. & $\operatorname{MOD}(J, 25)$.EQ. 0) WRITE $(6,1400)$ & HGKSAT \\
\hline CONTINUE & & HGKSAT \\
\hline$M P=J$ & & HGKSAT \\
\hline IF(ISCRI .EQ. O) & G0 T0 199 & HGKSAT \\
\hline$L A X=-1$ & & HGKSAT \\
\hline$X M I=X M A$ & & HGKSAT \\
\hline CALL FENST8(MP, $X, X F, X N$ & $I$, XMA, XED, LAX, KAXE, MASX) & HGKSAT \\
\hline KLASSE $=K L A S S E+1000$ & & HGKSAT \\
\hline$F M I=F M A$ & & HGKSAT \\
\hline CALL FENST8(MP,FL,XF, & MI , FMA, FED, LAX, KAXE, MASF) & HGKSAT \\
\hline CALL SDING8(KLASSE, NUN & MER,MP & HGKSAT \\
\hline$=, X, X M I, X M A, X E D, N A M T, M A$ & ST, FL, FMI , FMA, FED, NAMF, MASF, MODUS) & HGKSAT \\
\hline IF(KLASSE .EQ. 1001) & THEN & HGKSAT \\
\hline$K L A S S V=1002$ & & HGKSAT \\
\hline ELSE & & HGKSAT \\
\hline$K L A S S V=K L A S S E+40$ & & HGKSAT \\
\hline ENDIF & & HGKSAT \\
\hline$F M I=F M A$ & & HGKSAT \\
\hline CALL FENST8(MP,FV,XF, & MI, FMA, FED, LAX, KAXE, MASF) & HGKSAT \\
\hline CALL SDING8(KLASSV, NUN & MER,MP & HGKSAT \\
\hline$=, X, X M I, X M A, X E D, N A M T, M A$ & ST, FV, FMI , FMA , FED, NAMV ,MASF, MODUS) & HGKSAT \\
\hline 9 WRITE $(6,2000)$ & & HGKSAT \\
\hline GO TO 200 & & HGKSAT \\
\hline FORMAT $(2 \mathrm{H}+, 39(2 \mathrm{H}++) / 2$ & $\mathrm{H}+, 77 \mathrm{X}, 1 \mathrm{H}+/ 2 \mathrm{H}+, 6 \mathrm{X}, 14 \mathrm{HPROGRAM} \mathrm{HGKSAT}$ & HGKSAT \\
\hline$=, 34 X, 17$ HSTATUS $: 94 / 07$ & $/ 29,6 \mathrm{X}, 1 \mathrm{H}+/ 2 \mathrm{H}+, 77 \mathrm{X}, 1 \mathrm{H}+/ 2 \mathrm{H}+, 14 \mathrm{X}$ & HGKSAT \\
\hline$=, 48 \mathrm{HCALCULATES}$ THE SAT & URATED PROPERTIES OF THE WATER, $15 \mathrm{X}, 1 \mathrm{H}+$ & HGKSAT \\
\hline$=/ 2 \mathrm{H}+, 13 \mathrm{X}, 51 \mathrm{HAS}$ FUNCT & IONS OF THE TEMPERATURE WITH THE H.G.K- & HGKSAT \\
\hline
\end{tabular}


$=, 13 X, 1 \mathrm{H}+/ 2 \mathrm{H}+, 7 \mathrm{X}, 30 \mathrm{HUSING}$ A SAMPLE $(\mathrm{T}, \mathrm{P})$-FUNCTION

HGKSAT

$=, 33$ HAS A TEMPERATURE/PRESSURE-PATTERN, $7 \mathrm{X}, 1 \mathrm{H}+$

HGKSAT

$=/ 2 \mathrm{H}+, 77 \mathrm{X}, 1 \mathrm{H}+/ 2 \mathrm{H}+, 39(2 \mathrm{H}++))$

1100 FORMAT (31H NEW PROPERTY ? $(0=$ STOP $)=:$ )

HGKSAT

1200 FORMAT ( 37 HUNCTION TO BE SAVED ? $(\theta=$ NO $)=$ : )

HGKSAT

1400 FORMAT $(/ / / /)$

1500 FORMAT ( $1 H 0,2 X, 1 H \mathrm{H}, 8 \mathrm{X}, 2 \mathrm{HT}, 8 \mathrm{X}, 2 \mathrm{HP}, 11 \mathrm{X}, \mathrm{A8}, 8 \mathrm{X}, \mathrm{A} 8)$

HGKSAT

HGKSAT

HGKSAT

1700 FORMAT (I $4, \mathrm{~F} 12.3,3 \mathrm{G} 16.8)$

2000 FORMAT $(/ / / / / / / / / / / / / / / / / / / / / / / / / / / / /)$

999 STOP

END

HGKSAT

HGKSAT

HGKSAT

HGKSAT

\section{I.3 INR105.AQUA.FORT(TRNSAT)}

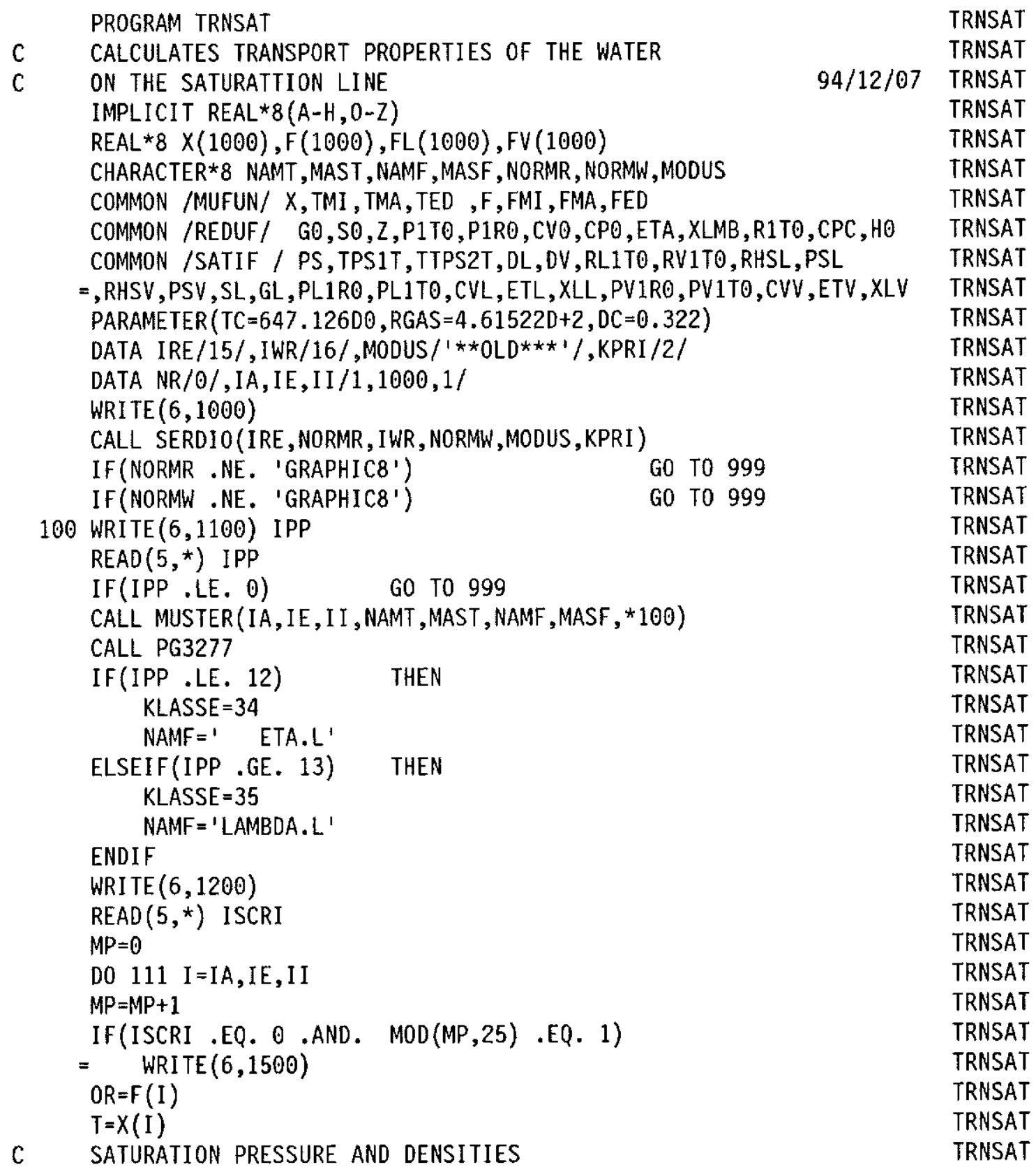


CALL ONLYT (T, IECCH)

TRNSAT

CALL SUBCRI (T)

C CORRECTED VALUES FOR PS, RHOL, RHOV

TRNSAT

$D L K=D L$

$D V K=D V$

TRNSAT

TRNSAT

CALL GPCORR(T,Q,DLK,DVK, IECCH)

TRNSAT

TRNSAT

C

HEAT CONDUCTIVITIES

TRNSAT

IF (T . LE. 645.0DO) THEN

TRNSAT

SATURATED LIQUID

TRNSAT

CALL REDUK(T,DLK, IECCH)

TRNSAT

$E T A L=E T A$

$X L A L=X L M B$

TRNSAT

TRNSAT

SATURATED VAPOR

CALL REOUK(T,DVK, IECCH)

TRNSAT

TRNSAT

ETAV $=E T A$

$X L A V=X L M B$

ELSE

CALL TWOPHA(T)

RHL $=D L * 1 . D 3$

CALL TRANSP( $T, R H L, P L 1 R 0, P L 1 T 0, E T A L, X L A L)$

RHV $=D V * 1 . D 3$

TRNSAT

TRNSAT

TRNSAT

TRNSAT

TRNSAT

TRNSAT

CALL TRANSP(T, RHV,PV1RO, PV1TO, ETAV, XLAV)

TRNSAT

TRNSAT

TRNSAT

IF(IPP .LE. 12) THEN

TRNSAT

$\mathrm{FL}(\mathrm{I})=\mathrm{ETAL}$

TRNSAT

TRNSAT

TRNSAT

ELSEIF(IPP .GE. 13) THEN

TRNSAT

$F L(I)=X L A L$

TRNSAT

ENDIF

$F V(I)=X L A V$

TRNSAT

TRNSAT

TRNSAT

TRNSAT

TRNSAT

TRNSAT

ENDIF

WRITE $(6,1400)$

TRNSAT

TRNSAT

TRNSAT

TRNSAT

TRNSAT

TRNSAT

TRNSAT

TRNSAT

TRNSAT

TRNSAT

TRNSAT

TRNSAT

TRNSAT

TRNSAT

TRNSAT

TRNSAT

TRNSAT

TRNSAT

TRNSAT

TRNSAT 
1000 FORMAT $(2 \mathrm{H}+, 39(2 \mathrm{H}++) / 2 \mathrm{H}+, 77 \mathrm{X}, 1 \mathrm{H}+/ 2 \mathrm{H}+, 6 \mathrm{X}, 14 \mathrm{HPROGRAM}$ TRNSAT

TRNSAT

$=, 34 X, 17 H S T A T U S: 94 / 12 / 07,6 X, 1 H+$

$=/ 2 \mathrm{H}+, 77 \mathrm{X}, 1 \mathrm{H}+/ 2 \mathrm{H}+, 22 \mathrm{X}, 32 \mathrm{HCALCULATING}$ A TRANSPORT PROPERTY

TRNSAT

$=, 23 \mathrm{X}, 1 \mathrm{H}+/ 2 \mathrm{H}+, 77 \mathrm{X}, 1 \mathrm{H}+/ 2 \mathrm{H}+, 39(2 \mathrm{H}++))$

TRNSAT

TRNSAT

1100 FORMAT $(/ 11 \mathrm{H}$ PROPERTY $/, \mathrm{I} 3,5 \mathrm{H} /=$ :

TRNSAT

$=/ 50 \mathrm{H} " 0 "$ "STOP :

TRNSAT

$=/ 52 \mathrm{H} " 12 " \quad$ VISCOSITY OF THE SATURATED STATES :

TRNSAT

$=/ 52 \mathrm{H} " 13 "$ THERMAL CONDUCTIVITY OF THE SAT. STATES : )

TRNSAT

1200 FORMAT (37H FUNCTION TO BE SAVED ? $(0=$ NO $)=:$ )

TRNSAT

1400 FORMAT $(/ / /)$

1500 FORMAT( $/ 1 H O, 3 X, 1 H I, 3 X, 2 H M P, 6 X, 8 H T S$ ( $K$ ), 5X,10HOR ( S.I ), 2X

TRNSAT

$=$, 8HFU.APPR., 3X,13HR. DEV. ( $\%)$ )

TRNSAT

TRNSAT

1700 FORMAT $(2 \mathrm{I} 5, \mathrm{~F} 12.4,2 \mathrm{G} 15.6, \mathrm{~F} 14.8)$

2000 FORMAT $(/ / / / / / / / / / / / / / / / / / / / / / / / / / / / / / /)$

TRNSAT

999 STOP

TRNSAT

END

TRNSAT

TRNSAT 


\section{Appendix J. The IVA Routines}

The following routines are specially fitted for the codesystem IVA3, /21/. The main variables are the temperature and the pressure, the corresponding density must be gained by inverting the isotherm T. All the properties used are strictly in Si-units.

\section{J.1 INR105.AQUA.FORT(SAET01)}

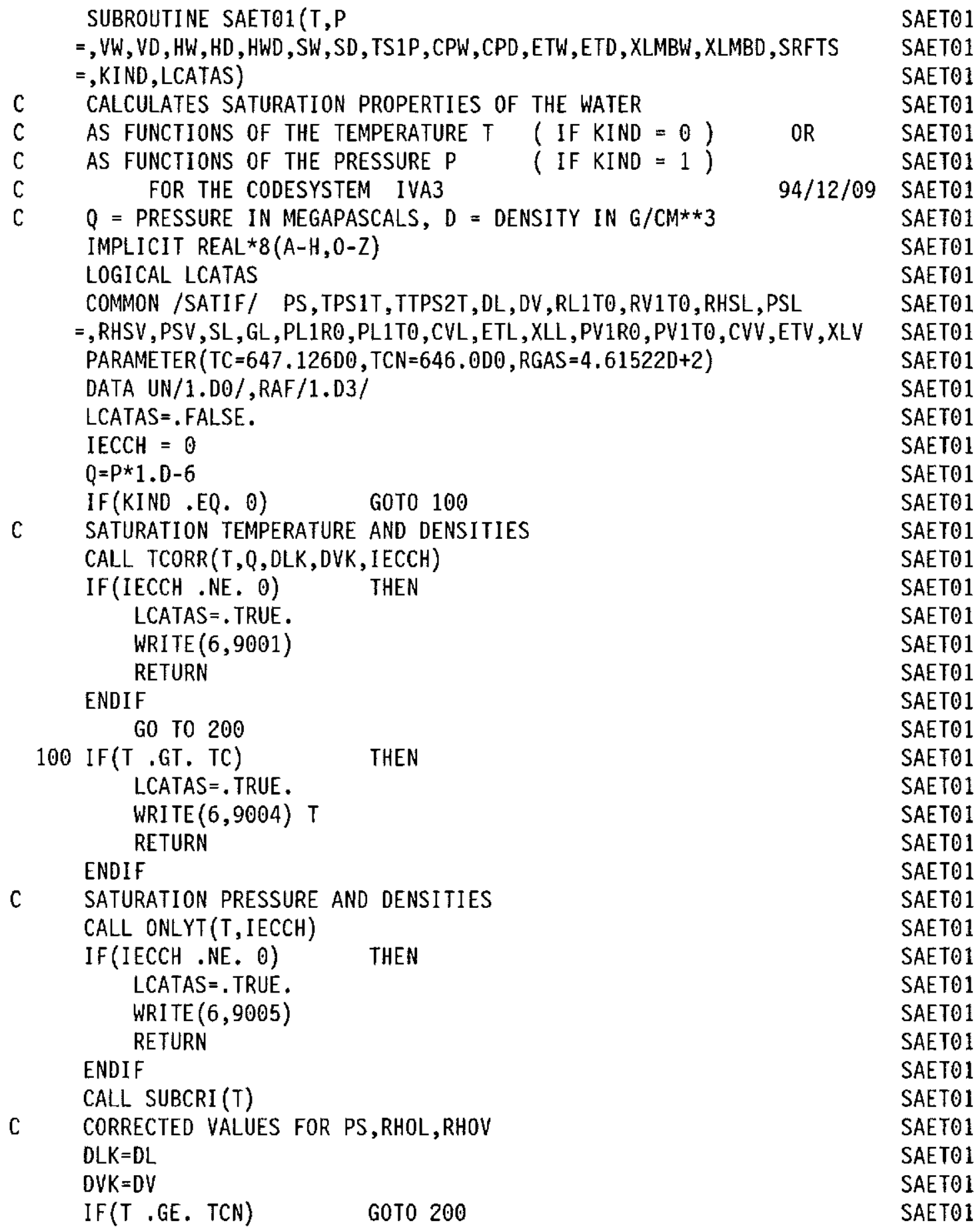




\begin{tabular}{|c|c|c|}
\hline & $\operatorname{CALL} \operatorname{GPCORR}(T, Q, D L K, D V K, I E C C H)$ & SAETO1 \\
\hline C & OTHER PROPERTIES OF THE SATURATED STATES & SAETO1 \\
\hline c & VAPOR PRESSURE DERIVATIVE T*DPS/DT & SAETO1 \\
\hline \multirow[t]{3}{*}{200} & $R O T=T * R G A S$ & SAETO1 \\
\hline & $T S 1 P=T / T P S 1 T$ & SAETO1 \\
\hline & CALL. TWOPHA $(T)$ & SAETO1 \\
\hline \multirow[t]{11}{*}{ c } & LIQUID PROPERTIES & SAETO1 \\
\hline & $R H L=D L K * R A F$ & SAETO1 \\
\hline & $V W=U N / R H L$ & SAETO1 \\
\hline & $\mathrm{GW}=\mathrm{GL} * \mathrm{ROT}$ & SAETO1 \\
\hline & $S W=S L * R G A S$ & SAETO1 \\
\hline & $H W=G W+S W * T$ & SAETO1 \\
\hline & $C P L=C V L+P L 1 T 0 * P L 1 T 0 / P L 1 R 0$ & SAETO1 \\
\hline & $C P W=C P L * R G A S$ & SAETO1 \\
\hline & $\mathrm{ETW}=\mathrm{ETL}$ & SAETO1 \\
\hline & $\mathrm{XL} M \mathrm{MBW}=\mathrm{XLL}$ & SAETO1 \\
\hline & SRFTS=SIGMA(T) & SAETO1 \\
\hline \multirow[t]{11}{*}{ c } & VAPOR PROPERTIES & SAETO1 \\
\hline & $R H V=D V K * R A F$ & SAET01 \\
\hline & $V D=U N / R H V$ & SAETO1 \\
\hline & $\mathrm{GD}=\mathrm{GW}$ & SAETO1 \\
\hline & $H W D=T P S 1 T^{*}(V D-V W)$ & SAETO1 \\
\hline & $S D=S W+H W D / T$ & SAETO1 \\
\hline & $H D=H W+H W D$ & SAETO1 \\
\hline & $C P V=C V V+P V 1 T 0 * P V 1 T 0 / P V 1 R 0$ & SAETO1 \\
\hline & $C P D=C P V * R G A S$ & SAETO1 \\
\hline & $\mathrm{ETD}=\mathrm{ETV}$ & SAETO1 \\
\hline & $\mathrm{XLMBD}=\mathrm{XLV}$ & SAETO 1 \\
\hline 9001 & FORMAT(40H SAETO1-ERROR. PRESSURE RANGE EXCEEDED. ) & SAETO1 \\
\hline 9004 & FORMAT(' $T={ }^{\prime}, F 12.2, '$ IS A SUPERCRITICAL. TEMPERATURE !' ) & SAETO1 \\
\hline 9005 & FORMAT(42H SAETO1-ERROR. TEMPERATURE BELOW FREEZING. ) & SAETO1 \\
\hline \multirow[t]{3}{*}{9008} & FORMAT(39H SAETO1-ERROR. DENSITY RANGE EXCEEDED. ) & SAETO1 \\
\hline & RETURN & SAETO1 \\
\hline & END & SAETO1 \\
\hline
\end{tabular}

\section{J.2 INR105.AQUA.FORT(WASSER)}

SUBROUTINE WASSER ( $T, P$ WASSER

$=, R W, H W, S W, C P W, V S W, E T W, X L M B W, P R N W, H W 1 P, R W 1 T, R W 1 P$, SRFTS, LCATAW) WASSER

CALCULATES THERMOPHYSICAL PROPERTIES OF THE WATER WASSER

AS FUNCTIONS OT THE TEMPERATURE ANO PRESSURE WASSER

$\begin{array}{llll}\text { C AS FUNCTIONS OT THE TEMPERATURE ANO PRESSURE } & \\ \text { C } & \text { FOR THE CODESYSTEM IVA3 } & 94 / 12 / 07 & \text { WASSER } \\ & & \text { WASSER }\end{array}$

C $Q=$ PRESSURE IN MEGAPASCALS, $D=$ DENSITY IN G/CM**3 WASSER

IMPLICIT REAL*8(A-H,O-Z) $\quad$ WASSER

COMMON /REDUF/ GO,SO,Z,P1TO,P1RO,CVO,CPO,ETA,XLMB,R1TO,CPC, HO WASSER

PARAMETER $(T C=647.12600, \mathrm{RGAS}=4.61522 \mathrm{D}+2) \quad$ WASSER

DATA ZER0/0.DO/,UN/1.DO/ WASSER

LCATAW $=$. FALSE. WASSER

$Q=P * 1 . D-6 \quad$ WASSER

IECCH $=0 \quad$ WASSER

CALL ONLYT(T,IECCH) WASSER

IF(IECCH.NE. O) THEN WASSER 
WRITE $(6,9001)$

WASSER

LCATAW $=$. TRUE.

WASSER

GO TO 99

WASSER

ENDIF

C CALCULATING THE DENSITY

IF ( $T$, GE. TC)

CALL DGFIND ( $T, Q, D X, I E C C H)$

WASSER

IF (T .LT. TC)

CALL DLFIND $(T, Q, D X$, IECCH)

WASSER

IF(IECCH .NE. O)

THEN

IF (IECCH .LT. O)

WRI TE $(6,9005)$

WASSER

IF(IECCH .GT. 0) WRITE $(6,9006)$

WASSER

WASSER

WASSER

LCATAW $=$. TRUE.

WASSER

GO TO 99

WASSER

ENDIF

WASSER

$\mathrm{RW}=\mathrm{DX} \star 1.03$

WASSER

$V=U N / R W$

C PROPERTIES AS TEMPERATURE-DENSITY-FUNCTIONS

WASSER

WASSER

ROT $=T *$ RGAS

WASSER

CALL REDUK ( $T, D X, I E C C H)$

C WRITE $\left(6,,^{\prime}(16 \mathrm{H} \text { PREDUK IECCH }=, \mathrm{I} 6)^{\prime}\right)$ IECCH

WASSER

WASSER

IF (P1RO .LE. ZERO) THEN

WRITE $(6,9003)$

WASSER

LCATAW $=$. TRUE .

WASSER

WASSER

WASSER

GO TO 99

WASSER

ENDIF

WASSER

$H W=H O *$ ROT

WASSER

$\mathrm{SW}=\mathrm{S} O *$ RGAS

WASSER

$C P W=C P O * R G A S$

WASSER

$P 1 R=P 1 R 0 * R 0 T$

WASSER

$E T W=E T A$

WASSER

$X L M B W=X L M B$

WASSER

C VELOCITY OF SOUND

WASSER

$P 1 R S=C P C \star P 1 R$

WASSER

$V S W=S Q R T$ (P1RS)

WASSER

C DH/DP, DRHO/DT, DRHO/DP

WASSER

$H W 1 P=(U N+R 1 T O) \star V$

WASSER

$R W 1 T=(R W / T) * R 1 T 0$

WASSER

$R W 1 P=U N / P 1 R$

C

PRANDTL \# , SURFACE TENSION

WASSER

WASSER

WASSER

$P R N W=C P W^{*} E T W / X L M B$

WASSER

SRFTS $=0$. DO

$I F(T, L T . T C) \quad$ SRFTS=SIGMA(T)

WASSER

9001 FORMAT (34H WASSER-ERROR. TEMPERATURE TO LOW. )

WASSER

9002 FORMAT (55H WASSER-ERROR. NO WATER DENSITY FOUND AT THIS PRESSURE.) WASSER

9003 FORMAT (45H WASSER-ERROR. DP/DRHO OF THE WATER VANISHES.) ) WASSER

9005 FORMAT (51H WASSER-ERROR. PRESSURE TO LOW FOR A WATER DENSITY. ) WASSER

9006 FORMAT (52H WASSER-ERROR. PRESSURE TO HIGH FOR A WATER DENSITY.) WASSER

99 RETURN

END

WASSER

WASSER 


\section{J.3 INR105.AQUA.FORT(DAMPF)}

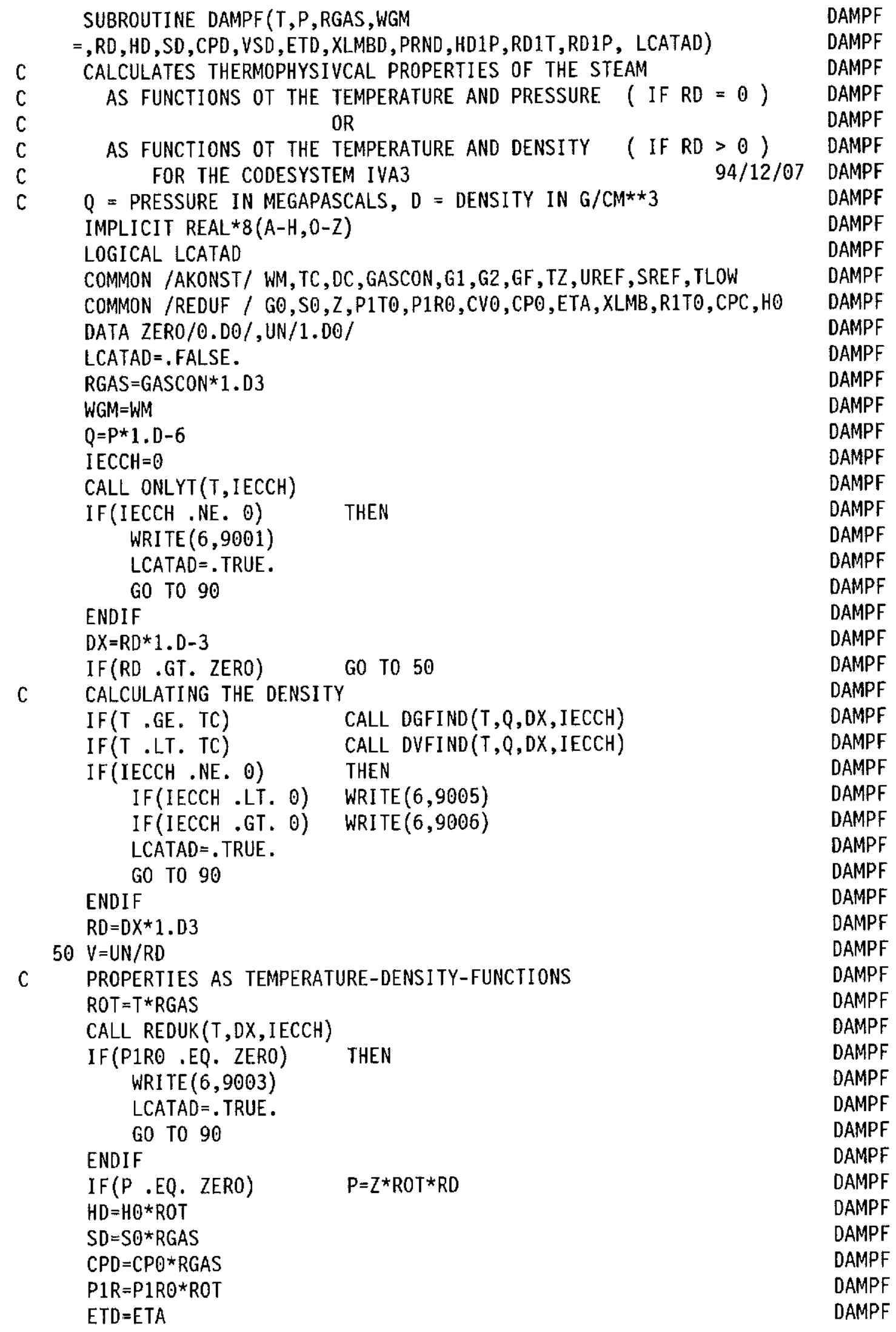




\begin{tabular}{|c|c|c|}
\hline & $X L M B D=X L M B$ & DAMPF \\
\hline \multirow[t]{3}{*}{ C } & VELOCITY OF SOUND & DAMPF \\
\hline & $P 1 R S=C P C * P 1 R$ & DAMPF \\
\hline & VSD =SQRT (P1RS) & DAMPF \\
\hline \multirow[t]{4}{*}{ C } & $\mathrm{DH} / \mathrm{DP}, \mathrm{DRHO} / \mathrm{DT}, \mathrm{ORHO} / \mathrm{DP}$ & DAMPF \\
\hline & $H D 1 P=(U N+R 1 T 0) * V$ & DAMPF \\
\hline & $R D 1 T=(R D / T) * R 1 T 0$ & DAMPF \\
\hline & $\mathrm{RD} 1 \mathrm{P}=\mathrm{UN} / \mathrm{P} 1 \mathrm{R}$ & DAMPF \\
\hline \multirow[t]{2}{*}{ C } & PRANDTL \# & DAMPF \\
\hline & $P R N D=C P D \star E T D / X L M B$ & DAMPF \\
\hline 9001 & FORMAT (33H DAMPF-ERROR. TEMPERATURE TO LOW. ) & DAMPF \\
\hline 9002 & FORMAT (54H DAMPF-ERROR. NO STEAM DENSITY FOUND AT THIS PRESSURE. & JDAMPF \\
\hline 9003 & FORMAT (44H DAMPF-ERROR. DP/DRHO OF THE STEAM VANISHES. ) & DAMPF \\
\hline 9005 & FORMAT(50H DAMPF-ERROR. PRESSURE TO LOW FOR A STEAM DENSITY. ) & DAMPF \\
\hline \multirow{3}{*}{$\begin{array}{r}9006 \\
90\end{array}$} & FORMAT(51H DAMPF-ERROR. PRESSURE TO HIGH FOR A STEAM DENSITY. ) & DAMPF \\
\hline & RETURN & DAMPF \\
\hline & END & DAMPF \\
\hline
\end{tabular}

\section{J.4 INR105.AQUA.FORT(RDRDP)}

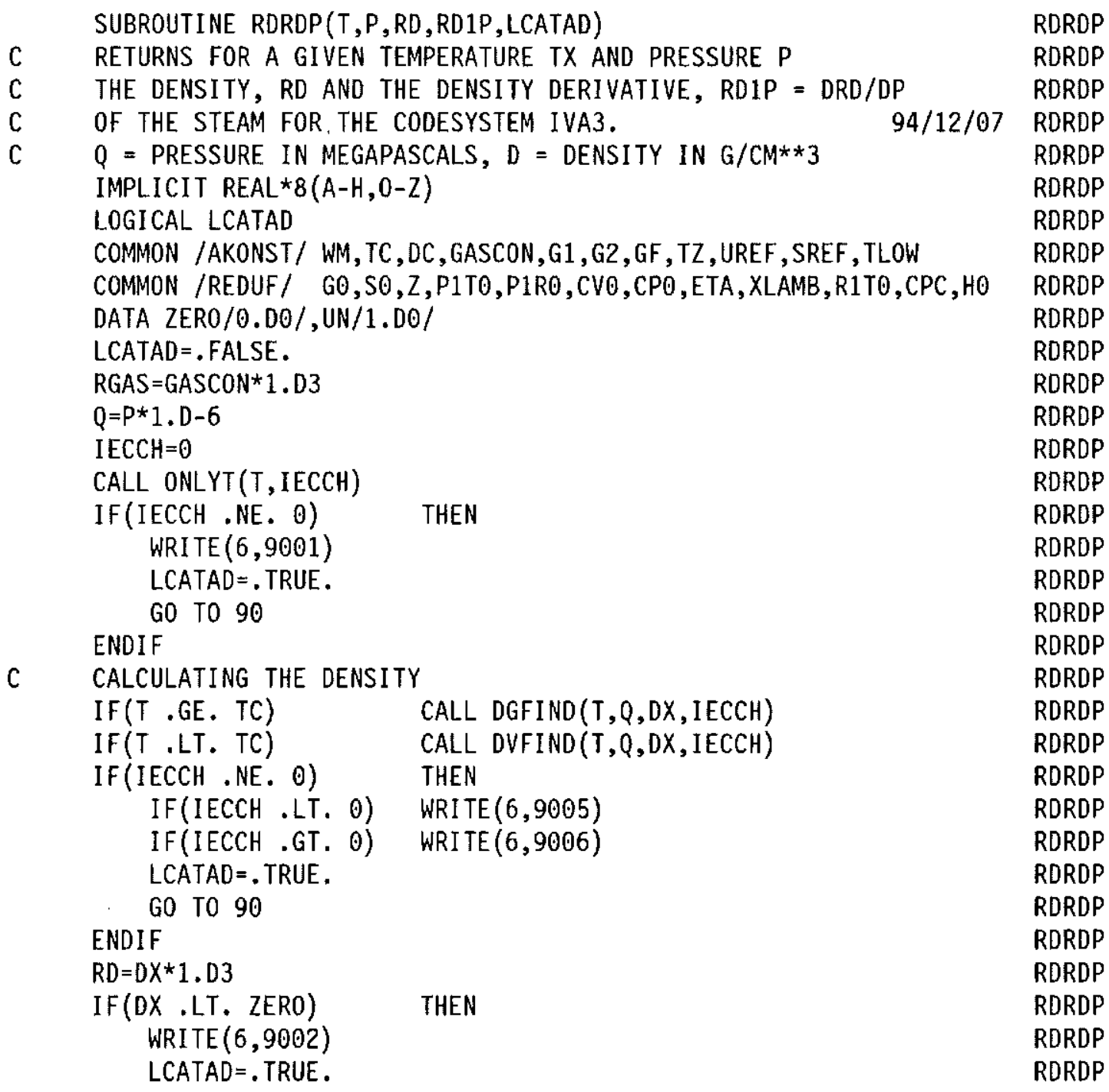


ENDIF

C PROPERTIES AS TEMPERATURE-DENSITY-FUNCTIONS

RDRDP

50 CALL REDUK (T,DX, IECCH)

IF (P1RO .EQ. ZERO) THEN

RDRDP

WRITE $(6,9003)$

$\angle C A T A D=$. TRUE.

RDRDP

GO TO 90

RDRDP

RDRDP

RDRDP

ENDIF

RDRDP

$P 1 R=P 1 R O * T * R G A S$

RDRDP

RDRDP

C

\section{DRHO/DP}

RD1P =UN / P1R

RDRDP

RDRDP

RDRDP

9001 FORMAT (33H RDRDP-ERROR. TEMPERATURE TO LOW. )

RDRDP

9003 FORMAT (44H RDRDP-ERROR. DP/DRHO OF THE STEAM VANISHES.) RDRDP

9005 FORMAT (5OH RDRDP-ERROR. PRESSURE TO LOW FOR A STEAM DENSITY. ) RDRDP

9006 FORMAT(51H RDRDP-ERROR. PRESSURE TO HIGH FOR A STEAM DENSITY. ) RDRDP

90 RETURN

END

ROROP

RDRDP

\section{J.5 INR105.AQUA.FORT(VD1)}

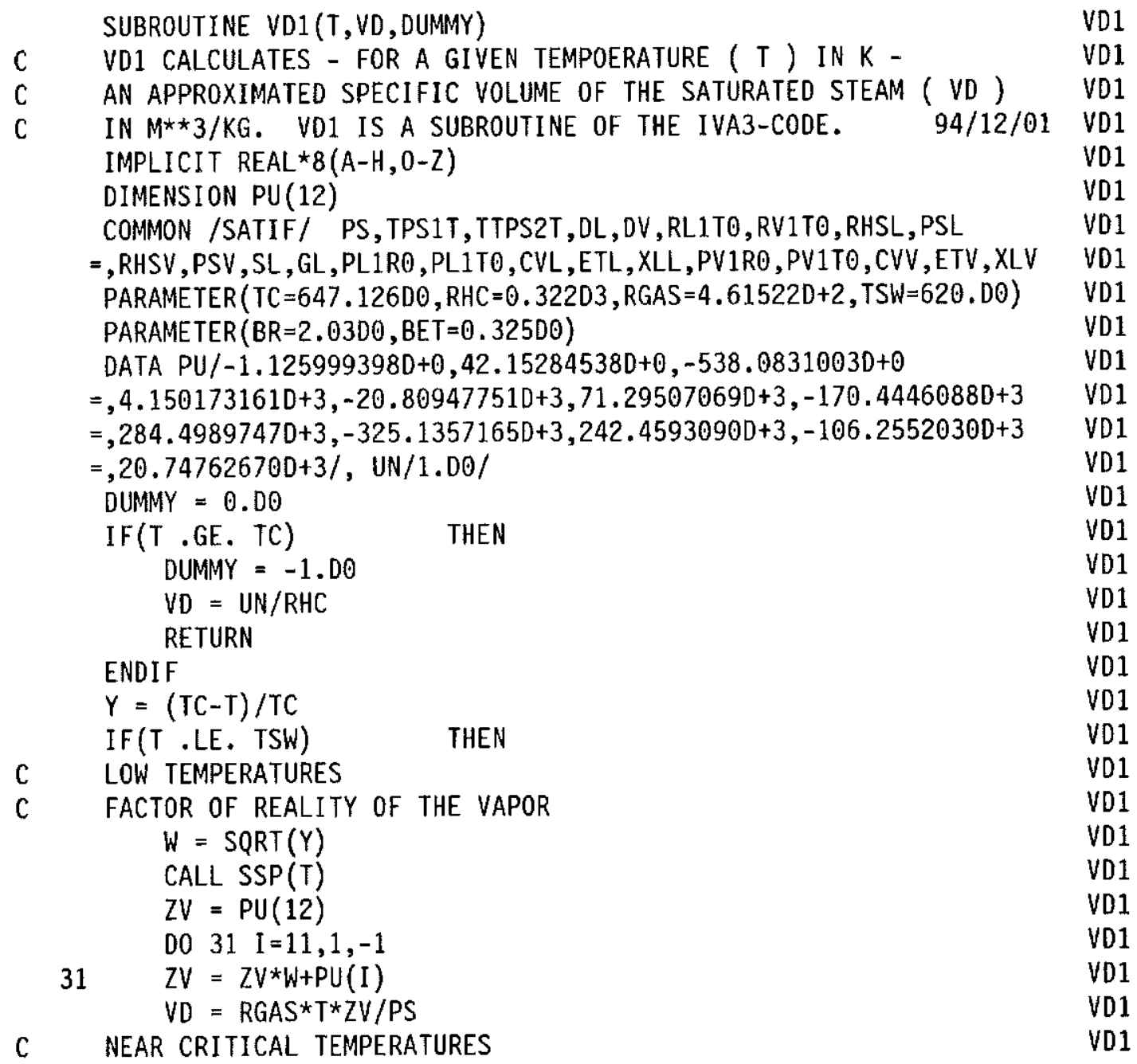


ELSE

VD1

$A V=Y^{*}\left(1.451962241 D-0-Y^{*}(5.0413255590-0-Y * Y * 611.1810749 D-0)\right) V D 1$

OMV $=U N-B R * Y * * B E T+A V \quad$ VD1

$V D=U N /(R H C * O M V) \quad V D 1$

ENDIF

VD1

RETURN

VD1

END

VD1 


\section{Appendix K. Service routines}

The following routines are needed only by the 'string'-routines KAISOT and KAISOK

\section{K.1 INR105.AQUA.FORT(SIGNAT)}

SIGNAT creates the labels and distinguishing names for the properties calculated.

The first label of the property, KLASSE will be set according to the Table 38 on page 156, the second label, NUMMER will be equated with the date of the calculation.

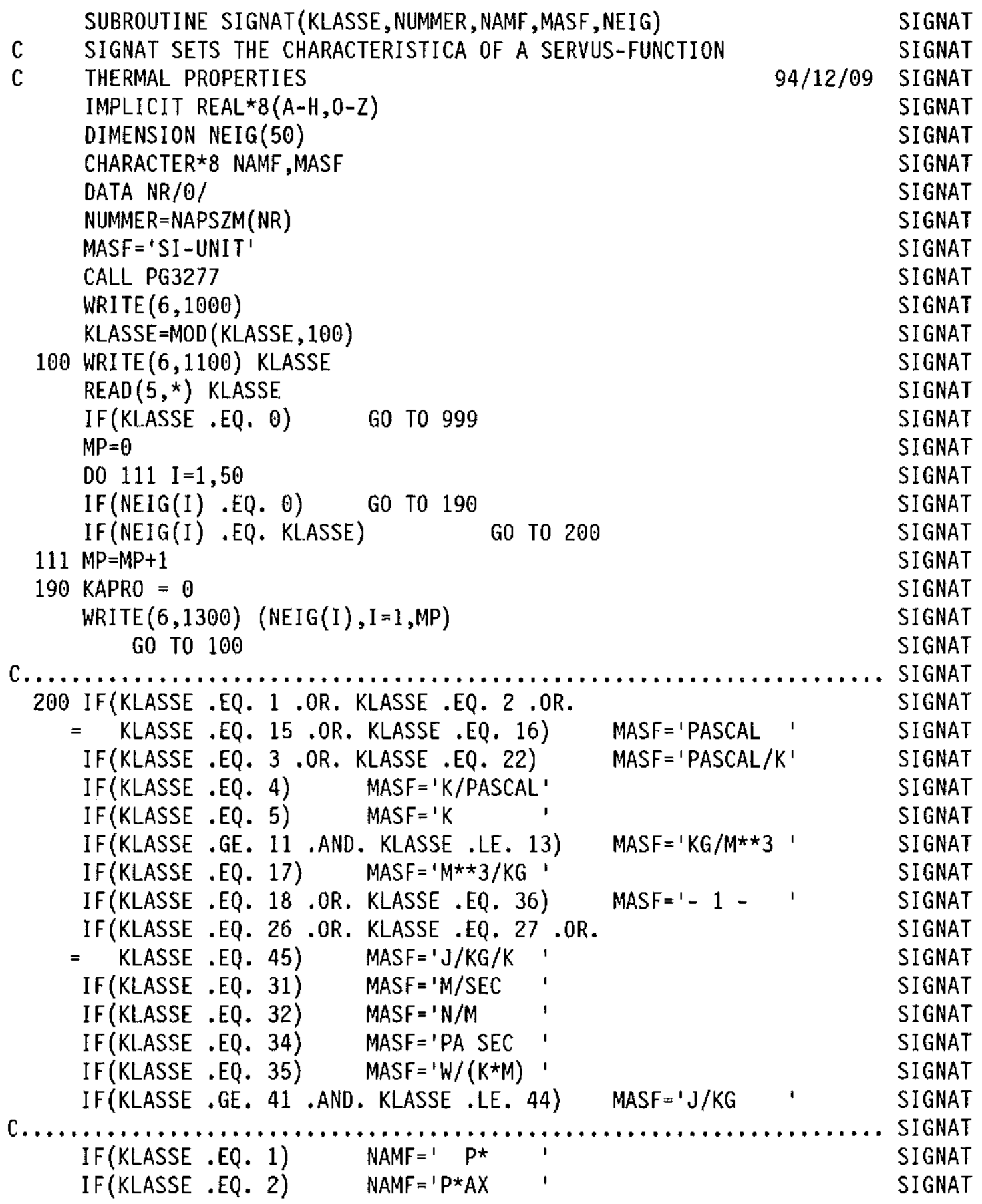




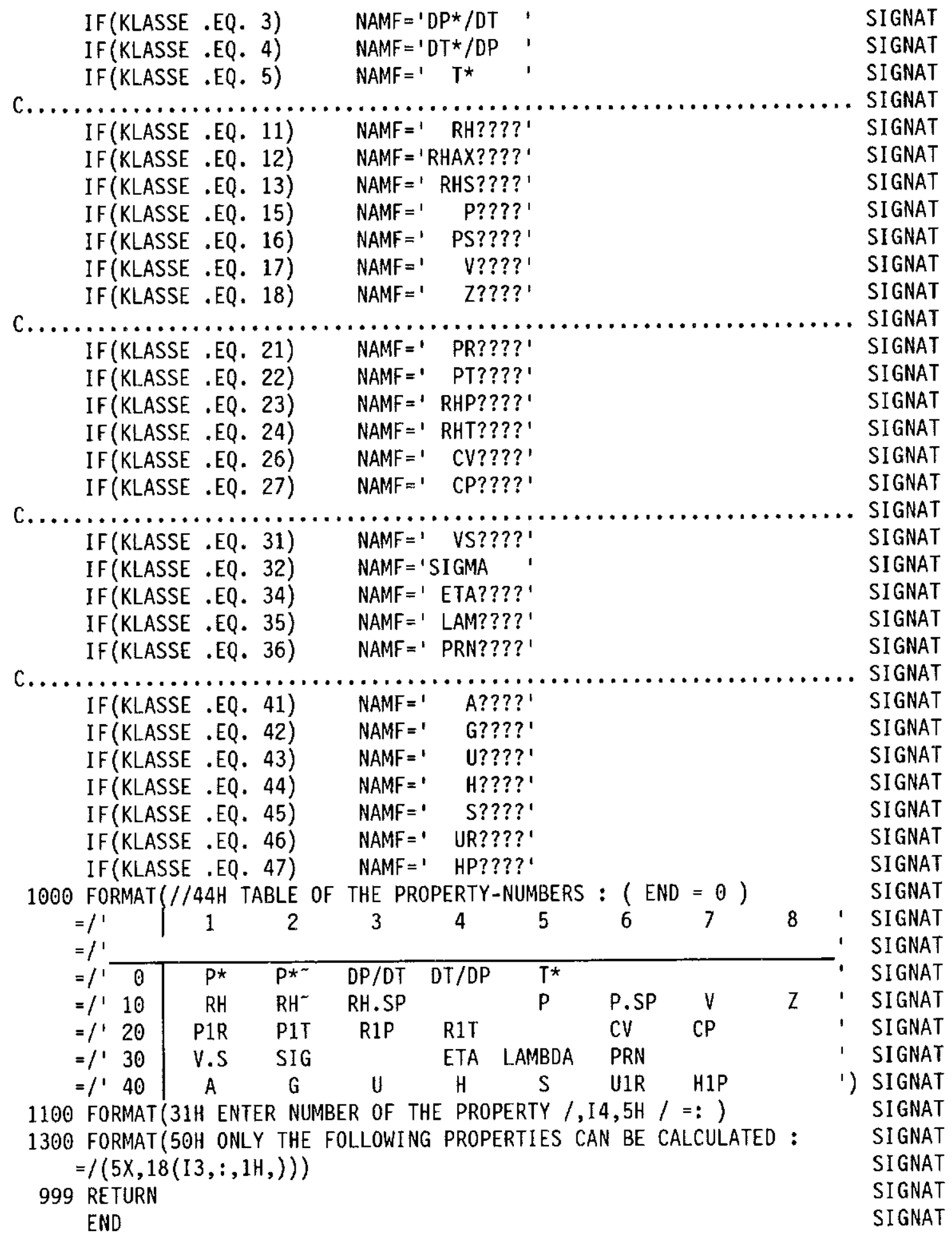




\section{K.2 INR105.AQUA.FORT(MUSTER)}

MUSTER helps to select a sample function from a SERVUS dataset.

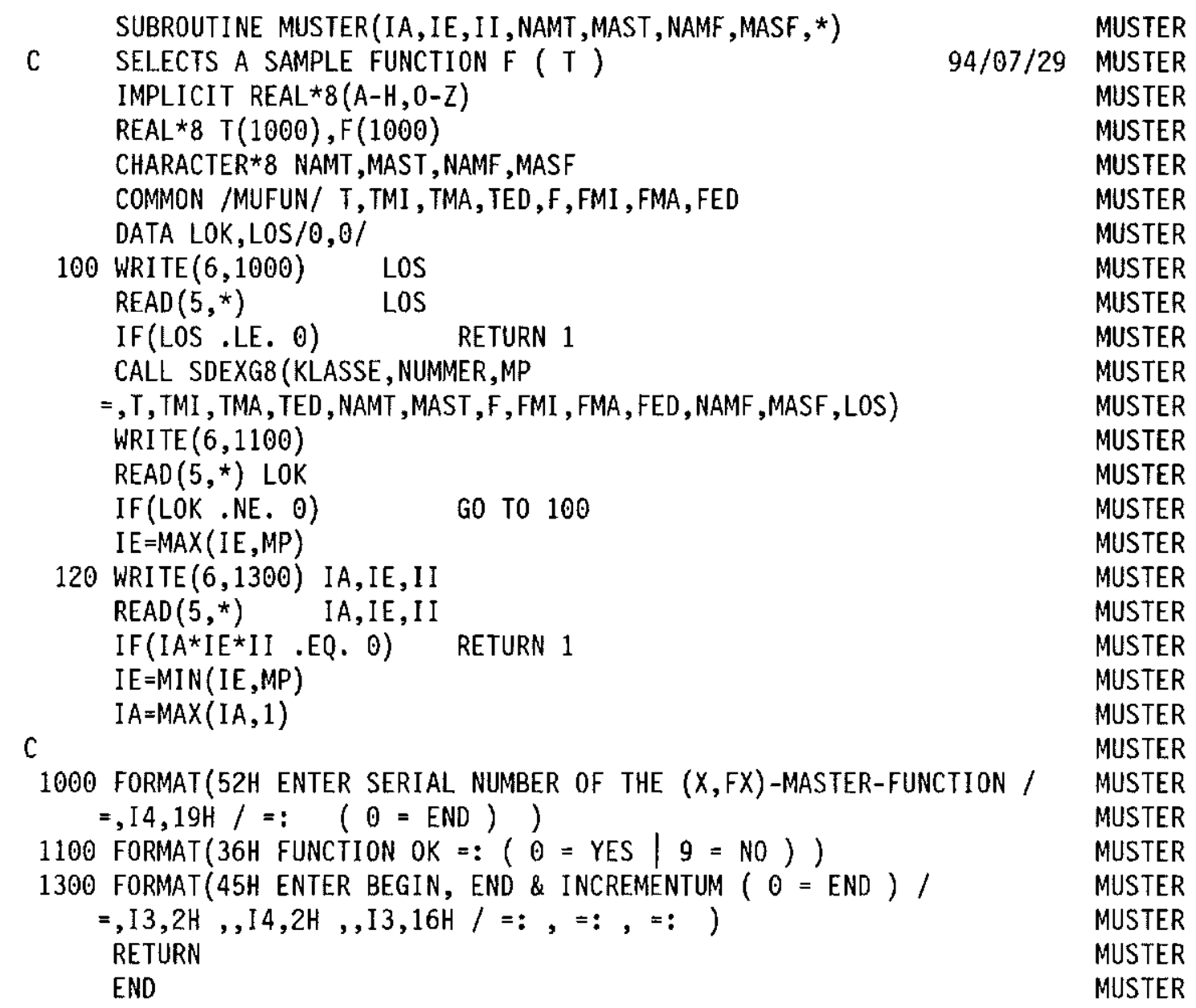

\section{K.3 INR105.AQUA.FORT(NAPSZM)}

NAPSZM turns the actual date into a number, the number of the day in the year.

INTEGER FUNCTION NAPSZM(K)

C REURNS THE NUMBER OF THE DAY

CHARACTER JAN*64

92/01/13 NAPSZM

CALL JOBINF(JAN)

NAPSZM

NAPSZM $=K-K$

NAPSZM

JUF $=1$

NAPSZM

DO $11 \mathrm{~J}=32,30,-1$

NAPSZM

$\mathrm{I}=\operatorname{ICHAR}(\operatorname{JAN}(\mathrm{J}: \mathrm{J}))$

NAPSZM

IF(I .GT. 240 .AND. I .LT. 250)

NAPSZM

$11 \mathrm{JUF}=\mathrm{JUF} * 10$

NAPSZM $=$ NAPSZM $+(I-240) * J U F$

NAPSZM

NAPSZM

RETURN

NAPSZM

END

NAPSZM 


\section{Appendix L. Return codes}

Table 36. Table of return codes, IECCH

\begin{tabular}{|c|c|}
\hline IECCH & Reason \\
\hline 0 & density found \\
\hline$-1,-2$ & pressure to low for a density \\
\hline 1,2 & pressure to high for a density \\
\hline 3 & iteration failed \\
\hline-4 & temperature to low for any density \\
\hline 4 & density too high for any temperature \\
\hline
\end{tabular}



Appendix M. TSO-procedures, calculating thermal properties of the water 


\begin{tabular}{|c|c|c|c|}
\hline Member & Routine & Procedure & Dataset needed \\
\hline WATER & WATER & Water properties point by point $/$ results $=>$ dataset & - \\
\hline KAISOT & KAISOT & Explores water properties along isochores & AQUAT.DATA \\
\hline KAISOK & KAISOK & Explores water properties along isotherms & AQUA.DATA \\
\hline HGK & NBSNRC & Water properties point by point / H.G.K. code & - \\
\hline HGKIST & HGKIST & Explores water properties along isotherms / H.G.K. code & AQUA.DATA \\
\hline HGKSAT & HGKSAT & Calculates properties in the saturated states / H.G.K. code & AQUAT.DATA \\
\hline HGKSPN & HGKSPN & Calculates the spinodals / H.G.K. code & AQUAT.DATA \\
\hline TRNSAT & TRNSAT & Calculates transport properties in the saturated states & AQUAT.DATA \\
\hline TCORR & \$TCORR & Checks the routines TCORR, GPCORR & - \\
\hline TDFIND & \$TDFND & Checks the routines DGFIND, DLFIND, DVFIND & - \\
\hline TAXSL & \$TAXSL & Checks properties in the saturated states & AQUAT.DATA \\
\hline TWASSER & \$TWSSR & Checks the routine WASSER & AQUA.DATA \\
\hline TDAMPF & \$TDMPF & Checks the routine DAMPF & AQUA.DATA \\
\hline TST01 & \$TST01 & Checks the routine SAET01 & AQUAT.DATA \\
\hline TSTEX & \$TSTEX & Checks the routine SAETEX & AQUAT.DATA \\
\hline
\end{tabular}


Appendix N. Thermal property labels 


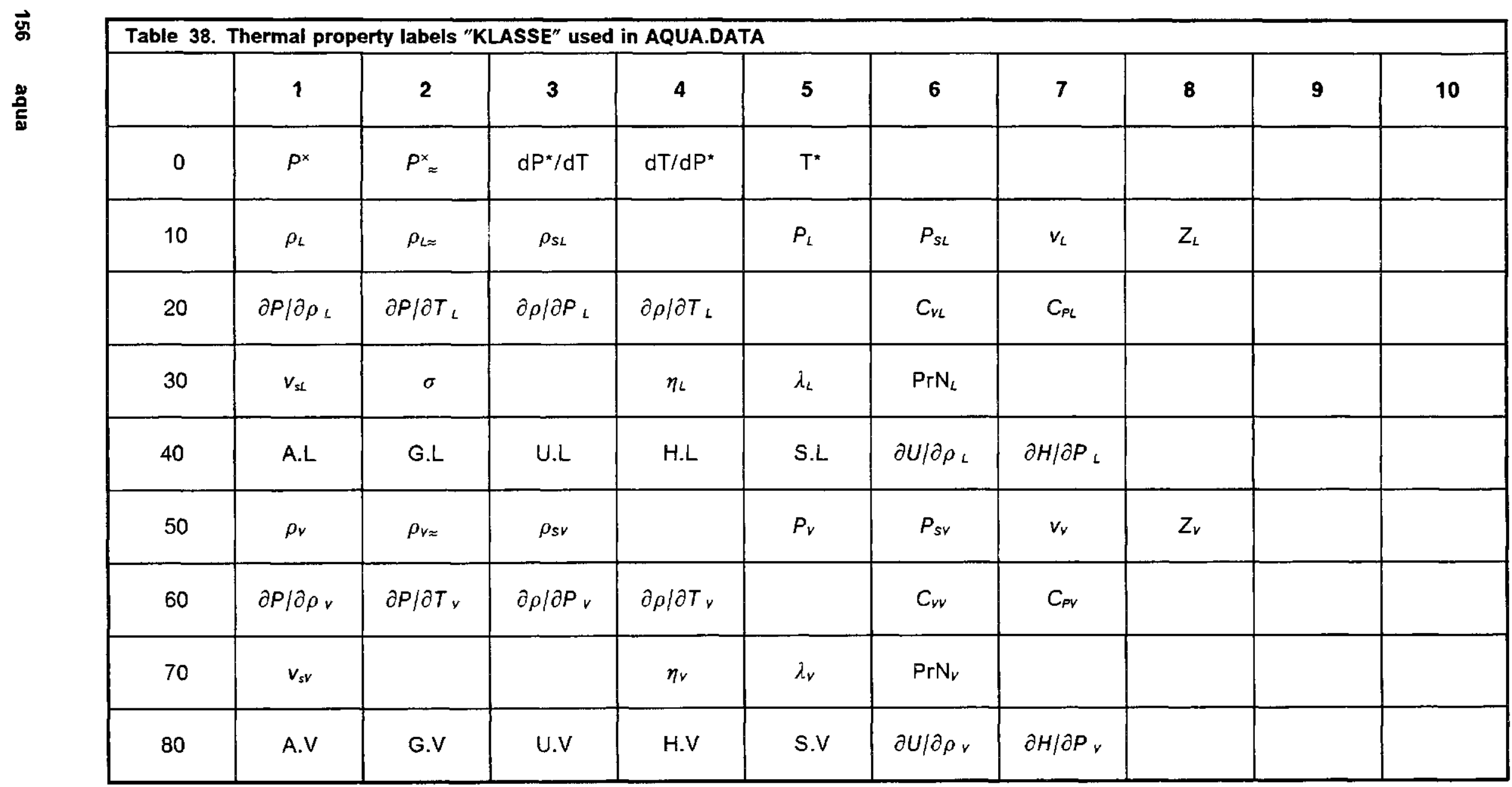

